\title{
Sedimentation und Phosphorhaushalt im Vierwaldstättersee (Horwer Bucht) und im Rotsee
}

\author{
Von JÜRG BLOESCH \\ Eidg. Technische Hochschule Zürich \\ Institut für Gewässerschutz und Wassertechnologie ${ }^{1}$ ) \\ Manuskript eingegangen am 1.5. Mai 1974
}

\begin{abstract}
In 1969/70, chemical and physical parameters, phytoplankton and recent sedimentation at different levels were investigated in the mesotrophic Lake of Lucerne (Horw Bay) and in the highly eutrophic Rotsee.

The rates of sedimentation came to $1277.4 \mathrm{~g}$ dry matter $/ \mathrm{m}^{2} \cdot$ year in Horw Bay and to $879.3 \mathrm{~g}$ dry matter $/ \mathrm{m}^{2}$.year in the Rotsee. The chemical analysis of sediments included the following components: total organic substance (loss on ignition), organic $\mathrm{C}$, clay minerals (HCl-insoluble fraction), $\mathrm{Ca}, \mathrm{Mg}, \mathrm{P}, \mathrm{N}, \mathrm{Fe}$ and $\mathrm{Mn}$. The Rotsee is distinguished by higher nutrient concentrations, higher rates of sedimentation (exceptions: clay minerals, Fe, to a certain extent $\mathrm{N}$ and $\mathrm{Mn}$ ) and by a greater biomass of phytoplankton.

The distribution and succession of selected species and groups of phytoplankton are discussed, the velocity of sinking, the degradation, the growth dynamics and the measure of trophic state are calculated.

For both lakes, a phosphorus and a nitrogen balance have been drawn up. The $\mathrm{N}: \mathrm{P}$ ratio continually decreases running through the nutrient cycle from the input to the storing into the bottom sediments. The intrabiocoenotic phosphorus cycle in the epilimnion is very intensive and supplies approximately two thirds of the nutrient requirements for primary production in both the Horw Bay and the Rotsee.
\end{abstract}

INHALTSVERZEICHNIS

1. Einleitung und Problemstellung . . . . . . . . . . . . . . . . . . . . . 73

2. Die untersuchten Seen . . . . . . . . . . . . . . . . . . . . . . . . . . 74

2.1 Geographische Lage . . . . . . . . . . . . . . . . . . . . . . . . . . . . . . . . 74

2.2 Orographie. . . . . . . . . . . . . . . . . . . . . . . . . . . . . . 74

2.3 Typisierung . . . . . . . . . . . . . . . . . . . 75

1) Die Arbeit wurde an der Eidg. Anstalt für Wasserversorgung, Abwasserreinigung und Gewässerschutz (EAWAG) ausgeführt. 
3. Methodik. . . . . . . . . . . . . . . . . . . . . . . . . . . . . . . . . 75

3.1 Physihalische Bestimmungsmethoden des Seewassers . . . . . . . . . . . . . . . 76

3.2 Chemische Analysenmethoden des Seewassers . . . . . . . . . . . . . . . . . . 76

3.3 Chemische Analysenmethoden des Sedimentes . . . . . . . . . . . . . . . . . . 78

3.4 Biologische Untersuchungsmethoden . . . . . . . . . . . . . . . . . . . . . . 79

3.5 Sedimentationsmessungen . . . . . . . . . . . . . . . . . . . . . . . . . . 80

4. Chemie des Wassers und des Sedimentes . . . . . . . . . . . . . . . . . . . . 81

4.1 Charaktevisierung des Vierwaldstättersees (Horwer Bucht) . . . . . . . . . . . . . . . . . 81

4.11 Gesamtsalzgehalt $\left(x_{20}\right)$ und Temperatur . . . . . . . . . . . . . . . . . . . . 82

4.12 Lichtverhältnisse und Sichttiefe . . . . . . . . . . . . . . . . . . . . . . . 82

4.13 Karbonathärte (SBV oder Alkalinität) und pH . . . . . . . . . . . . . . . . . 83

4.14 Sauerstoff . . . . . . . . . . . . . . . . . . . . . . . . . . . . 83

4.15 Phosphor . . . . . . . . . . . . . . . . . . . . . . . . . . . . . . . 84

4.16 Stickstoff . . . . . . . . . . . . . . . . . . . . . . . . . . . . . 88

4.17 Eisen . . . . . . . . . . . . . . . . . . . . . . . . . . . . . . . . 88

4.18 Kieselsäure $\left(\mathrm{SiO}_{2}\right)$. . . . . . . . . . . . . . . . . . . . . . . . . . . . . 88

4.2 Sedimentation im Vierwaldstättersee (Hovwer Bucht) . . . . . . . . . . . . . . . . . . . 91

4.21 Sedimentationsraten (Trockensubstanz) . . . . . . . . . . . . . . . . . . . . 91

4.22 Organische Substanz und organischer Kohlenstoff . . . . . . . . . . . . . . . 91

4.23 Salzsäure-unlöslicher Anteil . . . . . . . . . . . . . . . . . . . . . . . . . . . 94

4.24 Kalzium und Magnesium . . . . . . . . . . . . . . . . . . . . . . . . . . 94

4.25 Phosphor und Stickstoff . . . . . . . . . . . . . . . . . . . . . . . . . . 96

4.26 Eisen und Mangan . . . . . . . . . . . . . . . . . . . . . . . . . . . . . 97

4.3 Chavakterisierung des Rotsees . . . . . . . . . . . . . . . . . . . . . . . . . 99

4.31 Gesamtsalzgehalt $\left(x_{20}\right)$ und Temperatur . . . . . . . . . . . . . . . . . . . . 99

4.32 Lichtverhältnisse und Sichttiefe . . . . . . . . . . . . . . . . . . . . . . 101

4.33 Karbonathärte (SBV oder Alkalinität) und pH . . . . . . . . . . . . . . . . . 101

4.34 Sauerstoff und Schwefelwasserstoff $\left(\mathrm{H}_{2} \mathrm{~S}\right)$. . . . . . . . . . . . . . . . . . . 102

4.35 Phosphor . . . . . . . . . . . . . . . . . . . . . . . . . . . . 102

4.36 Stickstoff . . . . . . . . . . . . . . . . . . . . . . . . . . . . 104

4.37 Eisen . . . . . . . . . . . . . . . . . . . . . . . . . . . . . . . 104

4.38 Kieselsäure $\left(\mathrm{SiO}_{2}\right)$. . . . . . . . . . . . . . . . . . . . . . . . . . . . . 107

4.4 Sedimentation im Rotsee . . . . . . . . . . . . . . . . . . . . . . . . . . . 107

4.41 Sedimentationsraten (Trockensubstanz) . . . . . . . . . . . . . . . . . . . . 107

4.42 Organische Substanz und organischer Kohlenstoff . . . . . . . . . . . . . . . 107

4.43 Salzsäure-unlöslicher Anteil . . . . . . . . . . . . . . . . . . . . . . . . . 109

4.44 Kalzium und Magnesium . . . . . . . . . . . . . . . . . . . . . . . . . . 111

4.45 Phosphor und Stickstoff . . . . . . . . . . . . . . . . . . . . . . . . . . . 111

4.46 Eisen und Mangan . . . . . . . . . . . . . . . . . . . . . . . . . . . . 113

5. Verteilung und Sedimentation des Phytoplanktons . . . . . . . . . . . . . 117

5.1 Horwer Bucht . . . . . . . . . . . . . . . . . . . . . . . . . . . . . . . . 117

5.11 Gesamtbiomasse . . . . . . . . . . . . . . . . . . . . . . . . . . . . . 117

5.12 Cyanophyceae . . . . . . . . . . . . . . . . . . . . . . . . . . . . . 117

5.13 Chlorophyceae . . . . . . . . . . . . . . . . . . . . . . . . . . . . . . 118

5.14 Konjugatae . . . . . . . . . . . . . . . . . . . . . . . . . . . . . . . 120

5.15 Chrysophyceae . . . . . . . . . . . . . . . . . . . . . . . . . . . . . 121

5.16 Diverse Flagellaten . . . . . . . . . . . . . . . . . . . . . . . . . . . . 122

5.17 Diatomeae. . . . . . . . . . . . . . . . . . . . . . . . . . . . . . . 124

5.18 Cryptophyceae . . . . . . . . . . . . . . . . . . . . . . . . . . . . . . 127

5.19 Peridineae . . . . . . . . . . . . . . . . . . . . . . . . . . . . . . 128

5.2 Rotsee . . . . . . . . . . . . . . . . . . . . . . . . . . . . . . . . . . 129

5.21 Gesamtbiomasse . . . . . . . . . . . . . . . . . . . . . . . . . . . 129

5.22 Cyanophyceae . . . . . . . . . . . . . . . . . . . . . . . . . 129

5.23 Chlorophyceae . . . . . . . . . . . . . . . . . . . . . . . . . . . . . . . 132 
5.24 Konjugatae . . . . . . . . . . . . . . . . . . . . . . . . . . . . . 136

5.25 Chrysophyceae . . . . . . . . . . . . . . . . . . . . . . . . . . . . 137

5.26 Diverse Flagellaten . . . . . . . . . . . . . . . . . . . . . . . . . . . . . 138

5.27 Diatomeae . . . . . . . . . . . . . . . . . . . . . . . . . . . 138

5.28 Cryptophyceae . . . . . . . . . . . . . . . . . . . . . . . . . . . . . 141

5.29 Peridineae . . . . . . . . . . . . . . . . . . . . . . . . . . . 143

5.3 Diskussion der Ergebnisse . . . . . . . . . . . . . . . . . . . . . . . . . . . 143

5.31 Algensukzessionen im Vierwaldstättersee (Horwer Bucht) und im Rotsee . . . . . 143

5.32 Unterschiede im Phytoplankton des Rotsees und des Vierwaldstättersees
(Horwer Bucht)
. . . . . . . . . . . . . . . . . . . . . . . . . . . . . . . 146

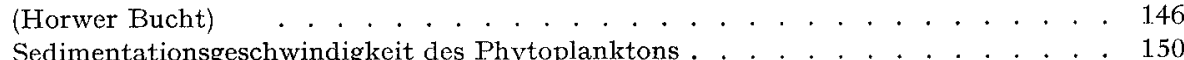

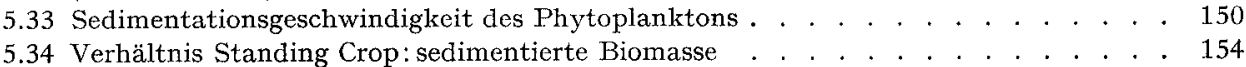

5.35 Abbau des Phytoplanktons . . . . . . . . . . . . . . . . . . . . . . . . . 158

5.36 Methodik: Probenahme-Intervalle . . . . . . . . . . . . . . . . . . . . . 163

6. Phosphorhaushalt und Sedimentation . . . . . . . . . . . . . . . . . . 163

6.1 Die Jahressedimentation im Vierwaldstättersee (Horwer Bucht) und im Rotsee . . . . . 163

6.2 Phosphorhaushalt im Vievroldstättersee (Horwer Bucht) und im Rotsee . . . . . . . 167

6.3 Stickstoffbilanz und N:P-Vevhältnis im Vievwaldstättersee (Horwer Bucht) und im Rotsee .172

6.4 Der «kurgeschlossene» P-Kreislauf im Vierwaldstättersee (Horwer Bucht) und im Rotsee während der Sommerstagnation 1969 . . . . . . . . . . . . . . . . . . . . . . 174

7. Zusammenfassung . . . . . . . . . . . . . . . . . . . . . . . 178

Résumé . . . . . . . . . . . . . . . . . . . . . . . . . . . . . . . . 179

Summary . . . . . . . . . . . . . . . . . . . . . . . . . . . 180

Verdankung . . . . . . . . . . . . . . . . . . . . . . . . . . 181

Literaturverzeichnis . . . . . . . . . . . . . . . . . . . . . . . . . . . 181

\section{Einleitung und Problemstellung}

Limnologische Untersuchungen am Stoffhaushalt eines Sees sind die Voraussetzungen jeder praktischen Bekämpfung der Eutrophierung unserer Gewässer und damit zur Erhaltung ihrer Funktion als Erholungsgebiete und Trinkwasserreservoirs $[50,7]$.

Nachdem GÄchter [31, 32] mit Untersuchungen an der planktischen Primärproduktion die wachstumsbegrenzende Bedeutung des Phosphors im Vierwaldstättersee nachgewiesen hatte, lag es nahe, den P-Kreislauf auch aus dem Blickwinkel der Destruktion näher zu beleuchten. In einer Arbeitsgruppe wurden nebst dem P-Haushalt und der Sedimentation auch der N-Kreislauf [101] sowie einige limnobakteriologische Aspekte $[93,11]$ in zwei voralpinen Seen untersucht. Der Horwer Bucht des Vierwaldstättersees, die als mesotroph einzustufen ist [125], wurde der polytrophe Rotsee gegenübergestellt, denn es erschien reizvoll, das Zusammenspiel von Produktion und Destruktion eines grossen, zur Trinkwassergewinnung benutzten Sees mit demjenigen eines kleinen, zum Teil natürlich eutrophierten Sees zu vergleichen.

In der vorliegenden Arbeit ging es darum, den Vorgang der rezenten Sedimentation zu quantifizieren. Das abgelagerte Bodensediment und Rücklösungsvorgänge in der Schlamm-Wasser-Grenzschicht wurden nicht untersucht. Bei der Sedimentation spielen vor allem die P-Verluste durch das Absinken abgestorbener Phyto- und Zooplankter eine Rolle sowie die Zersetzung dieser Organismen und die damit verbundene Phosphat-Freisetzung. Die Stoffwechseldynamik eines Sees hängt neben der allochthonen P-Zufuhr weitgehend von diesem "kurzgeschlossenen» Stoffkreislauf ab [73, 
31, 101, 93]. Es sollte einerseits das Ziel chemischer Analysen sein, eine Angabe über die Grösse dieser autochthonen P-Quelle machen zu können, andrerseits sollten biologische Untersuchungen am Phytoplankton mehr Klarheit über Sedimentations- und Abbaugeschwindigkeiten der einzelnen Arten geben. Schliesslich sollte aufgezeigt werden, wieweit beide Fragenkomplexe in den zwei verschiedenen Seen voneinander abweichen würden.

Die Arbeit ist in zwei Abschnitte gegliedert. Zunächst werden die Seen einzeln und möglichst umfassend beschrieben (Chemismus des Wassers, 4.1, S. 81 und 4.3, S. 99), dann werden die Resultate der chemischen Sedimentanalysen (4.2, S. 91 und 4.4, S. 107) sowie der Phytoplanktonauszählungen (5.1, S. 117 und 5.2, S. 129) aufgeführt. Im zweiten Teil wird auf die eigentliche Problemstellung eingegangen, und die beiden Seen werden direkt miteinander verglichen (Planktonergebnisse 5.3, S. 143, und Phosphorhaushalt und Phosphorsedimentation 6, S. 163).

\section{Die untersuchten Seen}

\subsection{Geographische Lage}

Die geographische Lage der beiden Seen und der Probenahmestellen ist aus der Kartenskizze (Abb. 1) ersichtlich. Luftaufnahmen davon finden sich bei STADELManN [101].

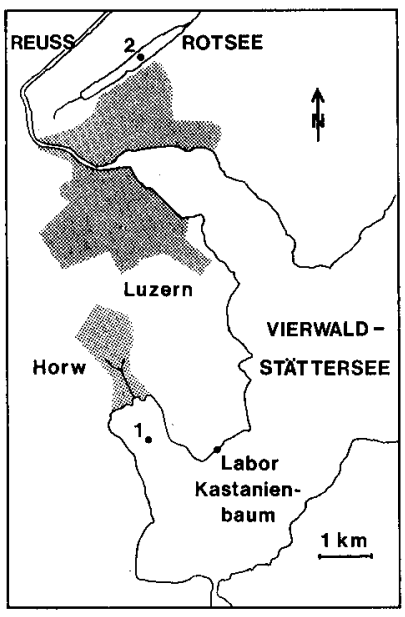

Abb. 1. Geographische Lage der Probenahmestellen. 1 Vierwaldstättersee (Horwer Bucht), 2 Rotsee. Fig. 1. Geographical position of the sampling stations. 1 Lake of Lucerne (Horw Bay), 2 Rotsee.

\subsection{Orographie}

Die morphologischen Daten der untersuchten Seen wurden schon von STADELMANN [101] und SCHEGG [93] publiziert; sie basieren im wesentlichen auf den Angaben von Minder [64] und Gächter [31] und sind in Tabelle 1 zusammengestellt. Die Morphologie des gesamten Vierwaldstättersees ist bei АмвӥнL [5] beschrieben. Der Rotsee ist berühmt wegen seiner extrem windgeschützten Lage. 
Tabelle 1. Morphologie der untersuchten Seen. Zusammengestellt aus [64, 31, 101, 93].

Table 1. Morphology of the lakes investigated. Compiled from [64, 31, 101, 93].

\begin{tabular}{lll}
\hline & $\begin{array}{l}\text { Horwer Bucht } \\
\text { Vierwaldstättersee }\end{array}$ & Rotsec \\
\hline Länge & $1,5 \mathrm{~km}$ & $2,5 \mathrm{~km}$ \\
Breite & $1 \mathrm{~km}$ & $0,15-0,25 \mathrm{~km}$ \\
Fläche & $1,69 \mathrm{~km}^{2}$ & $0,47 \mathrm{~km}^{2}$ \\
Isobathenfläche an der Grenzschicht Epilimnion- & & \\
Hypolimnion (Horwer Bucht 15 m, Rotsee $5 \mathrm{~m})$ & $1,43 \mathrm{~km}^{2}$ & $0,34 \mathrm{~km}^{2}$ \\
Maximale Tiefe & $72 \mathrm{~m}$ & $\mathbf{1 6 m}$ \\
Mittlere Tiefe & $42,6 \mathrm{~m}$ & $9 \mathrm{~m}$ \\
Volumen total & $71,85 \cdot 10^{6} \mathrm{~m}^{3}$ & $4,30 \cdot 10^{6} \mathrm{~m}^{3}$ \\
Volumen Epilimnion total & $22,925 \cdot 10^{6} \mathrm{~m}^{3}$ & $2,015 \cdot 10^{6} \mathrm{~m}^{3}$ \\
Volumen Epilimnion ohne Ufer & $21,45 \cdot 10^{6} \mathrm{~m}^{3}$ & $1,70 \cdot 10^{6} \mathrm{~m}^{3}$ \\
Volumen Hypolimnion & $46,145 \cdot 10^{6} \mathrm{~m}^{3}$ & $1,59 \cdot 10^{6} \mathrm{~m}^{8}$ \\
\hline
\end{tabular}

\subsection{Typisierung}

'Tabelle 2. Trophiezustand und Abwasserbelastung der untersuchten Seen. Nach SchEGG [93], verändert.

Table 2. Trophic state and waste water load of the lakes investigated. Adapted from ScHEGG [93].

\begin{tabular}{|c|c|c|c|}
\hline See & Gewässerzustand & Abwasserbelastung & Literatur \\
\hline $\begin{array}{l}\text { Horwer Bucht } \\
\text { Vierwaldstättersee }\end{array}$ & Mesotroph & $\begin{array}{l}\text { Etwa } 10000 \text { Einwohner- } \\
\text { gleichwerte; praktisch } \\
\text { ungereinigt (Häuser mit Klär- } \\
\text { gruben). } \\
\text { Ab Ende 1972: keine } \\
\text { Belastung mehr; Abwasser- } \\
\text { sammelkanal in Betrieb. }\end{array}$ & $\begin{array}{l}\text { АMBÜHL [5] } \\
\text { GÄCHTER [31] }\end{array}$ \\
\hline Rotsee & $\begin{array}{l}\text { Stark } \\
\text { eutrophiert }\end{array}$ & $\begin{array}{l}\text { Bis } 1933 \text { von Stadtteil } \\
\text { Luzerns ungereinigt, seither } \\
\text { mechanisch gereinigt. } \\
\text { Seit Mitte } 1969 \text { keine direkte } \\
\text { Belastung mehr; indirekte } \\
\text { Kontamination durch ab- } \\
\text { wasserbelastetes Reusswasser. } \\
\text { Ab August } 1974 \text { ARA Luzern in } \\
\text { Betrieb; keine Belastung mehr. }\end{array}$ & $\begin{array}{l}\text { DÜGGELI [18] } \\
\text { MrNDER [64] } \\
\text { STADELMANN [101] } \\
\end{array}$ \\
\hline
\end{tabular}

\section{Methodik}

Die beiden Seen wurden in den Jahren 1969/70 monatlich einmal (Sedimentationsmessungen zweimal) (Tab.3) in folgenden Tiefenstufen untersucht:

Horwer Bucht Wasser $0 ; 2,5 ; 5 ; 7,5 ; 10 ; 12,5 ; 15 ; 25 ; 45 ; 60 \mathrm{~m}$ (= Grund)

Sediment 7,$5 ; 15 ; 25 ; 45 ; 60 \mathrm{~m}$

Rotsee Wasser $\quad 0 ; 1 ; 2,5 ; 5 ; 7,5 ; 14 \mathrm{~m}$ (= Grund)

Sediment 2,$5 ; 5 ; 14 \mathrm{~m}$ 
Tabelle 3. Untersuchungsdaten.

Table 3. Dates of investigation.

\begin{tabular}{|c|c|c|c|}
\hline \multicolumn{2}{|c|}{ Horwer Bucht Vierwaldstättersee } & \multirow{2}{*}{$\begin{array}{l}\text { Rotsee } \\
\text { Wasser }\end{array}$} & \multirow[b]{2}{*}{ Sediment } \\
\hline Wasser & Sediment & & \\
\hline 21. 1.1969 & & 20. 3.1969 & \\
\hline \multirow{2}{*}{ 19. 2. 1969} & $\begin{array}{rr}6.2 .1969 \\
10 & 21069\end{array}$ & & $\begin{array}{rr}1 . & 4.1969 \\
17 & 4.1969\end{array}$ \\
\hline & $\begin{array}{rr}19 . & 2.1969 \\
5 . & 3.1969\end{array}$ & 17. 4.1969 & $\begin{array}{rr}17 . & 4.1969 \\
1 . & 5.1969\end{array}$ \\
\hline \multirow[t]{2}{*}{ 18. 3.1969} & 17. 3.1969 & 22. 5.1969 & 19. 5. 1969 \\
\hline & 1. 4.1969 & & 4. 6.1969 \\
\hline \multirow{2}{*}{ 20. 5.1969} & 30. 4.1969 & 10. 6.1969 & 16. 6.1969 \\
\hline & 19. 5.1969 & & 1. 7.1969 \\
\hline \multirow{2}{*}{ 17. 6.1969} & 3. 6.1969 & 10. 7.1969 & $\begin{array}{rr}14 . & 7.1969 \\
4 . & 8.1969\end{array}$ \\
\hline & $\begin{array}{ll}18 . & 6.1969 \\
30 . & 6.1969\end{array}$ & 14. 8.1969 & 18. 8.1969 \\
\hline \multirow{2}{*}{ 8. 7.1969} & 15. 7.1969 & & 3. 9.1969 \\
\hline & 29. 7.1969 & 11. 9.1969 & 16. 9.1969 \\
\hline \multirow[t]{2}{*}{ 5. 8.1969} & 11. 8.1969 & & 1. 10.1969 \\
\hline & 25. 8.1969 & 10.10 .1969 & 14. 10.1969 \\
\hline \multirow[t]{2}{*}{ 9. 9.1969} & 8. 9.1969 & & 30.10 .1969 \\
\hline & 22. 9.1969 & 6.11 .1969 & 14.11. 1969 \\
\hline \multirow{2}{*}{ 7. 10.1969} & 4.10.1969 & 3. 12.1969 & 1.12 .1969 \\
\hline & 22. 10.1969 & & 17. 12.1969 \\
\hline \multirow[t]{2}{*}{ 4. 11.1969} & 3.11.1969 & 15. 1.1970 & 12. 1.1970 \\
\hline & 17. 11.1969 & 18. 2. 1970 & \\
\hline \multirow[t]{2}{*}{2.12 .1969} & 3. 12.1969 & 23. 3.1970 & \\
\hline & 19.12. 1969 & & \\
\hline \multirow[t]{2}{*}{ 6. 1.1970} & 7. 1.1970 & & \\
\hline & 30. 1.1970 & & \\
\hline 4. 2. 1970 & 23. 2. 1970 & & \\
\hline
\end{tabular}

3.1 Physikalische Bestimmungsmethoden des Seewassers

3.11 Temperatur und Leitfähigkeit

Die Temperatur und die elektrische Leitfähigkeit wurden mit dem Oxytester nach АмвÜнL [3] bestimmt. Die Werte der Leitfähigkeit wurden auf die einheitliche Temperatur von $20^{\circ} \mathrm{C}\left(x_{20}\right)$ umgerechnet [19].

\subsection{Lichtverhältnisse und Sichttiefe}

Die vertikalen Extinktionen verschiedener Spektralbereiche wurden nach den Empfehlungen von SAUBERER [91] mit einem Sperrschichtphotometer mit vorgeschalteten Filtern (Fa. Schott und Gen., Mainz, VG 9, BG 12 und RG 2) gemessen.

Die Sichttiefe wurde mit der Secchi-Scheibe (Durchmesser $30 \mathrm{~cm}$ ) bestimmt.

\subsection{Chemische Analysenmethoden des Seewassers}

\subsection{Sauerstoff}

Der Sauerstoffgehalt wurde nach der Winkler-Methode [127], modifiziert nach AlsterberG [2], bestimmt.

\section{$3.22 \mathrm{pH}$}

Der pH-Wert wurde elektrometrisch mit dem pH-Messgerät Typ 25 der Fa. Radiometer Copenhagen (Glaselektroden) auf $1 / 10 \mathrm{pH}$-Einheit genau bestimmt $[19,28]$. 


\subsection{Freie Kohlensäure}

Der Gehalt an freier Kohlensäure wurde durch potentiometrische Titration mit $0,01 \mathrm{~N}$ Natronlauge auf den empirisch festgelegten $\mathrm{pH}$-Wert von 8,1 bestimmt (theoretischer $\mathrm{pH}$-Wert 8,35). Wasserproben, deren $\mathrm{pH}$-Wert bereits 8,1 oder mehr beträgt, werden als kohlensäurefrei betrachtet [19].

\subsection{Karbonathärte (SBV oder Alkalinität)}

Die Karbonathärte wurde nach der modifizierten Vorschrift im Schweizerischen Lebensmittelbuch [58] mit 0,1 N Salzsäure und gegen Methylorange als Indikator titrimetrisch bestimmt.

\subsection{Gesamtkohlenstoff (anorganisch)}

Der Gesamtkohlenstoff wurde aus pH und SBV mit Hilfe der Tabelle nach HARVEY und RODHE [45] berechnet.

\subsection{Kieselsäure}

Die freie Kieselsäure wurde nach den Deutschen Einheitsverfahren [19] mit Ammoniummolybdat photometrisch bestimmt (Modifikation EAWAG).

\subsection{Stickstoffkomponenten}

Nitrat wurde mit der Natriumsalicylat-Methode nach MülLER und WidemanN [66], Nitrit mit Sulfanilamid und $N$-(1-Naphthyl)-äthylendiamin nach STRICriLAND und PARsons [106] und Ammonium nach Schmid [96] bestimmt. Die Bestimmung des gelösten organischen und des partikulären organischen Kjeldahl-Stickstoffs wurde nach der Methode von STADELManN [101] durchgeführt.

\subsection{Phosphorkomponenten}

Das Orthophosphat wurde mit der Ammoniummolybdat-Zinnchlorid-Methode nach OHLE [71], modifiziert nach AmbüHL und Schmid [8], bestimmt.

Für die Bestimmung des Gesamtphosphors wurde der nasse Aufschluss mit Schwefelsäure und Wasserstoffperoxid als Oxydationsmittel und anschliessender Neutralisation mit Ammoniak angewandt [71], modifiziert nach ScHMId und AMBÜHL [97].

Der partikuläre Phosphor wurde aus der Differenz des Gesamtphosphors im Rohwasser und dem Gesamtphosphor im Filtrat ermittelt, der organisch lösliche Phosphor aus der Differenz des Gesamtphosphors im Filtrat und dem Orthophosphat, obwohl dieser Berechnung der Fehler anhaftet, dass bei diesem Verfahren nicht nur die organisch gebundenen Phosphorverbindungen, sondern auch die anorganischen kondensierten Phosphate hydrolisiert und erfasst werden [122, 123]. Nach AмвüHL [6] ist aber dieser Fehler zumindest im Vierwaldstättersee nicht von grosser Bedeutung, da in diesem Gewässer nur Spuren von kondensierten Phosphaten zu finden sind. Im Zusammenhang mit diesen Problemen sei darauf hingewiesen, dass VoGLER [124] die analytische Trennung verschiedener Phosphatkomponenten weiter vorangetrieben hat. 


\subsection{Gesamteisen}

Das Gesamteisen im Rohwasser und im Filtrat wurde kolorimetrisch mit der Orthophenanthrolin-Methode bestimmt [102]; leicht modifiziert. Das partikuläre Eisen wurde aus der Differenz des Gesamteisens im Rohwasser und dem Gesamteisen im Filtrat ermittelt.

\subsection{Sulfid (Schwefelwasserstoff)}

Die quantitative Sulfidbestimmung erfolgte kolorimetrisch mit $N N$-Dimethyl- $p$ phenylendiammoniumdichlorid und Eisen(III)-ammoniumsulfat [62].

\subsection{Filtration}

Das zur Analyse benötigte Filtrat wurde mittels Filtration durch Membranfilter mit einer Porenweite von $0,45 \mu$ (Millipore HA) gewonnen.

\subsection{Chemische Analysenmethoden des Sedimentes}

\subsection{Trockengewicht}

Das aufgefangene Sediment wurde in $1 / 2-11$ Restwasser gut aufgewirbelt; davon wurden $320 \mathrm{ml}$ bei $2600 \mathrm{rpm} 15$ Minuten lang zentrifugiert. Nach Dekantieren des überstehenden Wassers wurde das Sediment während mindestens 12 Stunden bei $50^{\circ} \mathrm{C}$ getrocknet [119].

\subsection{Glühverlust-Asche (organische Substanz)}

Ungefähr 0,1 g getrocknetes, im Achatmörser fein zerriebenes Sediment wurde in der Platinschale 2 Stunden bei $550^{\circ} \mathrm{C}$ im Muffelofen verascht. Die Temperatur darf nicht höher liegen, da sonst die Karbonate zersetzt werden; bei $500^{\circ} \mathrm{C}$ ist die Verbrennung dagegen noch unvollständig [119]. Stichprobenanalysen mit einem TGDTG-DTA-Thermoanalyzer der Fa. Mettler Greifensee zeigten, dass die Zersetzung der Karbonate in den Sedimenten bei $550-570^{\circ} \mathrm{C}$ einsetzt. Es ist daher äusserst wichtig, die genaue Glühtemperatur von $550^{\circ} \mathrm{C}$ nicht zu überschreiten, da sonst zu hohe Glühverluste gemessen werden.

\subsection{Organischer Kohlenstoff}

Der organische Kohlenstoff wurde nach vorherigem Abrauchen der Karbonate mit Salzsäure im C, H, N-Analyzer (Modell 185 F \& M, Fa. Hewlett \& Packard) bestimmt.

\subsection{Salzsäure-unlöslicher Anteil der Asche}

(Mineralische Grundsubstanz, vor allem schwerlösliche Siliziumverbindungen $\left(\mathrm{SiO}_{2}\right)$ )

Die in der Platinschale veraschte Probe wurde mit $10 \mathrm{ml}$ 12\%iger Salzsäure vorsichtig versetzt $\left(\mathrm{CO}_{2}\right.$-Entwicklung) und mit dest. Wasser verdünnt. Nach 2stündigem Digerieren bei $80^{\circ} \mathrm{C}$ wurde filtriert (Weissbandfilter, Schleicher \& Schuell Nr. $589^{2}$ $\varnothing 9 \mathrm{~cm})$ und der Rückstand samt Filter während 30 Minuten bei $700-800^{\circ} \mathrm{C}$ verascht [119].

\subsection{Kalzium und Magnesium}

Im Filtrat wurden nach entsprechender Verdünnung die $\mathrm{Ca}^{2+}$ und $\mathrm{Mg}^{2+}-\mathrm{Ionen}$ titrimetrisch mit Komplexon III bestimmt [98]. 


\subsection{Gesamtphosphor}

Die Gesamtphosphor-Methode nach Scнмгd und АмвӥнL [97] musste leicht modifiziert werden, da das vorhandene Eisen störte. Der Aufschluss erfolgte erst vollständig bei dreimaliger $\mathrm{H}_{2} \mathrm{O}_{2}$-Zugabe (alle 10 Minuten 3 Tropfen) statt einmaliger $\mathrm{Zu}$ gabe. Die Neutralisation hatte wegen des sonst ausfallenden $\mathrm{Fe}(\mathrm{OH})_{3}$ so zu erfolgen, dass kein alkalischer $\mathrm{pH}$ erreicht wurde. Vor der Farbreaktion mussten die Proben filtriert und verdünnt werden.

\subsection{Gesamtstickstoff}

Der Gesamtstickstoff wurde im gleichen Analysengang mit dem organischen Kohlenstoff im $\mathrm{C}, \mathrm{H}, \mathrm{N}$-Analyzer bestimmt.

\subsection{Gesamteisen und Gesamtmangan}

Das Eisen und das Mangan im Sediment wurden mit dem Atomabsorptions-Spektrophotometer (Flammenmethode) bestimmt. Zur Vorbehandlung wurden etwa $0,1 \mathrm{~g}$ Trockensubstanz mit $2 \mathrm{ml}$ konz. Salzsäure versetzt, anschliessend während 5 Minuten auf dem Dampfbad erhitzt und dann auf $100 \mathrm{ml}$ Probelösung verdünnt.

\subsection{Biologische Untersuchungsmethoden}

3.41 Quantitative Erfassung des Phytoplanktons und Ermittlung der Biomasse

Während im Rotsee die Planktonproben aus allen Tiefenstufen (vgl. S. 75) berücksichtigt wurden, stellte man von denjenigen der Horwer Bucht Mischproben, entsprechend den Wassersäulen über den Sedimentationsstufen, wie folgt her:

$$
\text { 0-7,5 m, 7,5-15 m, 15-25 m, 25-45 m, 45-60 m }
$$

Die Planktonproben wurden mit Lugol fixiert (vgl. Schwoerbel [99], S. 65), in Röhrenkammern $\left(50 \mathrm{~cm}^{3}\right)$ eingefüllt und nach mindestens 48 Stunden Absetzzeit im Umkehrmikroskop nach UTERMÖHL [120] ausgezählt. Úber die statistische Genauigkeit dieser Methode informiert die Arbeit von Uehlinger [118]. Die Proben aus dem Rotsee mussten infolge der hohen Zelldichten 5mal, die Sedimentproben 100-bis $500 \mathrm{mal}$ verdünnt werden.

Die Berechnung der Biomasse erfolgte durch Summierung der Zellvolumina der einzelnen Arten [59]. Die Zellvolumina wurden durch eigene Ausmessungen und gestützt auf Literaturangaben von PAvoni [81] und NAUWERCK [67] ermittelt.

\subsection{Primärproduktion}

Die Primärproduktion wurde mit der C ${ }^{14}$-Methode nach SteEmann Nielsen [104] gemessen. Die 125-ml-Expositionsflaschen wurden von 10 bis 14 Uhr in den entsprechenden Tiefenstufen exponiert. Die Vorbereitung und Weiterverarbeitung der Proben erfolgten nach der bei STADELMANN [101] und SchEGG [93] angeführten Vorschrift.

\subsection{Bakterien}

Die bakteriologischen Untersuchungen erfolgten nach der Plattenmethode und der Membranfiltermethọde [93]. 


\subsection{Sedimentationsmessungen}

Mit Hilfe von selbstkonstruierten Auffanggefässen aus PVC (Abb. 2) wurde das herabsinkende Material in den auf Seite 75 angegebenen Tiefenstufen gesammelt. Die Aufhängevorrichtung ist aus Abb. 3 ersichtlich. Die Expositionszeit betrug durchschnittlich 14 Tage (vgl. Tab. 3).



Abb. 2. Sedimentiergefäss aus PVC.

Innendurchmesser $14 \mathrm{~cm}$, Höhe $50 \mathrm{~cm}$, Wanddicke $1 \mathrm{~cm}$, Inhalt 7,7 1 , Gewicht 3,6 kg; montiert an Aluminiumstange, Länge $130 \mathrm{~cm}$.

Fig. 2. Sedimentation vessel made of PVC.

Inside diameter $14 \mathrm{~cm}$, height $50 \mathrm{~cm}$, wall thickness $1 \mathrm{~cm}$, volume 7.71 , weight $3.6 \mathrm{~kg}$; fitted on a rod of aluminium, length $130 \mathrm{~cm}$.

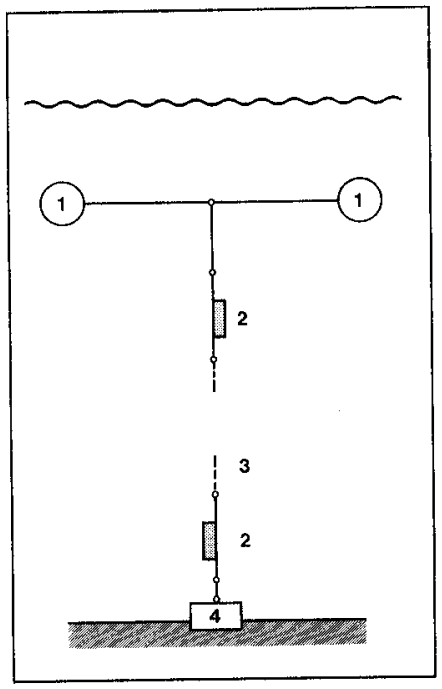

Abb. 3. Aufhängevorrichtung der Sedimentiergefässe. 1 Schwimmkörper, 2 Auffanggerät, 3 Tragleine aus Nylon, 4 Ankergewicht.

Fig. 3. Mechanism for rigging the sedimentation vessels. 1 buoy, 2 sedimentation vessel, 3 nylon rope, 4 anchor weight. 
Diese Versuchsanordnung erlaubt eine horizontale Auffangfläche und eine stabile Aufhängung ([90], S. 57 f., [68]). Die Schwimmbojen wurden mit einem Seil markiert, das, mit einigen Gewichten beschwert, am Seegrund bis ans Ufer führte [111]. Auf einen Schliessmechanismus $[111,52,51,68]$ wurde verzichtet, da übereinstimmend mit anderen Autoren [51, 117, 47] während des Heraufziehens der Gefässe niemals ein Aufwirbeln des Bodensatzes festgestellt werden konnte. Um während der Expositionszeit das Eindringen von Fischen zu verhindern, wurde ein von Thomas [113, 114] empfohlenes Gitter (Nylonnet $z$, Maschenweite $3360 \mu$ ) über der Öffnung befestigt.

Der Auffangmethodik mittels Sedimentationsgefässen haften einige mehr oder weniger unvermeidbare Schwächen an. Als "Trichtereffekt» bezeichnet man die Erscheinung, dass in den tieferen Schichten regelmässig mehr Sinkstoffe anfallen [73]; er wird im wesentlichen von der Morphologie des Seebeckens beeinflusst und ist deshalb in den trogförmigen Becken der Horwer Bucht und des Rotsees kaum von grosser Bedeutung. Dass sich die Sedimentiergefässe als «Sedimentfallen» auswirken ([38], S.403f., [112]), beruht auf der Tatsache, dass die von den Gefässen bewirkte Wasserberuhigung eine künstlich gesteigerte Sedimentation bewirken kann. Schliesslich sind infolge der relativen Abgeschlossenheit der Gefässe und den dadurch entstehenden besonderen Bedingungen [42] Mineralisierungseffekte und damit unnatürliche chemische Veränderungen der Sedimente nicht völlig auszuschliessen. KLEEREKOPER [52] versuchte, mit einem sehr flachen und grossen Sedimentationsgerät (Fläche $1 \mathrm{~m}^{2}$, Höhe $5 \mathrm{~cm}$ ) diese bei engen und tiefen Sedimentiergefässen auftretenden Fehler auszuschalten. In den vorliegenden Verhältnissen war der Mineralisationseffekt, der durch kurze Probenahmeintervalle möglichst klein gehalten wurde, unbedeutend. Untersuchungen am überstehenden Gefässwasser [10] ergaben keine Phosphatanreicherung; ein wesentlicher P-Abbau im aufgefangenen Sediment ist somit auszuschliessen. Damit wurden die Ergebnisse von THomas [112] bestätigt. Eigene Versuche, mit Bakterizidbeigaben den bakteriellen Abbau im Gefäss zu unterbinden, führten zu Störungen in der chemischen Sedimentanalyse.

\section{Chemie des Wassers und des Sedimentes}

Eine generelle Charakterisierung der beiden untersuchten Seen findet sich schon in den Arbeiten von Stadelmann [101] und Schegg [93]. Während Parameter wie Temperatur, Lichtverhältnisse, Sichttiefe und Sauerstoffgehalt zum allgemeinen Untersuchungsprogramm gehörten, brachte ScHEGG in diesem Zusammenhang zusätzlich meteorologische Daten, und Stadelmann befasste sich ausführlich mit den Stickstoffkomponenten Nitrat, Nitrit, Ammonium und partikulärem N. Neu zu diesen schon publizierten Daten kommen nun Leitfähigkeit $\left(\varkappa_{20}\right), \mathrm{pH}$, Karbonathärte (SBV) und Kieselsäure $\left(\mathrm{SiO}_{2}\right)$ hinzu, und zudem soll im speziellen auf die Phosphor- und Eisenkomponenten näher eingegangen werden.

\subsection{Charakterisierung des Vierwaldstättersees (Horwer Bucht)}

Im Vierwaldstättersee sind sowohl die Schichtungs- wie die Trophieverhältnisse in den einzelnen Seebecken sehr unterschiedlich [5]. Die Horwer Bucht ist dem temperierten, dimiktischen Seetyp zuzuordnen, obwohl die Herbst- und Frühlingszirkulationen nur selten durch eine ausgeprägte inverse Schichtung voneinander getrennt 
sind (vgl. auch [31]). Aufgrund der Morphologie (Tab. 1) war die Horwer Bucht ur. sprünglich oligotroph [110]; im Zeitpunkt der Untersuchungen befand sie sich jedoch infolge der massiven menschlichen Einflüsse im mesotrophen Zustand [125].

\subsection{Gesamtsalzgehalt $\left(\varkappa_{20}\right)$ und Temperatur}

Die Leitfähigkeitswerte (Abb. 4) im Vierwaldstättersee schwankten zwischen 166 und $205 \mu \mathrm{S} / \mathrm{cm}$. Sie waren nur von der Alkalinität (SBV) abhängig und zeigten keine Korrelation mit irgendeinem der Produktionsparameter ([93], S.449). Die Frühlingsund Herbstvollzirkulation sind gut zu erkennen und decken sich sehr genau mit den Isothermen (Abb. 5, nach [101] und [93]).

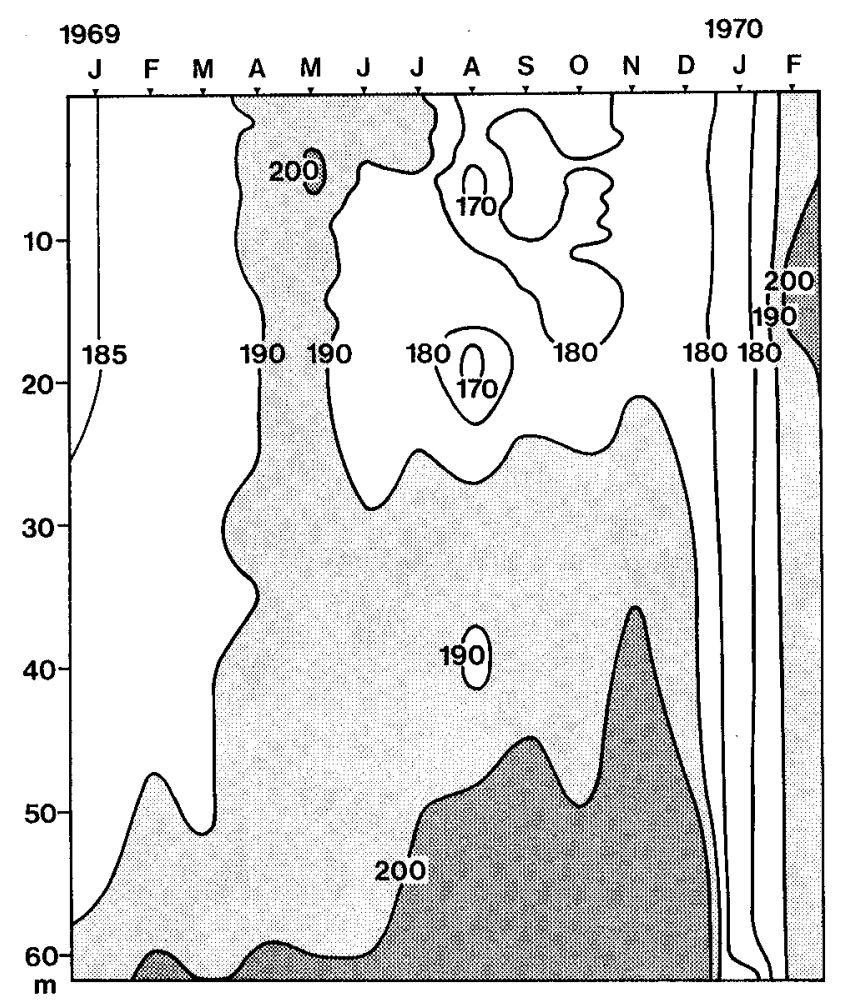

Abb. 4. Elektrische Leitfähigkeit $\left(\varkappa_{2_{0}}\right)$ der Horwer Bucht $(\mu S / \mathrm{cm})$. Fig. 4. Specific conductance (= conductivity) $\left(\varkappa_{20}\right)$ in Horw Bay ( $\mu$ mho).

Die Temperatur (Abb. 5) betrug während der Vollzirkulation (Januar, Februar) $4,5^{\circ} \mathrm{C}$ und erreichte während der Sommerstagnation im August mit $22,7^{\circ} \mathrm{C}$ ihren Höchstwert. Die Stabilität der thermischen Schichtung (Ausbildung des Epilimnions) stieg vom April bis Mai sprungartig an, erreichte im August das Maximum und dauerte bis Ende Oktober (vgl. [101], Abb. 7 und [93], Abb. 8).

\subsection{Lichtverhältnisse und Sichttiefe}

Die Lichtverhältnisse geben Aufschluss über die Mächtigkeit der euphotischen (trophogenen) Schicht. RodHE [88] definiert die Kompensationstiefe mit der 1\%Eindringtiefe des grünen Lichtes (VG 9). Diese 1\%-Grenze des grünen Lichtes, das 


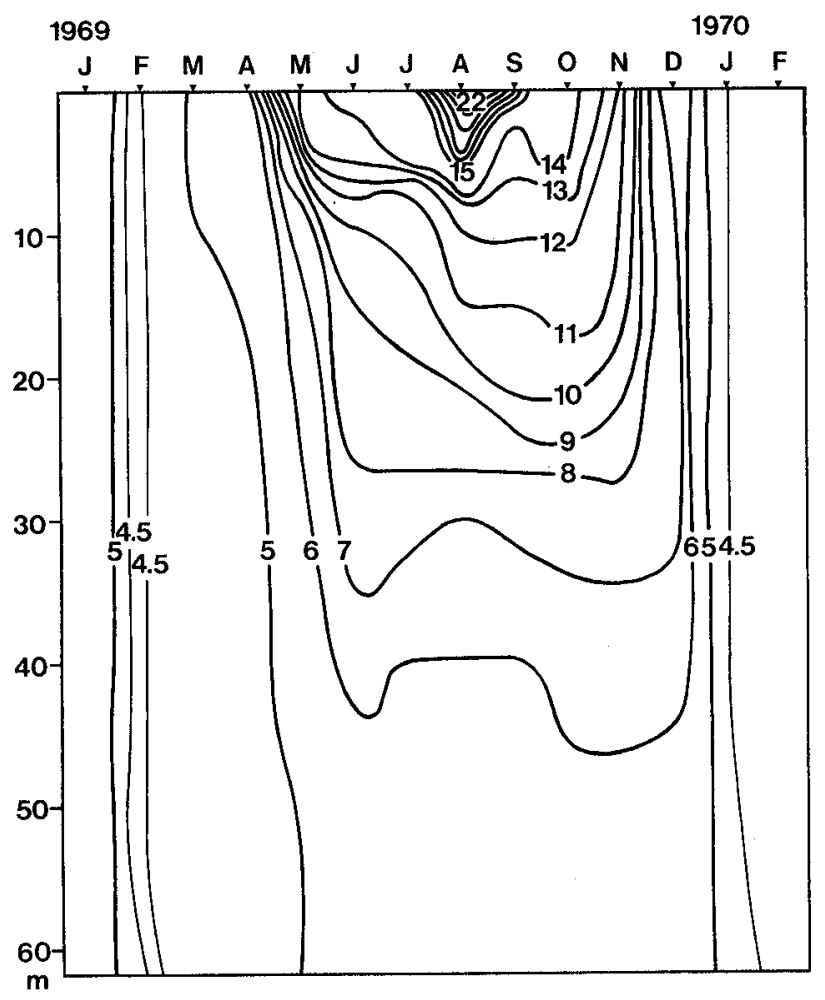

Abb. 5. Isothermen der Horwer Bucht $\left({ }^{\circ} \mathrm{C}\right)$. Nach $[101,93]$.

Fig. 5. Isotherms in Horw Bay $\left({ }^{\circ} \mathrm{C}\right)$. Adapted from $[101,93]$.

tiefer als Blau und Rot eindrang, lag in der Horwer Bucht zwischen 4,3 m (September 1969) und 19,0 m (Januar 1970). Da die Eindringtiefe sehr variabel ist, wurde die Grenze der trophogenen Schicht für die Horwer Bucht auf $15 \mathrm{~m}$ festgelegt. In der Arbeit Stadelmanns [101] sind die Lichtwerte tabellarisch zusammengestellt, bei SCHEGG [93] finden sich Graphiken der grünen Komponente.

Die Sichttiefe betrug in der Horwer Bucht 1,7 m (September 1969) bis 8,5 m (Januar 1970) und fiel mehr oder weniger mit VG $920 \%$ zusammen (vgl. [93]).

\subsection{Karbonathärte (SBV oder Alkalinität) und pH}

Die Alkalinität (SBV) (Abb. 6) war relativ niedrig und bewegte sich wie die Leitfähigkeit in engen Grenzen (1,6-2,0 mval/1). Sie machte im Durchschnitt $80 \%$ des Gesamtsalzgehaltes aus (Berechnung nach Rutrner [90], S. 74).

Der $p H$-Wert (Tab. 4), dem SBV generell entgegengesetzt, variierte zwischen $\mathrm{pH}$ 7,5 im Hypolimnion und $\mathrm{pH} 8,8$ im Epilimnion.

\subsection{Sauerstoff}

Die Sauerstoffverteilung (Abb. 7, nach [101] und [93]) erlaubt eine grobe Abschätzung der Produktionsverhältnisse in der Horwer Bucht. Während der Sommerstagnation kam es im Epilimnion zu geringen Übersättigungen; die hypolimnische $\mathrm{O}_{2}$-Zehrung betrug in dieser Zeitspanne nur $5 \mathrm{mg} \mathrm{O} / \mathrm{l}$. Daraus kann gefolgert werden, dass die Produktion mittelgross war. 


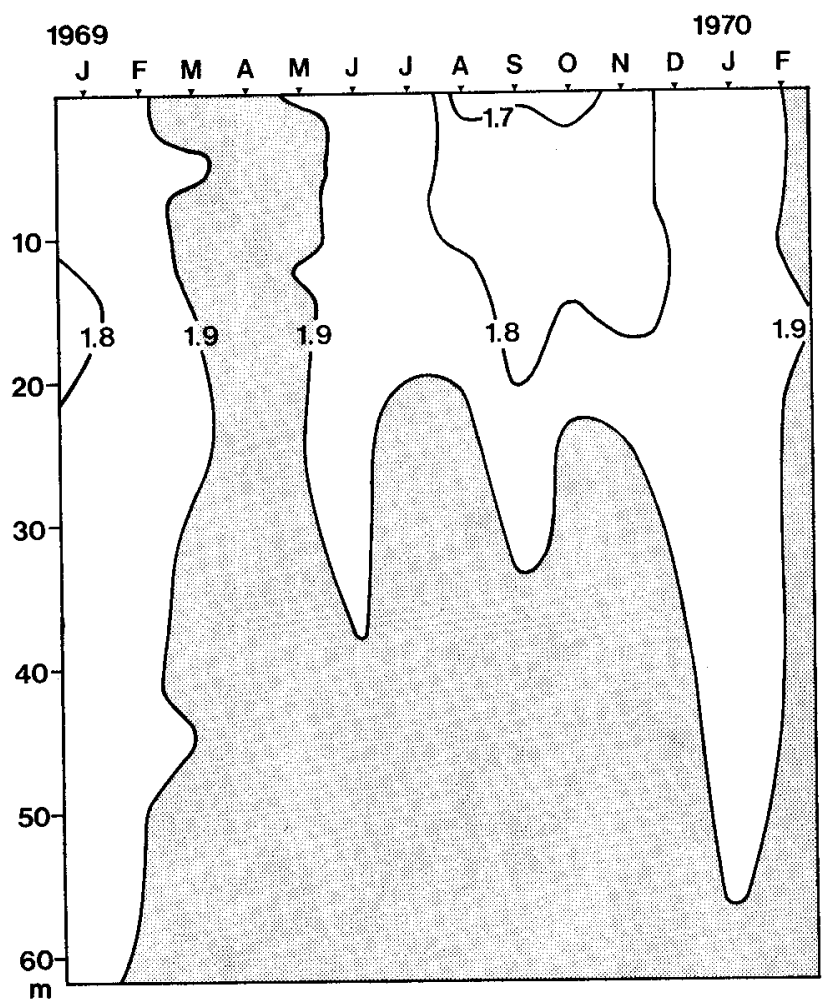

Abb. 6. Alkalinität (SBV) der Horwer Bucht (mval/1).

Fig. 6. Alkalinity in Horw Bay (mval/l).

Tabelle 4. pH-Werte, Horwer Bucht.

Table 4. $\mathrm{pH}$ values, Horw Bay.

\begin{tabular}{|c|c|c|c|c|c|c|c|c|c|c|c|c|c|c|}
\hline $\begin{array}{l}\text { Tiefe } \\
\mathrm{m}\end{array}$ & $\begin{array}{l}1969 \\
23.1\end{array}$ & 19.2 & 18.3 & 17.4 & 20.5 & 17.6 & 8.7 & 6.8 & 9.9. & 7.10 . & 4.11 & 2.12 & $\begin{array}{l}1970 \\
6.1\end{array}$ & 24.2. \\
\hline 0 & 8,0 & 8,0 & 8,2 & 8,1 & 8,7 & 8,5 & 8,7 & 8,6 & 8,8 & 8,7 & 8,2 & 8,0 & 7,8 & 7,9 \\
\hline 2,5 & 8,1 & 8,1 & 8,2 & 8,2 & 8,7 & 8,5 & 8,7 & 8,6 & 8,6 & 8,7 & 8,2 & 8,0 & - & - \\
\hline 5 & 8,0 & 8,1 & 8,1 & 8,2 & 8,4 & 8,2 & 8,2 & 8,7 & 8,4 & 8,5 & 8,2 & 8,0 & 7,8 & 7,9 \\
\hline 7,5 & 8,0 & 8,1 & 8,2 & 8,4 & 8,2 & 7,9 & 8,2 & 8,8 & 8,1 & 7,7 & 8,2 & 8,0 & - & - \\
\hline 10 & 8,0 & 8,1 & 8,2 & 8,3 & 8,2 & 7,9 & 8,1 & 8,8 & 8,0 & 7,7 & 8,2 & 7,9 & 8,0 & 7,9 \\
\hline 12,5 & 8,0 & 8,1 & 8,2 & 8,3 & 8,2 & 7,9 & 8,0 & 8,3 & 7,9 & 7,7 & 8,0 & 8,0 & - & - \\
\hline 15 & 8,0 & 8,1 & 8,2 & 8,2 & 8,1 & 7,8 & 7,9 & 7,9 & 7,8 & 7,6 & 7,6 & 8,0 & - & 7,8 \\
\hline 25 & 8,1 & 8,1 & 8,1 & 8,2 & 8,1 & 7,9 & 7,9 & 7,8 & 7,8 & 7,6 & 7,6 & 8,0 & - & 7,9 \\
\hline 35 & 8,1 & 8,1 & 8,1 & 8,1 & 8,1 & 7,8 & 7,9 & 7,8 & 7,8 & 7,7 & 7,6 & 7,7 & 8,0 & 7,9 \\
\hline 45 & 8,0 & 8,1 & 8,1 & 8,1 & 8,0 & 7,9 & 7,8 & 7,7 & 7,8 & 7,6 & 7,6 & 7,6 & 8,0 & 7,9 \\
\hline 60 & 8,0 & 8,1 & 8,2 & 8,1 & 7,9 & 7,6 & 7,8 & 7,8 & 7,7 & 7,6 & 7,5 & 7,6 & 7,8 & 7,9 \\
\hline $62=\mathrm{G}$ & 7,9 & 7,9 & 8,2 & 8,1 & 7,9 & - & - & 7,5 & - & - & 7,5 & - & - & - \\
\hline
\end{tabular}

\subsection{Phosphor}

Da das Phosphat im Vierwaldstättersee meistens wachstumsbegrenzender Faktor ist $[31,32,101]$, können die P-Gehalte des Seewassers weitere Aufschlüsse hinsichtlich der Produktion geben. 


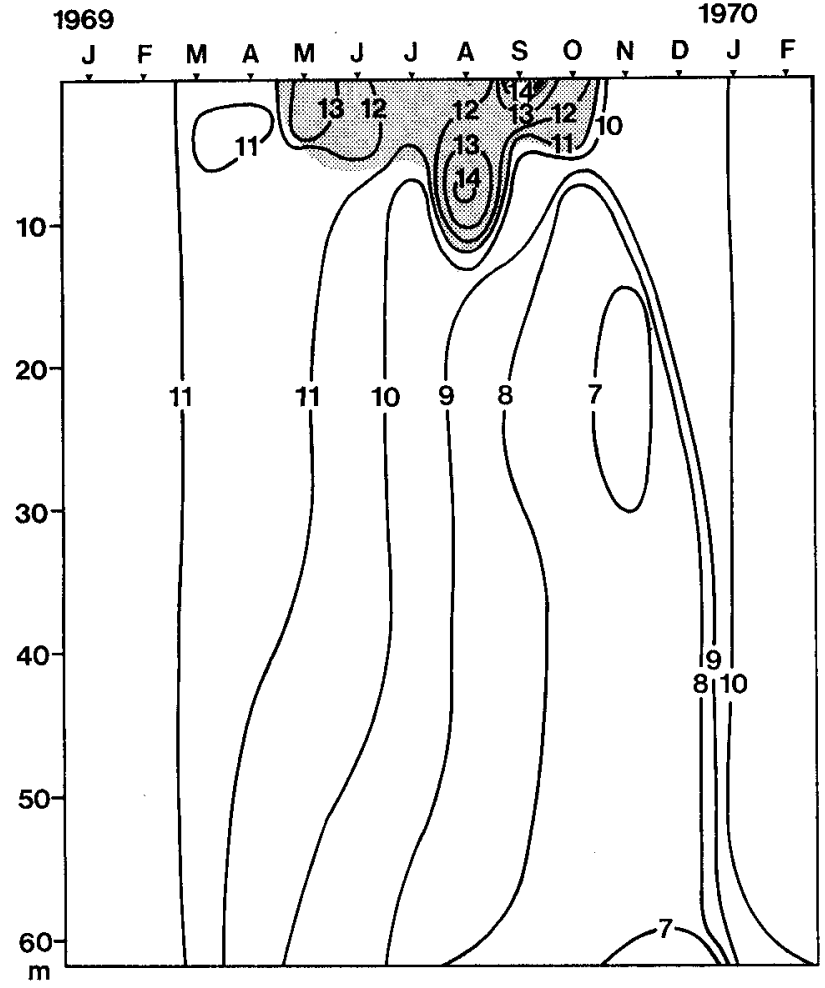

Abb, 7. Sauerstoff der Horwer Bucht ( $\left.\mathrm{mg} \mathrm{O}_{2} / 1\right)$. Schwacher Raster $>100 \%$ Sättigung, starker Raster $>150 \%$ Sättigung. Nach $[101,93]$.

Fig. 7. Oxygen in Horw Bay (mg $\left.\mathrm{O}_{2} / 1\right)$. Light shading $>100 \%$ saturation, heavy shading $>150 \%$ saturation. Adapted from $[101,93]$.

In der Horwer Bucht betrugen die Gesamtphosphorkonzentrationen 10-50 $\mu \mathrm{g} / 1$ (Abb. 8). Im Mai und im September-Oktober wurden die Maxima im Epilimnion, im März und vom August bis Dezember im untersten Hypolimnion erreicht, während sich vom Mai bis Dezember in 10-40 m Tiefe eine Zone vermehrter Zehrung mit den Minimalwerten im Oktober ausbildete. Dieses metalimnische Gesamt-P-Minimum in der Horwer Bucht wurde schon von GÄCHTER [31] festgestellt.

Die epilimnischen Gesamt-P-Isopleten werden durch den partikulären Phosphor (Abb. 9) geprägt, welcher in beiden Maxima Werte über $30 \mu \mathrm{g} / \mathrm{l}$ erreichte und damit die Produktionsdynamik im See andeutet. Wie die Planktonuntersuchungen (vgl. 5.1, S. 117 ff.) zeigen, wurde das Frühlingsmaximum vor allem durch Grünalgen und Flagellaten, das Herbstmaximum vor allem durch Blaualgen (Oscillatoria rubescens) hervorgerufen. Das Hypolimnion war an partikulärem $P$ verarmt, was zum Teil auf Abbauvorgänge zurückzuführen ist; die relativ hohen Werte über Grund im Oktober rührten wahrscheinlich von abgesunkenen Oscillatoriafäden her (vgl. 5.12, S. 117).

Das dem partikulären P entgegengesetzte Bild zeigte das Phosphat (Abb. 10), welches im Epilimnion mit fortschreitender Jahreszeit vom Phytoplankton sukzessive aufgezehrt wurde. Im September sanken die Werte auf 0,0, und auch die 2,5 $\mu \mathrm{g} / 1$-Isoplete lag erstaunlich tief. Dagegen ergaben sich durch Destruktion im Hypolimnion die bekannten Phosphatanreicherungen, die sich in der Horwer Bucht jedoch in bescheidenem Rahmen hielten (nur 1 Wert über $30 \mu \mathrm{g} / \mathrm{l}$ ). 




Abb. 8. Gesamtphosphorkonzentrationen der Horwer Bucht ( $\mu$ g Gesamt-P/l). Fig. 8. Total phosphorus concentration in Horw Bay ( $\mu$ g $\left.P_{\text {tot }} / \mathrm{l}\right)$.

Abb. 9. Partikulärer Phosphor der Horwer Bucht ( $\mu \mathrm{g}$ PP/1). Fig. 9. Particulate phosphorus concentration in Horw Bay ( $\mu$ g PP/l).

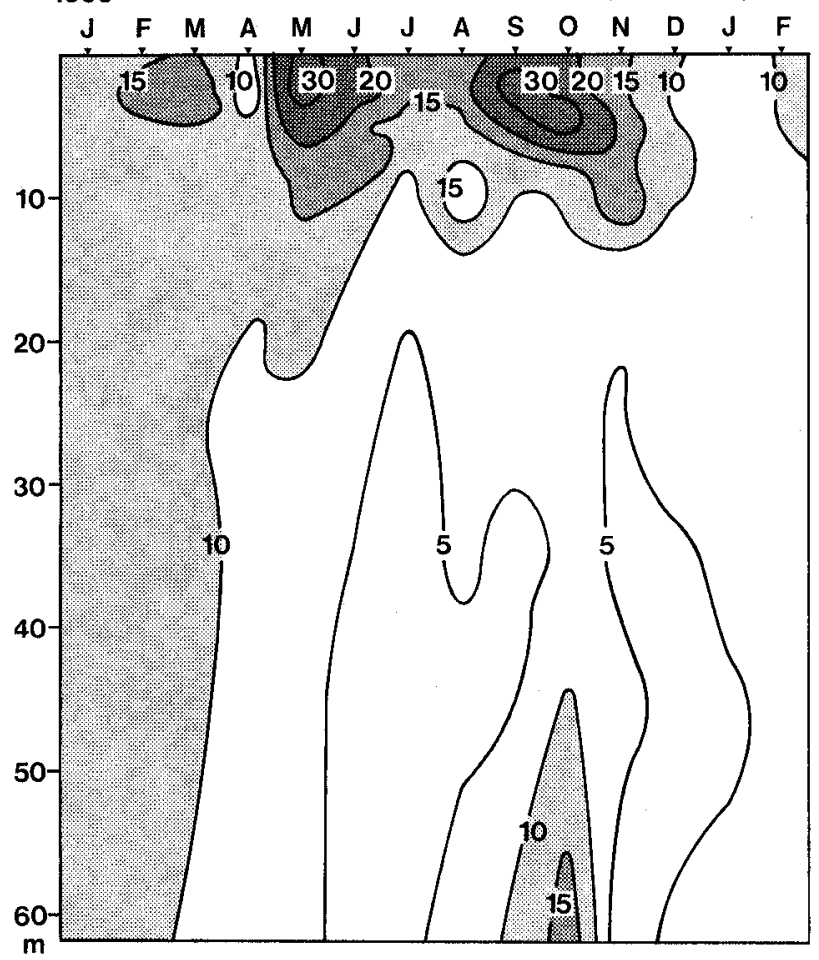




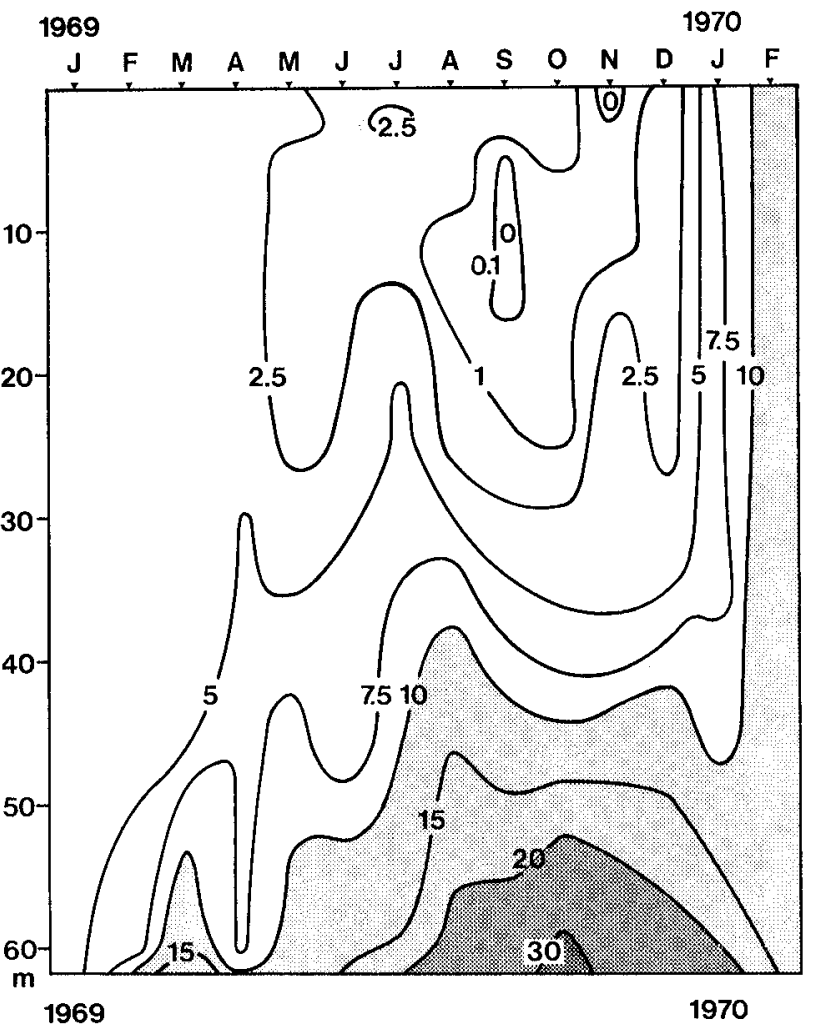

Abb. 10. Orthophosphat der Horwer Bucht ( $\mu \mathrm{g} \mathrm{PO}_{4}-\mathrm{P} / 1$ ). Fig. 10. Ortho-phosphate concentration in Horw Bay $\left(\mu g \mathrm{PO}_{4}-\mathrm{P} / 1\right)$.

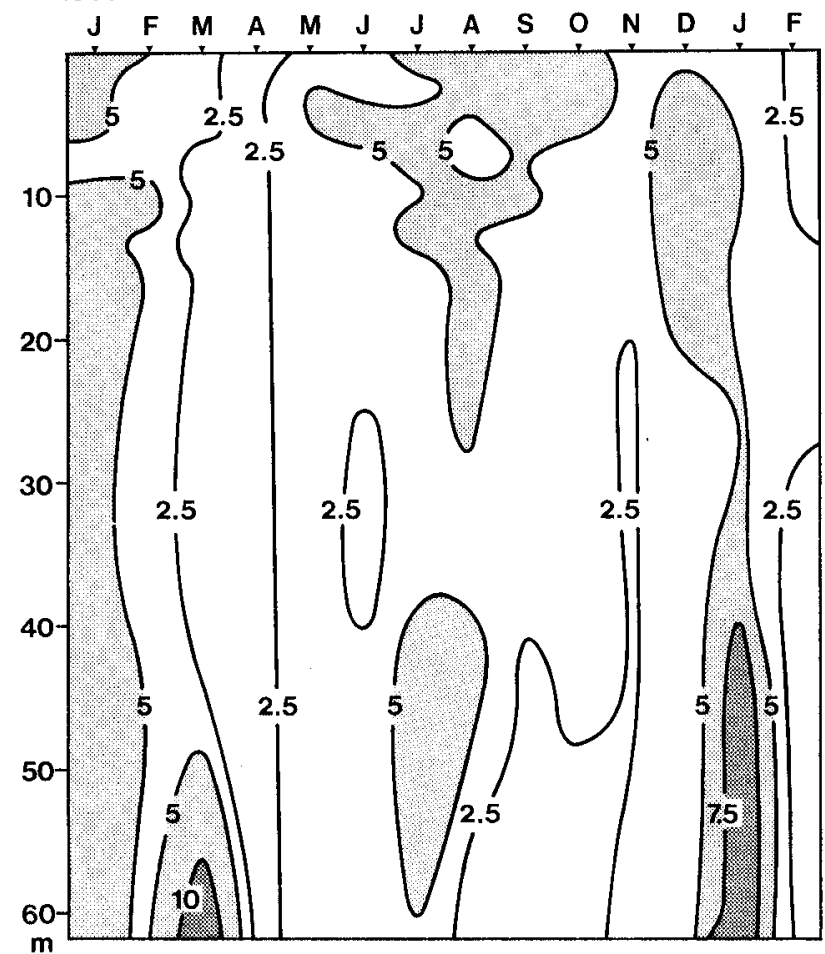

Abb. 11. Gelöste organische Phosphorverbindungen der Horwer Bucht ( $\mu g \mathrm{P} / \mathrm{l}$ ).

Fig. 11. Dissolved organic phosphorus compounds in Horw Bay ( $\mu \mathrm{g} \mathrm{P} / \mathrm{l}$ ). 
Dass nebst dem Orthophosphat auch lösliche organische $P$-Verbindungen von Algen direkt oder indirekt (via bakteriellen Abbau) aufgenommen werden können, wurde schon von vielen Autoren bestätigt $[14,87,1,83,77,36,26]$. Ob die gefundene Verteilung (Abb. 11) der tatsächlich vorhandenen Konzentration an gelöstem organischem $P$ entsprach, ist aus methodischen Gründen nicht sicher [86, 31, 122, 123]. Die Werte waren nicht hoch und schwankten ziemlich unregelmässig zwischen 0,5 und 13,3 $\mu \mathrm{g} / \mathrm{l}$.

\subsection{Stickstoff}

Die N-Komponenten wurden von STADELMANN [101] eingehend untersucht. Es sei hier deshalb nur noch eine knappe Zusammenstellung (Tab. 5) gebracht, die einen Vergleich mit den P-Konzentrationen ermöglichen soll. Die Isopletendarstellungen sind bei STADELMANN zu finden.

Tabelle 5. N-Komponenten, Horwer Bucht. Aus [101].

Table 5. N components, Horw Bay. From [101].

\begin{tabular}{llll}
\hline N-Komponente & $\begin{array}{l}\text { Basiskonzentration } \\
\text { (Zirkulation) }\end{array}$ & $\begin{array}{l}\text { Konzentration am Ende } \\
\text { der Stagnation im } \\
\text { Epilimnion } \\
\mu g / 1\end{array}$ & $\begin{array}{l}\text { Maximale } \\
\text { Konzentration in } \\
\text { Hypolimnion } \\
\mu \mathrm{g} / \mathrm{l}\end{array}$ \\
\hline $\mathrm{NO}_{3} \mathrm{M} / \mathrm{N}$ & $300-440$ & $5-28$ & 460 \\
$\mathrm{NO}_{\mathbf{2}} \mathrm{-N}$ & $0,2-1,2$ & $0-1,0$ & 11,4 \\
$\mathrm{NH}_{\mathbf{4}}-\mathrm{N}$ & $0-10$ & $0-60$ & $70-90$ \\
Partikulärer $\mathrm{N}$ & $40-120$ & $200-390$ & $5-60$ \\
Gelöster organischer & & & \\
Kjeldahl-N & $60-170$ & $60-90$ & $160-170$ \\
\hline
\end{tabular}

\subsection{Eisen}

Die Gesamteisenkonzentrationen im Rohwasser (Abb. 12) lagen im Vierwaldstättersee grösstenteils zwischen 15 und $60 \mu \mathrm{g} / \mathrm{l}$. Ihre Verteilung, die sich weitgehend mit derjenigen des partikulären Eisens (Abb. 13) deckte, zeigte im Sommer ein ausgeprägtes epilimnisches Maximum. Im Hypolimnion folgte einem Minimum im Juni-Juli unmittelbar ein Maximum von August bis Oktober.

Das gelöste Eisen (Abb. 14) erreichte nur sehr selten Werte über $10 \mu g / 1$. Die Isopleten verlaufen recht unübersichtlich und korrelieren schlecht mit anderen Parametern [93]. Insbesondere der gestörte Zusammenhang mit dem Sauerstoff, aber auch die Tatsache, dass sich das partikuläre Eisen nicht gegenläufig zum gelösten Eisen verhält, sind mit grosser Wahrscheinlichkeit auf die methodische Schwierigkeit zurückzuführen, das gelöste Eisen analytisch quantitativ vom partikulären Eisen abzutrennen $[102,12]$.

\subsection{Kieselsäure $\left(\mathrm{SiO}_{2}\right)$}

Wie das Phosphat wird auch die Kieselsäure $\mathrm{SiO}_{2}$ (Abb. 15) im Epilimnion stark aufgezehrt (die Konzentrationen sinken von Juli bis September unter 0,5 mg/l) und im Hypolimnion angereichert (Maxima im Herbst bei $62 \mathrm{~m}$ Tiefe um $3 \mathrm{mg} / \mathrm{l}$ ). Dieses 




Abb. 12. Gesamteisen-

konzentrationen der Horwer Bucht ( $\mu$ g Gesamt-Fe/l).

Fig. 12. Total iron concentration in Horw Bay ( $\mu \mathrm{g} \mathrm{Fe} \mathrm{F}_{\text {tot }} / \mathrm{l}$ ).

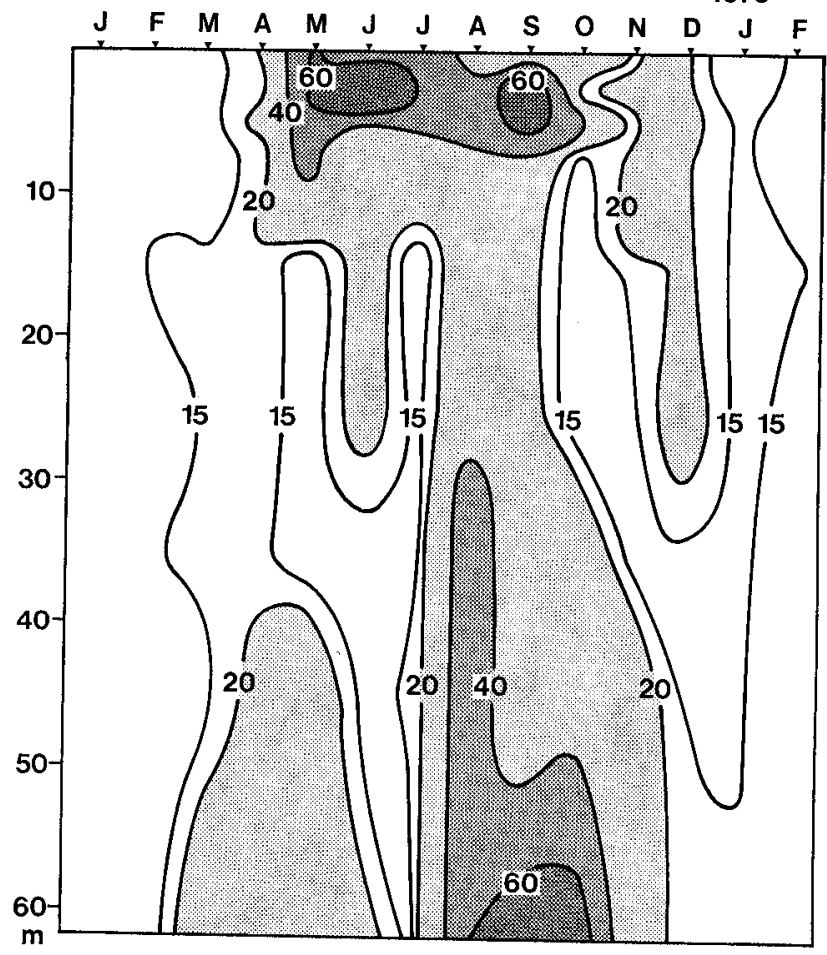

Abb. 13. Partikuläres Eisen der Horwer Bucht ( $\mu \mathrm{g}$ PFe/l). Fig. 13. Particulate iron concentration in Horw Bay ( $\mu \mathrm{g} \mathrm{PFe} / \mathrm{I}$ ). 


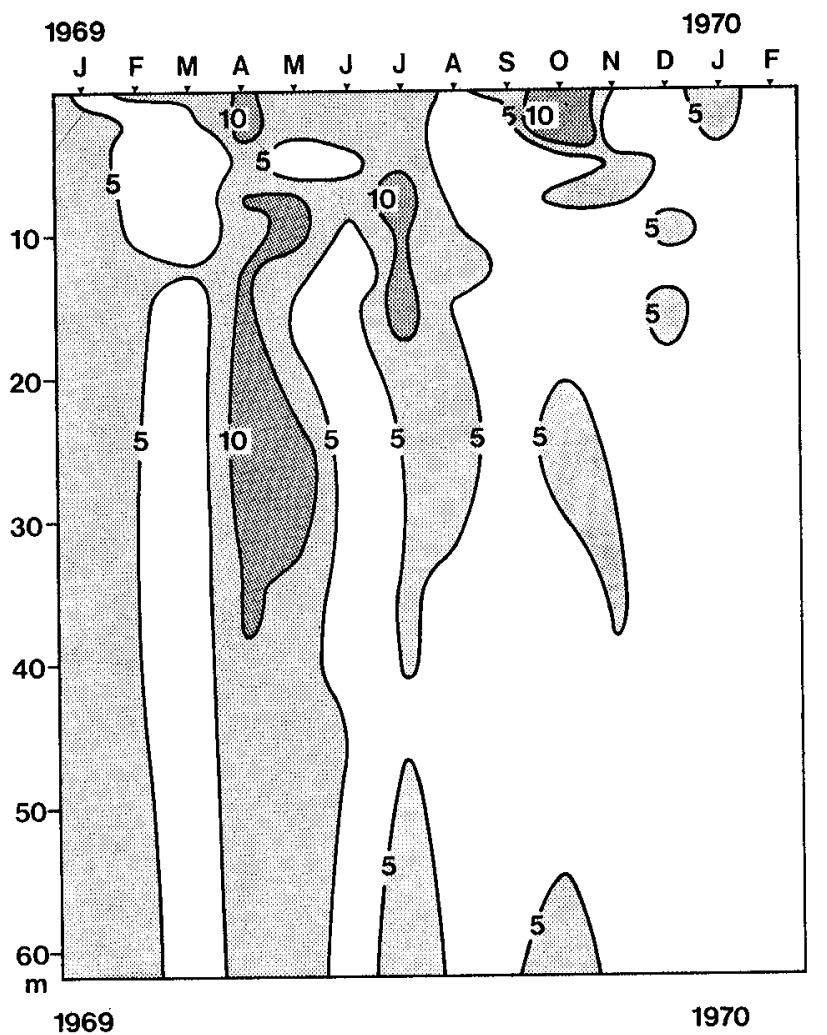

Abb. 14. Gelöstes Eisen der Horwer Bucht ( $\mu \mathrm{g} \mathrm{Fe} / 1)$.

Fig. 14. Dissolved iron concentration in Horw Bay ( $\mu \mathrm{g} \mathrm{Fe} / 1$ ).

Abb. 15. Kieselsäure $\left(\mathrm{SiO}_{2}\right)$ der Horwer Bucht (mg $\left.\mathrm{SiO}_{2} / 1\right)$. Fig. 15. Silicic acid $\left(\mathrm{SiO}_{2}\right)$ concentration in Horw Bay (mg SiO $2 / 1)$.

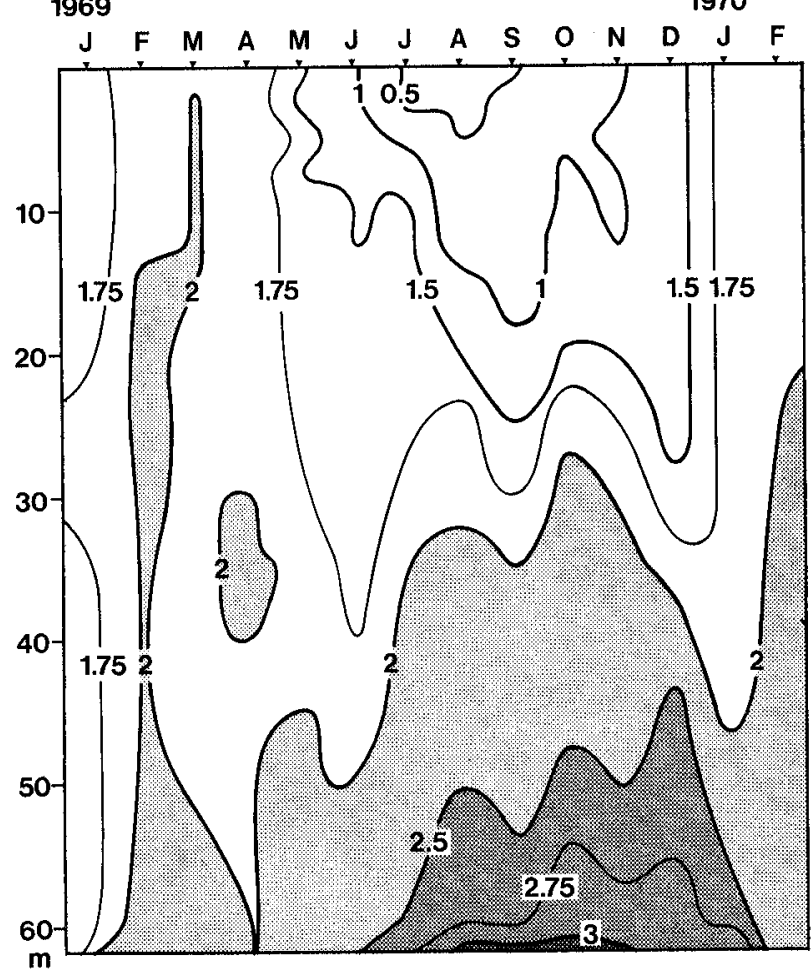


typische Verteilungsbild steht in offensichtlichem Zusammenhang mit den Diatomeen, die im Vierwaldstättersee eine dominierende Rolle spielen (vgl. Planktonuntersuchungen 5.17, S. 124).

\subsection{Sedimentation im Vierwaldstättersee (Horwer Bucht)}

4.21 Sedimentationsraten (Trockensubstanz)

Die Sedimentationsraten (Tab. 6) erreichten im Vierwaldstättersee Trockengewichtswerte von 0,1 bis $10,9 \mathrm{~g} / \mathrm{m}^{2}$. Tag. Sie widerspiegeln deutlich das produktionsbiologische Geschehen im Epilimnion und zeigten im Juni und August zwei Maxima, die gegenüber den entsprechenden Produktionsspitzen vom Mai bzw. August bis Oktober zeitlich nur wenig verschoben waren (Abb. 16). Während der hochproduktiven Sommerstagnation (Mai bis Oktober) lagen die Sedimentationsraten über $2 \mathrm{~g} / \mathrm{m}^{2} \cdot \mathrm{Tag}$, in den Zirkulationsperioden sanken sie meistens unter $1 \mathrm{~g} / \mathrm{m}^{2} \cdot \mathrm{Tag}$.

Die Unterschiede in der Tiefenverteilung waren unregelmässig und relativ gering, . jedoch wurden in $60 \mathrm{~m}$ meist grössere Raten als in 7,5 $\mathrm{m}$ festgestellt. Dies kann einerseits auf die Auswirkungen des "Trichtereffektes» [73] zurückgeführt, andrerseits durch Produktion oder Einschwemmung von Sedimentgut unterhalb 7,5 m erklärt werden.

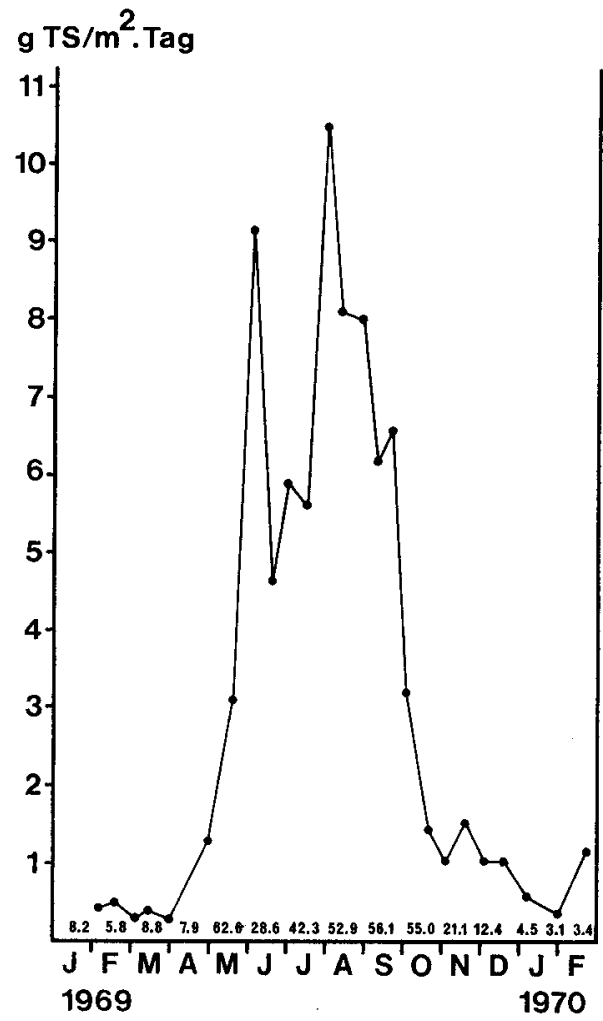

Abb. 16. Sedimentationsraten, Horwer Bucht, in $\mathrm{g} \mathrm{TS} / \mathrm{m}^{2} \cdot$ Tag (Durchschnittswerte der Stufen 7,5-60 m).

Zahlen unter der Kurve = maximale monatliche Photosyntheseraten in $\mathrm{mg} \mathrm{C}_{\text {ass }} / \mathrm{m}^{3} \cdot \mathrm{h}$, aus Stadelmann [101], S. 35.

Fig. 16. Rates of sedimentation, Horw Bay, in $\mathrm{g}$ of dry matter $/ \mathrm{m}^{2}$. day (average values of the levels $7.5-60 \mathrm{~m}$ ).

Numbers below the curve correspond to maximum monthly rates of photosynthesis in $\mathrm{mg} \mathrm{C}_{\text {ass }} / \mathrm{m}^{3} \cdot$ hour, from STADELMANN [101], p. 35. 
Tabelle 6. Sedimentationsraten, Horwer Bucht, in $\mathrm{g} \mathrm{TS} / \mathrm{m}^{2} \cdot$ Tag.

Table 6. Rates of sedimentation, Horw Bay, in $\mathrm{g}$ of dry matter $/ \mathrm{m}^{2} \cdot$ day.

\begin{tabular}{lllllllllllll}
\hline $\begin{array}{l}\text { Tiefe } \\
\mathrm{m}\end{array}$ & $\begin{array}{l}1969 \\
\mathbf{6 . 2} .\end{array}$ & $\mathbf{1 9 . 2 .}$ & $\mathbf{5 . 3}$ & $\mathbf{1 7 . 3 .}$ & 1.4. & 30.4 & 19.5. & 3.6. & 18.6. & 30.6. & $\mathbf{1 5 . 7 .}$ & 29.7. \\
\hline 7,5 & 0,420 & 0,490 & 0,295 & 0,233 & 0,309 & 0,756 & 3,455 & 8,312 & 4,732 & 6,275 & 4,774 & $\mathbf{1 0 , 1 7 5}$ \\
15 & 0,416 & 0,410 & 0,285 & - & 0,221 & 0,897 & 3,368 & 8,696 & 4,739 & 6,328 & $\mathbf{5 , 6 1 0}$ & $\mathbf{1 0 , 9 3 3}$ \\
25 & 0,429 & 0,460 & 0,247 & 0,306 & 0,328 & 1,019 & 3,116 & 10,055 & 4,567 & 5,475 & 5,782 & 10,601 \\
45 & 0,443 & 0,545 & 0,285 & - & 0,464 & 1,221 & 2,634 & 9,463 & 4,432 & 5,380 & 5,824 & 9,897 \\
60 & 0,504 & 0,683 & 0,365 & 0,474 & 0,104 & 2,571 & 2,909 & 9,225 & 4,767 & 6,022 & 6,116 & 10,751
\end{tabular}

Tiefe 1969

1970

$\mathrm{m} \quad$ 11.8. 25.8. 8.9. 22.9. 4.10. 22.10. 3.11. 17.11.3.12. 19.12. 7.1. 30.1. 23.2.

\begin{tabular}{clllllllllllll}
\hline 7,5 & 6,766 & 7,740 & 6,067 & 6,076 & 3,088 & 1,016 & 0,938 & 1,332 & 0,882 & 1,042 & 0,597 & 0,354 & 0,563 \\
15 & 7,911 & 8,112 & 6,260 & 6,473 & 2,919 & 1,248 & 0,999 & 1,571 & 0,942 & 1,060 & 0,547 & 0,352 & 0,639 \\
25 & 7,849 & 8,002 & 5,901 & 6,723 & 3,347 & 1,601 & 1,083 & 1,525 & 1,078 & 1,018 & 0,601 & 0,364 & 0,620 \\
45 & 8,891 & 7,674 & 6,272 & 6,456 & 3,364 & 1,485 & 1,068 & 1,401 & 1,112 & 1,115 & 0,607 & 0,404 & 1,004 \\
60 & 9,147 & 8,578 & 6,407 & 7,290 & 3,414 & 1,925 & 1,210 & 1,844 & 1,263 & 1,040 & 0,618 & 0,424 & 3,050 \\
\hline
\end{tabular}

4.22 Organische Substanz und organischer Kohlenstoff

Der Anteil der organischen Substanz (Glühverlust) (Tab. 7), die vor allem leicht zerstörbare Bestandteile wie Proteine, Reserve-Kohlenwasserstoffe und Fette der sedimentierten Biomasse enthält, betrug im Vierwaldstättersee 6-22\% der Trockensubstanz. Die Werte lassen einen Zusammenhang mit der Thermik und der Produktion erkennen (Tab. 9): Während der Stagnation vom Mai bis Oktober, in welche zu Beginn das absolute Produktionsmaximum fiel, waren die Glühverluste auffallend kleiner als in den Zeiten der Zirkulation. Der "kurzgeschlossene" Stoffkreislauf (das heisst vermehrter Abbau) und eine starke, infolge der erhöhten Produktion bedingte Zunahme der biogenen Entkalkung (siehe 4.24, S. 94) bewirkten diese Abnahme organischer Sedimentbestandteile im Sommer. Die - allerdings ziemlich unregelmässige

Tabelle 7. Organische Substanz (Glühverlust) im Sediment der Horwer Bucht in \% der Trockensubstanz (TS).

Table 7. Organic substance (loss on ignition) in the sediment of Horw Bay in \% of dry matter (TS).

\begin{tabular}{|c|c|c|c|c|c|c|c|c|c|c|c|c|c|}
\hline $\begin{array}{l}\text { Tiefe } \\
\mathrm{m}\end{array}$ & $\begin{array}{l}1969 \\
6.2 .\end{array}$ & 19.2 & 5.3 . & 17.3 & 1.4. & 30.4 & \multicolumn{2}{|c|}{19.5.} & 3.6 . & 18.6. & 30.6 & 15.7. & 29.7 . \\
\hline 7,5 & 17,3 & 17,9 & 18,6 & 18,9 & 18,4 & 15,1 & \multicolumn{2}{|c|}{11,4} & 5,9 & 8,1 & 11,9 & 14,7 & 7,6 \\
\hline 15 & 17,8 & 16,6 & 19,3 & - & 14,2 & 20,0 & \multicolumn{2}{|c|}{12,2} & 6,6 & 8,7 & 10,8 & 13,0 & 8,8 \\
\hline 25 & 16,5 & 16,9 & 16,2 & 21,6 & 17,6 & 20,2 & \multicolumn{2}{|c|}{13,2} & 7,1 & 8,4 & 11,5 & 10,7 & 9,0 \\
\hline 45 & 15,7 & 16,0 & 18,2 & - & 17,3 & 18,4 & \multicolumn{2}{|c|}{15,3} & 6,7 & 8,7 & 12,2 & 10,2 & 7,5 \\
\hline 60 & 16,1 & 14,8 & 22,0 & 20,7 & 17,4 & 16,4 & \multicolumn{2}{|c|}{15,1} & 7,6 & 9,9 & 12,4 & 14,6 & 7,7 \\
\hline Tiefe & 1969 & & & & & & & & & & 1970 & & \\
\hline $\mathrm{m}$ & 11.8. & 25.8 & 8.9. & 22.9. & 4.10. & 22.10 . & 3.11 . & & 1. 3.12 . & 19.12 . & 7.1 . & 30.1 . & 23.2 . \\
\hline 7,5 & 7,8 & 9,2 & 10,7 & 7,6 & 12,3 & 21,4 & 20,4 & & 4 & 14 & $\perp$ & 18,1 & 18,8 \\
\hline 15 & 8,2 & 7,9 & 11,0 & 7,1 & 13,6 & 19,8 & 15,5 & 14 & 18,6 & 15,7 & 17,1 & 19,4 & 17,9 \\
\hline 25 & 8,1 & 8,3 & 12,0 & 8,9 & 13,9 & 18,6 & 15,2 & 14, & 17,6 & 15,4 & 16,9 & 17,7 & 15,8 \\
\hline 45 & 7,7 & 8,6 & 12,5 & 8,7 & 14,5 & 16,7 & 15,7 & 17 & 17,2 & 12,7 & 18,9 & 17,7 & 13,1 \\
\hline 60 & 8,3 & 8,8 & 12,6 & 8,9 & 15,3 & 16,4 & 15,7 & 21 , & 14,6 & 14,3 & 14,5 & 15,8 & 11,2 \\
\hline
\end{tabular}


- Tiefenverteilung bestätigt diese Interpretation insofern, als im Frühling und HerbstWinter eher eine Abnahme nach unten (das heisst Abbau vor allem im Hypolimnion) und im Sommer eher eine Abnahme in den oberen Stufen (das heisst Abbau vor allem im Epilimnion) festzustellen war.

Der organische Kohlenstoff (Tab. 8) verlief im wesentlichen gleich wie der organische Anteil des Sedimentes, weshalb sein prozentualer Anteil an der totalen orga-

Tabelle 8. Organischer Kohlenstoff im Sediment der Horwer Bucht in \% der Trockensubstanz (TS). Table 8. Organic carbon in the sediment of Horw Bay in \% of dry matter (TS).

\begin{tabular}{|c|c|c|c|c|c|c|c|c|c|c|c|c|c|}
\hline $\begin{array}{l}\text { Tiefe } \\
\text { m }\end{array}$ & $\begin{array}{l}1969 \\
6.2 .\end{array}$ & 19. 2 . & 5.3 & 17.3 & 1.4 & 30.4 . & 19.5 & \multicolumn{2}{|c|}{3.6 . } & 18.6 & 30.6 & 15.7 & 29.7 \\
\hline 7,5 & 7,26 & 8,40 & 10,15 & 12,12 & 9,90 & 8,58 & 5,00 & 4,4 & & 4,06 & 4,22 & 5,27 & 3,00 \\
\hline 15 & 6,56 & - & 9,84 & - & - & 8,78 & 4,65 & 4,5 & & 4,50 & 4,56 & 4,94 & 3,69 \\
\hline 25 & 6,71 & 7,81 & - & - & 8,89 & 9,20 & 5,90 & 3,9 & & 4,35 & 5,01 & 4,60 & 3,45 \\
\hline 45 & 6,66 & 7,76 & - & - & 7,27 & 8,35 & 6,45 & 4,6 & & 4,80 & 4,71 & 4,75 & 3,74 \\
\hline 60 & 6,91 & 6,92 & 8,48 & 9,01 & - & 6,60 & 6,43 & 4,1 & & 4,90 & 4,97 & 4,70 & 3,79 \\
\hline Tiefe & 1969 & & & & & & & & & & 1970 & & \\
\hline $\mathrm{m}$ & 11.8 . & 25.8 & 8.9. & 22.9. & 4.10. & 22.10 & 3.11 . & 17.11. & 3.12 . & . 19.12 & 7.1 & 30.1 . & 23.2 \\
\hline 7,5 & 4,52 & 4,91 & 3,90 & 4,17 & 5,59 & 10,34 & 8,73 & 7,05 & 6,69 & 6,51 & 8,26 & 10,94 & 8,47 \\
\hline 15 & 4,72 & 4,31 & 4,20 & 4,52 & 6,17 & 9,01 & 9,03 & 6,95 & 7,15 & 7,42 & 9,45 & 11,79 & 8,89 \\
\hline 25 & 4,47 & 4,61 & 4,50 & 3,26 & 6,60 & 7,88 & 8,98 & 7,21 & 6,18 & 5,55 & 8,36 & 10,49 & 8,00 \\
\hline 45 & 4,07 & 4,51 & 4,30 & 3,66 & 6,89 & 7,58 & 8,98 & 7,00 & 6,59 & 5,10 & 9,10 & 10,70 & 6,93 \\
\hline 60 & 4,72 & 4,76 & 5,10 & 4,26 & 6,30 & 7,34 & 9,34 & 8,06 & 7,20 & 6,26 & 10,29 & 10,39 & 5,96 \\
\hline
\end{tabular}

Tabelle 9. Die organischen Bestandteile des Sedimentes in der jahreszeitlichen Veränderung. Horwer Bucht.

Table 9. Seasonal fluctuation in the organic components of the sediment. Horw Bay.

\begin{tabular}{|c|c|c|c|}
\hline Zeit & 6. 2.-30.4. 1969 & $19.5 .-4.10 .1969$ & $22.10 .1969-23.2 .1970$ \\
\hline Temperatur & Zirkulation & Stagnation & Zirkulation \\
\hline Biomasse & $\begin{array}{l}\text { Produktionsminimum } \\
\text { (+ relatives Maximum } \\
\text { am } 17.3 .1969 \text { ) }\end{array}$ & $\begin{array}{l}\text { Produktionsmaximum } \\
\text { vom 19. 5.-30. } 6.1969\end{array}$ & $\begin{array}{l}\text { Produktionsminimum } \\
\text { (+ relatives Maximum } \\
\text { am 3.12.1969) }\end{array}$ \\
\hline $\begin{array}{l}\text { Organische Substanz } \\
\text { (Glühverlust) }\end{array}$ & $\begin{array}{l}\text { viel } \\
14-22 \% \\
\varnothing 17,7 \%\end{array}$ & $\begin{array}{l}\text { wenig } \\
6-15 \% \\
\varnothing 10,2 \%\end{array}$ & $\begin{array}{l}\text { viel } \\
11-22 \% \\
\varnothing 16,6 \%\end{array}$ \\
\hline Organischer $\mathrm{C}$ & $\begin{array}{l}\text { viel } \\
6,6-12,1 \% \\
\varnothing 8,3 \%\end{array}$ & $\begin{array}{l}\text { wenig } \\
3,0-6,9 \% \\
\varnothing 4,7 \%\end{array}$ & $\begin{array}{l}\text { viel } \\
5,1-11,8 \% \\
\varnothing 8,2 \%\end{array}$ \\
\hline $\begin{array}{l}\% \text {-Anteil des } \\
\text { organischen } \mathrm{C} \text { in der } \\
\text { gesamten organischen } \\
\text { Substanz }\end{array}$ & $\begin{array}{l}\text { mittel } \\
37-64 \% \\
\varnothing 46,5 \%\end{array}$ & $\begin{array}{l}\text { mittel } \\
32-76 \% \\
\varnothing 47,6 \%\end{array}$ & $\begin{array}{l}\text { mittel } \\
35-71 \% \\
\varnothing 49,2 \%\end{array}$ \\
\hline $\begin{array}{l}\text { Tiefenverteilung der } \\
\text { Sedimentation }\end{array}$ & $\begin{array}{l}\text { Tendenz: Abnahme } \\
\text { nach unten; } \\
\text { Abbau nach Tiefe hin }\end{array}$ & $\begin{array}{l}\text { Tendenz: Zunahme } \\
\text { nach unten; } \\
\text { "Trichtereffekt"? }\end{array}$ & $\begin{array}{l}\text { Tendenz: Abnahme } \\
\text { nach unten; } \\
\text { Abbau nach Tiefe hin }\end{array}$ \\
\hline
\end{tabular}


nischen Substanz im Durchschnitt keine nennenswerten Änderungen erfuhr (46,5$49,2 \%$, Tab. 9). Die einzelnen Daten schwankten jedoch beträchtlich, und die höchsten Werte traten immer in Zeiten erhöhter Produktion auf, was darauf hindeutet, dass dann mehr Nährstoffe freigesetzt wurden und der schwerer abbaubare Kohlenstoff vermehrt aussedimentierte.

\subsection{Salzsäure-unlöslicher Anteil}

Der HCl-unlösliche Anteil des Sedimentes (Tab. 10) umfasst vor allem Tonmineralien und Kieselschalenreste $\left(\mathrm{SiO}_{2}\right)$. Diese Komponenten sind im Vierwaldstättersee besonders hoch, weil der See einerseits in einem typisch voralpinen Einzugsgebiet (= geologisch: Flysch [Pilatusgebiet] und Nagelfluh [Rigi]) liegt, und andrerseits die Diatomeen die dominierenden Phytoplankter sind. Während der Zirkulation wurden 43-56,5\% der TS erreicht, im Sommer sanken die Werte meist unter 30\% der TS. Es ist eine strenge Gegenläufigkeit zur Kalkausfällung (vgl. Tab. 11) festzustellen. So wurden auch im Sommer (19. Mai, 30. Juni, 8. September) höhere Werte als $40 \%$ der TS registriert, wenn die Ca-Werte unverhältnismässig tief sanken (unter 15\% der TS). Diese Fluktuation ist bedingt durch Phasen stärkerer und schwächerer Produktion (vgl. Gesamtbiomasse 5.11, S. 117). Die Sedimentationsraten dieses mineralischen Materials lagen im Winter um $0,2-0,6 \mathrm{~g} / \mathrm{m}^{2} \cdot$ Tag, im Sommer um $1-3 \mathrm{~g} / \mathrm{m}^{2} \cdot$ Tag.

Tabelle 10. Salzsäure-unlöslicher Anteil des Sedimentes der Horwer Bucht in \% der Trockensubstanz (TS).

Table 10. HCl-insoluble fraction of the sediment of Horw Bay in \% of dry matter (TS).

\begin{tabular}{llllllllllllll}
\hline Tiefe & 1969 & & & & & & & & & & \\
$\mathrm{~m}$ & 6.2. & 19.2. & 5.3. & 17.3. & 1.4. & 30.4. & 19.5. & 3.6. & 18.6. & 30.6. & 15.7. & 29.7. \\
\hline 7,5 & 50,8 & 48,8 & 46,3 & 43,0 & 48,3 & 56,0 & 33,3 & 24,3 & 24,7 & 51,5 & 34,9 & 18,6 \\
15 & 48,8 & 51,0 & 51,3 & - & 58,5 & 56,6 & 40,0 & 16,4 & 25,0 & 52,4 & 36,0 & 24,4 \\
25 & 51,2 & 54,2 & 47,7 & 49,3 & 50,7 & 55,5 & 44,7 & 17,6 & 26,8 & 50,5 & 36,5 & 28,1 \\
45 & 50,4 & 51,8 & 48,7 & - & 53,8 & 55,7 & 50,7 & 19,7 & 28,5 & 47,8 & 35,3 & 29,2 \\
60 & 50,8 & 53,0 & 53,3 & 49,0 & 50,0 & 56,5 & 52,5 & 20,4 & 29,5 & 45,0 & 34,7 & 30,0 \\
& & & & & & & & & & & & \\
\hline Tiefe & 1969 & & & & & & & & & & 1970 & & \\
$\mathrm{~m}$ & 11.8. & 25.8. & 8.9. & 22.9. & 4.10. & 22.10 .3 .11$. & 17.11 .3 .12$. & 19.12. & 7.1. & 30.1. & 23.2. \\
\hline 7,5 & 9,8 & 31,6 & 39,0 & 14,2 & 11,4 & 36,4 & 45,3 & 48,3 & 46,4 & 48,2 & 45,3 & 46,8 & 48,0 \\
15 & 13,0 & 33,9 & 42,6 & 16,1 & 13,2 & 39,2 & 53,2 & 49,4 & 47,9 & 48,3 & 45,3 & 45,0 & 50,2 \\
25 & 16,5 & 35,9 & 46,7 & 21,6 & 18,0 & 39,8 & 53,9 & 52,7 & 48,7 & 48,5 & 45,0 & 46,6 & 49,6 \\
45 & 18,9 & 36,5 & 48,9 & 23,9 & 17,6 & 37,8 & 52,5 & 51,3 & 51,4 & 50,0 & 44,9 & 46,6 & 48,4 \\
60 & 20,5 & 35,8 & 49,5 & 26,8 & 27,7 & 37,2 & 51,9 & 51,3 & 52,4 & 49,5 & 45,2 & 44,0 & 50,0 \\
\hline
\end{tabular}

\subsection{Kalzium und Magnesium}

Die $\mathrm{Ca}^{2+}$ - und $\mathrm{Mg}^{2+}$-Ionen liegen im sedimentierten Material vorwiegend als Karbonate vor. Die Löslichkeitsprodukte von $\mathrm{CaCO}_{3}$ und $\mathrm{MgCO}_{3}$ betragen bei $25^{\circ} \mathrm{C} 4,82$. $10^{-9} \mathrm{~mol} / \mathrm{kg}$ bzw. $1 \cdot 10^{-5} \mathrm{~mol} / \mathrm{kg}$ ([100], S. 71). Weil das $\mathrm{MgCO}_{3}$ wesentlich besser löslich ist als das $\mathrm{CaCO}_{3}$, und somit das $\mathrm{CaCO}_{3}$ bei der biogenen Entkalkung rascher aus- 
Tabelle 11. Kalzium ( $\mathrm{Ca}^{2+}$ ) im Sediment der Horwer Bucht in \% der Trockensubstanz (TS). Table 11. Calcium ( $\mathrm{Ca}^{2+}$ ) in the sediment of Horw Bay in \% of dry matter (TS).

\begin{tabular}{|c|c|c|c|c|c|c|c|c|c|c|c|c|c|}
\hline $\begin{array}{l}\text { Tiefe } \\
\mathrm{m}\end{array}$ & $\begin{array}{l}1969 \\
6.2 .\end{array}$ & 19.2. & 5.3 & 17.3 & 1.4. & 30.4 . & 19.5. & 3.6 & & 18.6. & 30.6 . & 15.7 & 29.7. \\
\hline 7,5 & 9,00 & 8,60 & 5,35 & 5,00 & 9,35 & 7,50 & 20,55 & 29 & 30 & 24,25 & 12,05 & 19,30 & 27,90 \\
\hline 15 & 9,60 & 9,70 & 6,50 & - & 8,00 & 6,90 & 17,15 & 28 & 40 & 23,95 & 12,75 & 19,20 & 25,95 \\
\hline 25 & 9,40 & 9,20 & 7,50 & 9,00 & 8,70 & 7,45 & 14,45 & 27 & 75 & 23,60 & 13,50 & 19,25 & 24,65 \\
\hline 45 & 9,60 & 9,90 & 8,00 & - & 8,50 & 8,15 & 11,30 & 27 & 15 & 22,55 & 14,25 & 20,05 & 21,35 \\
\hline 60 & 9,20 & 9,50 & 7,70 & 7,70 & 4,00 & 7,95 & 11,00 & 26 & 60 & 21,85 & 14,50 & 19,20 & 20,25 \\
\hline Ticfe & 1969 & & & & & & & & & & 1970 & & \\
\hline $\mathrm{m}$ & 11.8. & 25.8 & 8.9. & 9 & 4. 10 & 22.10 . & 3.11 . & 17.11 . & 3.12 . & . 19.12 & 7.1 & 30.1 & 23.2 \\
\hline 7,5 & 30,95 & 20,30 & 17,25 & 29,35 & 28,95 & 14,60 & 11,20 & 11,30 & 12,40 & $\begin{array}{ll}0 & 11,90\end{array}$ & 11,00 & $.8,40$ & 8,80 \\
\hline 15 & 29,35 & 20,15 & 15,60 & 28,45 & 27,15 & 14,00 & 7,70 & 11,20 & 12,25 & $5 \quad 12,20$ & 11,00 & 7,60 & 8,60 \\
\hline 25 & 28,65 & 18,60 & 13,40 & 26,35 & 25,05 & 14,35 & 7,90 & 9,70 & 11,65 & $5 \quad 11,40$ & 11,10 & 8,20 & 8,60 \\
\hline 45 & 26,50 & 19,20 & 12,65 & 24,75 & 18,85 & 15,95 & 7,40 & 9,80 & 9,90 & o 11,30 & 11,20 & 9,00 & 8,20 \\
\hline 60 & 26,35 & 18,45 & 12,05 & 23,25 & 22,60 & 15,45 & 7,70 & 9,65 & 9,60 & $0 \quad 10,40$ & 10,40 & 9,00 & 8,40 \\
\hline
\end{tabular}

fällt, spielt das Magnesium im Sediment gegenüber dem Kalzium eine untergeordnete Rolle. Die Magnesiumwerte (Tab. 12) lagen deshalb nur selten über 1,2\% der TS, dagegen erreichten die Kalziumwerte (Tab. 11) 4-31\% der TS; dies ergab während der Zirkulation ein Ca:Mg-Verhältnis von durchschnittlich 11,2:1 (5-25:1), während der Sommerstagnation ein solches von durchschnittlich 40:1 (9-110:1).

Das Kalzium war in der Tiefenverteilung abhängig von der Temperaturschichtung und der Produktionstätigkeit des Phytoplanktons. Bei Vollzirkulation waren die CaSedimentationsraten mehr oder weniger gleichmässig verteilt; bei Stagnation und hoher Produktion erfolgte ein starker Ca-Anfall (biogene Entkalkung), der die Werte

Tabelle 12. Magnesium $\left(\mathrm{Mg}^{2+}\right)$ im Sediment der Horwer Bucht in \% der Trockensubstanz (TS). Table 12. Magnesium $\left(\mathrm{Mg}^{2+}\right)$ in the sediment of Horw Bay in \% of dry matter (TS).

\begin{tabular}{|c|c|c|c|c|c|c|c|c|c|c|c|c|c|}
\hline $\begin{array}{l}\text { Tiefe } \\
\mathrm{m}\end{array}$ & $\begin{array}{l}1969 \\
6.2\end{array}$ & 19.2 & 5.3. & 17.3 & 1.4. & 30.4 & 19.5 & \multicolumn{2}{|c|}{3.6 . } & 18.6 & 30.6 & 15.7 & 29.7 \\
\hline 7,5 & 1,10 & 0,75 & 0,80 & 1,05 & 1,50 & 0,80 & 0,65 & 0 , & 40 & 0,65 & 0,75 & 0,40 & 0,45 \\
\hline 15 & 1,10 & 1,30 & 0,80 & - & 1,50 & 0,55 & 0,45 & 0 , & 30 & 0,75 & 0,65 & 0,40 & 0,60 \\
\hline 25 & 0,85 & 0,90 & 0,30 & 0,20 & 0,80 & 0,55 & 0,45 & & .55 & 0,75 & 0,35 & 0,70 & 0,55 \\
\hline 45 & 1,10 & 0,65 & 0,40 & - & 0,80 & 0,60 & 1,25 & & 25 & 0,55 & 0,05 & 0,50 & 0,55 \\
\hline 60 & 0,95 & 0,85 & 0,70 & 1,00 & 0,30 & 0,60 & 0,25 & & 50 & 0,50 & 1,25 & 0,65 & 0,60 \\
\hline Tiefe & 1969 & & & & & & & & & & 1970 & & \\
\hline $\mathrm{m}$ & 11.8. & 25.8. & 8.9. & 22.9 & 4.10 & 22.10 & 3.11 . & 17.11 & 3.12 . & 2. 19.12 . & 7.1 & 30.1 & 23.2 \\
\hline 7,5 & 0,55 & 0,70 & 0,80 & 0,85 & 0,55 & 0,60 & 0,75 & 1,10 & 0,85 & 0,90 & 1,00 & 1,70 & 1,10 \\
\hline 15 & 0,55 & 0,65 & 0,80 & 0,55 & 0,65 & 0,65 & 1,10 & 1,15 & 0,65 & 0,60 & 0,85 & 1,20 & 0,85 \\
\hline 25 & 0,60 & 0,70 & 1,00 & 0,45 & 0,60 & 1,10 & 0,70 & 0,95 & 1,10 & 1,05 & 0,95 & 0,95 & 0,85 \\
\hline 45 & 0,75 & 0,20 & 0,95 & 0,80 & 0,60 & 0,90 & 1,30 & 0,65 & 1,40 & 0,95 & 1,10 & 0,85 & 1,20 \\
\hline 60 & 0,50 & 0,80 & 1,20 & 0,60 & 0,95 & 1,10 & 0,95 & 0,75 & 0,95 & 2,05 & 0,95 & 1,10 & 1,35 \\
\hline
\end{tabular}


um das 2-3fache auf 20-30\% der TS ansteigen liess. Im Hypolimnion zeigte sich gegenüber dem Epilimnion eine Abnahme, weil aggressives $\mathrm{CO}_{2}$ das $\mathrm{CaCO}_{3}$ teilweise wieder in Lösung brachte.

Das Magnesium war im Vertikalprofil sehr konstant, im Gegensatz zum Kalzium; auch in Funktion der Zeit zeigten sich nur geringe Unterschiede: Während der Zirkulationsperioden lagen die Werte eher höher als während der Stagnation; damit verhielt sich das Magnesium konträr zum Kalzium.

\subsection{Phosphor und Stickstoff}

Die $P$-Werte (Tab. 13) lagen im Sediment der Horwer Bucht immer tiefer als die $N$-Werte (Tab. 14). Das N:P-Verhältnis im Sediment (Abb. 17), auf das im Abschnitt

Tabelle 13. Phosphor (Gesamt-P) im Sediment der Horwer Bucht in \% der Trockensubstanz (TS). Table 13. Total amount of phosphorus in the sediment of Horw Bay in \% of dry matter (TS).

\begin{tabular}{|c|c|c|c|c|c|c|c|c|c|c|c|c|c|}
\hline $\begin{array}{l}\text { Tiefe } \\
\mathrm{m}\end{array}$ & $\begin{array}{l}1969 \\
6.2 .\end{array}$ & 19.2. & 5.3 & 17.3 & 1.4. & 30.4 . & 19.5. & 3.6. & & 18.6 & 30.6 . & 15.7 & 29.7. \\
\hline 7,5 & 0,16 & 0,19 & 0,33 & 0,41 & 0,17 & 0,20 & 0,08 & 0,12 & & 0,07 & 0,11 & 0,09 & 0,05 \\
\hline 15 & 0,18 & 0,21 & 0,36 & - & 0,19 & 0,18 & 0,21 & 0,07 & & 0,09 & 0,11 & 0,09 & 0,05 \\
\hline 25 & 0,16 & 0,19 & 0,29 & 0,25 & 0,14 & 0,20 & 0,11 & 0,08 & & 0,08 & 0,09 & 0,08 & 0,04 \\
\hline 45 & 0,16 & 0,19 & 0,22 & - & 0,14 & 0,12 & 0,13 & $0,0^{\prime}$ & & 0,09 & 0,10 & 0,07 & 0,08 \\
\hline 60 & 0,20 & 0,18 & 0,20 & 0,23 & 0,24 & 0,14 & 0,14 & 0,10 & & 0,09 & 0,11 & 0,08 & 0,09 \\
\hline Tiefe & 1969 & & & & & & & & & & 1970 & & \\
\hline $\mathrm{m}$ & 11.8 & 25.8. & 8.9. & 22.9 & 4.10 & 22.10 . & 3.11 . & 17.11 & 3.12 . & . 19.12 & 7.1. & 30.1 . & 23.2 . \\
\hline 7,5 & 0,04 & 0,06 & 0,06 & 0,06 & 0,08 & 0,16 & 0,17 & 0,10 & 0,11 & 0,14 & 0,19 & 0,21 & 0,19 \\
\hline 15 & 0,04 & 0,06 & 0,06 & 0,05 & 0,09 & 0,14 & 0,15 & 0,11 & 0,13 & 0,14 & 0,16 & 0,26 & 0,16 \\
\hline 25 & 0,03 & 0,06 & 0,07 & 0,06 & 0,09 & 0,14 & 0,14 & 0,12 & 0,10 & 0,15 & 0,18 & 0,24 & 0,16 \\
\hline 45 & 0,05 & 0,08 & 0,08 & 0,06 & 0,10 & 0,12 & 0,16 & 0,11 & 0,12 & 0,15 & 0,17 & 0,20 & 0,13 \\
\hline 60 & 0,08 & 0,07 & 0,11 & 0,08 & 0,14 & 0,15 & 0,19 & 0,15 & 0,14 & 0,16 & 0,21 & 0,23 & 0,10 \\
\hline
\end{tabular}

Tabelle 14. Stickstoff (Gesamt-N) im Sediment der Horwer Bucht in \% der Trockensubstanz (TS). Table 14. Total amount of nitrogen in the sediment of Horw Bay in \% of dry matter (TS).

\begin{tabular}{|c|c|c|c|c|c|c|c|c|c|c|c|c|c|}
\hline $\begin{array}{l}\text { Tiefe } \\
\mathrm{m}\end{array}$ & $\begin{array}{l}1969 \\
6.2\end{array}$ & 19.2 & 5.3 & 17.3 & 1.4. & 30.4 & 19.5. & \multicolumn{2}{|c|}{3.6.} & 18.6. & 30.6 & 15.7 & 29.7 . \\
\hline 7,5 & 1,13 & 1,36 & 1,81 & 2,11 & 1,48 & 1,45 & 0,68 & 0,5 & & 0,75 & 1,00 & 0,99 & 0,66 \\
\hline 15 & 0,95 & - & 1,64 & - & - & 1,51 & 0,71 & 0,7 & & 0,76 & 1,01 & 1,01 & 0,81 \\
\hline 25 & 0,99 & 1,26 & - & - & 1,36 & 1,51 & 0,93 & 0,7 & & 0,80 & 0,96 & 1,00 & 0,74 \\
\hline 45 & 0,93 & 1,20 & - & - & 1,19 & 1,44 & 1,03 & 0,8 & & 0,82 & 1,04 & 0,91 & 0,92 \\
\hline 60 & 1,09 & $\mathbf{1}, 12$ & 1,34 & 1,53 & - & 1,07 & 1,29 & 0,7 & & 0,80 & 1,02 & 0,89 & 0,88 \\
\hline Tiefe & 1969 & & & & & & & & & & 1970 & & \\
\hline $\mathrm{m}$ & 11.8. & 25.8 & 8.9. & 22.9 & 4.10 & 22.10. & 3.11 . & 17.11. & 3.12 . & 19.12 & 7.1 & 30.1 & 23.2 . \\
\hline 7,5 & 0,77 & 0,86 & 0,95 & 1,59 & 1,86 & 2,35 & 1,24 & 0,94 & 0,75 & 0,79 & 1,16 & 1,54 & 1,12 \\
\hline 15 & 0,80 & 0,78 & 0,84 & 1,43 & 1,80 & 2,01 & 1,23 & 0,85 & 0,78 & 0,80 & 1,12 & 1,61 & 1,03 \\
\hline 25 & 0,92 & 0,94 & 1,00 & 1,36 & 1,79 & 1,73 & 1,17 & 0,85 & 0,69 & 0,76 & 1,19 & 1,58 & 0,94 \\
\hline 45 & 0,89 & 0,90 & 1,01 & 1,31 & 1,74 & 1,84 & 1,18 & 0,90 & 0,78 & 0,61 & 1,30 & 1,49 & 0,83 \\
\hline 60 & 0,92 & 0,97 & 1,01 & 1,55 & 1,78 & 1,95 & 1,14 & 0,91 & 0,76 & 0,79 & 1,48 & 1,58 & 0,63 \\
\hline
\end{tabular}


6.3 (S. 172) näher eingegangen wird, betrug im Jahresdurchschnitt etwa 10-11:1. Im Winter lag der Quotient etwa bei 4-8:1, im Sommer etwa bei 9-27:1. Diese saisonale Änderung hatte schon Stadelmann [101] beim partikulären Material in der Horwer Bucht festgestellt.

Während der Sommerstagnation vom Mai bis Oktober fiel der P-Anteil des sedimentierten Materials meist unter $0,1 \%$ bis auf $0,03 \%$ der TS, der N-Anteil auf 0,5 $1.0 \%$ der TS; Maxima wurden in der Zirkulationszeit erreicht (Phosphor: 0,2-0,4\% der TS, Stickstoff: 1,5-2,35\% der TS). Die sedimentierten P- und N-Raten lagen jedoch infolge vermehrter Produktion im Sommer wesentlich höher (Phosphor: 3-9 $\mathrm{mg} / \mathrm{m}^{2} \cdot$ Tag gegenüber $0,4-2 \mathrm{mg} / \mathrm{m}^{2} \cdot$ Tag im Winter, Stickstoff: $23-113 \mathrm{mg} / \mathrm{m}^{2} \cdot$ Tag gegenüber $4-17 \mathrm{mg} / \mathrm{m}^{2} \cdot$ Tag im Winter).



4.26 Eisen und Mangan

Das Eisen wie auch das Mangan stehen im Seewasser wesentlich im Zusammenhang mit den Parametern $\mathrm{O}_{2}, \mathrm{pH}$ und $\mathrm{CO}_{2}$. Da in der Horwer Bucht immer über $6 \mathrm{mg} \mathrm{O} / 1$ festgestellt wurden, dürfte das Eisen im dreiwertigen $Z$ ustand vorliegen. Wie auch im Abschnitt 4.37, Seite 104, dargelegt, handelt es sich nicht um $\mathrm{Fe}(\mathrm{OH})_{3}$ oder $\mathrm{FePO}_{4}$, sondern um Goethit $(\mathrm{FeOOH})$, der eine Hülle um vorhandene Tonmineralpartikeln bildet $[94,108,126,121]$.

Das Mangan ist schwerer oxidierbar als das Eisen, daher wird es schon bei einem Redoxpotential von $p \varepsilon+10$ bis +1 reduziert gegenüber einem $p \varepsilon$ von +1 bis -9 beim Eisen [108]. Weil es zudem, im Gegensatz zum Eisen, als freies Oxid $\left(\mathrm{MnO}_{2}\right)$ vorkommt [108], nimmt es intensiver an Redoxreaktionen teil und bleibt deshalb eher in Lösung. Aus diesem Grund, und weil Mangan in unseren Seen in geringerer Menge 
vorhanden ist als Eisen, spielt es im Sediment gegenüber dem Eisen eine untergeordnete Rolle (Fe: Mn-Verhältnis = 10-40:1).

Das Mangan (Tab. 15) zeigte im Profil im Gegensatz zum Eisen immer eine Zunahme nach unten. Die aufgrund der hypolimnischen Sauerstoffzehrung erwartete Abnahme trat deshalb nicht ein, weil offenbar die vorherrschenden Milieubedingungen für eine Reduktion und Rücklösung des Mangans noch nicht günstig genug waren $\left(\mathrm{O}_{2}\right.$ nie unter $7 \mathrm{mg} / 1, \mathrm{CO}_{2}$ nie über $0,5 \mathrm{mg} / 1[10]$, $\mathrm{pH}$ nie unter 7,5). Die saisonalen Veränderungen lassen sich in zwei deutlich verschiedene Perioden gliedern: während der Stagnation (ab 19. Mai bis 22. Oktober 1969) fiel wenig Mangan im Sediment an (unter $0,10 \%$ der TS); während der beiden Zirkulationszeiten (6. Februar bis 30. April 1969 und 3. November 1969 bis 23. Februar 1970) betrug der Mn-Anteil im Sediment hingegen über $0,10 \%$ bis $0,30 \%$ der TS.

'Tabelle 15. Mangan (Gesamt-Mn) im Sediment der Horwer Bucht in \% der Trockensubstanz (TS). Table 15. Total amount of manganese in the sediment of Horw Bay in \% of dry matter (TS).

\begin{tabular}{|c|c|c|c|c|c|c|c|c|c|c|c|c|c|}
\hline $\begin{array}{l}\text { Tiefe } \\
\mathrm{m}\end{array}$ & $\begin{array}{l}1969 \\
6.2 .\end{array}$ & 19.2. & 5.3. & 17.3 & 1.4. & 30.4 & 19.5 & 3. & & 18.6. & 30.6 . & 15.7 & 29.7 \\
\hline 7,5 & 0,20 & 0,15 & - & 0,25 & 0,10 & 0,09 & 0,04 & 0 , & & 0,04 & 0,04 & 0,03 & 0,03 \\
\hline 15 & 0,20 & 0,25 & 0,29 & - & 0,20 & 0,10 & 0,05 & 0 , & & 0,04 & 0,04 & 0,03 & 0,03 \\
\hline 25 & 0,17 & 0,24 & 0,25 & 0,15 & 0,14 & 0,09 & 0,05 & 0 & & 0,04 & 0,04 & 0,03 & 0,03 \\
\hline 45 & 0,22 & 0,23 & 0,25 & - & 0,17 & 0,08 & 0,06 & 0 & & 0,05 & 0,05 & 0,04 & 0,04 \\
\hline 60 & 0,26 & 0,30 & 0,35 & 0,22 & 0,25 & 0,16 & 0,09 & 0 , & & 0,08 & 0,08 & 0,06 & 0,06 \\
\hline Tiefe & 1969 & & & & & & & & & & 1970 & & \\
\hline $\mathrm{m}$ & 11.8 & 25.8 & 8.9. & 22.9 & 4.10 . & 22.10 & 3.11 . & 17.11 & 3.12 & 2. 19.12 . & 7.1 & 30.1 . & 23.2 . \\
\hline 7,5 & 0,02 & 0,04 & 0,05 & 0,02 & 0,02 & 0,05 & 0,08 & 0,07 & 0,10 & 0,13 & 0,22 & 0,27 & 0,25 \\
\hline 15 & 0,02 & 0,04 & 0,06 & 0,03 & 0,03 & 0,06 & 0,10 & 0,08 & 0,10 & 0,13 & 0,30 & 0,38 & 0,26 \\
\hline 25 & 0,03 & 0,05 & 0,07 & 0,04 & 0,04 & 0,07 & 0,11 & 0,12 & 0,11 & 0,13 & 0,21 & 0,30 & 0,27 \\
\hline 45 & 0,05 & 0,07 & 0,10 & 0,07 & 0,05 & 0,09 & 0,21 & 0,17 & 0,18 & 0,15 & 0,23 & 0,29 & 0,25 \\
\hline 60 & 0,07 & 0,11 & 0,14 & 0,12 & 0,08 & 0,12 & 0,36 & 0,21 & 0,31 & 0,30 & 0,31 & 0,30 & 0,18 \\
\hline
\end{tabular}

Beim Eisen (Tab. 16) lassen sich die beim Mangan gefundenen Erscheinungen ebenfalls, jedoch weniger deutlich, feststellen. Nur während der Stagnationsperiode (19. Mai bis 22. Oktober 1969) zeigte sich hier eine gesicherte Zunahme nach unten, wogegen vom 6. Februar bis 30. April 1969 und vom 3. November 1969 bis 23. Februar 1970 die Verteilung unregelmässig war mit einer Tendenz zur Zunahme nach unten. Eine Rücklösung des Eisens im Verlauf der Sedimentation ist noch unwahrscheinlicher als beim Mangan. Die Eisengehalte im Sediment lagen in den Zirkulationsperioden durchschnittlich um 1,5-3,2\% der TS, während der Stagnation um 0,5-1,5\% der TS; allerdings stachen im Sommer zwei relative Maxima mit 1,8\% (30. Juni) und $1,7-2,3 \%$ (8. September) hervor.

Nebst den rein chemischen Vorgängen können im Fe-Mn-Kreislauf auch die Bakterien eine bedeutende Rolle spielen [57]. Im Vierwaldstättersee trat in den tiefen Wasserschichten und Sedimentationsstufen das Eisenbakterium Leptothrix echinata Beger massenhaft auf, ein Organismus, über den bis heute noch verschiedene Unklarheiten bestehen (vgl. [15]). In den Mischproben von 45 bis $60 \mathrm{~m}$ wurden im August 1969 
Tabelle 16. Eisen (Gesamt-Fe) im Sediment der Horwer Bucht in \% der Trockensubstanz (TS). Table 16. Total amount of iron in the sediment of Horw Bay in \% of dry matter (TS).

\begin{tabular}{|c|c|c|c|c|c|c|c|c|c|c|c|c|c|}
\hline $\begin{array}{l}\text { Tiefe } \\
\mathrm{m}\end{array}$ & $\begin{array}{l}1969 \\
6.2 .\end{array}$ & 19.2. & 5.3 & 17.3 & 1.4 & 30.4 & 19. & & 6. & 18.6. & 30.6 & 15.7 & 29.7. \\
\hline 7,5 & 2,70 & 1,67 & - & 2,00 & 1,95 & 1,68 & 1,28 & & 64 & 1,20 & 1,80 & 0,95 & 0,80 \\
\hline 15 & 2,50 & 4,00 & 2,62 & - & 1,50 & 1,72 & 1,50 & & 68 & 1,15 & 1,80 & 1,01 & 0,90 \\
\hline 25 & 2,25 & 2,75 & 1,50 & 1,50 & 2,21 & 1,70 & 1,58 & & 76 & 1,15 & 1,80 & 1,10 & 1,00 \\
\hline 45 & 2,61 & 2,34 & 1,50 & - & 2,20 & 1,80 & 1,70 & & 80 & 1,28 & 1,80 & 1,11 & 1,15 \\
\hline 60 & 2,50 & 2,31 & 2,50 & 2,33 & 1,25 & 2,00 & 1,80 & & 90 & 1,35 & 1,80 & 1,20 & 1,30 \\
\hline Tiefe & 1969 & & & & & & & & & & 1970 & & \\
\hline $\mathrm{m}$ & 11.8. & 25.8 & 8.9. & 22.9 & 4.10. & 22.10 & 3.11 . & 17.11. & . 3.12. & . 19.12 . & 7.1. & 30.1 & 23.2. \\
\hline 7,5 & 0,45 & 1,50 & 1,70 & 0,61 & 0,55 & 1,50 & 2,31 & 2,40 & 2,60 & 2,50 & 2,92 & 2,20 & 2,25 \\
\hline 15 & 0,60 & 1,53 & 1,77 & 0,71 & 0,68 & 1,79 & 2,71 & 2,46 & 2,40 & 2,62 & 5,00 & 3,23 & 2,41 \\
\hline 25 & 0,76 & 1,60 & 2,00 & 0,97 & 0,97 & 1,90 & 2,84 & 2,69 & 2,51 & 2,64 & 2,87 & 2,54 & 2,44 \\
\hline 45 & 0,87 & 1,64 & 2,00 & 1,09 & $\mathbf{1 , 1 9}$ & 1,90 & 2,86 & 2,80 & 2,70 & 2,59 & 3,14 & 2,70 & 2,50 \\
\hline 60 & 0,92 & 1,70 & 2,30 & 1,28 & 1,32 & 1,92 & 1,73 & 2,80 & 2,90 & 2,77 & 3,08 & 1,40 & 2,64 \\
\hline
\end{tabular}

bis Februar 1970 immer 50-600 $10^{3}$ Zellen/l gezählt und im Sedimentiergefäss auf $60 \mathrm{~m}$ während der ganzen Untersuchungsperiode $2-200 \cdot 10^{6} \mathrm{Zellen} / \mathrm{dm}^{2}$ aufgefangen. Ein eindeutiger Zusammenhang mit den chemischen Eisen- und Mangananalysen im Wasser bzw. Sediment konnte allerdings nicht gefunden werden, doch ist anzunehmen, dass Leptothrix echinata im Eisenkreislauf der Horwer Bucht von einiger Bedeutung ist.

\subsection{Charakterisierung des Rotsees}

Minder [64] berichtet, dass im Rotsee schon um 1910 die ersten Wasserblüten (Oscillatoria rubescens, Anabaena catenula) aufgetreten waren. Der natürliche Eutrophierungsvorgang dieses kleinen Sees, bedingt durch geringe Tiefe, windgeschützte Lage und bewaldete Ufer, wurde durch Abwassereinleitungen der Stadt Luzern noch zusätzlich beschleunigt. Im Zeitpunkt der Untersuchungen war der Rotsee hochgradig eutroph (polytroph).

Trot $z$ auftretender Homothermie ist der Rotsee als fakultativ meromiktisch einzustufen, denn der hohe Salzgehalt und die dadurch bedingte erhöhte Dichte im sauerstofffreien Tiefenwasser dürften eine Vollzirkulation zum Teil verunmöglichen (vgl. dazu die Situation im Dezember 1969, Abb. 18 und 19). Die Meromixis ist aber nicht nur rein chemisch, sondern wohl auch topographisch (windgeschützte Lage) bedingt.

\subsection{Gesamtsalzgehalt $\left(\varkappa_{20}\right)$ und Temperatur}

Der Rotsee zeigte im Vergleich mit der Horwer Bucht $(170-200 \mu \mathrm{S} / \mathrm{cm})$ wesentlich grössere Leitfähigkeitswerte (Abb. 18). Nur im Juli bis September sank die Leitfähigkeit in den obersten drei Metern unter $200 \mu \mathrm{S} / \mathrm{cm}$ (hohe Produktion, starke Nährstoffzehrung); ausser diesem epilimnischen Minimum lagen die Werte durchwegs über $250 \mu \mathrm{S} / \mathrm{cm}$ und stiegen gegen den Seegrund hin zeitweise sogar über $400 \mu \mathrm{S} / \mathrm{cm}$ an (Rücklösungsprozesse, hypolimnische Nährstoffanreicherung). Im Gegensatz zum Vierwaldstättersee korrelierte der Gesamtsalzgehalt im Rotsee nicht nur mit der 



Abb. 18. Elektrische Leitfähigkeit $\left(\varkappa_{20}\right)$ des Rotsees $(\mu S / \mathrm{cm})$.

Fig. 18. Specific conductance (= conductivity) $\left(x_{20}\right)$ in the Rotsee ( $\mu \mathrm{mho})$.
Abb. 19. Isothermen des Rotsees $\left({ }^{\circ} \mathrm{C}\right)$. Nach $[101,93]$.

Fig. 19. Isotherms in the Rotsee $\left({ }^{\circ} \mathrm{C}\right)$. Adapted from $[101,93]$.

Alkalinität (SBV), sondern auch mit den Komponenten Phosphat, Kieselsäure und Ammonium ([93], S. 449/50). Die beiden Zirkulationen im Frühling und im Herbst sind aus der Isopletendarstellung (Abb. 18) gut ersichtlich; während im April nahezu Vollzirkulation herrschte, reichte die Zirkulation im Dezember nicht bis zum Grund (fakultative Meromixis).

Die höchsten Temperaturen (Abb. 19) wurden im August gemessen $\left(23,5^{\circ} \mathrm{C}\right.$ ). Die kurzen Perioden der Homothermie im Frühling (1969 nur noch andeutungsweise erfasst) und im Spätherbst wurden im Sommer von einer längeren und im Winter von einer kürzeren Stagnationszeit eingerahmt. Die thermische Schichtung war wesentlich stabiler als diejenige in der Horwer Bucht (vgl. [101] und [93]). Die Sommerstagnation dauerte vom April-Mai bis November 1969, die Winterstagnation vom Januar bis Februar 1970 (Eisdecke). Die Thermokline (Metalimnion) lag während der Sommerstagnation in 2-6 m Tiefe; die Grenze des Epilimnions wurde vereinfachend in $5 \mathrm{~m}$ Tiefe angenommen. 


\subsection{Lichtverhältnisse und Sichttiefe}

Die 1\%-Eindringtiefe des grünen Lichtes (VG 9), welche die Kompensationstiefe darstellt [88], lag im Rotsee zwischen 3,7 m (April) und 9,2 $\mathrm{m}$ (Oktober). Wegen der grossen Schwankungen wurde die Grenze der trophogenen Schicht durchschnittlich bei $5 \mathrm{~m}$ angenommen (vgl. [101] und [93]).

Die Sichttiefe betrug im Rotsee 1,0 m (März 1969 und 1970) bis 3,5 m (Oktober) und fiel wie im Vierwaldstättersee mit VG $920 \%$ zusammen. Interessant ist die Feststellung, dass die Sichttiefen im Mai-Juni und September-Oktober im Rotsee grösser waren als in der Horwer Bucht.

\subsection{Karbonathärte (SBV oder Alkalinität) und pH}

Die Alkalinität (SBV) (Abb. 20) erreichte im Tiefenwasser Maximalwerte über 4,0 mval/1 und sank nur im Epilimnion (Juli bis Oktober) unter 2,0 mval/1. Sie machte im Durchschnitt 75\% der Gesamtleitfähigkeit aus (Berechnung nach [90], S. 74) und deckte sich ziemlich genau mit deren Verteilung.

Die $p H$-Werte (Tab. 17) verhielten sich gegenläufig zum SBV und stiegen infolge der hohen Produktion im Epilimnion über 9 an (Maximalwerte von pH 9,2 im September).



Abb. 20. Alkalinität (SBV) des Rotsees (mval/1).

Fig. 20. Alkalinity in the Rotsee (mval/l).

Tabelle 17. pH-Werte, Rotsee

Table 17. $\mathrm{pH}$ values, Rotsee.

\begin{tabular}{|c|c|c|c|c|c|c|c|c|c|c|c|c|c|}
\hline $\begin{array}{l}\text { Tiefe } \\
\mathrm{m}\end{array}$ & $\begin{array}{l}1969 \\
20.3\end{array}$ & 17.4 . & 22.5 & 10.6 & 10.7 & 14.8 & 11.9 & 10.10 & 6.11 & 3.12 & $\begin{array}{l}1970 \\
15.1\end{array}$ & 18.2. & 23.3 . \\
\hline 0 & 8,6 & 8,2 & 8,5 & 8,7 & 8,3 & 8,4 & 9,2 & 8,3 & 7,9 & 7,3 & 8,0 & 7,5 & 8,1 \\
\hline 1 & - & 8,1 & 8,5 & 8,7 & 8,4 & 8,4 & 9,2 & 8,3 & 7,9 & 7,3 & 7,8 & 7,6 & 7,8 \\
\hline 2,5 & 8,5 & 8,0 & 8,1 & 8,6 & 8,3 & 8,1 & 8,0 & 8,3 & 7,9 & 7,2 & 7,6 & 7,5 & 7,7 \\
\hline 5 & 7,4 & 7,7 & 7,4 & 7,4 & 7,5 & 7,3 & 7,5 & 8,3 & 7,9 & 7,3 & 7,4 & 7,3 & 7,5 \\
\hline 7,5 & 7,4 & 7,5 & 7,4 & 7,3 & 7,4 & 7,2 & 7,3 & 7,2 & 7,9 & 7,3 & 7,3 & 7,5 & 7,4 \\
\hline $14=G$ & 6,9 & 7,2 & 7,4 & 7,1 & 7,2 & 7,0 & 7,0 & 6,9 & 6,9 & 6,9 & 7,1 & 7,1 & 7,1 \\
\hline
\end{tabular}




\subsection{Sauerstoff und Schwefelwasserstoff $\left(\mathrm{H}_{2} \mathrm{~S}\right)$}

Ein Bild von der Intensität der Produktion im Rotsee vermitteln die Sauerstoffkonzentrationen (Abb. 21, nach [101] und [93]). Úbersättigungen in den obersten Schichten traten nicht nur im Sommer, sondern schon im Frühling (März) auf. Im Hypolimnion herrschten ausser während den Zirkulationsperioden anaerobe Verhältnisse. Der Sauerstoffschwund reichte im Sommer bis auf $5 \mathrm{~m}$; gleichzeitig wurden erhebliche Konzentrationen an Schwefelwasserstoff $\left(\mathrm{H}_{2} \mathrm{~S}\right)$ gemessen.



Abb. 21. Sauerstoff $\left(\mathrm{mg} \mathrm{O}_{2} / \mathrm{l}\right)$ und Schwefelwasserstoff ( $\mathrm{mg} \mathrm{S} \mathrm{S}^{2-} / \mathrm{l}$ ) des Rotsees.

Schwacher Raster $>100 \%$

Sättigung, starker Raster $>150 \%$ Sättigung. Schwefelwasserstoff in $14 \mathrm{~m}$ angegeben. Nach [101, 93].

Fig. 21. Oxygen $\left(\mathrm{mg} \mathrm{O}_{2} / 1\right)$ and hydrogen sulphide ( $\left.\mathrm{mg} \mathrm{S}^{2-} / \mathrm{I}\right)$ in the Rotsee.

Light shading $>100 \%$ saturation, heavy shading $>150 \%$ saturation. $\mathrm{H}_{2} \mathrm{~S}$ mentioned in $14 \mathrm{~m}$. Adapted from $[101,93]$.

\subsection{Phosphor}

Die Phosphorwerte im Rotsee lagen um etwa eine Zehnerpotenz höher als diejenigen im Vierwaldstättersee und erreichten im Hypolimnion zeitweise Gehalte von über $1 \mathrm{mg} / \mathrm{l}$.

Das Isopletenbild des Gesamtphosphors (Abb. 22) deckt sich im wesentlichen mit demjenigen des Phosphats (Abb. 23). Vom Juli bis Oktober fand eine starke Phosphatzehrung statt, während im März 1969 und vom September 1969 bis Januar 1970 eine hypolimnische P-Anreicherung festzustellen war. Die Zirkulationen vom April und Dezember brachten eine stattliche Menge Phosphat (etwa 185 bzw. $225 \mu \mathrm{g} / \mathrm{l}$ ) in die produktive Schicht.

Der gelösteorganische Phosphor (Abb. 24) wurde im Sommer wie das Orthophosphat stark aufgezehrt (Konzentrationen unter $10 \mu \mathrm{g} / \mathrm{l}$ ). Maximalwerte fanden sich im März 1969 mit über 300-600 $\mu \mathrm{g} / \mathrm{l}$.

Die Verteilung des partikulären Phosphors (Abb. 25) zeigt zwei Maxima im März 1969 und im Januar 1970 sowie eine weitgehende Verarmung im Epilimnion vom Mai bis Dezember. Wie die spätere Betrachtung des Phytoplanktons (vgl. 5.2, S. 129 ff.) ergibt, waren die Maxima vor allem auf Massenentfaltungen von Stephanodiscus hantzschii (März 1969) sowie Cryptomonas spp. und Rhodomonas lacustris und lens (Januar 1970) zurückzuführen. 

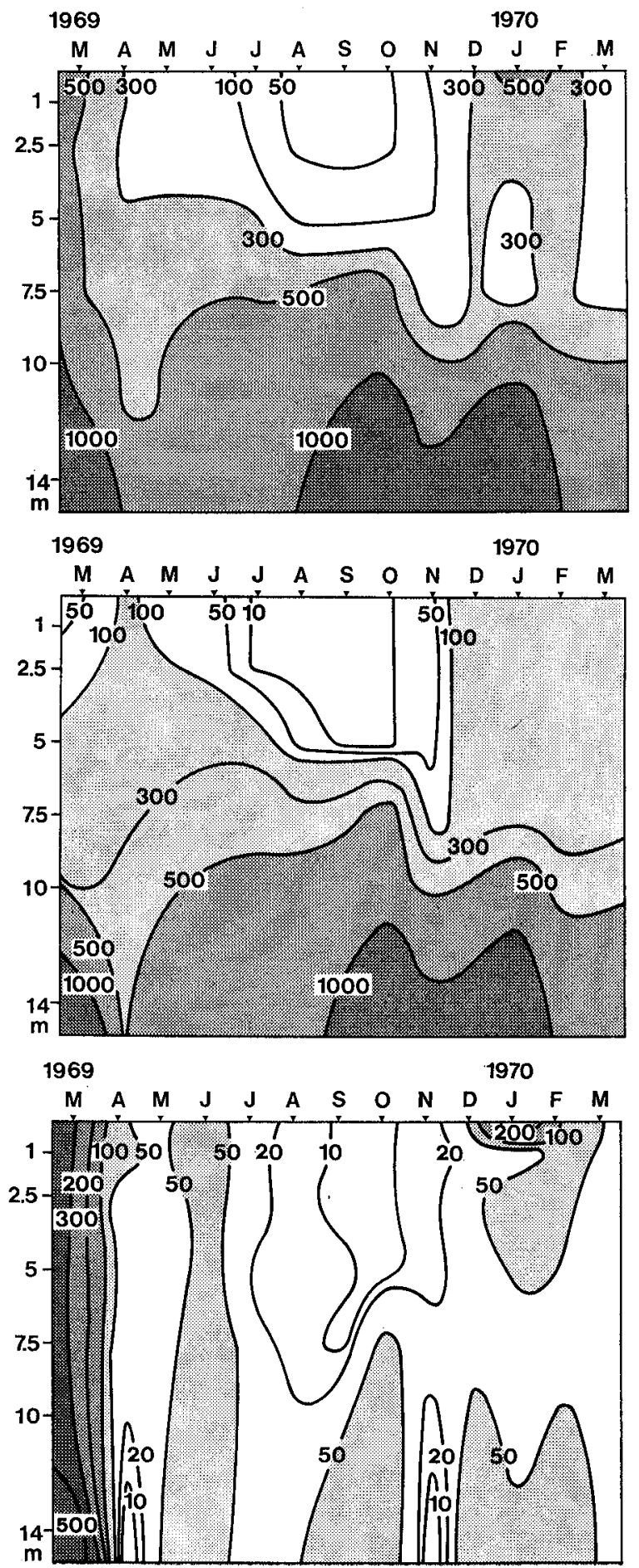

Abb. 22. Gesamtphosphorkonzentrationen des Rotsees ( $\mu$ g Gesamt-P/1).

Fig. 22. Total phosphorus concentration in the Rotsee ( $\mu g \mathrm{P}_{\text {tot }} / \mathbf{l}$ ).

Abb. 23. Orthophosphat des Rotsees ( $\left.\mu \mathrm{PO}_{4}-\mathrm{P} / 1\right)$.

Fig. 23. Ortho-phosphate concentration in the Rotsee (ug $\mathrm{PO}_{4}-\mathrm{P} / \mathrm{l}$ ).

Abb. 24. Gelöste organische Phosphorverbindungen des Rotsees ( $\mu \mathrm{g} \mathrm{P} / \mathrm{l}$ ).

Fig. 24. Dissolved organic phosphorus compounds in the Rotsee ( $\mu \mathrm{g} \mathrm{P} / \mathrm{l}$ ). 


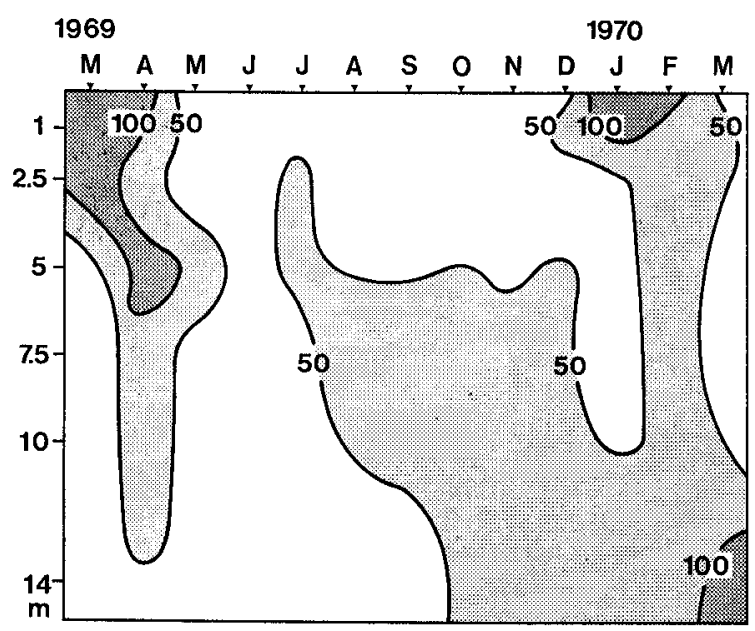

Abb. 25. Partikulärer Phosphor des Rotsees ( $\mu$ g PP/1).

Fig. 25. Particulate phosphorus concentration in the Rotsec ( $\mu \mathrm{g} \mathrm{PP} / \mathrm{l})$.

\subsection{Stickstoff}

Wie beim Vierwaldstättersee werden die N-Komponenten, die von STADELMANN [101] untersucht und in Isopletenform dargestellt wurden, in einer Tabelle (Tab. 18) zusammengefasst.

Tabelle 18. N-Komponenten, Rotsee. Aus [101].

Table 18. $\mathrm{N}$ components, Rotsee. From [101].

\begin{tabular}{|c|c|c|c|c|}
\hline \multirow[t]{2}{*}{ N-Komponente } & \multicolumn{2}{|c|}{$\begin{array}{l}\text { Basiskonzentration } \\
\text { (Zirkulation } 0-7,5 \mathrm{~m} \text { ) }\end{array}$} & \multirow{2}{*}{$\begin{array}{l}\text { Konzentration am } \\
\text { Ende der Stagnation } \\
\text { im Epilimnion } \\
\text { Oktober } 1969 \\
\mu \mathrm{g} / 1\end{array}$} & \multirow{2}{*}{$\begin{array}{l}\text { Maximale Kon- } \\
\text { zentration } \\
\text { in } 14 \mathrm{~m} \\
\text { März } 1969 \text { bis } \\
\text { März } 1970 \\
\mu \mathrm{g} / 1\end{array}$} \\
\hline & $\begin{array}{l}\text { März } 1969 \\
\mu \mathrm{g} / \mathrm{l}\end{array}$ & $\begin{array}{l}\text { April } 1969 \\
\mu \mathrm{g} / 1\end{array}$ & & \\
\hline $\mathrm{NO}_{3}-\mathrm{N}$ & $550-690$ & $235-390$ & $10-20$ & $30-55$ \\
\hline $\mathrm{NO}_{2}-\mathrm{N}$ & $3,8-7,0$ & $15,3-76,0$ & 0,4 & $\begin{array}{c}0 \\
\text { (April: } 60,0)\end{array}$ \\
\hline $\mathrm{NH}_{4}-\mathrm{N}$ & $90-1050$ & $170-1430$ & $0-10$ & 9560 \\
\hline $\begin{array}{l}\text { partikulärer } \mathrm{N} \\
\text { gelöster } \\
\text { organischer }\end{array}$ & $160-1290$ & $580-1280$ & $240-320$ & 1470 \\
\hline Kjeldahl-N & $260-430$ & $200-880$ & $210-340$ & 1440 \\
\hline
\end{tabular}

\subsection{Eisen}

EINSELE [20, 21, 22] hat den Eisen- und Mangankreislauf in eutrophen Seen mit zeitweise sauerstoffreiem Hypolimnion eingehend beschrieben und die Zusammenhänge mit dem Phosphorkreislauf aufgezeigt. Seine Darstellung als einfache Redoxreaktion: 
$4 \mathrm{Fe}^{\mathrm{II}}\left(\mathrm{HCO}_{3}\right)_{2}+\mathrm{O}_{2}+12 \mathrm{H}_{2} \mathrm{O} \rightleftharpoons 4 \mathrm{Fe}^{\mathrm{III}}(\mathrm{OH})_{3}+8 \mathrm{H}_{2} \mathrm{CO}_{3}+2 \mathrm{H}_{2} \mathrm{O}$ und damit die modellmässige Vorstellung von der Ausfällung und Wiederauflösung des Eisens in Abhängigkeit vom Sauerstoffgehalt des Wassers muss heute allerdings als überholt betrachtet werden. Neue chemische Untersuchungen erbrachten die Erkenntnis, dass Eisen nur äusserst selten als einfaches Kation vorliegt, sondern meist in Form hochdispergierter Kolloide oder als Eisenkomplexe, z. B. als amorpher Goethitüberzug $(\mathrm{FeOOH})[94,108]$, der eine Hülle um Tonmineralpartikel bildet und als Kern zur Bildung eines Eisen-Phosphor-Komplexes betrachtet werden muss [126, 121]. Man nimmt an, dass diese hydratisierten Eisenoxid-Phosphat-Komplexe weniger gut löslich sind als Eisenphosphat $\left(\mathrm{FePO}_{4}\right)$ oder Eisenhydroxid $\left(\mathrm{Fe}(\mathrm{OH})_{3}\right)$. Da das Eisen zudem bei einem relativ niedrigen Redoxpotential von $p \varepsilon+1$ bis -9 [108] reduziert wird, ist es nicht quantitativ an den Redoxvorgängen beteiligt.

Qualitativ sind die Erkenntnisse EINSELEs zweifellos richtig. Ein Hypolimnion, das sauerstofffrei ist, mit freiem $\mathrm{CO}_{2}$ und zersetzbarem organischem Material angereichert ist und einen $\mathrm{pH}$-Wert unter 7,5 aufweist, ist ein bevorzugtes Milieu, welches das partikuläre Eisen reduziert und als Eisen(II)-Verbindungen in Lösung bringt [100]. Nebst diesen Rücklösungsvorgängen treten aber auch, beim Vorhandensein von $\mathrm{H}_{2} \mathrm{~S}$ als Reduktionsmittel, Fällungsreaktionen in Form von FeS auf. Bei Sauerstoffzutritt (Frühlings- und Herbstzirkulation) wird das zweiwertige Eisen zu dreiwertigem aufoxidiert und ausgefällt. Dabei bildet sich zwar kein $\mathrm{FePO}_{4}[108]$, jedoch wird das Phosphat mit dem dreiwertigen Eisen in einem bis jetzt noch unbekannten Mechanismus gefällt. Nun laufen aber diese chemischen Vorgänge in einem See nie so vollständig ab, wie es aufgrund von Berechnungen zu erwarten wäre. Nebst den äusserst komplizierten chemischen Abläufen ist dies offenbar auch eine Folge der im Vergleich zu den Lösungen in Laborexperimenten geringen Konzentrationen, und in unserem Falle reichten selbst Gesamteisengehalte von über $200 \mu \mathrm{g} / 1$. nicht aus. Die Korrelationsberechnungen von ScHEGG [93] (S. 449 und 502) bestätigen, dass im Rotsee trotz eines mächtigen sauerstofffreien Hypolimnions kein enger, quantitativer Zusammenhang zwischen dem Eisengehalt und dem Sauerstoffgehalt des Wassers besteht. Die eigenen, später zu besprechenden chemischen Analysen des Sedimentes unterstreichen diese Feststellung (siehe Abschnitt 4.46, S. 113).

Trotzdem lassen sich aufgrund der Isopletendarstellungen gewisse Zusammenhänge in der Verteilung erkennen.

Vergleicht man das gelöste Eisen (Abb. 26) mit den Sauerstoffverhältnissen (Abb. 21, S. 102), so ersieht man, dass sich die sauerstofffreie Tiefenzone mehr oder weniger genau mit den hypolimnischen Eisenanreicherungen (Werte über $20 \mu \mathrm{g} / \mathrm{l}$ ) deckt, während die Eisengehalte in den Wasserschichten über 7,5 m nur sporadisch über $20 \mu \mathrm{g} / \mathrm{l}$ anstiegen.

Beim partikulären Eisen (Abb. 27) vermisst man die erwartete, zum gelösten Eisen streng antagonistische Verteilung; schwer erklärbar sind vor allem die hohen hypolimnischen Konzentrationen (über $100 \mu \mathrm{g} / \mathrm{l}$ ). Diese können entweder auf die bekannten Unzulänglichkeiten der o-Phenanthrolin-Methode [102, 12] oder auf Fällungen von FeS oder Vivianit (Fe-II-Phosphat) zurückgeführt werden.

Das Gesamteisen (Abb. 28) zeigt, wie im Vierwaldstättersee, ein Verteilungsbild, welches demjenigen des partikulären Eisens sehr ähnlich ist und erreichte meistens Konzentrationen zwischen 30 und $200 \mu \mathrm{g} / \mathrm{l}$, über Grund zeitweise sogar über $300 \mu \mathrm{g} / \mathrm{l}$. 

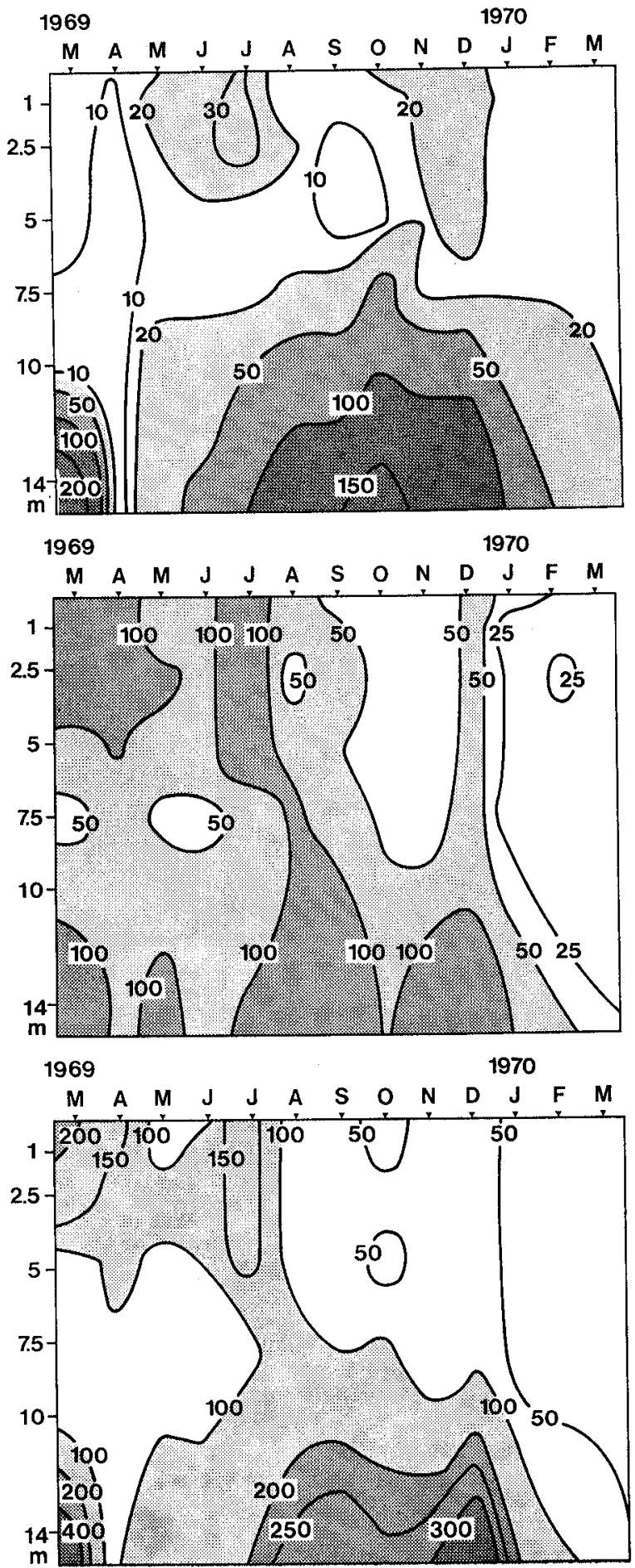

Abb. 26. Gelöstes Eisen des Rotsees ( $\mu \mathrm{g} \mathrm{Fe} / 1$ ).

Fig. 26. Dissolved iron concentration in the Rotsee ( $\mu \mathrm{g} \mathrm{Fe} / \mathrm{l}$ ).
Abb. 27. Partikuläres Eisen des Rotsees ( $\mu \mathrm{g}$ PFe/1).

Fig. 27. Particulate iron concentration in the Rotsee ( $\mu$ g PFe/l).

Abb. 28. Gesamteisenkonzentrationen des Rotsees ( $\mu$ g Gesamt-Fe/1). Fig. 28. Total iron concentration in the Rotsee ( $\mu \mathrm{g} \mathrm{Fe}$ tot $/ 1$ ). 


\subsection{Kieselsäure $\left(\mathrm{SiO}_{2}\right)$}

Die Kieselsäuregehalte (Abb. 29) erreichten im Hypolimnion des Rotsees Werte über 5 bis gegen $8 \mathrm{mg} / 1$ (Juli 1969 bis Januar 1970) und waren somit etwa doppelt so hoch wie diejenigen in der Horwer Bucht. Die epilimnischen $\mathrm{SiO}_{2}$-Zehrungen im März-April und August bis Oktober deuten zwei Maxima in der Kieselalgenentwicklung an, auf die später bei der Besprechung des Phytoplanktons (Abschnitt 5.27, S. 138) eingegangen werden soll.

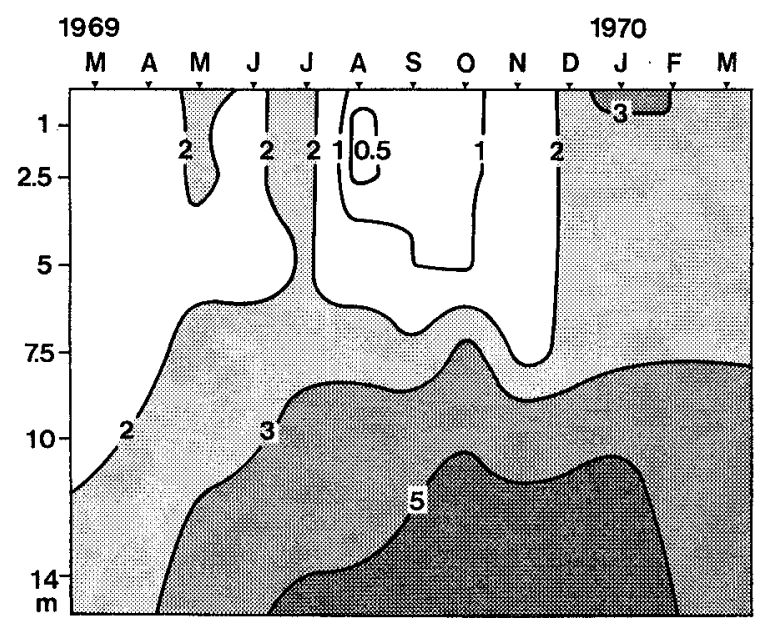

Abb. 29. Kieselsäure $\left(\mathrm{SiO}_{2}\right)$ des Rotsees $\left(\mathrm{mg} \mathrm{SiO}_{2} / \mathrm{l}\right)$. Fig. 29. Silicic acid $\left(\mathrm{SiO}_{2}\right)$ concentration in the Rotsee ( $\mathrm{mg} \mathrm{SiO} / 2 /)$.

\subsection{Sedimentation im Rotsee}

\subsection{Sedimentationsraten (Trockensubstanz)}

Die Sedimentationsraten (Tab. 19) im polytrophen Rotsee schwankten zwischen 0,4 und $13,8 \mathrm{~g}$ Trockengewicht $/ \mathrm{m}^{2} \cdot \mathrm{Tag}$ und lagen damit nur wenig über denjenigen im mesotrophen Vierwaldstättersee (vgl. Tab. 6, S. 92). Die Maximalwerte wurden während der Hauptvegetationszeit der Diatomeen im Juni bis September mit über $5 \mathrm{~g} / \mathrm{m}^{2} \cdot$ Tag erreicht (Abb. 30). Die Zirkulation verminderte die Sedimentation auf weniger als $2 \mathrm{~g} / \mathrm{m}^{2}$.Tag; immerhin kamen die Produktionsspitzen im Frühling 1969 (Chlorophyceen) und im Winter 1969/70 (Cryptophyceen) in zwei relativen Sedimentationsmaxima zum Ausdruck.

Wie schon im Vierwaldstättersee ergab sich im Rotsee eine unregelmässige Verteilung der Sedimentationsraten in den verschiedenen Tiefenstufen.

\subsection{Organische Substanz und organischer Kohlenstoff}

Der Anteil der organischen Substanz (Glühverlust) (Tab. 20) umfasst alle leicht zerstörbaren Bestandteile der sedimentierten Biomasse (Proteine, Reserve-Kohlenwasserstoffe, Fette) und war in den aufgefangenen Sedimenten des äusserst produktiven Rotsees sehr hoch (12-75\% der TS). Im zeitlichen Verlauf war ein klarer Zusammenhang mit der Produktion und der Biomasse festzustellen, während die Sedimentation in der Tiefenverteilung sehr unausgeglichen war (Tab. 22). Die Maxima der Sedimentationsraten organischen Materials im April, Juni-September und De- 
Tabelle 19. Sedimentationsraten, Rotsee, in $\mathrm{g} \mathrm{TS} / \mathrm{m}^{2}$ + Tag.

Table 19. Rates of sedimentation, Rotsee, in $\mathrm{g}$ of dry matter $/ \mathrm{m}^{2} \cdot$ day.

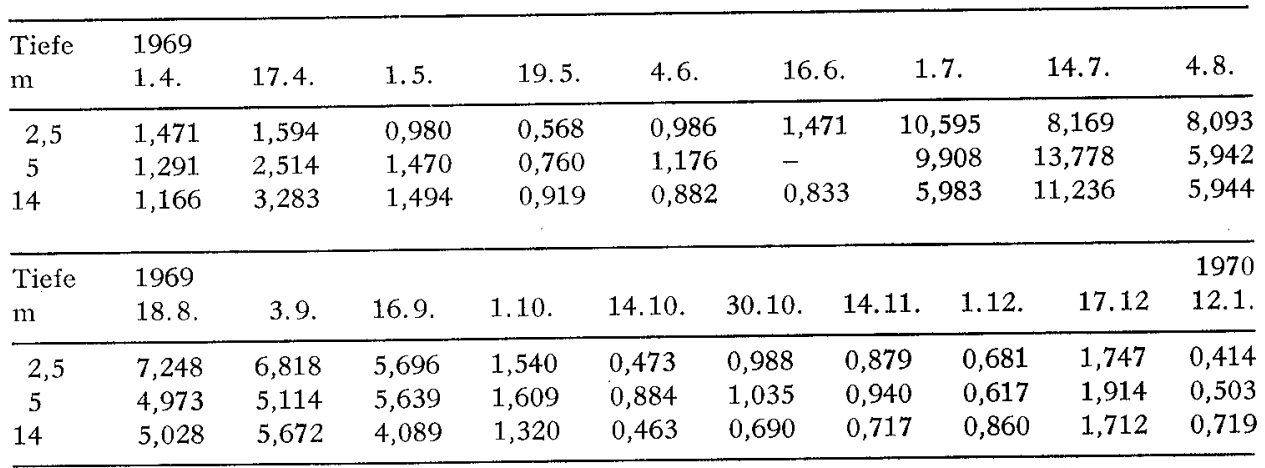

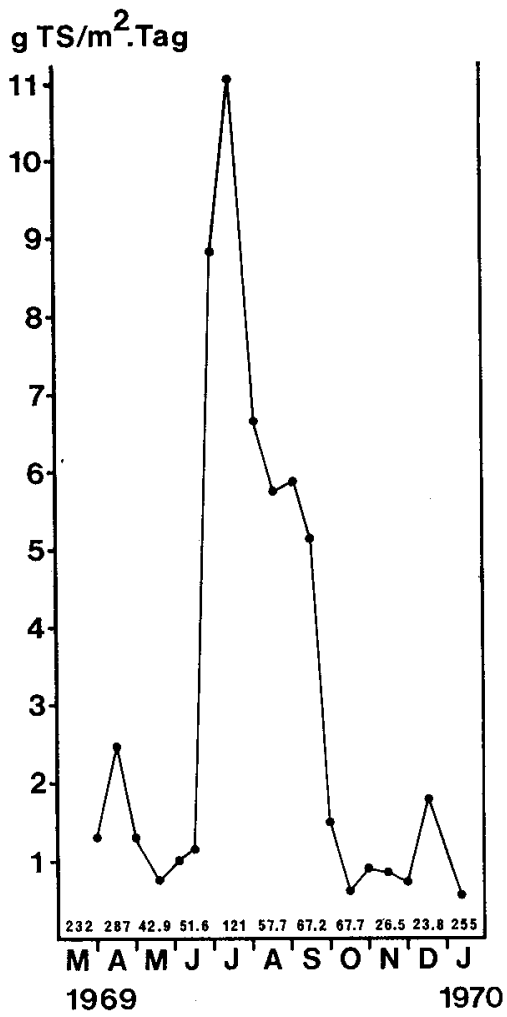

Abb. 30. Sedimentationsraten, Rotsee, in $\mathrm{g} \mathrm{TS} / \mathrm{m}^{2} \cdot \mathrm{Tag}$ (Durchschnittswerte der Stufen 2,5-14 m).

Zahlen unter der Kurve = maximale monatliche Photosyntheseraten in $\mathrm{mg} \mathrm{C}_{\text {ass }} / \mathrm{m}^{3} \cdot \mathrm{h}$, aus Stadelmann [101], S. 35.

Fig. 30. Rates of sedimentation, Rotsee, in $\mathrm{g}$ of dry matter $/ \mathrm{m}^{2} \cdot$ day (average values of the levels $2.5-14 \mathrm{~m}$ ). Numbers below the curve correspond to maximum monthly rates of photosynthesis in $\mathrm{mg} \mathrm{C} \mathrm{C}_{\text {ass }} / \mathrm{m}^{3} \cdot$ hour, from Stadelmann [101], p. 35.

zember fielen immer bei festgestellten Biomassemaxima im Seewasser an, die ihrerseits durch erhöhte Produktionsmessungen angezeigt wurden (vgl. [101], S. 35). Der prozentuale Anteil der organischen Substanz an der gesamten Trockensubstanz verhielt sich umgekehrt: während der Produktionsminima war der Anteil hoch, während der Produktionsmaxima infolge der intensivierten biogenen Entkalkung (vgl, 4.44, S. 111) klein. 
Tabelle 20. Organische Substanz (Glühverlust) im Sediment des Rotsees in \% der Trockensubstanz (TS).

Table 20. Organic substance (loss on ignition) in the sediment of the Rotsee in \% of dry matter (TS).

\begin{tabular}{|c|c|c|c|c|c|c|c|c|c|c|}
\hline $\begin{array}{l}\text { Tiefe } \\
\text { m }\end{array}$ & $\begin{array}{l}1969 \\
1.4 .\end{array}$ & 17.4 & 1.5. & 19.5. & 4.6. & \multicolumn{2}{|c|}{16.6.} & .7 & 14.7 & 4.8 \\
\hline 2,5 & 45,2 & 32,5 & 41,7 & 65,7 & 45,5 & \multicolumn{2}{|c|}{34,9} & 12,1 & 15,6 & 20,0 \\
\hline 5 & 42,5 & 42,7 & 46,4 & 59,3 & 50,0 & \multicolumn{2}{|l|}{-} & 12,7 & 13,4 & 17,7 \\
\hline 14 & 38,1 & 39,5 & 37,3 & 68,4 & 39,8 & \multicolumn{2}{|c|}{30,0} & 13,1 & 14,5 & 20,3 \\
\hline Tiefe & 1969 & & & & & & & & & 1970 \\
\hline $\mathrm{m}$ & 18.8 & 3.9. & 16.9 & 1.10. & 14.10 & 30.10 & 14.11 & 1.12. & 17.12 & 12.1 \\
\hline 2,5 & 20,4 & 17,6 & 18,0 & 47,2 & 67,3 & 73,1 & 43,5 & 55,3 & 76,1 & 97,7 \\
\hline 5 & 24,0 & 19,9 & 20,0 & 37,7 & 57,8 & 58,0 & 43,5 & 50,9 & 74,5 & 55,9 \\
\hline 14 & 27,0 & 24,1 & 23,4 & 42,1 & 63,2 & 67,6 & 60,7 & 58,7 & 75,2 & 66,8 \\
\hline
\end{tabular}

Der organische Kohlenstoff (Tab. 21) durchlief etwa die gleichen saisonalen Veränderungen wie der totale organische Anteil des Sedimentes, variierte aber - quantitativ gesehen - nicht parallel, weshalb im prozentualen Anteil des organischen $\mathrm{C}$ an der gesamten organischen Substanz eine deutliche Differenz zu Tage trat (Tab. 22): wenn prozentual viel $(>30 \%)$ organisches Material anfiel, betrug dieser Anteil durchschnittlich $48-50 \%$; bei geringem organischem Substanzgehalt stieg er auf durchschnittlich $61 \%$ an. Dass gerade in der Zeit vom 1. Juli bis 16 . September 1969 die minimalen Sedimentanteile an Gesamt-P und Gesamt-N vorlagen (vgl. Tab. 27 und 28, S. 113), könnte ein Hinweis darauf sein, dass im «kleinen Stoffkreislauf» vor allem Pund N-Komponenten freigesetzt wurden, während der schwerer abbaubare Kohlenstoff $\mathbf{z u}$ einem grösseren Teil aussedimentierte.

Tabelle 21. Organischer Kohlenstoff im Sediment des Rotsees in \% der Trockensubstanz (TS). Table 21. Organic carbon in the sediment of the Rotsee in $\%$ of dry matter (TS).

\begin{tabular}{|c|c|c|c|c|c|c|c|c|c|c|c|}
\hline $\begin{array}{l}\text { Tiefe } \\
\text { m }\end{array}$ & $\begin{array}{l}1969 \\
1.4 .\end{array}$ & 17.4 & 1.5 . & 19.5. & 4.6. & \multicolumn{2}{|c|}{16.6.} & \multicolumn{2}{|c|}{1.7.} & 14.7 & 4.8 \\
\hline 2,5 & 22,11 & 16,13 & 22,15 & 30,58 & 22,65 & 18 & & 5 , & & 9,22 & 12,52 \\
\hline 5 & 21,22 & 19,05 & 24,45 & 26,95 & 22,16 & - & & 9 & & 7,88 & 13,91 \\
\hline 14 & 19,33 & 19,24 & 18,96 & 31,95 & 20,41 & 18 & & 10 , & & 7,01 & 14,69 \\
\hline Tiefe & 1969 & & & & & & & & & & 1970 \\
\hline $\mathrm{m}$ & 18.8 & 3.9. & 16.9. & 1.10. & 14.10 & 30.10 & 14 & 11 & 1.12. & 17.12 & 12.1 \\
\hline 2,5 & 12,44 & 8,77 & 12,89 & 23,80 & 29,49 & 33,96 & 21 &, 79 & 26,09 & 36,89 & 30,36 \\
\hline 5 & 16,27 & 11,27 & 12,64 & 20,45 & 22,94 & 29,08 & 19 &, 87 & - & 37,69 & 32,96 \\
\hline 14 & 12,85 & 13,04 & 11,62 & 23,24 & 29,13 & 31,91 & 28 & 17 & 28,11 & 38,54 & 30,89 \\
\hline
\end{tabular}

\subsection{Salzsäure-unlöslicher Anteil}

Die mineralische Grundsubstanz (Tab. 23) lag auf Kosten des wesentlich höheren organischen Anteils tiefer als im Sediment des Vierwaldstättersees und erreichte Werte von 5 bis $31 \%$ der TS. Die zeitliche Verteilung der mineralischen Sedimentation ging parallel mit derjenigen der organischen Substanz mit Minimalanteilen während 
Tabelle 22. Die organischen Bestandteile des Sedimentes in der jahreszeitlichen Veränderung. Rotsee.

Table 22. Seasonal fluctuation in the organic components of the sediment. Rotsee.

\begin{tabular}{|c|c|c|c|c|c|c|}
\hline$\overline{\text { Zeit }}$ & $1.4 .-17.4 .1969$ & 1. 5.-16.6. 1969 & 1.7.-16.9. 1969 & 1. 10.-1. 12. 1969 & 17.12 .1969 & 12. 1. 1970 \\
\hline Temperatur & Zirkulation & Stagnation & Stagnation & Zirkulation & $\begin{array}{l}\text { Stagnation } \\
\text { invers }\end{array}$ & $\begin{array}{l}\text { Stagnation } \\
\text { invers }\end{array}$ \\
\hline $\begin{array}{l}\text { Produktion (Höchstwerte) } \\
\mathrm{mg} \mathrm{C}_{\text {ass }} / \mathrm{m}^{3} \cdot \mathrm{h}\end{array}$ & $232-287$ & $43-52$ & $56-121$ & $22-68$ & - & 255 \\
\hline Biomasse & Maximum & Minimum & Maximum & Minimum & Maximum & Maximum \\
\hline $\begin{array}{l}\text { Organische Substan } z \\
\text { (Glühverlust) } \\
\mathrm{g} / \mathrm{m}^{2} \cdot \text { Tag }\end{array}$ & $\begin{array}{l}\text { viel } \\
0,5-1,3 \\
\varnothing 0,75\end{array}$ & $\begin{array}{l}\text { wenig } \\
0,25-0,7 \\
\varnothing 0,45\end{array}$ & $\begin{array}{l}\text { sehr viel } \\
0,8-1,85 \\
\varnothing 1,25\end{array}$ & $\begin{array}{l}\text { wenig } \\
0,3-0,7 \\
\varnothing 0,50\end{array}$ & $\begin{array}{l}\text { sehr viel } \\
\mathbf{1}, 3-1,45 \\
\varnothing 1,35\end{array}$ & $\begin{array}{l}\text { wenig (?) } \\
0,3-0,5 \text { (?) } \\
\varnothing 0,40(?)\end{array}$ \\
\hline $\begin{array}{l}\text { Organische Substanz } \\
\text { (Glühverlust) } \\
\% \text { der TS }\end{array}$ & $\begin{array}{l}\text { viel } \\
32-46 \\
\varnothing 40\end{array}$ & $\begin{array}{l}\text { viel } \\
30-68 \\
\varnothing 47\end{array}$ & $\begin{array}{l}\text { wenig } \\
12-27 \\
\varnothing 18,5\end{array}$ & $\begin{array}{l}\text { sehr viel } \\
37-98 \\
\varnothing 61\end{array}$ & & \\
\hline $\begin{array}{l}\text { Organischer C } \\
\% \text { der TS }\end{array}$ & $\begin{array}{l}\text { viel } \\
16-22 \\
\varnothing 19,5\end{array}$ & $\begin{array}{l}\text { viel } \\
18-32 \\
\varnothing 23,4\end{array}$ & $\begin{array}{l}\text { wenig } \\
5-16 \\
\varnothing 11,2\end{array}$ & $\begin{array}{l}\text { viel } \\
20-38,5 \\
\varnothing 28,8\end{array}$ & & \\
\hline $\begin{array}{l}\% \text {-Anteil des organischen C } \\
\text { in der gesamten } \\
\text { organischen Substanz }\end{array}$ & $\begin{array}{l}\text { mittel } \\
44-51 \\
\varnothing 48,7\end{array}$ & $\begin{array}{l}\text { mittel } \\
44-61 \\
\varnothing 50,4\end{array}$ & $\begin{array}{l}\text { hoch } \\
47-78 \\
\varnothing 61,2\end{array}$ & $\begin{array}{l}\text { mittel } \\
31-59 \\
\varnothing 47,8\end{array}$ & & \\
\hline $\begin{array}{l}\text { Tiefenverteilung } \\
\text { der Sedimentation }\end{array}$ & \multicolumn{2}{|c|}{$\begin{array}{l}\text { uneinheitlich, Tendenz: } \\
\text { Abnahme nach unten; } \\
\text { Abbau nach Tiefe hin }\end{array}$} & $\begin{array}{l}\text { Zunahme } \\
\text { nach unten }\end{array}$ & \multicolumn{3}{|c|}{$\begin{array}{l}\text { uneinheitlich, Tendenz: } \\
\text { Abnahme nach unten; } \\
\text { Abbau nach Tiefe hin }\end{array}$} \\
\hline
\end{tabular}


des Sommerproduktionsmaximums (1. Juli bis 16. September 1969); in dieser Zeitspanne trat eine gesteigerte Kalkausfällung (biogene Entkalkung) in Erscheinung (vgl. 4.44). Die mineralischen Sedimentationsraten stiegen nur am 14. Juli wesentlich über $1 \mathrm{~g} / \mathrm{m}^{2} \cdot$ Tag, während sie sonst im Sommer um $0,5-1 \mathrm{~g} / \mathrm{m}^{2} \cdot$ Tag lagen und im Winter zum Teil unter $0,1 \mathrm{~g} / \mathrm{m}^{2} \cdot$ Tag herabsanken.

Tabelle 23. Salzsäure-unlöslicher Anteil des Sedimentes des Rotsees in \% der Trockensubstanz (TS).

Table 23. HCl-insoluble fraction of the sediment of the Rotsee in \% of dry matter (TS).

\begin{tabular}{|c|c|c|c|c|c|c|c|c|c|c|}
\hline $\begin{array}{l}\text { Tiefe } \\
\text { m }\end{array}$ & $\begin{array}{l}1969 \\
1.4 .\end{array}$ & 17.4 . & 1.5. & 19.5. & 4.6. & 16 & & 1.7. & 14.7 & 4.8 \\
\hline 2,5 & 31,0 & 13,9 & 26,0 & 23,0 & 26,8 & 29 & & 9,8 & 17,3 & 8,2 \\
\hline 5 & 30,0 & 18,2 & 24,1 & 29,0 & 27,5 & - & & $9, \mathbf{1}$ & 22,7 & 10,5 \\
\hline 14 & 23,8 & 19,4 & 19,5 & 27,2 & 22,3 & 23 & & 10,3 & 21,5 & 8,2 \\
\hline $\begin{array}{l}\text { Tiefe } \\
\text { m }\end{array}$ & 1969 & 30 & 160 & 110 & 14.10 & 3010 & 1411 & 12 & 1712 & 1970 \\
\hline 2,5 & 15,4 & 10,5 & 5,3 & 7,9 & 11,5 & 10,9 & 21,2 & 13,4 & 9,3 & 0,8 \\
\hline 5 & 13,7 & 12,4 & 6,2 & 11,7 & 14,0 & 15,8 & 21,9 & 17,0 & 17,9 & 19,5 \\
\hline 14 & 14,4 & 11,8 & 5,8 & 12,2 & 10,5 & 11,1 & 17,4 & 13,1 & 20,6 & 12,0 \\
\hline
\end{tabular}

\subsection{Kalzium und Magnesium}

Die Kalzium- wie die Magnesiumgehalte im Sediment des Rotsees lagen in der gleichen Grössenordnung wie in jenem des Vierwaldstättersees. Das Kalzium (Tab. 24) machte $3-44 \%$ und das Magnesium (Tab. 25) 0,15-3\% der TS aus. Es liessen sich hier die gleichen Tendenzen feststellen, nämlich eine ziemlich regelmässige Magnesiumverteilung sowohl in der Zeit wie in der Tiefe und eine gewisse, allerdings nicht mehr so klare Abhängigkeit des Kalziums von der Temperaturschichtung und der Produktion (Tab. 26). Während der Produktionsspitzen stiegen die Ca-Gehalte im Sediment als Folge der biogenen Entkalkung an. Eine besondere Situation herrschte im Winter 1969/70: Die sehr geringen Ca-Werte sind dadurch zu erklären, dass viel $\mathrm{CaCO}_{3}$ in Lösung gehen konnte, weil durch die Zirkulation grosse hypolimnische, sauerstofffreie und $\mathrm{CO}_{2}$-reiche Wassermassen bis an die Oberfläche des Sees transportiert wurden.

Das Ca:Mg-Verhältnis war ähnlich wie im Vierwaldstättersee; es schwankte, von einigen Ausnahmen abgesehen, zwischen 8 und 80:1 und lag während der Sommerstagnation höher (um 40:1) als während der Zirkulation (um 20:1).

\subsection{Phosphor und Stickstoff}

Sowohl die P- und N-Gehalte im Sediment des Rotsees (Tab. 27 und 28) wie auch die P- und N-Sedimentationsraten waren entsprechend den höheren Konzentrationen dieser Hauptnährstoffe im Seewasser gegenüber dem Vierwaldstättersee erhöht. Die $P$-Sedimentationsraten lagen in produktionsintensiven Perioden bei $5-14 \mathrm{mg} / \mathrm{m}^{2} \cdot \mathrm{Tag}$, in den $Z$ wischenzeiten $1,5-4,5 \mathrm{mg} / \mathrm{m}^{2}$.Tag. Die $N$-Sedimentationsraten erreichten Werte von 30 bis $120 \mathrm{mg} / \mathrm{m}^{2}$.Tag bei Produktionsmaxima bzw. 16 bis $50 \mathrm{mg} / \mathrm{m}^{2} \cdot$ Tag bei 
Tabelle 24. Kalzium ( $\mathrm{Ca}^{2+}$ ) im Sediment des Rotsees in \% der Trockensubstanz (TS).

Table 24. Calcium $\left(\mathrm{Ca}^{2+}\right)$ in the sediment of the Rotsee in \% of dry matter (TS).

\begin{tabular}{|c|c|c|c|c|c|c|c|c|c|c|}
\hline $\begin{array}{l}\text { Tiefe } \\
\text { m }\end{array}$ & $\begin{array}{l}1969 \\
1.4 .\end{array}$ & 17.4. & 1.5. & 19.5. & 4.6. & \multicolumn{2}{|c|}{16.6} & 1.7. & 14.7. & 4.8 \\
\hline 2,5 & 4,75 & 16,80 & 8,70 & 4,00 & 5,45 & \multicolumn{2}{|c|}{9,20} & 29,40 & 21,70 & 26,30 \\
\hline 5 & 5,00 & 12,00 & 8,10 & 3,35 & 6,25 & \multicolumn{2}{|c|}{-7170} & \multirow{2}{*}{$\begin{array}{l}44,30 \\
28,90\end{array}$} & 19,00 & 25,90 \\
\hline 14 & 10,50 & 12,10 & 11,90 & 2,40 & 10,00 & & & & 19,10 & 25,50 \\
\hline Tiefe & 1969 & & & & & & & & & 1970 \\
\hline $\mathrm{m}$ & 18.8 & 3.9. & 16.9. & 1.10. & 14.10 & 30.10 . & 14.11 & 1.12. & 17.12 . & 12.1 \\
\hline 2,5 & 22,50 & 24,60 & 27,90 & 15,10 & 5,80 & 3,35 & 9,65 & 6,95 & 2,80 & 3,55 \\
\hline 5 & 21,90 & 22,70 & 26,90 & 16,95 & 8,20 & 6,30 & 10,10 & 8,00 & 3,00 & 6,05 \\
\hline 14 & 20,30 & 21,10 & 25,80 & 15,20 & 7,75 & 5,55 & 6,90 & 7,30 & 2,70 & 2,60 \\
\hline
\end{tabular}

Tabelle 25. Magnesium $\left(\mathrm{Mg}^{2+}\right)$ im Sediment des Rotsees in \% der Trockensubstanz (TS). Table 25. Magnesium $\left(\mathrm{Mg}^{2+}\right)$ in the sediment of the Rotsee in \% of dry matter (TS).

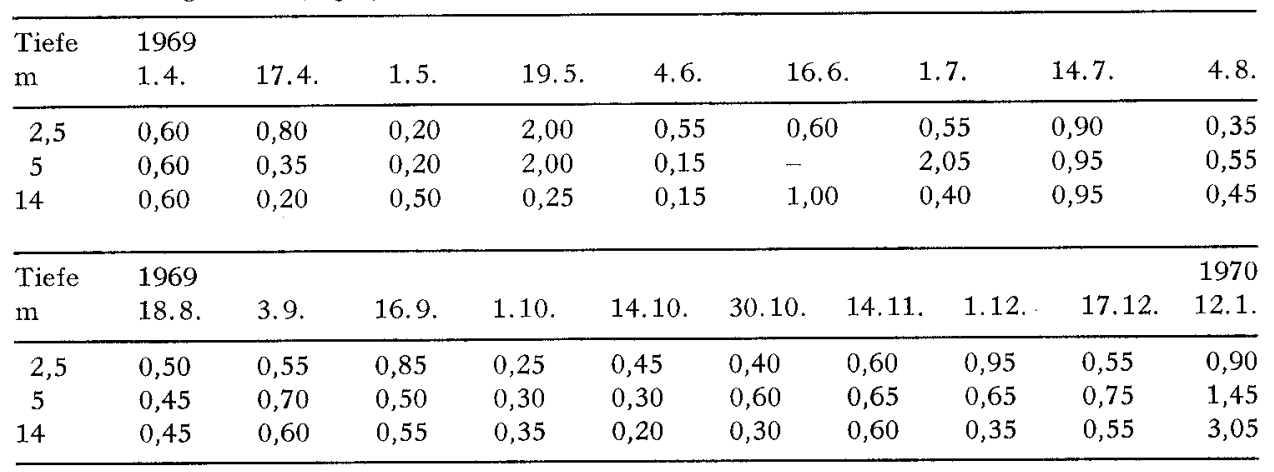

Tabelle 26. Die Kalziumsedimentation in der jahreszeitlichen Veränderung. Rotsee.

Table 26. Seasonal fluctuation in the sedimentation of calcium. Rotsee.

\begin{tabular}{|c|c|c|c|c|c|}
\hline Zeit & $\begin{array}{l}\text { 1. 4.- } \\
17.4 .1969\end{array}$ & $\begin{array}{l}1.5 .- \\
16.6 .1969\end{array}$ & $\begin{array}{l}\text { 1. } 7 .- \\
1.10 .1969\end{array}$ & $\begin{array}{l}14.10 .- \\
1.12 .1969\end{array}$ & $\begin{array}{l}17.12 .1969 m \\
12.1 .1970\end{array}$ \\
\hline Temperatur & Zirkulation & Stagnation & Stagnation & Zirkulation & $\begin{array}{l}\text { Stagnation } \\
\text { invers }\end{array}$ \\
\hline $\begin{array}{l}\text { Produktion (Höchst- } \\
\text { werte) } \mathrm{mg} \mathrm{C}_{\mathrm{ass}} / \mathrm{m}^{3} \cdot \mathrm{h}\end{array}$ & $232-287$ & $43-52$ & $56-121$ & $22-68$ & 255 \\
\hline Biomasse & Maximum & Minimum & Maximum & Minimum & Maximum \\
\hline $\begin{array}{l}\mathrm{Ca}^{2+} \\
\mathrm{mg} / \mathrm{m}^{2} \cdot \mathrm{Tag}\end{array}$ & $\begin{array}{l}65-400 \\
\varnothing 204\end{array}$ & $\begin{array}{l}22-180 \\
\varnothing 82\end{array}$ & $\begin{array}{l}200-4390 \\
\varnothing 1600\end{array}$ & $\begin{array}{c}27-95 \\
\varnothing 55\end{array}$ & $\begin{array}{l}15-57 \\
\varnothing 36\end{array}$ \\
\hline $\begin{array}{l}\mathrm{Ca}^{2+} \\
\% \text { der TS }\end{array}$ & $\begin{array}{l}5-17 \\
\varnothing 10,2\end{array}$ & $\begin{array}{l}3-12 \\
\varnothing 7,4\end{array}$ & $\begin{array}{l}19-44 \\
\varnothing 25,2\end{array}$ & $\begin{array}{l}3-10 \\
\varnothing 7,2\end{array}$ & $\begin{array}{l}3-6 \\
\varnothing 3,4\end{array}$ \\
\hline $\begin{array}{l}\text { Tiefenverteilung } \\
\text { der Sedimentation }\end{array}$ & $\begin{array}{l}\text { unregel- } \\
\text { mässig }\end{array}$ & $\begin{array}{l}\text { unregel- } \\
\text { mässig }\end{array}$ & $\begin{array}{l}\text { Abnahme } \\
\text { nach unten }\end{array}$ & $\begin{array}{l}\text { unregel- } \\
\text { mässig }\end{array}$ & $\begin{array}{l}\text { unregel- } \\
\text { mässig }\end{array}$ \\
\hline
\end{tabular}


Tabelle 27. Phosphor (Gesamt-P) im Sediment des Rotsees in \% der Trockensubstanz (TS).

Table 27. Total amount of phosphorus in the sediment of the Rotsee in \% of dry matter (TS).

\begin{tabular}{|c|c|c|c|c|c|c|c|c|c|c|}
\hline $\begin{array}{l}\text { Tiefe } \\
\mathrm{m}\end{array}$ & $\begin{array}{l}1969 \\
1.4 .\end{array}$ & 17.4 . & 1.5 & 19.5. & 4.6. & \multicolumn{2}{|c|}{16.6.} & 1.7. & 14.7 & 4.8. \\
\hline 2,5 & 0,51 & 0,32 & 0,37 & 0,42 & 0,32 & \multicolumn{2}{|c|}{0,26} & 0,10 & 0,11 & 0,11 \\
\hline 5 & 0,49 & 0,49 & 0,29 & 0,38 & 0,26 & \multicolumn{2}{|l|}{$\ldots$} & 0,10 & 0,10 & 0,18 \\
\hline 14 & 0,39 & 0,39 & 0,32 & 0,49 & 0,24 & \multicolumn{2}{|c|}{0,23} & & 0,12 & 0,19 \\
\hline Tiefe & 1969 & & & & & & & & & 1970 \\
\hline $\mathrm{m}$ & 18.8 & 3.9 . & 16.9. & 1.10 & 14.10 . & 30.10 . & 14.11. & 1.12 . & 17.12. & 12.1. \\
\hline 2,5 & 0,12 & 0,13 & 0,11 & 0,23 & 0,33 & 0,42 & 0,30 & 0,28 & 0,69 & 1,29 \\
\hline 5 & 0,24 & 0,18 & 0,14 & 0,25 & 0,29 & 0,28 & 0,27 & 0,71 & 0,29 & 0,69 \\
\hline 14 & 0,21 & 0,21 & 0,18 & 0,32 & 0,39 & 0,29 & 0,23 & 0,34 & 0,53 & 0,41 \\
\hline
\end{tabular}

Tabelle 28. Stickstoff (Gesamt-N) im Sediment des Rotsees in \% der Trockensubstanz (TS). Table 28. Total amount of nitrogen in the sediment of the Rotsee in \% of dry matter (TS).

\begin{tabular}{|c|c|c|c|c|c|c|c|c|c|c|}
\hline $\begin{array}{l}\text { Tiefe } \\
\mathrm{m}\end{array}$ & $\begin{array}{l}1969 \\
1.4 .\end{array}$ & 17.4 . & 1.5. & 19.5 . & 4.6. & \multicolumn{2}{|c|}{16.6.} & 7. & 14.7 & 4.8. \\
\hline 2,5 & 3,00 & 2,16 & 3,23 & 4,97 & 3,05 & \multicolumn{2}{|c|}{2,19} &, 29 & 0,72 & 0,97 \\
\hline 5 & 2,70 & 2,63 & 3,46 & 4,26 & 2,88 & \multicolumn{2}{|l|}{-} & 0,37 & 0,46 & 1,07 \\
\hline 14 & 2,36 & 2,69 & 2,37 & 4,91 & 2,53 & \multicolumn{2}{|c|}{1,98} & & 0,47 & 1,18 \\
\hline $\begin{array}{l}\text { Tiefe } \\
\mathrm{m}\end{array}$ & $\begin{array}{l}1969 \\
18.8\end{array}$ & 3.9 . & 16.9. & 1.10. & 14.10 & 30.10 & 14.11 . & 1.12. & 17.12 & $\begin{array}{c}1970 \\
12.1 .\end{array}$ \\
\hline 2,5 & 0,86 & 0,63 & 0,82 & 2,41 & 3,55 & 4,43 & 2,88 & 3,98 & 6,48 & 4,39 \\
\hline 5 & 1,17 & 0,95 & 0,93 & 2,33 & 3,03 & 3,58 & 2,47 & - & 6,16 & 4,87 \\
\hline 14 & 1,28 & 1,14 & 1,02 & 2,74 & 4,06 & 4,37 & 4,27 & 4,48 & 6,52 & 4,71 \\
\hline
\end{tabular}

Produktionsminima. Während der Stagnationszeit vom 1. Juli bis 16. September 1969 waren die P- und N-Anteile im Sediment kleiner als während der Zirkulationsperioden. Diese Tatsache weist auf einen vermehrten Umsatz des Phosphors und des Stickstoffs im «kleinen Stoffkreislauf» des Epilimnions hin.

Das N:P-Verhältnis (Abb. 31) war im Jahresdurchschnitt mit etwa 7-8:1 etwas kleiner als in der Horwer Bucht (10-11:1). Es streute zwar im Rotsee mehr als dort, doch scheinen die Quotienten im Sommer kleiner zu sein (im Durchschnitt 5,5:1) als im Winter (im Durchschnitt 10:1). Dieser Unterschied zur Horwer Bucht, wo die Werte im Sommer höher waren (vgl. 4.25, S. 96), könnte ein Hinweis auf eine zeitweilige wachstumslimitierende Wirkung des Stickstoffs im Rotsee sein (siehe auch Abschnitt 6.3, S. 172).

\subsection{Eisen und Mangan}

Im Gegensatz zur mesotrophen, relativ tiefen $(62 \mathrm{~m})$ Horwer Bucht des Vierwaldstättersees herrschten im polytrophen, flachen $(14 \mathrm{~m})$ Rotsee im Hypolimnion die anaeroben Verhältnisse vor, welche es ermöglichen, das Eisen und das Mangan theoretisch in Lösung zu halten: 


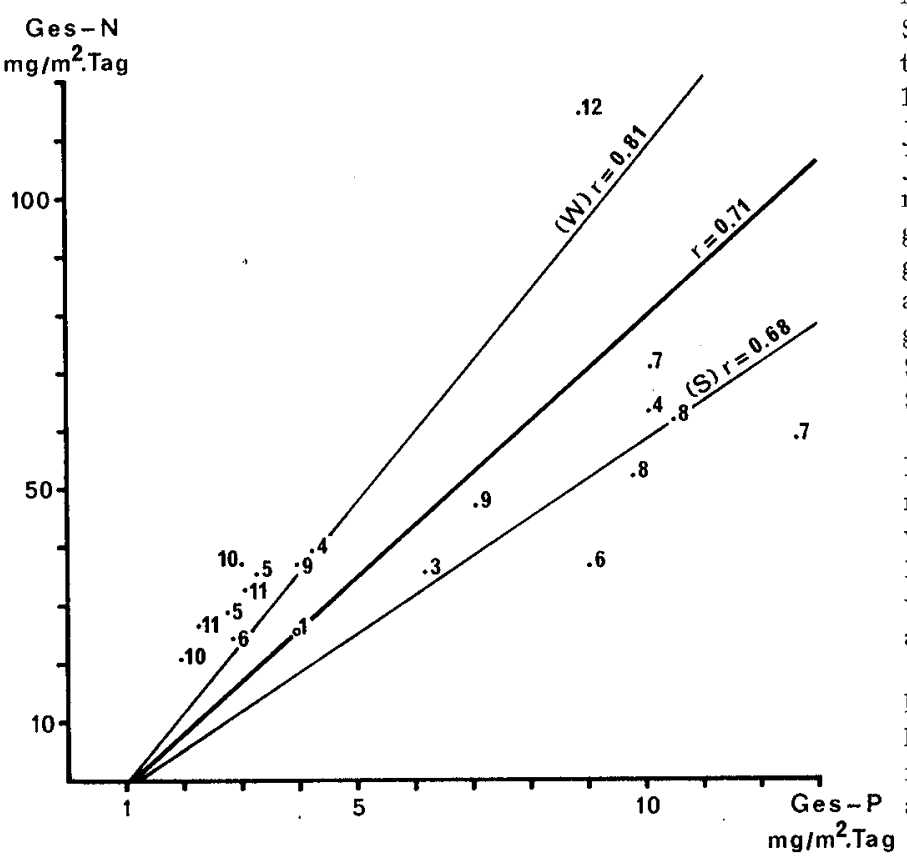

Abb. 31. N : P-Verhältnis mi Sediment des Rotsees. Mit telwerte aus 3 Stufen $(2,5,5$, $14 \mathrm{~m})$; - Werte aus dem Jahre 1969 , oWert aus dem Jahre 1970, die Monate sind numeriert. Stark ausgezogene Linie $=$ Regressionsgerade für alle Werte, dünn ausgezogene Linien $=\mathrm{Re}$ gressionsgeraden für die Sommermonate Juni bis September (S) und für die Wintermonate (W).

Fig.31. N: Pratio in the sediment of the Rotsee. Mean values from 3 levels $(2.5,5$, $14 \mathrm{~m})$; - values for 1969 , ० value for 1970 , the months are numbered. Heavy line $=$ regression line for all values, thin lines = regression lines for the summer months from June to September (S) and for the winter months (W).

- wenig $\mathrm{O}_{2}$ : unter $10 \mathrm{~m}$ immer $0 \mathrm{mg} \mathrm{O} / \mathrm{l}$ (vgl. 4.34, S. 102)

- hoher Gehalt an freiem $\mathrm{CO}_{2}: 12-33 \mathrm{mg} / \mathrm{l}$ (berechnet nach [90] und [95])

- pH unter 7,5: ab 5-14 m meist der Fall (vgl. 4.33, S. 101)

- Anwesenheit von zersetzbaren organischen Substanzen: zu erwarten (vgl. hoher organischer Gehalt im Sediment, 4.42, S. 107), so dass p $\varepsilon<+1$.

Am Mangan (Tab. 29), welches, ähnlich wie im Vierwaldstättersee, in einem Fe:MnVerhältnis von 6:1 (bei Anwesenheit von Sauerstoff) bis 33:1 (bei Abwesenheit von Sauerstoff) gefunden wurde (Ausnahme: am 12. Januar 1970 in 2,5 m Tiefe $3 \mathrm{mal}$ mehr Mn als Fe), kann die Ausfällung bzw. die Rücklösung in Abhängigkeit der Sauerstoff- und Schichtungsverhältnisse sehr schön aufgezeigt werden (Tab. 31): In der sauerstofffreien 14-m-Stufe waren die Redoxprozesse weniger intensiv als in den oberen Schichten, wo durch die Zirkulationen Sauerstoff eingetragen wurde. Das Mangan war über Grund zum grössten Teil gelöst, und die Mn-Gehalte im Sediment lagen deshalb nie über $0,05 \%$ der TS. Die beiden oberen Stufen zeigten bei viel gelöstem Sauerstoff viel $\mathrm{Mn}$ im Sediment (Oxidation und Ausfällung als $\mathrm{MnO}_{2}$ ); bei Sauerstoffschwund unter $1 \mathrm{mg} \mathrm{O}_{2} / 1$ sanken die $\mathrm{Mn}$-Werte im Sediment unter $0,1 \%$ der TS (Reduktion und Auflösung in Mn-II-Verbindungen). Hervorzuheben ist die Situation im Dezember 1969 bis Januar 1970: zunächst (17. Dezember) wurde durch eine volle Umwälzung des Seewassers viel gelöstes zweiwertiges $\mathrm{Mn}$ bis an die Oberfläche verfrachtet, das dann (12. Januar) bei eintretender inverser Schichtung und einer intensiv einsetzenden Produktion (Cryptomonas-Blüte unter der Eisdecke, vgl. 5.28 , S. 141) zu vierwertigem Mn aufoxidiert und in grossen Mengen wieder ausgefällt wurde. 
Wie im Vierwaldstättersee zeigte das Eisen (Tab. 30) ein völlig unregelmässiges Bild und verhielt sich nicht analog dem Mangan. Das Eisen ist viel weniger an Redoxvorgängen beteiligt, als man aufgrund der Arbeiten von EINSELE [20, 21, 22] angenommen hatte, weil es meist als Goethit-Úberzug (FeOOH) an Tonmineralien angelagert ist $[94,108,126,121]$ und bei tieferem Redoxpotential reduziert wird als das Mangan [108]. Eine $\mathrm{Fe}(\mathrm{OH})_{3}$ - oder $\mathrm{FePO}_{4}$-Fällung findet nicht statt [108]. Das sedimentierte Eisen rührt teils von rein chemischen Prozessen her (FeS oder Vivianit [Fe-II-Phosphat]), teils von bakterieller Tätigkeit (Eisenbakterien). Da die im Rotsee auftretende Leptothrix pseudovacuolata (Perfiliev) Dorff (siehe [93], S. 488/9) vermutlich auch Mangan verwerten kann [49, 57, 84], und da offensichtlich bedeutende Mengen von Mangan im Hypolimnion in Lösung sind (siehe Situation am 12. Januar 1970), liegt die Annahme nahe, dass im Rotsee der Mn-Kreislauf eine ebensowichtige Rolle spielt wie der Fe-Kreislauf.

Tabelle 29. Mangan (Gesamt-Mn) im Sediment des Rotsees in \% der Trockensubstanz (TS).

Table 29. Total amount of manganese in the sediment of the Rotsee in $\%$ of dry matter (TS).

\begin{tabular}{|c|c|c|c|c|c|c|c|c|c|c|}
\hline $\begin{array}{l}\text { Tiefe } \\
\mathrm{m}\end{array}$ & $\begin{array}{l}1969 \\
1.4 .\end{array}$ & 17.4. & 1.5. & 19.5. & 4.6. & \multicolumn{2}{|c|}{16.6} & 7. & 14.7 & 4.8. \\
\hline 2,5 & 0,46 & 0,53 & 0,39 & 0,13 & 0,23 & \multicolumn{2}{|c|}{0,04} & 06 & 0,06 & 0,01 \\
\hline 5 & 0,44 & 0,70 & 0,22 & 0,15 & 0,07 & \multicolumn{2}{|l|}{-} & 03 & 0,04 & 0,02 \\
\hline 14 & 0,04 & 0,09 & 0,05 & 0,03 & 0,04 & \multicolumn{2}{|c|}{0,04} & 03 & 0,03 & 0,02 \\
\hline Tiefe & 1969 & & & & & & & & & 1970 \\
\hline $\mathrm{m}$ & 18.8 & 3.9 . & 16.9. & 1.10 & 14.10 & 30.10 & 14.11. & 1.12 . & 17.12. & 12.1. \\
\hline 2,5 & 0,02 & 0,02 & 0,01 & 0,01 & 0,21 & 0,17 & 0,60 & 0,37 & 0,07 & 4,88 \\
\hline 5 & 0,03 & 0,02 & 0,01 & 0,02 & 0,13 & 0,12 & 0,47 & - & 0,08 & 1,64 \\
\hline 14 & 0,03 & 0,03 & 0,02 & 0,02 & 0,05 & 0,04 & 0,03 & 0,03 & 0,03 & 0,05 \\
\hline
\end{tabular}

Tabelle 30. Eisen (Gesamt-Fe) im Sediment des Rotsees in \% der Trockensubstanz (TS). Table 30. Total amount of iron in the sediment of the Rotsee in \% of dry matter (TS).




Tabelle 31. Die Mn- und Fe-Sedimentation in der jahreszeitlichen Veränderung. Rotsee.

Table 31. Seasonal fluctuation in the sedimentation of manganese and iron. Rotsee.

\begin{tabular}{|c|c|c|c|c|c|c|}
\hline Zeit & 1. 4.-17. 4. 1969 & 1. $5 .-4.6 .1969$ & 16. 6.-1. 10.1969 & 14. 10.-1. 12. 1969 & 17. 12.1969 & 12. 1.1970 \\
\hline Temperatur & Zirkulation & Stagnation & Stagnation & Zirkulation & $\begin{array}{l}\text { Stagnation } \\
\text { invers }\end{array}$ & $\begin{array}{l}\text { Stagnation } \\
\text { invers }\end{array}$ \\
\hline $\mathrm{O}_{2}$ im Seewasser & $\begin{array}{l}\text { viel } \\
(5 \mathrm{~m}: 3-6 \mathrm{mg} / 1)\end{array}$ & $\begin{array}{l}\text { viel, aber } \\
\text { abnehmend } \\
(5 \mathrm{~m}: 2 \mathrm{mg} / 1)\end{array}$ & $\begin{array}{l}\text { wenig } \\
(5 \mathrm{~m}:<1 \mathrm{mg} / \mathrm{l})\end{array}$ & $\begin{array}{l}\text { viel } \\
(5 \mathrm{~m}: 7-9 \mathrm{mg} / \mathrm{l})\end{array}$ & $\begin{array}{l}\text { sehr wenig } \\
(<1 \mathrm{mg} / \mathrm{l})\end{array}$ & $\begin{array}{l}\text { viel } \\
(5 \mathrm{~m}: 7 \mathrm{mg} / \mathrm{l})\end{array}$ \\
\hline $\begin{array}{l}\text { Mn im Sediment, } \\
\% \text { der TS }\end{array}$ & $\begin{array}{l}\text { viel } \\
0,3-0,4 \%\end{array}$ & & $\begin{array}{l}\text { wenig } \\
0,03 \%\end{array}$ & $\begin{array}{l}\text { viel } \\
0,25-0,35 \%\end{array}$ & $\begin{array}{l}\text { wenig } \\
0,08 \%\end{array}$ & $\begin{array}{l}\text { sehv viel } \\
2,5 \mathrm{~m}: 4,9 \% \\
5 \mathrm{~m}: 1,6 \%\end{array}$ \\
\hline Mn im Sediment, $\mathrm{mg} / \mathrm{m}^{2} \cdot$ Tag & $\varnothing 9,58$ & $\varnothing 2,00$ & $\varnothing 1,90$ & $\begin{array}{r}\varnothing 2,49 \\
0,93\end{array}$ & $\varnothing 1,45$ & $\varnothing 14,24$ \\
\hline $\begin{array}{l}\text { Fe im Sediment, } \\
\% \text { der TS }\end{array}$ & $\begin{array}{l}\text { viel } \\
>1-2 \%\end{array}$ & & $\begin{array}{l}\text { wenig } \\
<1 \%\end{array}$ & $\begin{array}{l}\text { viel } \\
>1-2,3 \%\end{array}$ & & \\
\hline Fe im Sediment, $\mathrm{mg} / \mathrm{m}^{2} \cdot \mathrm{Tag}$ & $\varnothing 18,4$ & & $\varnothing 56,3$ & $\varnothing 13,1$ & & \\
\hline
\end{tabular}




\section{Verteilung und Sedimentation des Phytoplanktons}

Aus der Fülle der Planktonergebnisse wurden nur die systematischen Gruppen als ganzes und einige wichtige Gattungen bzw. Arten berücksichtigt. Die Beschreibung der Phytoplanktonentwicklung erfolgte mit Hilfe von Isopletendarstellungen. Diese sind mit der von ScHEGG [93] verwendeten Rasterdarstellung (Raum-Zeit-Diagramm) vergleichbar. Isopleten wurden auch für die Veranschaulichung der Phytoplanktonsedimentation gewählt: als Werte liegen die während der Expositionszeit (durchschnittlich 14 Tage) aufgefangenen Zellen bzw. Biomassen zugrunde. Diese Dauer ist bei der Interpretation der Diagramme, deren Zeitangabe auf den Probenahmedaten beruht, zu berücksichtigen. Diese Darstellungsart hat den Vorteil, dass Sedimentationsmaxima deutlich zum Ausdruck kommen, und dass ein direkter Vergleich mit den Verhältnissen im Seewasser möglich ist. Durch Unfall sind verschiedene Sedimentproben ausgefallen; dies wurde jeweils mit durchbrochenen Linien angedeutet.

Die kürzeren Probenahme-Intervalle (14 Tage statt 1 Monat) bei den Sedimentationsmessungen ermöglichten es, die Verteilungsdynamik des Phytoplanktons genauer zu erfassen; dies ist bei kurzlebigen und bei rasch sedimentierenden Formen unerlässlich.

\subsection{Horwer Bucht}

\subsection{Gesamtbiomasse (Abb. 32 und 33)}

See: Die Gesamtbiomasse in der Horwer Bucht erreichte im Mai-Juni Spitzenwerte von 1,2-2,7 mg/1 im Epilimnion und blieb im Durchschnitt recht gering (meist unter $0,5 \mathrm{mg} / \mathrm{l}$ ). Dieser Standing Crop entspricht etwa den. Werten, die Pavoni [81] im Zürich-, Brienzer- und Thunersee gefunden hat.

Sediment: Die Sedimentation des Phytoplanktons erfolgte in zwei Hauptschüben Ende April und im Juni bis August, wobei im Juli die Höchstwerte von 400 bis 600 $\mathrm{mg} / \mathrm{dm}^{2} \cdot$ Expositionszeit gemessen wurden.

\subsection{Cyanophyceae (Abb. 34 und 35)}

See: Die Blaualgen, deren wesentlichster Vertreter Oscillatoria rubescens war, erreichten im Herbst-Winter ihre höchste Entwicklung (über $100 \mu \mathrm{g} / \mathrm{l}$ ) mit einem Maximum von $438 \mu \mathrm{g} / \mathrm{l} \mathrm{im}$ Dezember, wo sie $80 \%$ der Gesamtbiomasse ausmachten. Vom Mai bis August dagegen traten sie stark zurück (unter 20\% der Gesamtbiomasse).

Sediment: Die Cyanophyceen-Sedimentation war verhältnismässig gering (vgl. auch 5.34, S. 154). Dies scheint in Zusammenhang damit zu stehen, dass einzelne Blaualgen infolge ihrer Gasvakuolen spezifisch leichter als Wasser werden können und daher oft aufrahmen und zur Bildung von Wasserblüten neigen. Es kann angenommen werden, dass die Blaualgen zum grossen Teil in den obersten Schichten abgebaut werden und so ein wesentliches Glied im «kleinen Stoffkreislauf» sind (vgl. auch 5.35, S. 158).

Neben Oscillatoria rubescens D.C., die im Frühling 1969 zwischen 15 und $25 \mathrm{~m}$ und während der Stagnationsperiode in 5-12,5 m Tiefe eingeschichtet war, traten im Vierwaldstättersee noch Fäden von Aphanizomenon flos-aquae (L.) Ralfs., Oscillatoria obliqueacuminata Skuja, Pseudanabaena catenata Lauterb, und vereinzelt Anabaena flos-aquae (Lyngb.) Bréb. auf. 

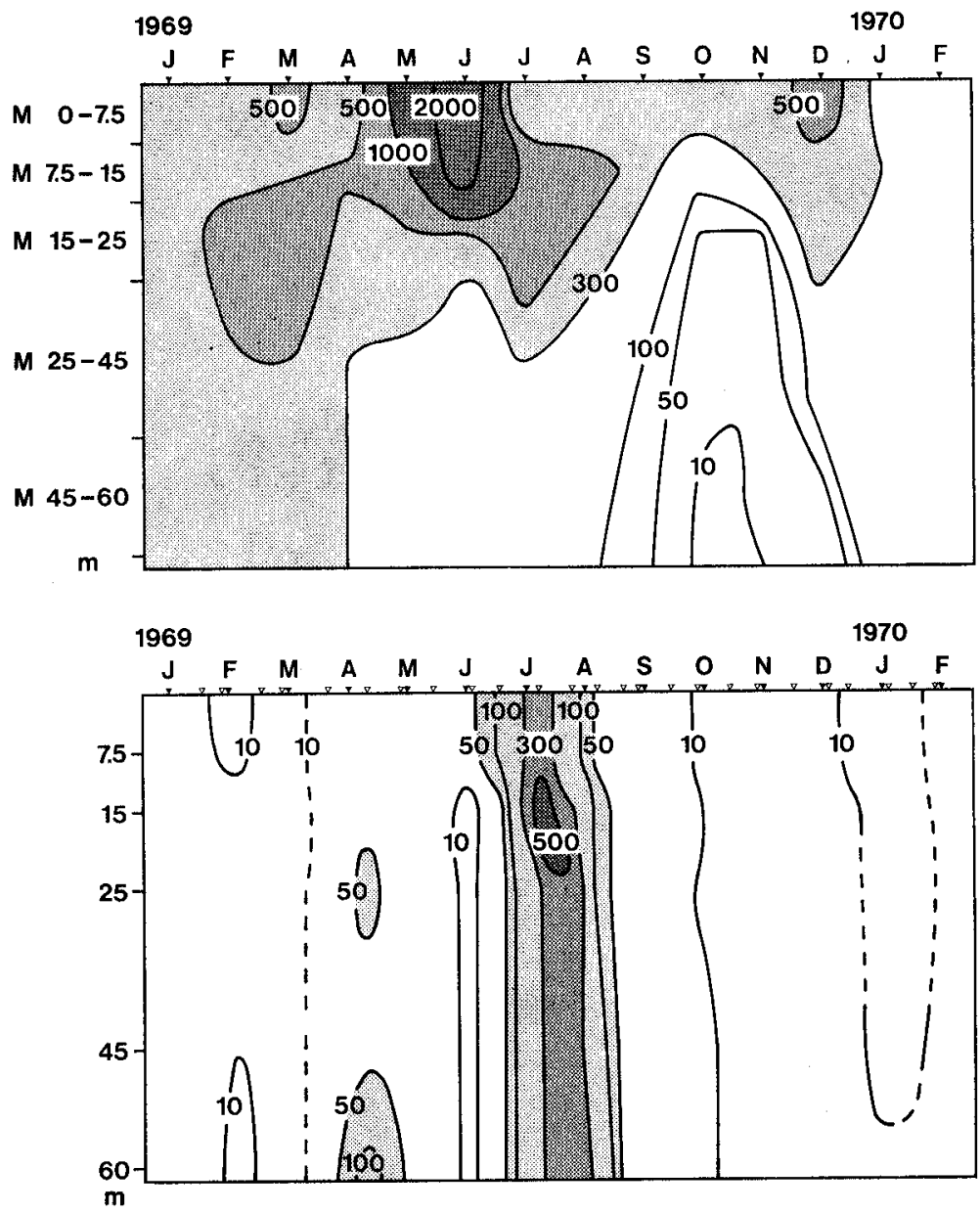

Abb. 32 und 33. Phytoplankton-Gesamtbiomasse (Frischgewicht), Horwer Bucht. See: $\mu g / 1$ (Mischproben), Sediment: $\mathrm{mg} / \mathrm{dm}^{2} \cdot$ Expositionszeit.

Durchbrochene Linien: Ausfall verschiedener Proben wegen Unfalls.

Fig. 32 and 33. Total phytoplankton biomass (fresh weight), Horw Bay. Lake: $\mu g / 1$ (mixed samples), sediment: $\mathrm{mg} / \mathrm{dm}^{2} \cdot$ exposure.

Dashed lines: accidental loss of different samples.

\subsection{Chlorophyceae (Abb. 36-39)}

See: Die Grünalgen traten im Vierwaldstättersee nur unbedeutend in Erscheinung (Abb. 36 und 37). Die Hauptentwicklung fand im April bis Juni und im August statt. Aber selbst in dieser Periode erreichte die Biomasse der Chlorophyceen (im Gegensatz zum Rotsee [vgl. 5.23, S. 132]) nie mehr als einige \% der Gesamtbiomasse. Das Januarmaximum 1970 in $45-60 \mathrm{~m}$ Tiefe rührte von $\mu$-Algen und Pseudosphaerocystis sp. (syn. (Gemellicystis sp.) her. 



Abb. 34 und 35. Cyanophyceae, Horwer Bucht.

See: $\mu g / l$ (Mischproben), Sediment: $\mathrm{mg} / \mathrm{dm}^{2} \cdot$ Expositionszeit.

Fig. 34 and 35. Cyanophyceae, Horw Bay.

Lake: $\mu g / 1$ (mixed samples), sediment: $\mathrm{mg} / \mathrm{dm}^{2} \cdot$ exposure.

Sediment: Die Sedimentation setzte mit der ersten Grünalgenentwicklung Ende April ein und erreichte nach einem relativen Minimum die absoluten Maximalwerte Ende Juli bis August. Das Januarmaximum 1970, gebildet von Coelastrum sp., war sofort aussedimentiert.

Nebst Ankistrodesmus convolutus Corda (Abb. 38 und 39) traten nur noch Characium sp. im Juli-August und November-Dezember, Phacotus lenticularis Ehrnb. im August, Oocystis sp. im August-September und Ulothrix amphigranulata Skuja im September-Oktober in vermehrtem Masse auf; nur vereinzelt fanden sich Zellen von Scenedesmus sp., Tetraëdron caudatum (Corda) Hansg., Elakatothrix gelatinosa Wille, Dictyosphaerium simplex Skuja, Pseudosphaerocystis sp. (syn. Gemellicystis sp.), 

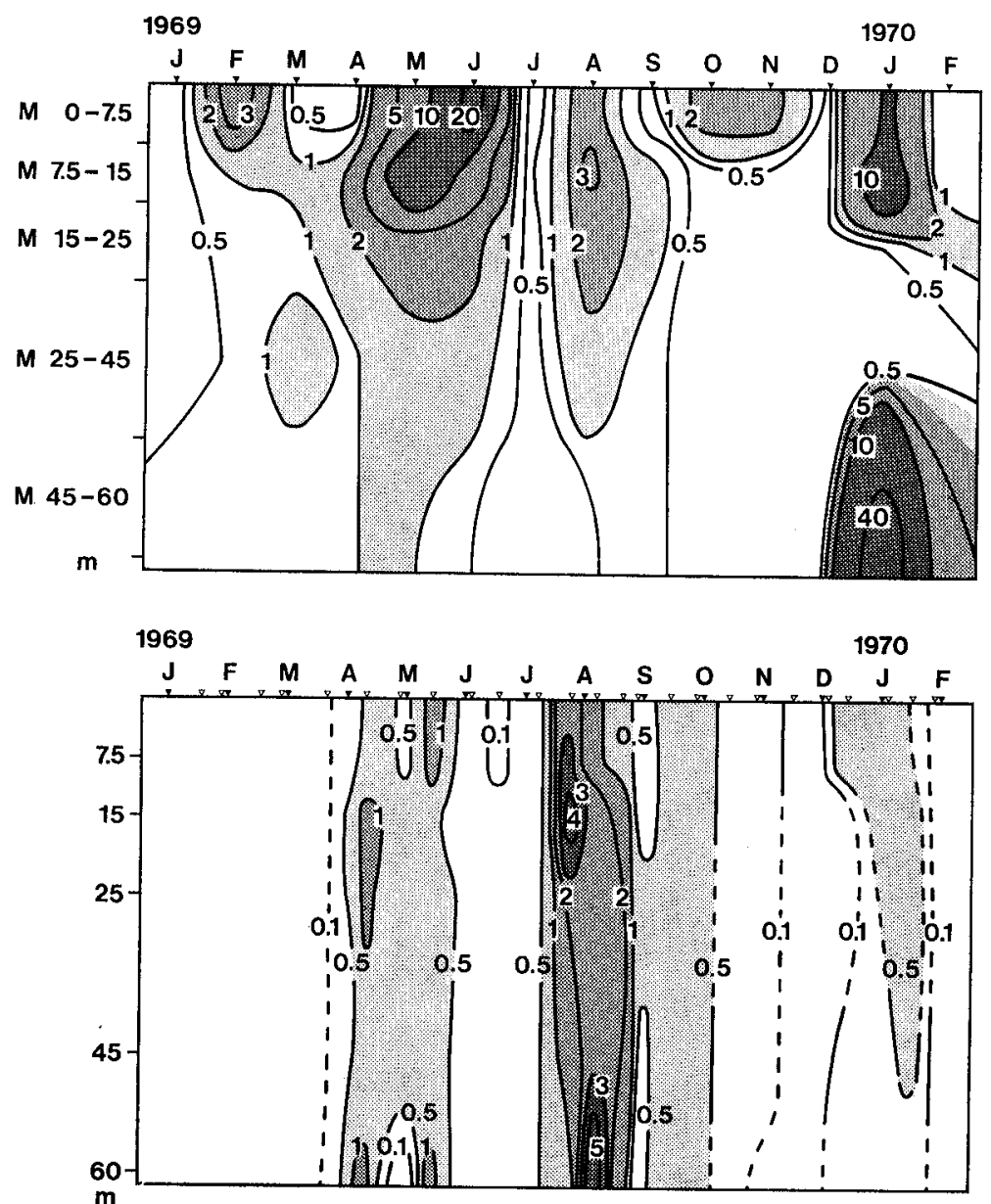

Abb. 36 und 37. Chlorophyceae, Horwer Bucht.

See : $\mu \mathrm{g} / \mathrm{l}$ (Mischproben), Sediment: $\mathrm{mg} / \mathrm{dm}^{2}$ - Expositionszeit.

Fig. 36 and 37. Chlorophyceae, Horw Bay.

Lake: $\mu \mathrm{g} / \mathrm{l}$ (mixed samples), sediment: $\mathrm{mg} / \mathrm{dm}^{2} \cdot$ exposure.

Sphaerocystis sp., Coelastrum reticulatum (Dang.) Senn. und Pediastrum boryanum (Turp.) Menegh.

\subsection{Konjugatae (Abb. 40 und 41)}

See: Die Hauptvegetationszeit der Konjugaten beschränkte sich auf die Monate August bis Oktober. Sie waren im Vierwaldstättersee eine unbedeutende Gruppe; nur während des Maximums im August machten sie 30-50\% der Gesamtbiomasse aus.

Sediment: Die Konjugaten waren sofort und in starkem Masse aussedimentiert. So wurden von Mougeotia sp. am 11. August auf den Sedimentationsstufen $45 \mathrm{~m}$ und $60 \mathrm{~m}$ nach einer Expositionszeit von 13 Tagen über $95 \cdot 10^{6} \mathrm{Zellen} / \mathrm{dm}^{2}$ aufgefangen, 



Abb. 38 und 39. Ankistrodesmus convolutus Corda, Horwer Bucht.

See : Zellen $\cdot 10^{3} / 1$ (Mischproben), Sediment: Zellen $\cdot 10^{6} / \mathrm{dm}^{2} \cdot$ Expositionszeit.

Fig. 38 and 39. Ankistrodesmus convolutus Corda, Horw Bay.

Lake: cells $\cdot 10^{3} / 1$ (mixed samples), sediment: cells $\cdot 10^{6} / \mathrm{dm}^{2} \cdot$ exposure.

bei einem Entwicklungsmaximum von $445 \cdot 10^{3}$ Zellen/l in 7,5-15 m Tiefe am 5. August (vgl. auch 5.34, S. 154).

Das Verteilungsbild der Konjugaten im See und im Sediment wurde praktisch vollständig von Mougeotia sp., dem Hauptvertreter dieser Gruppe, bestimmt. Daneben traten spärlich Zellen von Closterium spp., Cosmarium phaseolus Bréb. und Staurastrum sp. auf.

\subsection{Chrysophyceae (Abb. 42)}

See: Die Chrysophyceen erreichten im Juni ein Maximum und traten sonst nur noch im Frühling 1969 in grösserer Zahl auf. Häufigste Form war Dinobryon spp., während sich gelegentlich auch Zellen von Erkenia sp. und Mallomonas sp. fanden. 


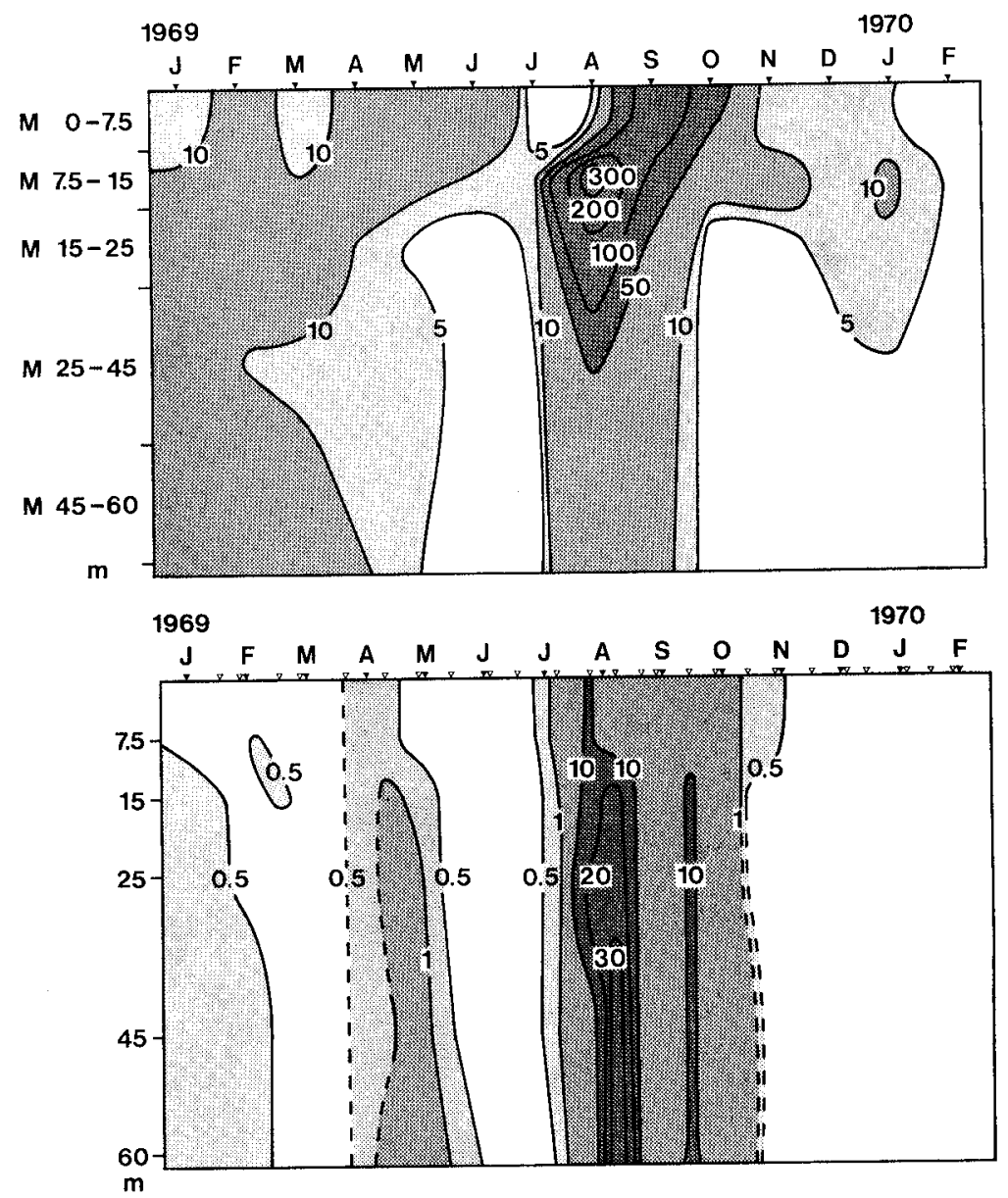

Abb. 40 und 41. Konjugatae, Horwer Bucht.

See: $\mu \mathrm{g} / 1$ (Mischproben), Sediment: $\mathrm{mg} / \mathrm{dm}^{2} \cdot$ Expositionszeit.

Fig. 40 and 41. Konjugatae, Horw Bay.

Lake: $\mu \mathrm{g} / 1$ (mixed samples), sediment: $\mathrm{mg} / \mathrm{dm}^{2} \cdot$ exposure.

Sediment: Im Sediment konnten nur vereinzelte Zellen gezählt werden; vor allem häuften sich im Juni bis August leere Dinobryongehäuse an, was auf einen raschen und vollständigen Abbau hindeutet, bevor die Zellen tiefere Wasserschichten erreichten (Maximalwerte am 29. Juli mit $31 \cdot 10^{6}$ Gehäuse/dm² 14 Tage).

\subsection{Diverse Flagellaten (Abb. 43 und 44)}

See: Die Flagellaten, ebenfalls eine relativ unbedeutende Gruppe, erreichten nur im Mai-Juni höhere Zellzahlen (über $500 \cdot 10^{3} \mathrm{Z} / \mathrm{l}$ ). Weniger ausgeprägt als im eutrophen Rotsee, verlief die Flagellatenentwicklung fluktuierend.

Sediment: Als verhältnismässig zarte Formen erreichten die herabsinkenden Flagellaten den Seegrund praktisch nie. Die Sedimentation war äusserst gering und in etwa $25 \mathrm{~m}$ Tiefe weitgehend abgeschlossen. Es wurden drei Sedimentationsspitzen im Februar-März, April-Mai und im Juni-Juli beobachtet. 


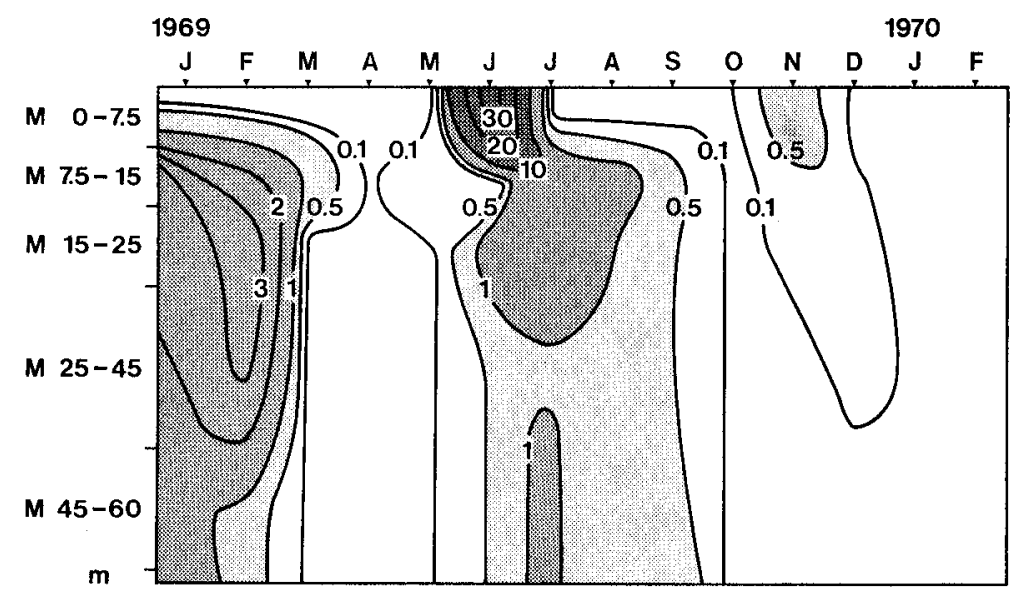

Abb. 42. Chrysophyceae, Horwer Bucht.

See: $\mu g / 1$ (Mischproben), Fig. 42. Chrysophyceae. Horw Bay. Lake: $\mu \mathrm{g} / \mathrm{l}$ (mixed samples).


Abb. 43 und 44. Diverse Flagellaten, Horwer Bucht. See: Zellen $\cdot 10^{3} / 1$ (Mischproben), Sediment: Zellen $\cdot 10^{3} / \mathrm{dm}^{2}$. Expositionszeit.

Fig. 43 and 44. Diverse flagellates, Horw Bay. Lake: cells $\cdot 10^{3} / 1$ (mixed samples), sediment: cells $\cdot 10^{3} / \mathrm{dm}^{2} \cdot$ exposure. 


\subsection{Diatomeae (Abb. 45-51)}

See: Die Kieselalgen waren in Artenzahl und Zellzahl die dominierende Algengruppe im Vierwaldstättersee (Abb. 45 und 46). Im Laufe der Diatomeensukzession wurden drei Maxima im April, Juli und September-Oktober festgestellt, wobei die

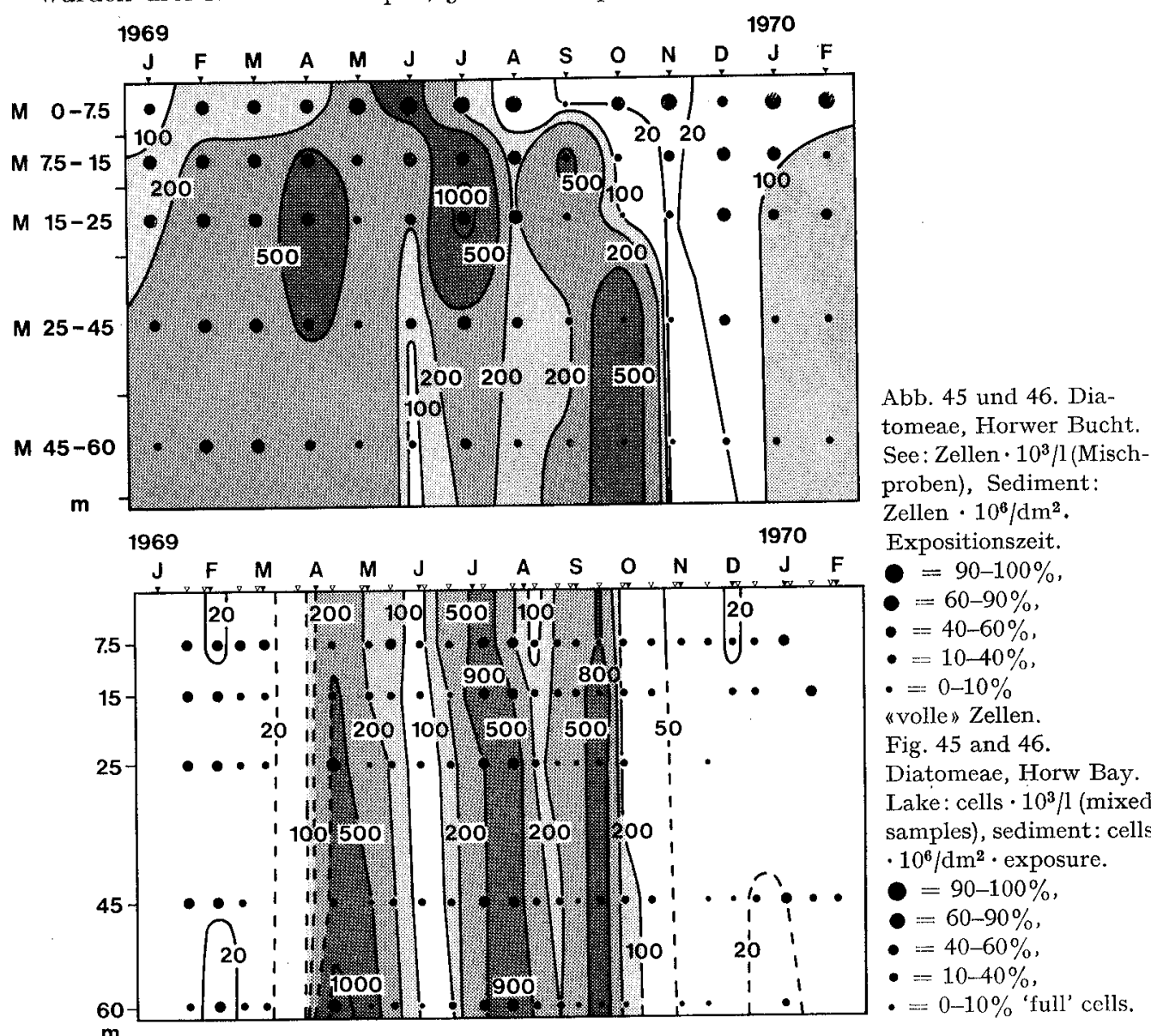

m



Abb. 47. Fragilaria crotonensis Kitton im Sediment der Horwer Bucht (15. Juli 1969, $15 \mathrm{~m}$ ). $837 \cdot 10^{6}$ Zellen/dm ${ }^{2} \cdot$ Expositionszeit, $40 \%$ davon leer (Probe $500 \times$ verdünnt, Vergrösserung etwa $300 \times)$.

Fig. 47. Fragilaria crotonensis Kitton in the sediment of Horw Bay (15. July 1969, $15 \mathrm{~m}$ ).

$837 \cdot 10^{6}$ cells $/ \mathrm{dm}^{2} \cdot$ exposure, $40 \%$ of them empty (sample $500 x$ diluted, enlargement about $300 \times$ ). 
herbstliche Anhäufung im Hypolimnion vorwiegend aus leeren Zellen bestand. Im absoluten Maximum vom Juli wurden über $1 \cdot 10^{6}$ Zellen/l gezählt.

Sediment: Die Diatomeen sedimentierten ohne Zeitverzögerung in drei Hauptschüben (Maxima von $800-1000 \cdot 10^{6}$ Zellen $/ \mathrm{dm}^{2} \cdot$ Expositionszeit). Die Auffangraten sanken nie unter $10 \cdot 10^{6}$ Zellen $/ \mathrm{dm}^{2} \cdot$ Expositionszeit. Meistens lag der Anteil der leeren Schalen über $50 \%$ bis $90 \%$ der gesamten Zellzahl.

Von den Kieselalgen erreichte Fragilaria crotonensis Kitton die höchsten Zellzahlen $\left(>1 \cdot 10^{6} \mathrm{Z} / \mathrm{l}\right.$, davon $36 \%$ leer, und $>800 \cdot 10^{6} \mathrm{Z} / \mathrm{dm}^{2} \cdot$ Expositionszeit sedimentiert,
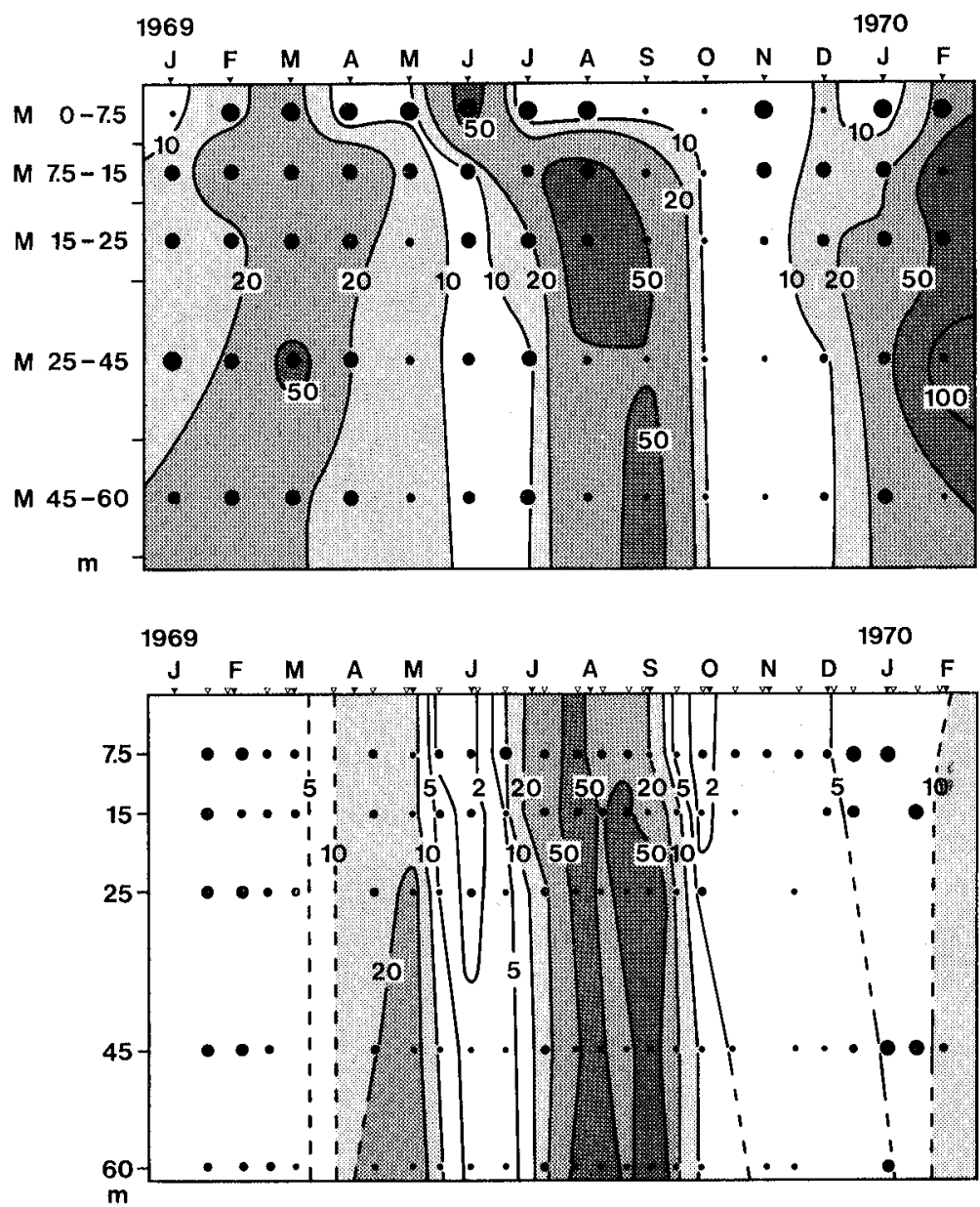

Abb. 48 und 49. Tabellaria fenestrata (Lyngb.) Kütz., Horwer Bucht.

See: Zellen $10^{3} / 1$ (Mischproben), Sediment: Zellen $\cdot 10^{6} / \mathrm{dm}^{2} \cdot$ Expositionszeit.

$-=90-100 \%, \bullet=60-90 \%, \bullet=40-60 \%, \bullet=10-40 \%, \cdot=0-10 \%$ "volle» Zellen.

Fig. 48 and 49. Tabellavia fenestrata (Lyngb.) Kütz., Horw Bay.

Lake: cells $\cdot 10^{3} / 1$ (mixed samples), sediment: cells $\cdot 10^{6} / \mathrm{dm}^{2} \cdot$ exposure.

$-=90-100 \%, \bullet=60-90 \%, \bullet=40-60 \%, \bullet=10-40 \%, \cdot=0-10 \%$ 'full' cells. 
davon $40 \%$ leer, im Juli [siehe Abb. 47]). Über $100 \cdot 10^{3}$ Zellen $/ 1$ erreichten die folgenden Formen: Stephanodiscus hantzschii Grun., Cyclotella comta (Ehrnb.) Kütz. und Diatoma elongatum (Lyngb.) Agardh. Ebenfalls von Bedeutung (mit $>10 \cdot 10^{3} \mathrm{Z} / \mathrm{l}$ ) waren im weiteren Cyclotella sp. (eine sehr kleine Form), Tabellaria fenestrata (Lyngb.) Kütz. (Abb. 48 und 49), Asterionella formosa Hassall (Abb. 50 und 51), Nitzschia acicularis W. Smith, Synedra berolinensis Lemmer., Synedra acus var. angustissima Grun., Synedra sp. und Melosira sp.

Auf die Diatomeensukzession wird im Abschnitt 5.31, S. 143, näher eingegangen.
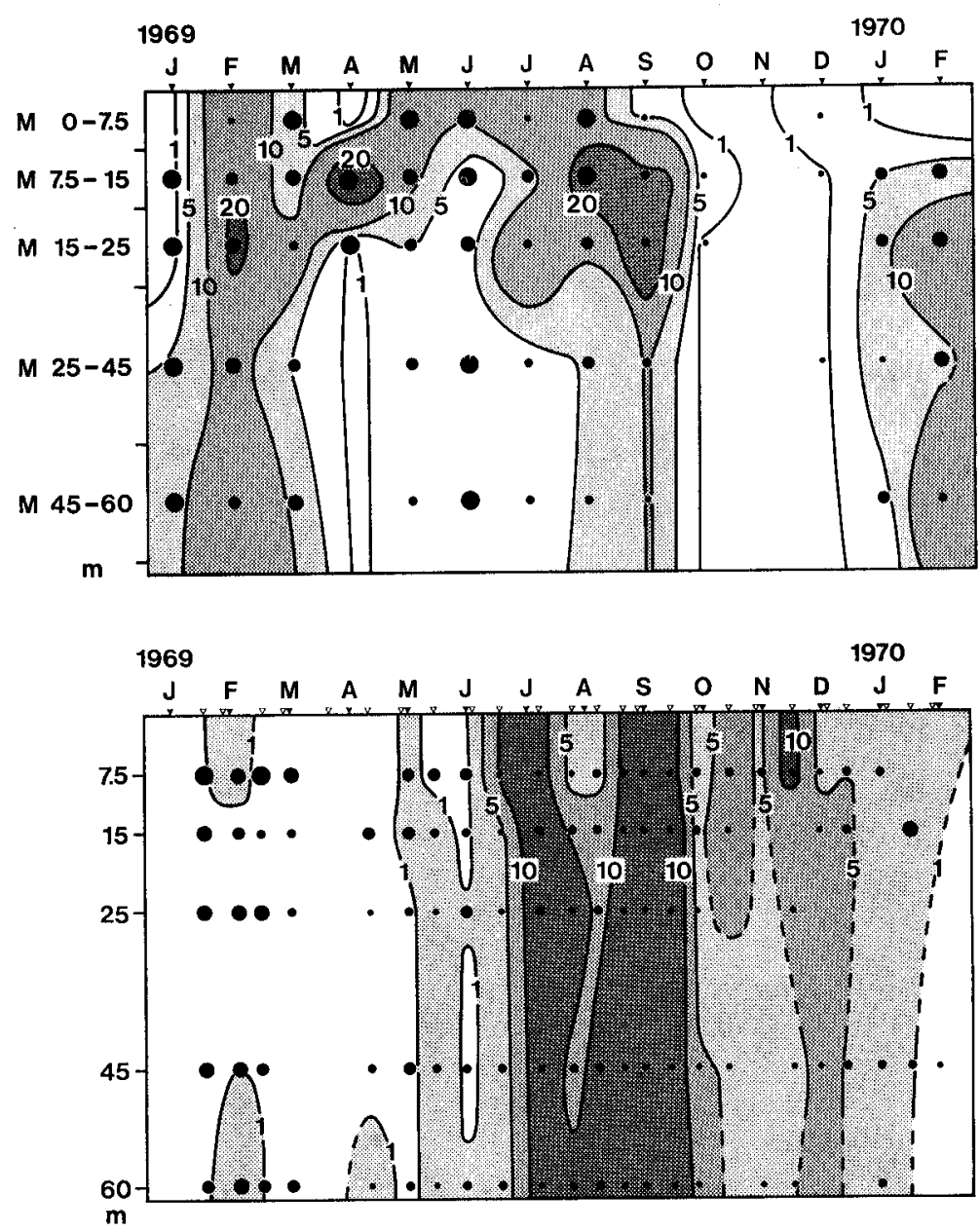

Abb. 50 und 51. Asterionella formosa Hassall, Horwer Bucht.

See: Zellen $10^{3} / 1$ (Mischproben), Sediment: Zellen $\cdot 10^{6} / \mathrm{dm}^{2} \cdot$ Expositionszeit.

$=90-100 \%, \bullet=60-90 \%, \bullet=40-60 \%, \bullet=10-40 \%, \cdot=0-10 \%$ "volle " Zellen.

Fig. 50 and 51. Asterionella formosa Hassall, Horw Bay.

Lake: cells $\cdot 10^{3} / 1$ (mixed samples), sediment: cells $\cdot 10^{6} / \mathrm{dm}^{2} \cdot$ exposure.

$=90-100 \%, \cdot=60-90 \%, \bullet=40-60 \%, \bullet=10-40 \%, \cdot=0-10 \%$ 'full' cells. 


\subsection{Cryptophyceae (Abb. 52 und 53)}

See: Die Cryptophyceen waren neben den dominierenden Diatomeen und den Cyanophyceen die drittgrösste Gruppe im Vierwaldstättersee. Sie verteilten sich auf das ganze Jahr und erreichten im Juni Maximalwerte von über $2 \mathrm{mg} / \mathrm{l} \mathrm{im}$ Epilimnion (80\% der Gesamtbiomasse). Im Januar bis Juni 1969 und Januar-Februar 1970 dominierten zahlenmässig Rhodomonas lens Pascher et Ruttner und Rhodomonas lacustris Pascher et Ruttner über Cryptomonas ovata Ehrnb. und Cryptomonas erosa Ehrnb., in der Zeit vom Juli bis Dezember war Cryptomonas häufiger.

Sediment: Analog wie im Rotsee (vgl. 5.28, S. 141) wurden im Sediment keine Rhodomonaszellen gefunden mit Ausnahme im März-April 1969, wo diese Form ihr absolutes Maximum erreichte. Die sedimentierte Cryptophyceenbiomasse war sonst
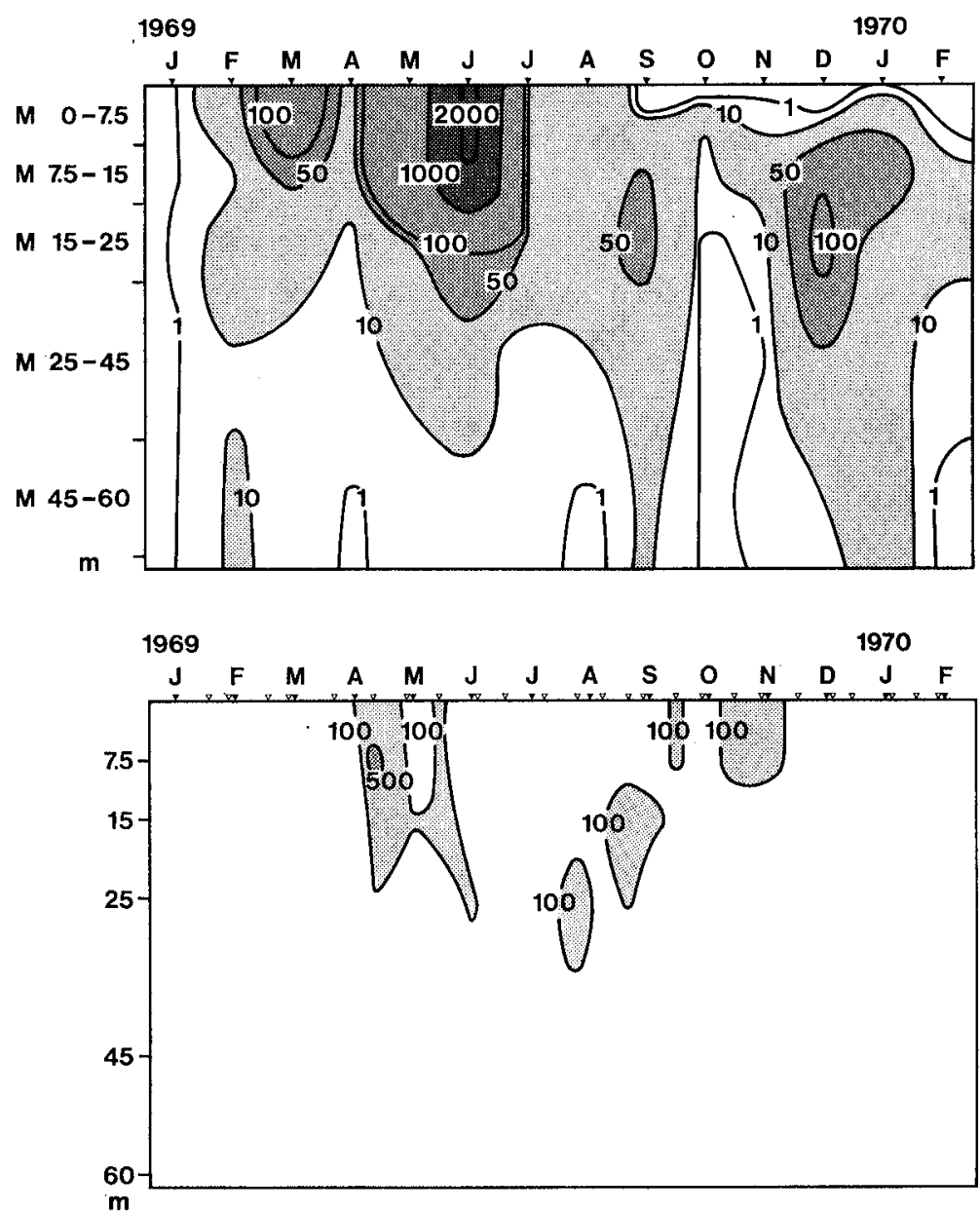

Abb. 52 und 53. Cryptophyceae, Horwer Bucht.

See $: \mu \mathrm{g} / \mathrm{I}$ (Mischproben), Sediment: $\mu \mathrm{g} / \mathrm{dm}^{2} \cdot$ Expositionszeit.

Fig. 52 and 53. Cryptophyceae, Horw Bay.

Lake: $\mu \mathrm{g} / 1$ (mixed samples), sediment: $\mu \mathrm{g} / \mathrm{dm}^{2}$ exposure. 
praktisch nur auf Cryptomonaszellen zurückzuführen, die allerdings nur vereinzelt anfielen. Es zeigt sich also auch hier, dass die Cryptophyceen sehr rasch und beinahe vollständig zersetzt werden, wobei Cryptomonas etwas resistenter gegen den Abbau ist als Rhodomonas (vgl. auch 5.35, S. 158).

\subsection{Peridineae (Abb. 54 und 55)}

See: Die Peridineen wurden das ganze Jahr hindurch gefunden. Hauptvertreter waren Gymnodinium lantzschii Utermöhl und Gymnodinium helveticum Penard (zahlenmässig geringer, aber wegen der Grösse biomassemässig etwa gleich); sie erreichten im April bis Juni ihr Maximum. Vereinzelte Zellen von Peridinium sp. und Cera-
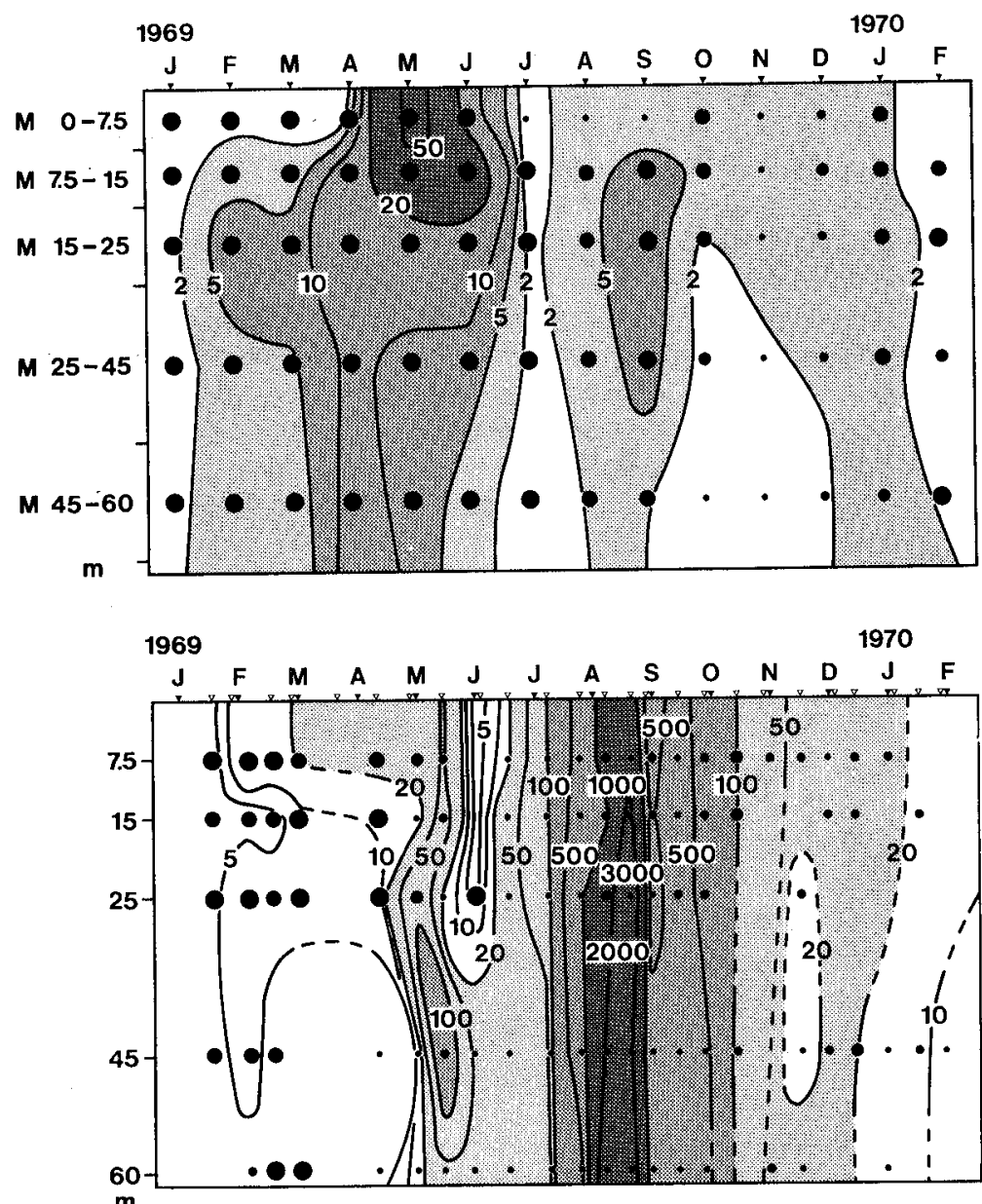

Abb. 54 und 55. Peridineae, Horwer Bucht.

See: Zellen $\cdot 10^{3} / 1$ (Mischproben), Sediment: Zellen $\cdot 10^{3} / \mathrm{dm}^{2} \cdot$ Expositionszeit.

- $=90-100 \%, \bullet=60-90 \%, \bullet=40-60 \%, \bullet=10-40 \%, \cdot=0-10 \%$ "volle "Zellen.

Fig. 54 and 55. Peridineae, Horw Bay.

Lake: cells $\cdot 10^{3} / 1$ (mixed samples), sediment: cells $\cdot 10^{3} / \mathrm{dm}^{2} \cdot$ exposure.

$=90-100 \%, \bullet=60-90 \%, \bullet=40-60 \%, \bullet=10-40 \%,=\bullet 0-10 \%$ 'full' cells. 
tium hirundinella (O.F. Müller) Schrank wurden vor allem im Winter erfasst. Obwohl die Peridineen grosse Formen sind, blieben sie meist unter $10 \%$ der Gesamtbiomasse.

Sediment: Das Sedimentationsbild fällt etwas aus dem Rahmen und ist nicht leicht mit der Verteilung im Wasser in Einklang zu bringen. Das Sedimentationsmaximum im August dürfte mit dem offensichtlich nicht vollständig erfassten Maximum vom August--September korrespondieren; das Frühsommermaximum fand sich, zeitlich nicht verschoben, vor allem in den Sedimentationsstufen des Hypolimnions wieder. Obwohl eine Interpretation in diesem Falle schwierig ist, scheinen die Verteilungsbilder ein sehr rasches Aussedimentieren anzuzeigen, was wegen der verhältnismässig grossen Formen durchaus zu erwarten ist. Zieht man schliesslich den zum Teil hohen prozentualen Anteil an leeren Zellen in Betracht, so ist zudem mit einem starken Abbau der Peridineen zu rechnen.

\subsection{Rotsee}

\subsection{Gesamtbiomasse (Abb. 56 und 57)}

See: Die Gesamtbiomasse nahm im Rotsee beträchtliche Ausmasse an. Im Wasser wurden im April 1969 und im Januar 1970 an der Oberfläche mit 31,9 mg/l und $35,2 \mathrm{mg} / \mathrm{l}$ die höchsten Werte gemessen. Vergleichszahlen anderer eutropher Seen $[81,125]$ liegen durchwegs tiefer. Auch während des ganzen Sommers betrug die Biomasse im Epilimnion noch 3-12 mg/l, und in den tieferen Schichten wurden im August-September durch die Cryptophyceen und im November durch die Cyanophyceen bedeutende Maxima gebildet.

Sediment: Die Biomasse-Sedimentationsraten waren gegenüber dem Standing Crop noch wesentlich höher. Die Maximalwerte fielen in 2,5 m Tiefe an und erreichten im August $725-1164 \mathrm{mg} / \mathrm{dm}^{2} \cdot$ Expositionszeit, anfangs Oktober $500 \mathrm{mg} / \mathrm{dm}^{2} \cdot$ Expositionszeit und im Dezember $420-820 \mathrm{mg} / \mathrm{dm}^{2} \cdot$ Expositionszeit. In $5 \mathrm{~m}$ und $14 \mathrm{~m}$ Tiefe wurden immer noch Biomassen von 8 bis $390 \mathrm{mg} / \mathrm{dm}^{2}$. Expositionszeit aufgefangen.

Die Tatsache, dass sich die Sedimentationsmaxima vom Sommer bis Herbst, also zur Zeit der minimalen Standing Crop, in kurzen Abständen folgten, scheint zunächst den Ergebnissen von OHLE [73] und SCHEGG [93] zu widersprechen, wonach nur ein kleiner Teil der Biomasse aus dem Epilimnion zum Grund sedimentiert und diese im «kurzgeschlossenen Kreislauf» im Zuge der Zersetzung eine äusserst wichtige Rolle in der Nachlieferung der zur Primärproduktion benötigten Nährstoffe spielt. Zieht man aber den durchschnittlichen Biomasseverlust nach der Tiefe in Betracht, der überschlagsmässig mit Abbau gleichgesetzt werden kann, so zeigt sich, dass im Epilimnion (2,5-5 m) tatsächlich wesentlich mehr Nährstoffe freigesetzt worden sein müssen als im Hypolimnion (5-14 m). Auch die berechneten Abbauraten (5.35, S. 158) und die chemischen Daten (organische Substanz:4.42, S. 107, und Nährstoffe N:6.3, S.172, und P: 6.4, S. 174) zeigen, dass der «kleine Stoffkreislauf» trotz den relativ hohen Sedimentationsraten im Rotsee äusserst intensiv war.

\subsection{Cyanophyceae (Abb. 58 und 59)}

See: Die Blaualgen waren während der ganzen Untersuchungszeit präsent, traten aber erst im August wesentlich in Erscheinung und hatten, nach einem vorübergehenden Rückgang im September, eine ziemlich scharf abgegrenzte Wachstumsperiode zwischen Oktober und Dezember mit einem ausgeprägten Maximum im November 

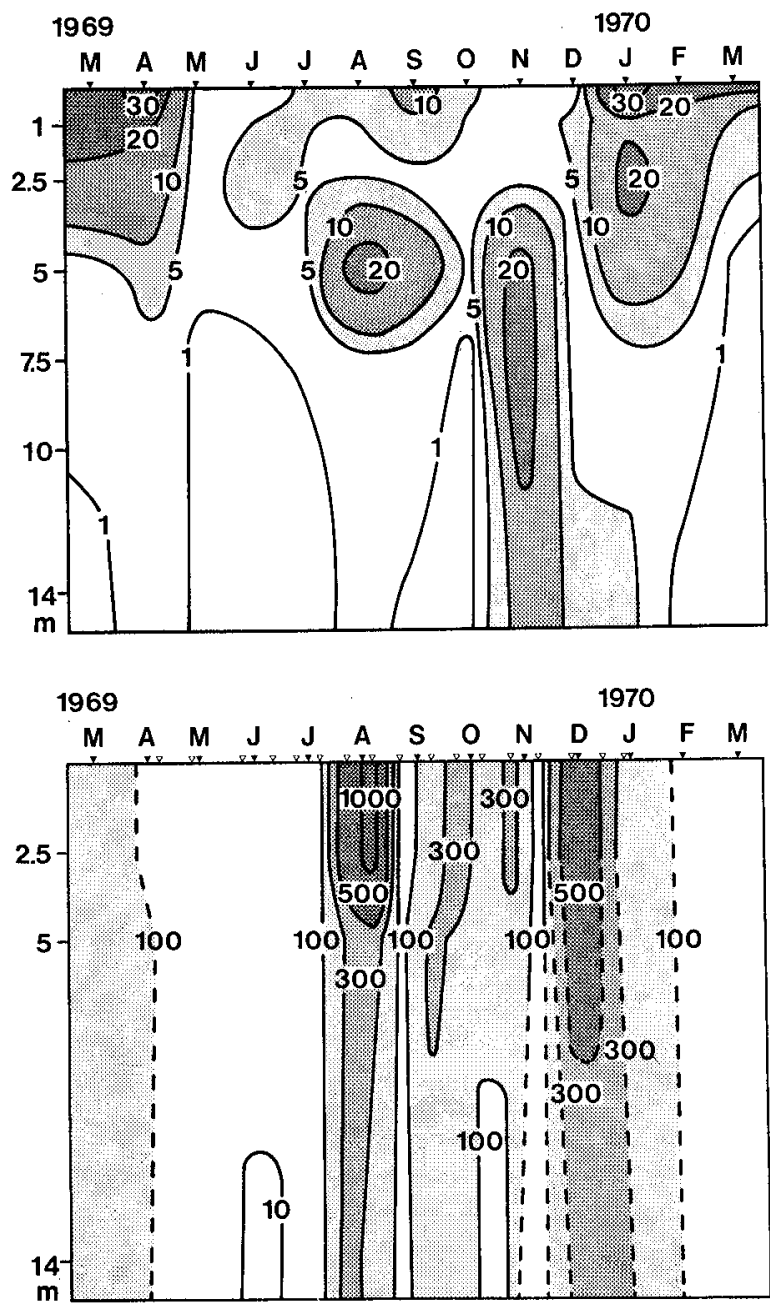

Abb. 56 und 57. PhytoplanktonGesamtbiomasse (Frischgewicht), Rotsee.

See: $\mathrm{mg} / 1$, Sediment: $\mathrm{mg} / \mathrm{dm}^{2}$. Expositionszeit.

Fig. 56 and 57. Total phytoplankton biomass (fresh weight), Rotsee.

Lake: $\mathrm{mg} / 1$, sediment: $\mathrm{mg} / \mathrm{dm}^{2}$. exposure.

(nach [93], S. 450, modifiziert). In der trophogenen Schicht spielten die Cyanophyceen im Verhältnis zur Gesamtbiomasse nur eine untergeordnete Rolle; ihr wichtigster Vertreter war Coelosphaerium naegelianum Ung., welche Form das Verteilungsbild im Wasser (vom Oktober bis Januar, vgl. [93], S. 451) wie im Sediment (vom August bis Januar) wesentlich prägte, weshalb auf eine spezielle Isopletendarstellung verzichtet wurde. Da im Sediment bereits ab 4. August 1969 Kolonien gefunden wurden, muss das Erscheinen dieser Blaualge wohl etwas früher angesetzt werden, als dies ScHEGG [93] tat (das heisst: in den Schöpfproben vom 14. August und 11. September wurden keine Zellen bzw. Kolonien erfasst, vgl. 5.36, S. 163).

Neben Coelosphaerium fanden sich vereinzelt Fäden von Oscillatoria rubescens D.C. und Oscillatoria Redekei van Goor, von A phanizomenon flos-aquae (L.) Ralfs., Pseudanabaena catenata Lauterb., Anabaena flos-aquae (Lyngb.) Bréb. und Zellen von Aphanocapsa sp. 
Sediment: Das Aussedimentieren der Cyanophyceen begann, der Verteilung gemäss, erst im August. Nach einer kurzen Baisse im Oktober erreichten die Sedimentationsraten im Dezember-Januar sehr hohe Maximalwerte von $135 \mathrm{bis} 810 \mathrm{mg} / \mathrm{dm}^{2}$. Expositionszeit ( $=92-98 \%$ der sedimentierten Gesamtbiomasse), die zum grössten Teil von Coelosphaerium naegelianum herrührten. Aufgrund dieser Sedimentationsraten muss angenommen werden, dass das Entwicklungsmaximum im November höher als in 5-10 $\mathrm{m}$ Tiefe lag, wie es zunächst die Verteilung im Wasser annehmen liesse. Die am 1. Dezember 1969 äusserst hohen Sedimentationsraten in 2,5 m Tiefe (Verzögerung $1 / 2$ bis 1 Monat) deuten auf eine starke Produktion in den obersten Schichten hin; in die gleiche Richtung weist auch die geringe Eindringtiefe des grünen Lichtes am 6. November 1969 (VG 9 1\% nur 4,9 m, vgl. [93], S. 441).
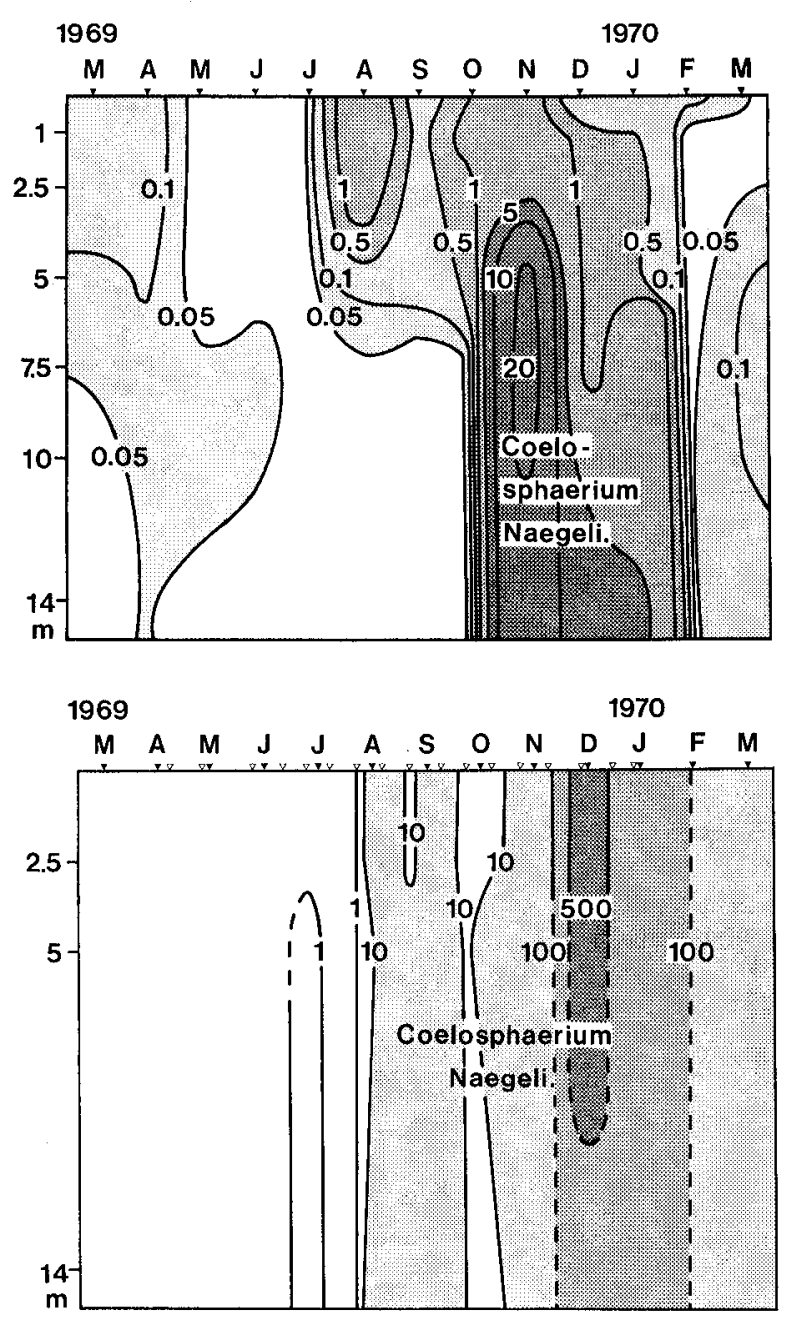

Abb. 58 und 59. Cyanophyceae, Rotsee.

See: $\mathrm{mg} / \mathrm{l}$, Sediment: $\mathrm{mg} / \mathrm{dm}^{2}$. Expositionszeit.

Fig. 58 and 59. Cyanophyceae, Rotsee.

Lake: $\mathrm{mg} / 1$, sediment: $\mathrm{mg} / \mathrm{dm}^{2}$. exposure. 


\subsection{Chlorophyceae (Abb. 60-68)}

See: Die Chlorophyceen waren nach der Artenzahl eine relativ bedeutende Gruppe (Abb. 60 und 61). Ihr Auftreten war im wesentlichen auf die erste Jahreshälfte beschränkt, mit zwei Entwicklungsmaxima im April und im Juni-Juli (vgl. [93], S. 450/2). Während die Grünalgen vom September 1969 bis März 1970 biomassemässig unbedeutend blieben, machten sie im April bis August 1969 den Hauptanteil der Biomasse aus (im Wasser vom Juni bis Juli 75-99,9\%, im Sediment vom 1. Mai bis 4. August mit 2 Ausnahmen 60-98\%).

Die wichtigsten Vertreter der Chlorophyceen waren: Coelastrum microporum Naegeli (Abb. 63 und 64), Oocystis lacustris Chodat (Abb. 65 und 66), Scenedesmus quadricauda (Turp.) Bréb. (Abb. 67 und 68), Ankistrodesmus convolutus Corda, Sphaerocystis schroeteri Chodat, Characium gracilipes F.D. Lambert und Phacotus spp. Vereinzelt wurden die folgenden Formen gefunden: $\mu$-Algen (unter anderem Chlorella
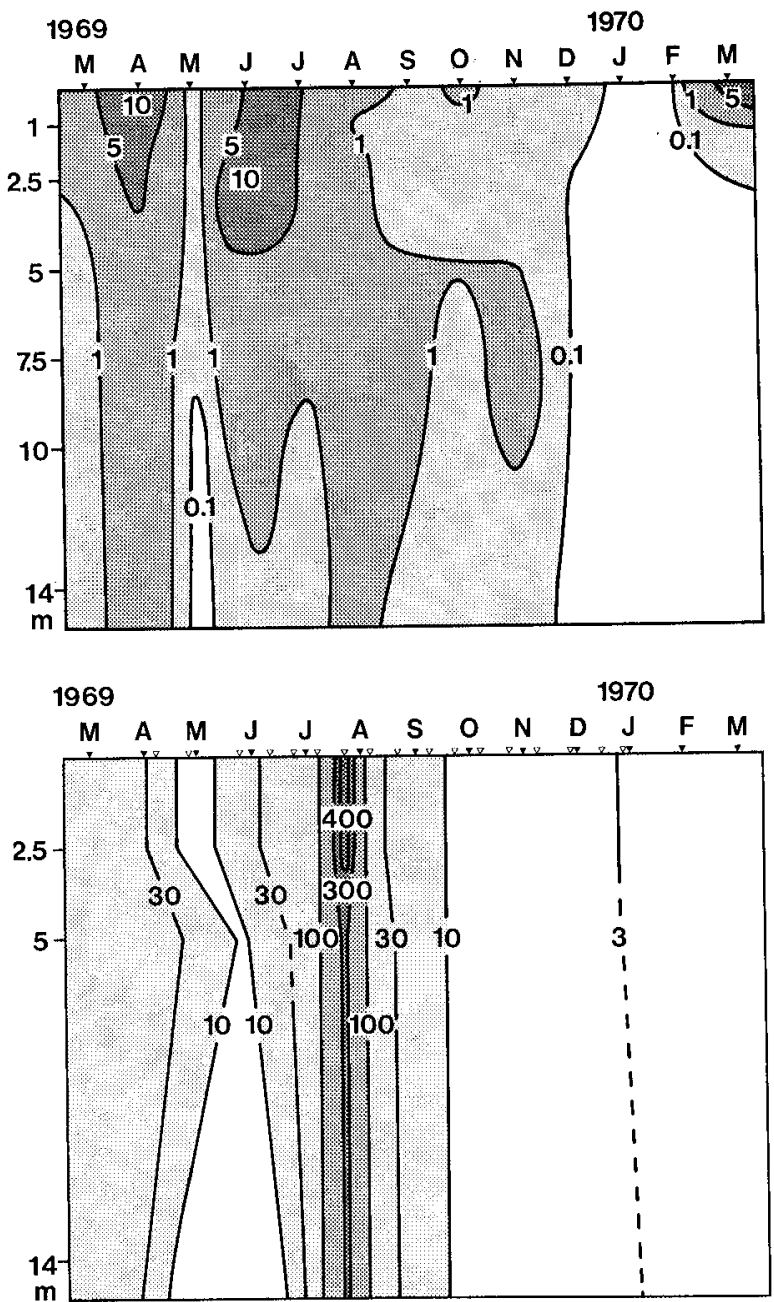

Abb. 60 und 61. Chlorophyceae, Rotsee.

See: $\mathrm{mg} / \mathrm{l}$, Sediment: $\mathrm{mg} / \mathrm{dm}^{2}$. Expositionszeit.

Fig. 60 and 61. Chlorophyceae, Rotsee.

Lake: $\mathrm{mg} / \mathrm{l}$, sediment: $\mathrm{mg} / \mathrm{dm}^{2}$, exposure. 
sp.), Chlamydomonas sp., Pseudosphaerocystis sp. (syn. Gemellicystis sp.), Gloeococcus sp. (syn. Gloeocystis sp.), Dictyosphaerium sp., Elakatothrix sp., Selenastrum sp., Tetrastrum sp., Tetraëdron sp., Pediastrum spp. und Ulothrix sp. Die Verteilungsbilder von Ankistrodesmus, Sphaerocystis, Characium und Chlamydomonas sind in der Arbeit ScHEGGS [93] enthalten.

Sediment: Die Sedimentation der Chlorophyceen folgte im wesentlichen ziemlich genau dem Verteilungsbild im Wasser. Da das Aprilmaximum in den Sedimentproben nicht mehr erfasst wurde, waren am 4. August, nach dem zweiten Entwicklungsmaximum, die höchsten Zellzahlen aufzufangen. Dieses Sedimentationsmaximum wurde hauptsächlich von den drei Arten Coelastrum microporum, Scenedesmus quadricauda und Oocystis lacustris gebildet (siehe Abb. 62). Sonst traten im Sediment nur noch Ankistrodesmus convolutus (1. Mai) und Sphaerocystis schroeteri (16. Juni), jeweils unmittelbar nach ihrem Biomassemaxium, als dominierende Formen auf.

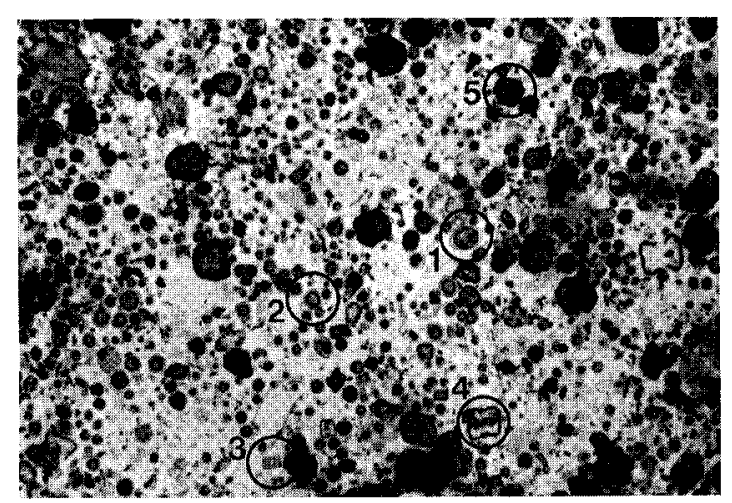

Coelastrum microporum Naegeli (Abb. 63 und 64)
Abb. 62. Sediment des Rotsees (4. August 1969, 14 m). Grünalgenmaximum mit Zellen von 1 Oocystis lacustris Chodat, 2 Coelastrum microporum Naegeli, 3 Scenedesmus quadricauda (Turp.) Bréb. und 4 Tetraëdron sp.; 5 Kalkpartikel (Probe $100 \times$ verdünnt Vergrösserung etwa $400 \times$ ). Fig. 62. Sediment of the Rotsee (4. August 1969, $14 \mathrm{~m}$ ). Maximum of green algae with cells of 1 Oocystis lacustris Chodat, 2 Coelastrum microporum Naegeli, 3 Scenedesmus quadricauda (Turp.) Bréb. and 4 Tetraëdron sp.; 5 particles of lime (sample $1.00 \times$ diluted, enlargement about $400 \times$ ).

See: Coelastrum microporum trat im Juli in Massen auf und blieb in geringer Zahl bis in den Winter erhalten (vgl. [93], S. 453). Erwähnenswert sind dabei die zum Teil hohen Koloniezahlen in der bereits anaeroben Zone auf 7,5 m.

Sediment: Das gewaltige Sedimentationsmaximum vom 4. August (250-315 $\mathrm{mg} / \mathrm{dm}^{2}$ - Expositionszeit) bestätigte mit einer Verzögerung von etwa 1 Monat das absolute und einzige Produktionsmaximum im Juli. Die Tatsachen, dass Coelastrum im Wasser immer bis Grund gefunden wurde und dass die Sedimentationsraten nach unten nicht wesentlich abnahmen, lassen auf eine ziemlich grosse Resistenz dieser Zellen gegen den Abbau schliessen.

\section{Oocystis lacustris Chodat (Abb. 65 und 66)}

See: Oocystis lacustris wurde im wesentlichen vom April bis August 1969 beobachtet und nur noch sehr vereinzelt im Oktober-November und im Januar 1970. Am 10. Juli trat in $5 \mathrm{~m}$ Tiefe an der Schwefelwasserstoff-Sauerstoff-Grenze eine Massenentwicklung auf, analog am 22. Mai ein relatives Maximum (vgl. [93], S. 452). 




Abb. 63 und 64. Coelastrum microporum Naegeli, Rotsee. See: $\mu \mathrm{g} / 1$, Sediment: $\mathrm{mg} / \mathrm{dm}^{2}$. Expositionszeit.

Fig. 63 and 64. Coelastrum microporum Naegeli, Rotsee. Lake: $\mu \mathrm{g} / \mathrm{l}$, sediment: $\mathrm{mg} / \mathrm{dm}^{2}$. exposure.

Sediment: Wie das Zwischenmaximum vom Mai sedimentierte das absolute Maximum im Juli mit $1 / 2$ bis 1 Monat Verzögerung ziemlich quantitativ aus. Aufgrund der Sedimentationszunahme gegen unten hin dürfte Oocystis lacustris wie Coelastrum zu den nur schwer abbaubaren Formen gezählt werden, wenn auch die sehr stark verminderte Sedimentationsrate in 2,5 m Tiefe zum Teil mit dem tiefer liegenden Schwerpunkt des Entwicklungsmaximums erklärt werden kann.

Scenedesmus quadricauda (Turp.) Bréb. (Abb. 67 und 68)

See: Die Scenedesmuskolonien traten nur sporadisch, hauptsächlich aber im Sommer, im Epilimnion auf (nach [93], S. 454).

Sediment: Der Verlauf der Sedimentation erlaubt eine detailliertere Aussage über die Verteilung dieser Grünalge:

- Im März-April 1969 nur geringe Zellzahlen/1 und schwache Sedimentation, die aber bis zum Grund reichten. 

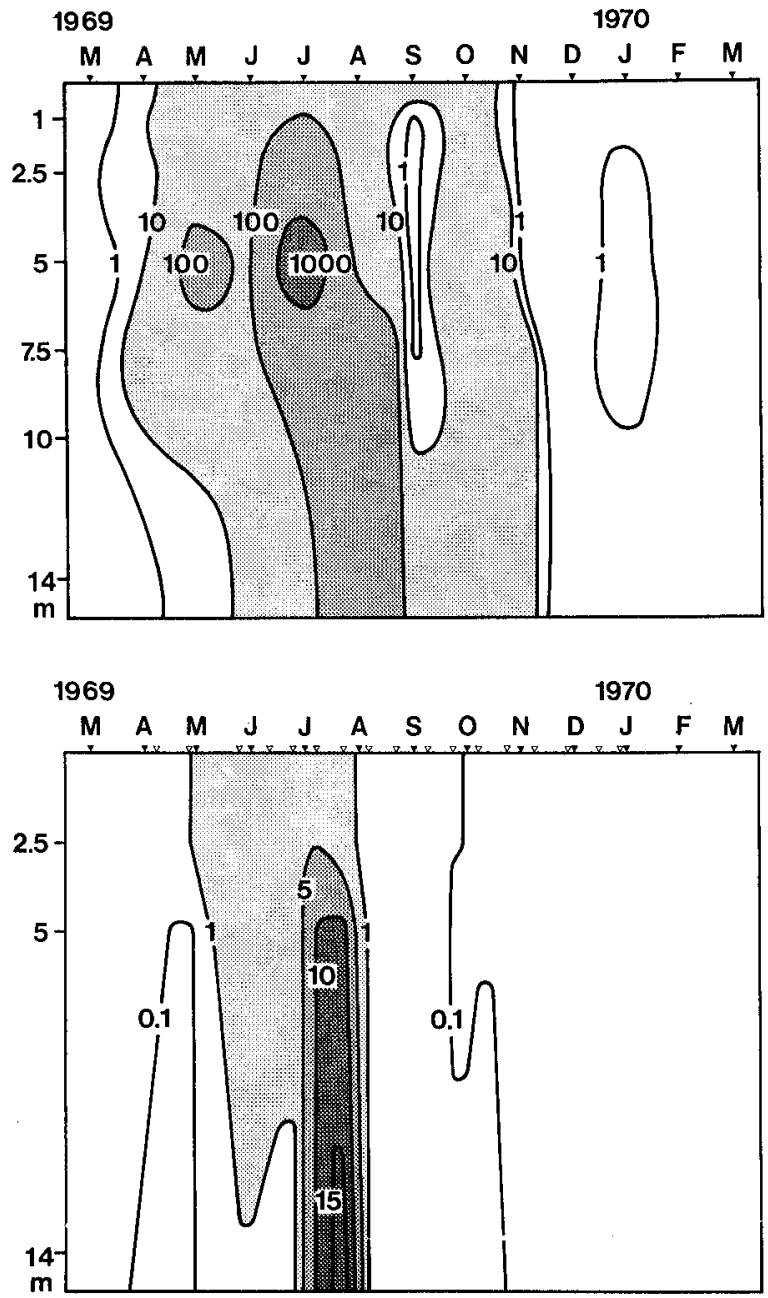

Abb. 65 und 66. Oocystis lacustris Chodat, Rotsee. See: $\mu \mathrm{g} / \mathrm{l}$, Sediment: $\mathrm{mg} / \mathrm{dm}^{2}$. Expositionszeit.

Fig. 65 and 66 . Oocystis lacustris Chodat, Rotsee. Lake: $\mu \mathrm{g} / \mathrm{l}$, sediment: $\mathrm{mg} / \mathrm{dm}^{2}$. exposure.

- Im Mai-Juni Verarmung im Epilimnion, jedoch in ewta 7-10 $\mathrm{m}$ ein relatives Maximum, das auf der 14-m-Stufe aussedimentierte.

- In der zweiten Julihälfte Beginn eines sehr hohen, kurzfristigen Maximums in 0-2 m, das in den Zellzahlen/l nur ungenügend erfasst wurde; sofortige Aussedimentierung bis Grund mit Abbauverlusten.

- Im August bildete sich in $5 \mathrm{~m}$ Tiefe ein zweites Maximum aus, welches in der 14-mStufe erfasst wurde; im Epilimnion nach dem Zusammenbruch der Population bis in den September hinein relativ hohe Zellzahlen/1 (relatives Produktionsmaximum?), die aber bei weitem nicht mehr jene Werte vom Juli erreichten und die sich in einem Sedimentationsanstieg am 16. September manifestierten.

- Im Oktober-November rasches Abklingen der Scenedesmuspopulation und der Sedimentationsintensität. 



Abb. 67 und 68. Scenedesmus quadricauda (Turp.) Bréb., Rotsee.

See: Kolonien $\cdot 10^{3} / 1$, Sediment: Kolonien $\cdot 10^{6} / \mathrm{dm}^{2} \cdot$ Expositionszeit.

Fig. 67 and 68. Scenedesmus quadricauda (Turp.) Bréb., Rotsee.

Lake: colonies $\cdot 10^{3} / 1$, sediment: colonies $\cdot 10^{6} / \mathrm{dm}^{2} \cdot$ exposure.

5.24 Konjugatae (Abb. 69 und 70)

See: Das Auftreten der Konjugaten war auf die Monate August bis Oktober beschränkt (vor allem Closterium sp.) und für die Gesamtbiomasse unbedeutend (vgl. [93], S. 454). Neben Closterium wurden noch sehr vereinzelt Zellen von Mougeotia sp., Staurastrum sp. und Cosmarium sp. gefunden.

Sediment: Ähnlich wie bei den Diatomeen gibt der Verlauf der Sedimentationskurven einen tieferen Einblick in die Entwicklungsdynamik der Konjugatae:

- Im März 1969 schienen die letzten Reste einer Frühahrspopulation (Februar? bis März) am Grund anzukommen.

- Im Juni musste ein gut ausgebildetes relatives Maximum vorhanden gewesen sein (Sedimentationspeak in $5 \mathrm{~m}$ Tiefe).

- Das absolute Maximum am 14. August drückte sich im raschen Ansteigen der Sedimentationsraten aus (Sedimentationsmaximum um knapp 1 Monat verschoben). 

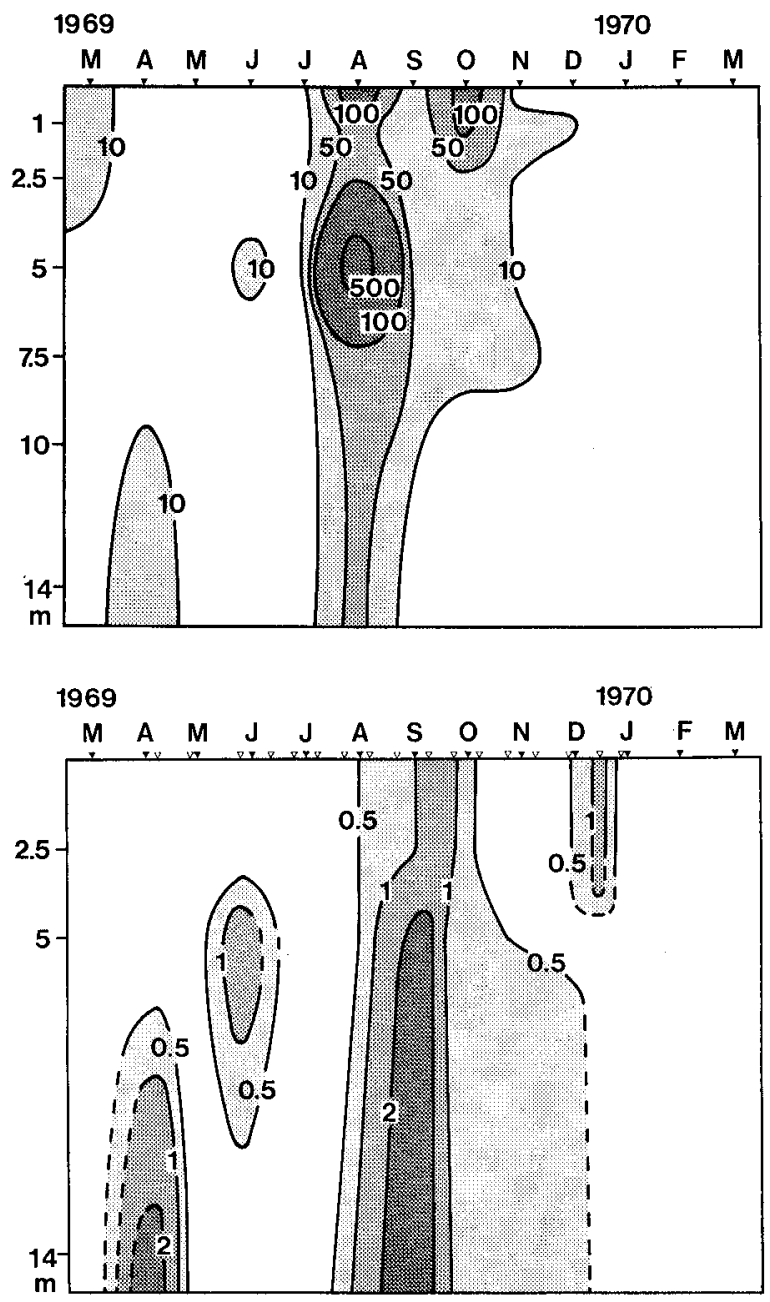

Abb. 69 und 70. Konjugatae, Rotsee.

See $: \mu g / 1$, Sediment: $\mathrm{mg} / \mathrm{dm}^{2}$.

Expositionszeit.

Fig. 69 and 70. Konjugatae,

Rotsee.

Lake: $\mu \mathrm{g} / \mathrm{l}$, sediment: $\mathrm{mg} / \mathrm{dm}^{2}$. exposure.

- Das relative Maximum im Oktober schlug sich rasch in der 5-m-Sedimentationsstufe nieder.

- Die permanente, vom Oktober 1969 bis Januar 1970 leicht abfallende Sedimentation beweist, dass sich geringe Zellzahlen bis in den Dezember im Wasser zu halten vermochten (relatives Maximum im Dezember?).

\subsection{Chrysophyceae (Abb. 71)}

See: Im Gegensatz zu den dynamischeren unbestimmten Flagellaten zeigten die Chrysophyceen, nach ScHEGG [93], Seite 456, im wesentlichen Erkenia subaequiciliata Skuja (März-April 1969) und Uroglena americana Calkins (September 1969 und Februar-März 1970), nur drei scharf abgegrenzte Maxima. Nebst den zwei vorherrschenden Formen wurden gelegentlich auch einige Zellen von Mallomonas sp., Dinobryon sp. und Kephyrion sp. gezählt. 




Abb. 71. Chrysophyceae, Rotsee. See: $\mathrm{mg} / \mathrm{l}$.

Fig. 71. Chrysophyceae, Rotsee. Lake: $\mathrm{mg} / \mathrm{l}$.

Sediment: Im Sediment traten die Chrysophyceen nur gerade am 15. Mai nach dem ersten Entwicklungsmaximum auf (nur $130-190 \mu \mathrm{g} / \mathrm{dm}^{2} \cdot$ Expositionszeit), was auf eine sehr rasche und vollständige Zersetzung schliessen lässt.

\subsection{Diverse Flagellaten (Abb. 72 und 73)}

See: Die äusserst rasche Fluktuation von Phytoplanktonpopulationen in hocheutro phen Gewässern kommt sehr deutlich im Verteilungsbild der Flagellaten (kleine und relativ zarte Formen) zum Ausdruck. Entwicklungsmaxima und -minima folgten sich fast monatlich; 4 hohe Maxima wurden im April und Oktober 1969, und im Januar und März 1970 erreicht, relative Maxima im Juni (nur gering) und im August.

Sediment: Die Sedimentation von Flagellaten war als Folge der leichten Zersetzung der zarten Zellkörper verhältnismässig gering, erfolgte aber bei jedem Produktionsmaximum nach etwa $1 / 2$ bis 1 Monat. Das Januarmaximum 1970 wurde dabei nur noch andeutungsweise erfasst. Die relativ hohen Sedimentationsraten auf Grund vom 18. August bis 16. September dürften vermutlich auf Flagellatenanhäufungen unterhalb $5 \mathrm{~m}$ Tiefe zurückzuführen sein, welche in den Schöpfproben nicht erfasst worden waren.

\subsection{Diatomeae (Abb. 74-77)}

See: Die Kieselalgen (Abb. 74 und 75) entfalteten sich in drei Vegetationsschüben, und zwar im März-April 1969, im August bis Oktober und im Februar-März 1970 (vgl. [93], S. 456). Ein Vergleich mit dem $\mathrm{SiO}_{2}$-Gehalt des Rotseewassers zeigt, dass die Kieselsäure nur im August bis unter $0,5 \mathrm{mg} / \mathrm{l}$ aufgezehrt wurde $\left(\mathrm{SiO}_{2}=\right.$ produktionsbegrenzend?, siehe [89], S. 181). Im Hypolimnion wurden nur noch geringe Zellzahlen vorgefunden; die hohen $\mathrm{SiO}_{2}$-Konzentrationen der Tiefenschichten (Maximalwerte bis $z u \quad 8 \mathrm{mg} / 1$, vgl. 4.38, S. 107) lassen auf eine teilweise Zersetzung der Kieselschalen schliessen. Eine starke Aussedimentierung ist aufgrund dieser Fakten zu erwarten.

Die häufigsten Diatomeenformen waren mit Abstand Fragilaria crotonensis Kitton und Stephanodiscus hantzschii Grun. (Abb. 76 und 77). Nur sporadisch und in 

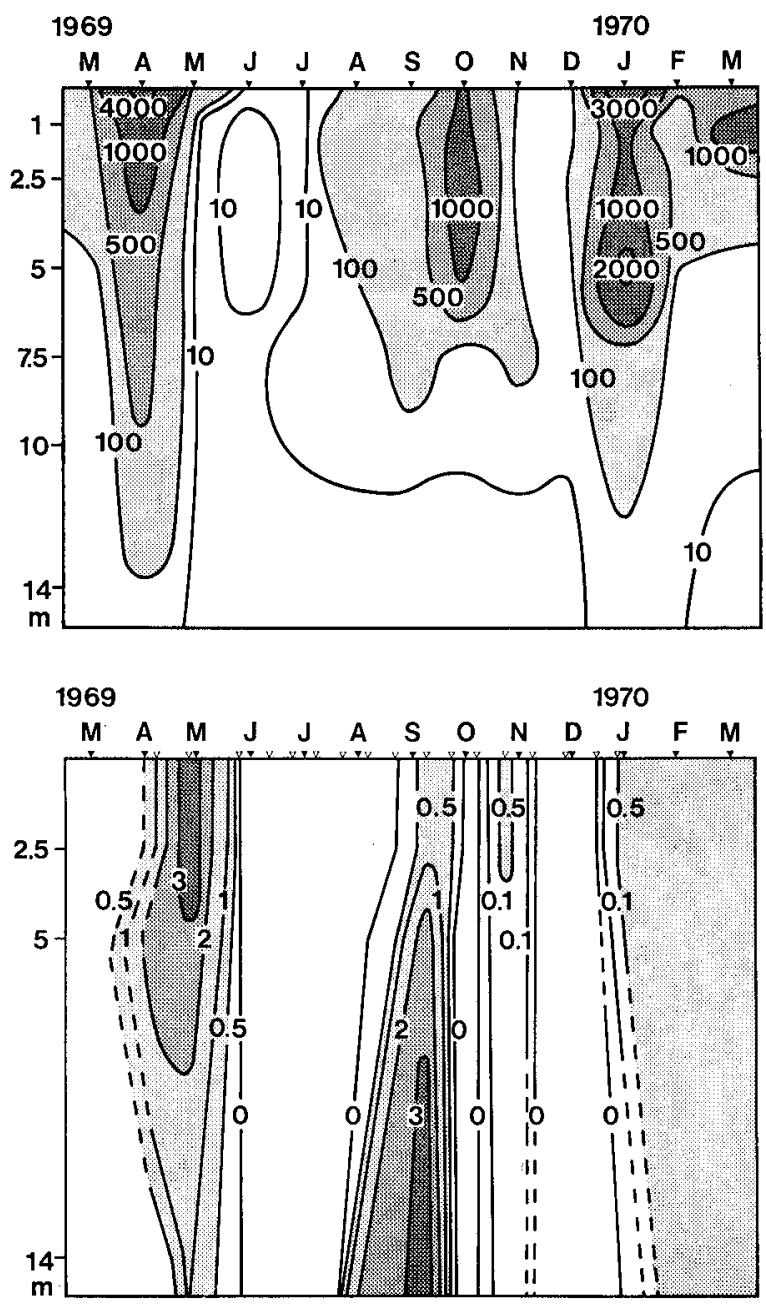

Abb. 72 und 73. Liverse Flagellaten, Rotsee. See: Zellen $\cdot 10^{3} / 1$, Sediment: Zellen $\cdot 10^{3} / \mathrm{dm}^{2} \cdot$ Expositionszeit. Fig. 72 and 73. Diverse flagellates, Rotsee.

Lake: cells $\cdot 10^{3} / \mathrm{l}$, sediment: cells $\cdot 10^{3} / \mathrm{dm}^{2} \cdot$ exposure.

weit geringerer Menge fanden sich die Centrales Stephanodiscus alpinus Hust., Stephanodiscus astraea (E.) Grun., Cyclotella operculata (Ag.) Kg. und Cyclotella sp. sowie die Pennales Asterionella formosa Hassall, Tabellaria fenestrata (Lyngb.) Kütz., Nitzschia acicularis W. Smith, Synedra acus Kütz. (siehe [93], Abb. 31, S. 457) und Synedra acus var. angustissima Grun. Über die Diatomeensukzession orientieren die Abschnitte 5.31, S. 143 und 5.36, S. 163.

Sediment: Das generelle Sedimentationsbild zeigt, dass das Sommermaximum der Diatomeen ohne grosse zeitliche Verzögerung und ziemlich vollständig aussedimentierte. Erstaunlich erscheint die geringe Zahl aufgefundener Zellen am Grund im Vergleich mit den riesigen Sedimentationsmaxima in $2,5 \mathrm{~m}$ und $5 \mathrm{~m}$ Tiefe. Die beiden Frühlingsmaxima wurden bei den Sedimentationsprobenahmen nicht mehr bzw. noch nicht erfasst. 
Leere Diatomeenschalen fielen in grösserer Menge nur am 4. Juni, 16. September, 1. Oktober 1969 und 12. Januar 1970 an; es handelte sich praktisch nur um Schalen von Stephanodiscus hantzschii (Juni, September und Januar; einzig im Oktober stellten leere Cyclotellaschalen den Hauptanteil).


Abb. 74 und 75. Diatomeae, Rotsee.

See: $\mathrm{mg} / 1$, Sediment: $\mathrm{mg} / \mathrm{dm}^{2}$. Expositionszeit.

Fig. 74 and 75. Diatomeae, Rotsee.

Lake: $\mathrm{mg} / \mathrm{l}$, sediment: $\mathrm{mg} / \mathrm{dm}^{2}$. exposure.

Stephanodiscus hantzschii Grun. (Abb. 76 und 77)

See: Stephanodiscus hantzschii war der wichtigste Vertreter der Diatomeen (vgl. [93], S. 457). Er trat in zwei Wintermaxima auf sowie sporadisch am 11. September in 2,5 $\mathrm{m}$ Tiefe und prägte weitgehend das Verteilungsbild der Diatomeen. In der übrigen Zeit wurden keine Stephanodiscus-hantzschii-Zellen gefunden.

Sediment: Stephanodiscus hantzschii sedimentierte praktisch sofort aus, wobei am Grund eine gewisse Verzögerung möglich war (Mai-Juni). Erstaunlich war das Ausmass des Sedimentationsmaximums vom 16 . September $\left(66-131 \cdot 10^{6} \mathrm{Z} / \mathrm{dm}^{2} \cdot\right.$ Expo- 
sitionszeit), welches ein höheres September-Entwicklungsmaximum als das festgestellte vermuten lässt. Die Zellen wurden dabei zum grossen Teil schon im Epilimnion abgebaut.
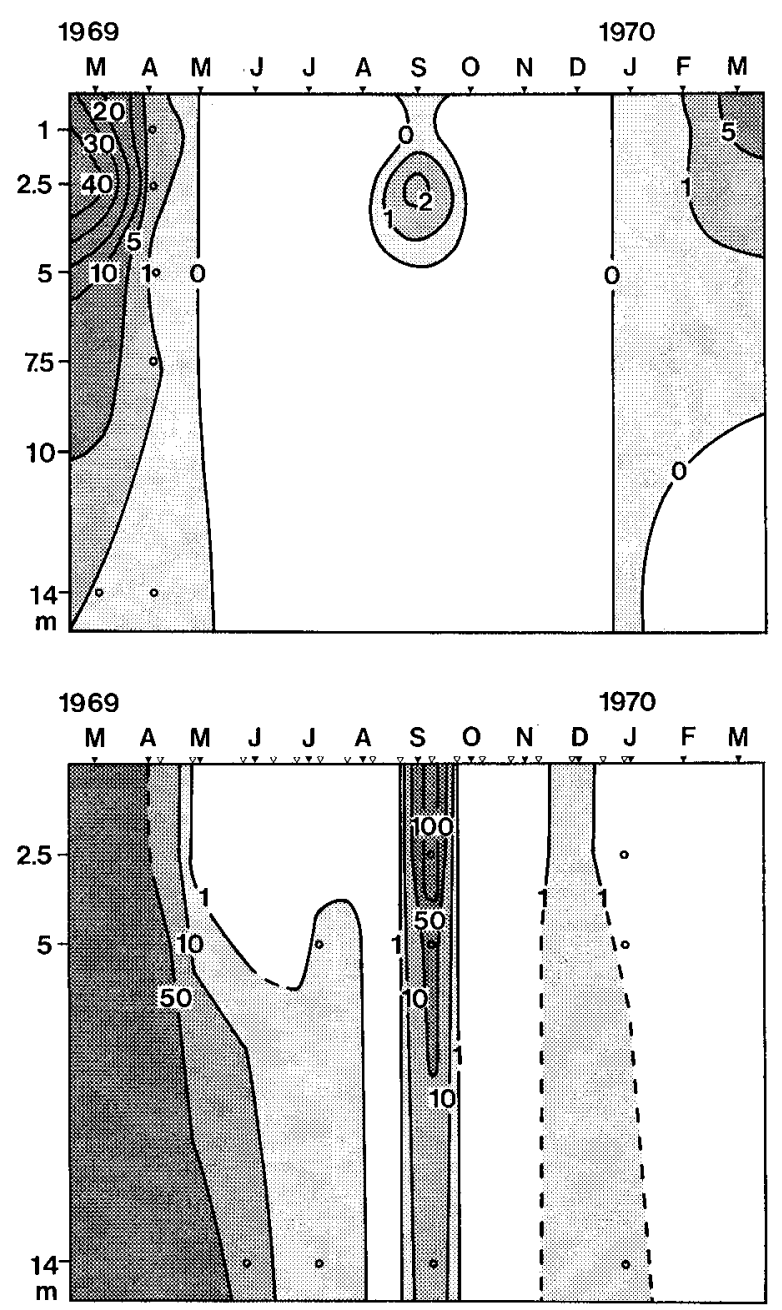

Abb. 76 und 77. Stephanodiscus hantzschii Grun., Rotsee. See: Zellen $10^{6} / 1$, Sediment: Zellen $\cdot 10^{6} / \mathrm{dm}^{2} \cdot$ Expositionszeit. $\circ=100 \%$ leere Zellen.

Fig. 76 and 77. Stephanodiscus hantzschii Grun., Rotsec.

Lake: cells $\cdot 10^{6} / 1$, sediment: cells $\cdot 10^{6} / \mathrm{dm}^{2} \cdot$ exposure. ${ }^{\circ}=$ $100 \%$ empty cells.

\subsection{Cryptophyceae (Abb. 78 und 79)}

See: Die Cryptophyceen waren die dominierende Algengruppe im Rotsee (vgl. [93], S. 457). Maxima fanden sich in den Wintermonaten (vor allem unmittelbar unter der Eisdecke) und im August-September (in $5 \mathrm{~m}$ Tiefe). ScHEGG erwähnt, dass ein Aussedimentieren der Zellen nicht festzustellen war, da ab 7,5 m nur noch geringe Zellzahlen angetroffen wurden.

Die Cryptophyceen des Rotsees setzten sich vor allem aus Rhodomonas lens Pascher et Ruttner, Rhodomonas lacustris Pascher et Ruttner und Cryptomonas spp. zusammen. Die Biomasseverteilung im Wasser deckte sich weitgehend mit dem Ver- 
teilungsbild von Cryptomonas, welcher im März-April $19699 \cdot 10^{6} \mathrm{Z} / \mathrm{l}$, im August $11 \cdot 10^{6} \mathrm{Z} / \mathrm{l}$ und im Januar $197015 \cdot 10^{6} \mathrm{Z} / \mathrm{l}$ erreichte (siehe [93], Abb. 35, S. 459). Rhodomonas entfaltete sich nur in den Wintermonaten in den obersten drei Metern massenhaft (absolutes Maximum im Januar bis März 1970 mit 10-15.106 Z/1); in den Monaten Juni bis August wurden im Wasser keine Zellen gefunden (siehe [93], Abb. 34, S. 458).

Sediment: Die von ScHEGG geäusserte Feststellung betreffend die Sedimentation hat sich generell bestätigt, doch lassen sich jetzt genauere Angaben über die Aussedimentierung der Cryptophyceen machen:

- Wie die Verteilung im Seewasser wurde auch das Sedimentationsbild von Cryptomonas geprägt. Im Sediment fielen mit einer Ausnahme (19. Mai) nie Rhodomonaszellen an.
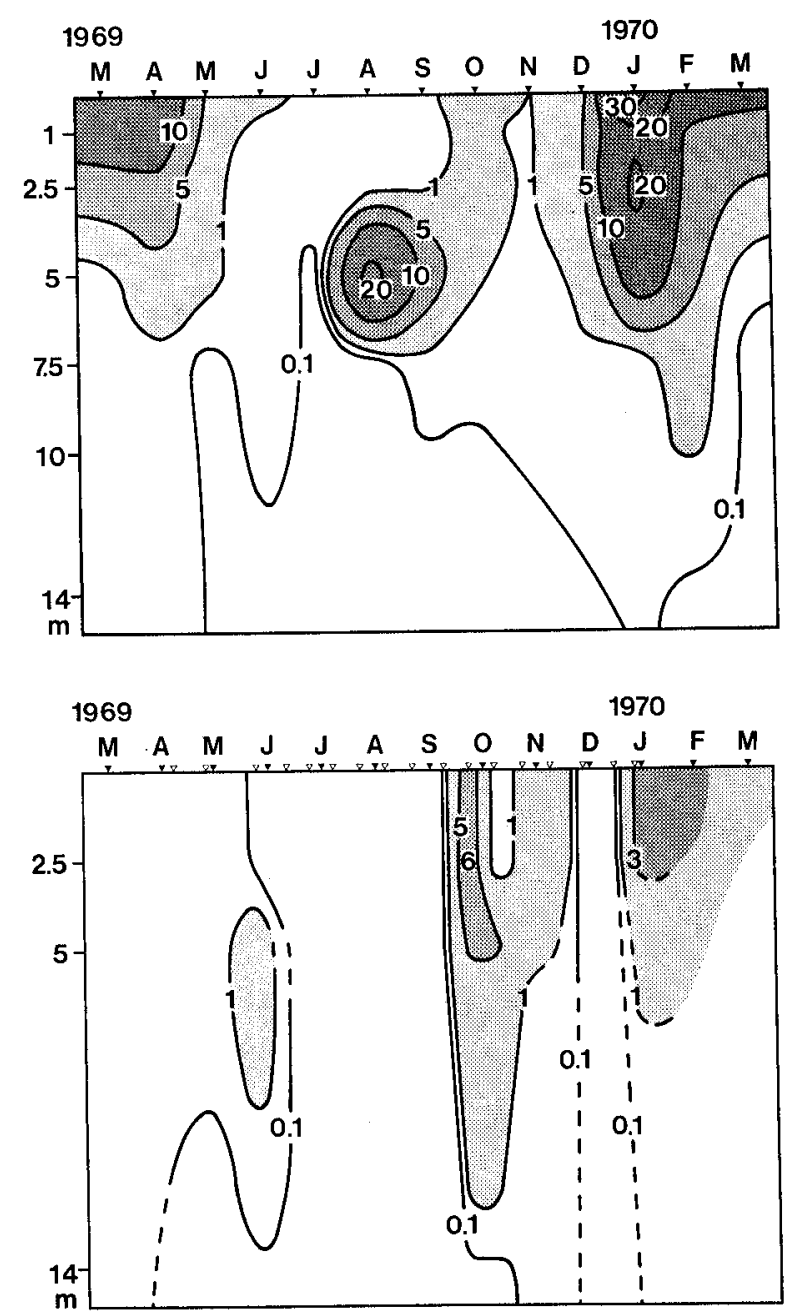

Abb. 78 und 79. Cryptophyceae, Rotsee.

See: $\mathrm{mg} / 1$, Sediment: $\mathrm{mg} / \mathrm{dm}^{2}$. Expositionszeit.

Fig. 78 and 79 . Cryptophyceae, Rotsee.

Lake: $\mathrm{mg} / 1$, sediment: $\mathrm{mg} / \mathrm{dm}^{2}$. exposure. 
- In 2,5 m und $5 \mathrm{~m}$ Tiefe fand eine zeitlich verschobene, starke Aussedimentierung der Zellmaxima statt:

17. April bis 4. Juni 1969: um etwa 11/2 Monate verschoben (Einfluss der Zirkulation); 14. August bis 16. September 1969: um 1 Monat verschoben (das Entwicklungsmaximum dürfte höher als in $5 \mathrm{~m}$ Tiefe gelegen haben);

15. Januar 1970: vermutlich etwa gleichzeitig.

- In $14 \mathrm{~m}$ Tiefe war praktisch keine Cryptophyceensedimentation mehr festzustellen.

Diese drei Tatsachen lassen den Schluss zu, dass von den Cryptophyceen Rhodomonas (im "kleinen Stoffkreislauf») sehr rasch abgebaut wurde und nur Cryptomonas am untern Rand des Epilimnions aussedimentierte, sich aber im Raum 5 bis $14 \mathrm{~m}$ beim weiteren Absinken rasch und weitgehend zersetzte.

\subsection{Peridineae (Abb. 80-82)}

See: Diese Algengruppe trat nur im September 1969 (Peridinium cinctum [Müller] Ehrnb.) und im Februar 1970 (Gymnodinium lantzschii Utermöhl) wesentlich in Erscheinung (Abb. 80 und 81) (vgl. [93], S. 459). Wegen des grossen Volumens machten die Zellen aber zu diesen Zeiten recht viel in der Biomasse aus (zum Beispiel im September in $0 \mathrm{~m} \mathrm{80 \% )}$. Das März-April-Maximum wurde von Gymnodinium lantzschii gebildet. Einzelfunde betrafen zusätzlich noch die Formen Gymnodinium helveticum Penard und Ceratium hirundinella (O.F.Müller) Schrank.

Sediment: Die Peridineen lassen aufgrund ihrer Grösse und der robusten Zellstruktur ein rasches und mehr oder weniger vollständiges Absinken erwarten. Leider wurden die beiden Frühlingsmaxima im Sediment nur ungenügend erfasst, so dass unsere Beobachtungen auf das relative Maximum im August-September beschränkt sind. Die Sedimentation erfolgte hier nur mit sehr kurzer Verzögerung (etwa $1 / 2$ Monat) und bis zum Grund, denn das Sedimentationsmaximum in $14 \mathrm{~m}$ Tiefe war zeitlich nicht verschoben. Ein Abbau fand zum Teil statt: im September waren 35-100\% der aufgefangenen Zellen leer, und vom unteren Rand des Epilimnions $(5 \mathrm{~m})$ bis Grund $(14 \mathrm{~m})$ betrug der Verlust überschlagsmässig 25-50\%. Durch den ganzen Oktober hindurch fielen massenweise Zysten, vermutlich von Peridinium cinctum, an (siehe Abb. 82).

\subsection{Diskussion der Ergebnisse}

\subsection{Algensukzessionen im Vierwaldstättersee (Horwer Bucht) und im Rotsee}

Die Phytoplanktonsukzession der beiden untersuchten Seen ist in Abb. 83 graphisch dargestellt.

Im Vierwaldstättersee waren bis April 1969 die Diatomeen und Cyanophyceen dominierend; darnach erschienen in rascher Folge Entwicklungsmaxima der Peridineen und Flagellaten (Mai), der Chlorophyceen, Chrysophyceen und Cryptophyceen (Juni), der Diatomeen (Juli) und Konjugaten (August); durch die hohe Diatomeenproduktion im Juli wurde die freie Kieselsäure im Epilimnion bis auf Spuren aufgezehrt (Werte von 0,35 bis 0,40 mg/l); während eines allgemeinen Zusammenbruches der Populationen im September-Oktober, der offensichtlich auf eine allgemeine Verknappung der Nährstoffe zurückzuführen war $\left(\mathrm{PO}_{4}-\mathrm{P}<1 \mu \mathrm{g} / 1, \mathrm{NO}_{3}-\mathrm{N}<10 \mu \mathrm{g} / \mathrm{I}\right)$, bahnte sich eine Cyanophyceenmassenentwicklung an, die im November-Dezember ihren 

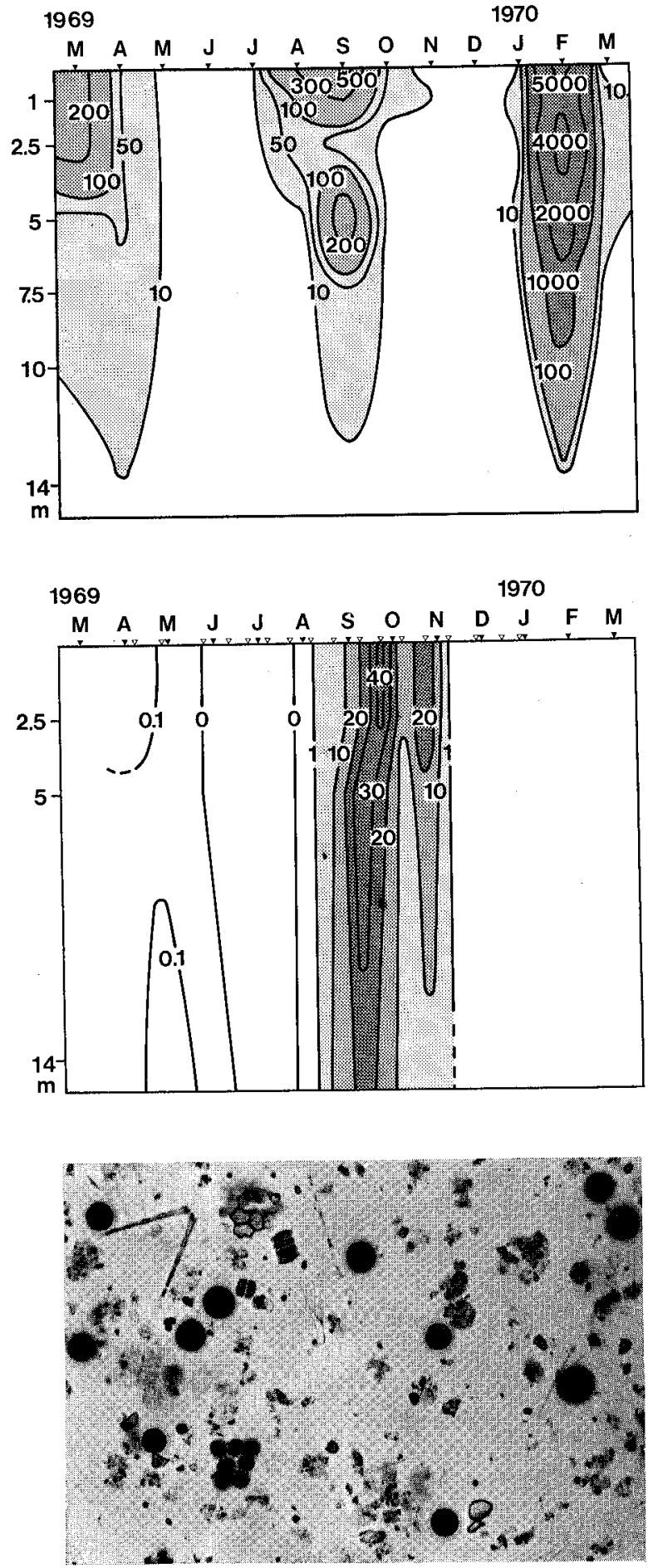

Abb. 80 und 81. Peridineae, Rotsee.

See: Zellen $\cdot 10^{3} / 1$, Sediment: Zellen $\cdot 10^{6} / \mathrm{dm}^{2} \cdot$ Expositionszeit. Fig. 80 and 81 . Peridineae, Rotsee.

Lake: cells $\cdot 10^{3} / 1$, sediment: cells $\cdot 10^{6} / \mathrm{dm}^{2} \cdot$ exposure.

Abb. 82. Peridineenzysten im Sediment des Rotsees (30. Oktober $1969,2,5 \mathrm{~m})$.

$28 \cdot 10^{6}$ Zysten $/ \mathrm{dm}^{2} \cdot$ Expositionszeit (Probe $100 \times$ verdünnt, Vergrösserung etwa $400 \times$ ).

Fig. 82. Cysts of peridineae in the sediment of the Rotsee (30 October $1969,2.5 \mathrm{~m}$ ).

$28 \cdot 10^{6}$ cysts $/ \mathrm{dm}^{2} \cdot$ exposure (sample $100 \times$ diluted, enlargement about $400 \times$ ). 


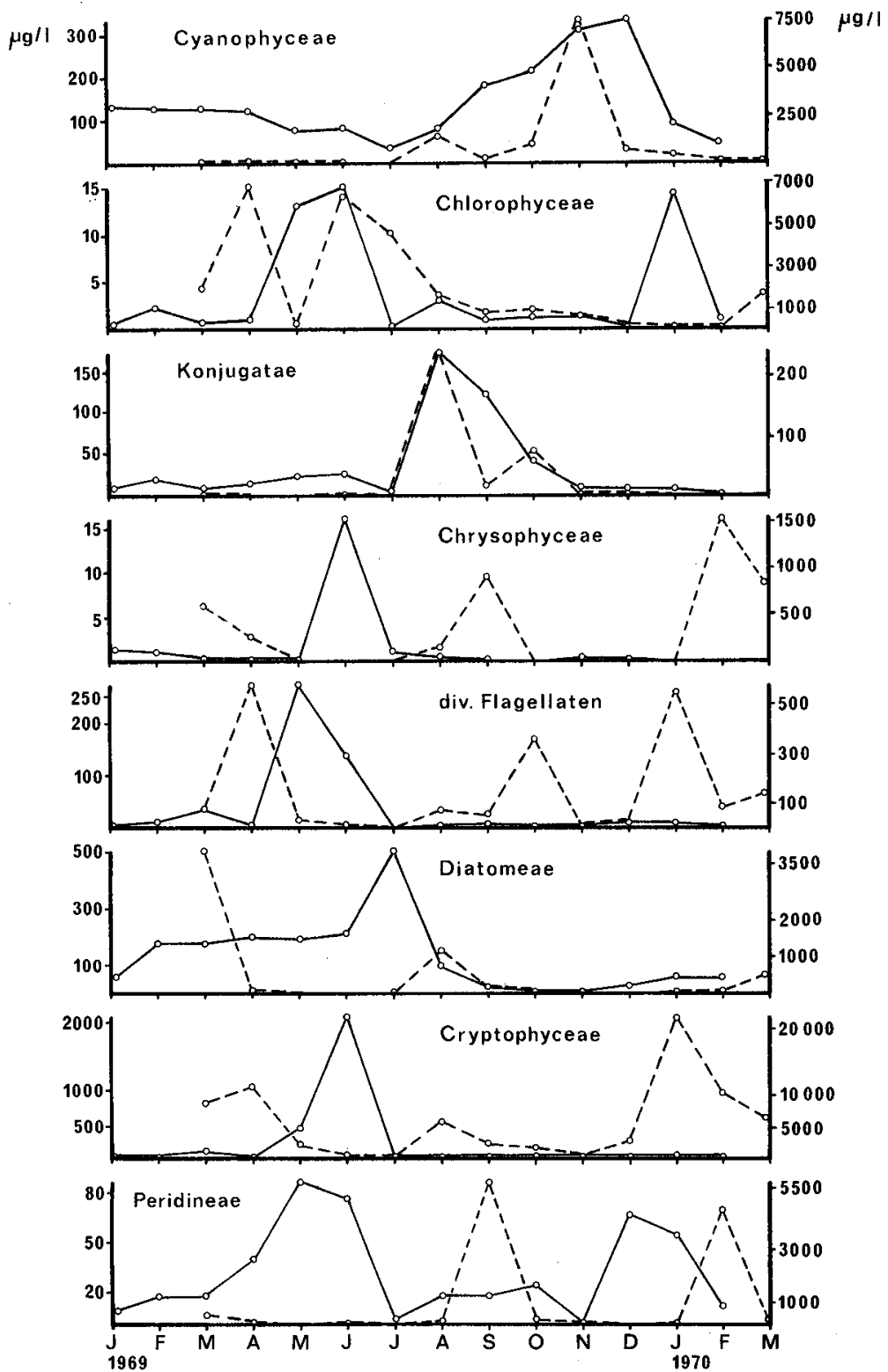

Abb. 83. Sukzession des Phytoplanktons im Epilimnion der Horwer Bucht (0-15 m) und des Rotsees $(0-5 \mathrm{~m}), \mu \mathrm{g}$ Frischgewicht $/ 1$.

Werte links und ausgezogene Linien $=$ Horwer Bucht,

Werte rechts und gestrichelte Linien = Rotsee.

Fig. 83. Succession of phytoplankton in the epilimnion of Horw Bay $(0-15 \mathrm{~m})$ and the Rotsee $(0-5 \mathrm{~m}), \mu \mathrm{g}$ fresh weight/1.

Values on the left and solid lines $=$ Horw Bay, values on the right and dashed lines $=$ Rotsee. 
Höhepunkt erreichte; diese Produktionssteigerung ist durch die Fähigkeit der im frühen Herbst dominierenden Blaualge Aphanizomenon flos-aquae zur N-Fixierung erklärbar (vgl. [101]) ; im Dezember zeigten die Peridineen, im Januar 1970 die Chlorophyceen ein zweites Maximum. Die Chlorophyceen, Chrysophyceen und Peridineen spielten in der Horwer Bucht biomassemässig eine untergeordnete Rolle; im ersten Halbjahr 1969 dominierten vor allem die Diatomeen, im zweiten Halbjahr 1969 die Cyanophyceen; die Flagellaten erreichten im Mai, die Cryptophyceen im Juni und die Konjugaten im August kurze, aber beträchtliche Spitzen.

Im eutrophen Rotsee zeigten sich trotz einiger Parallelen gewisse Unterschiede. Die Diatomeen und Cyanophyceen erreichten hier nur einmalige, kurze Maxima im März bzw. November 1969; als dominierende Gruppen traten im ersten Halbjahr 1969 die Chlorophyceen und Cryptophyceen, in der zweiten Jahreshälfte die Cryptophyceen allein auf; die Peridineen zeigten wie im Vierwaldstättersee zwei Entwicklungsmaxima und waren sonst wie die Chrysophyceen, Konjugaten und Flagellaten relativ unbedeutend. Die Nährstoffzehrung, die sich über die Monate August bis Oktober erstreckte $\left(\mathrm{PO}_{4}-\mathrm{P}<7 \mu \mathrm{g} / 1, \mathrm{NO}_{3}-\mathrm{N}<20 \mu \mathrm{g} / 1\right.$ - im September 40-70 $\left.\mu \mathrm{g} / \mathrm{l}\right)$, wirkte sich im Rotsee nicht so gravierend aus wie in der Horwer Bucht. Die Tatsache, dass in dieser Zeit Maxima der Konjugaten (August), der Peridineen und Chrysophyceen (September) und der Flagellaten (Oktober) sowie zum Teil beachtliche Biomassewerte (Cryptophyceen, Peridineen) registriert wurden, zeigt, dass die vorhandenen Nährstoffkonzentrationen immer noch für eine recht hohe Produktion ausreichten. Die $\mathrm{SiO}_{2}$-Zehrung ( $\left.<0,5 \mathrm{mg} / \mathrm{l}\right)$ fiel im Rotsee ebenfalls mit dem (relativen) Diatomeenmaximum (August) zusammen.

Die Sukzessionen der Chlorophyceen und der Diatomeen (Abb. 84 und 85) zeigen, unter Berücksichtigung der bedeutendsten Formen, dass sowohl die Horwer Bucht wie auch der Rotsee eine eigene Phytoplanktondynamik aufweist, obwohl sich die Artenlisten der beiden Seen erstaunlich wenig unterscheiden. Zum Teil ergaben sich deutliche Differenzen im jahreszeitlichen Auftreten der gleichen Formen (Coelastrum, Oocystis, Asterionella, Stephanodiscus). Ohne eingehende Untersuchungen der Mikronährstoffe, der Aufnahmekinetik und der ökologischen Ansprüche der einzelnen Arten ist eine genaue Deutung der Sukzession jedoch nicht möglich.

\subsection{Unterschiede im Phytoplankton des Rotsees und des Vierwaldstättersees} (Horwer Bucht)

Wenn sich auch die Artenlisten der beiden Seen in qualitativer Hinsicht nur geringfügig unterscheiden, so bestehen doch bezüglich der Quantität bedeutende Unterschiede (vgl. Abb. 83). Der eutrophere Rotsee zeichnet sich durch wesentlich grössere Zelldichten bzw. Biomassewerte aus. Dies kann bereits als Indiz einer höheren Eutrophiestufe angesehen werden, insbesondere die Massenentfaltungen der im Rotsee biomassemässig dominierenden Cryptophyceen (Cryptomonas spp. $32 \mathrm{mg} / 1$ ), Cyanophyceen (Coelosphaerium naegelianum 25,5 mg/l) und Peridineen (Peridinium cinctum $10 \mathrm{mg} / \mathrm{l}$ und Gymnodinium lantzschii $6 \mathrm{mg} / \mathrm{l}$ ), sowie der kokkalen Grünalgen Sphaerocystis schroeteri $(7,5 \mathrm{mg} / \mathrm{l})$, Coelastrum microporum $(5 \mathrm{mg} / \mathrm{l})$ und der Kieselalge Stephanodiscus hantzschii $(6,6 \mathrm{mg} / 1)$ (übereinstimmende Angaben bei Huber-PestalozzI [49] und FotT [27]). In der Horwer Bucht des Vierwaldstättersees erreichten nur einige Diatomeen (Diatoma elongatum, Synedra acus var. angustissima und S. berolinen- 

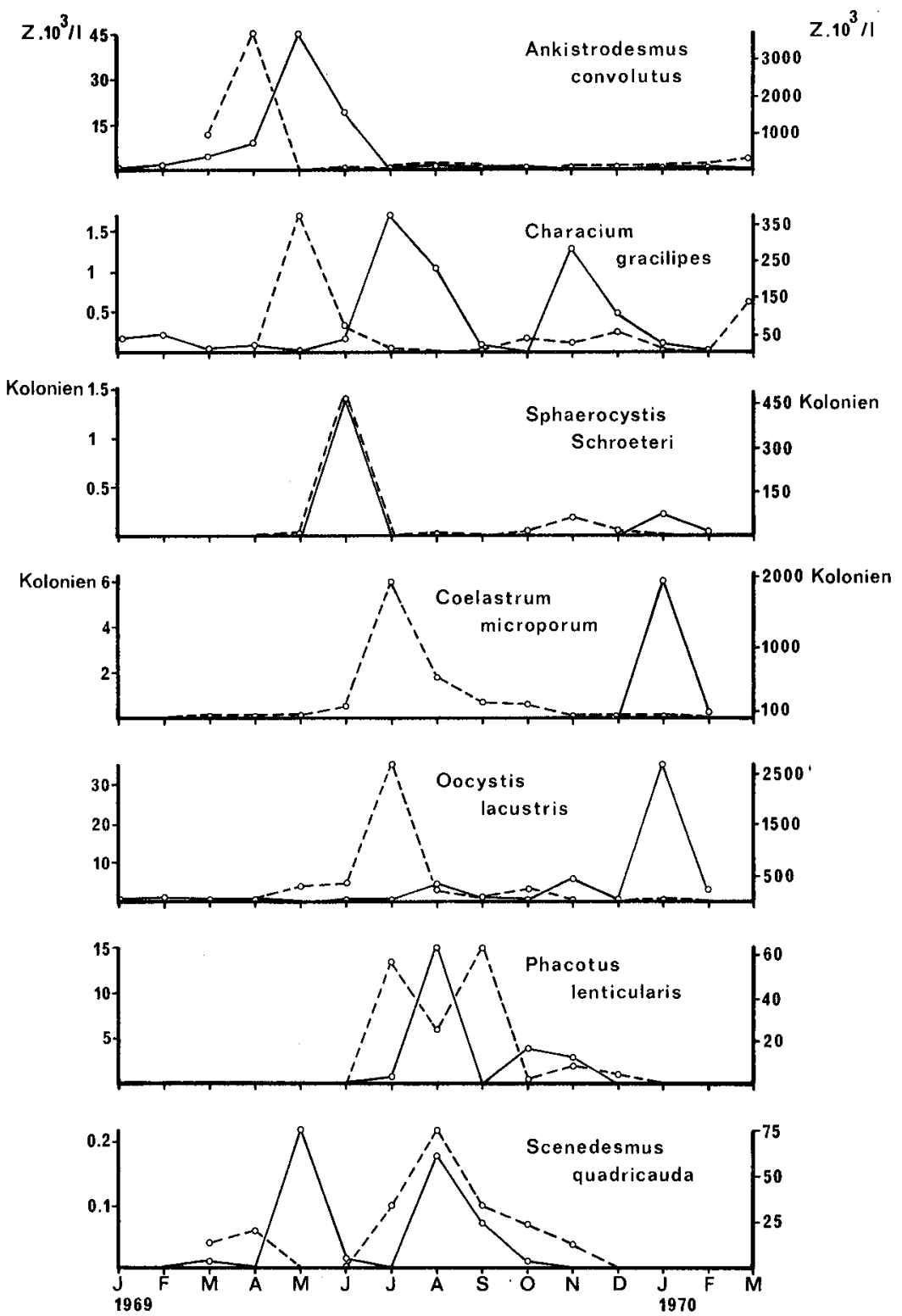

Abb. 84. Sukzession der Chlorophyceen im Epilimnion der Horwer Bucht $(0-15 \mathrm{~m})$ und des Rotsces $(0-5 \mathrm{~m})$, Zellen $\cdot 10^{3} / 1$.

Werte links und ausgezogene Linien $=$ Horwer Bucht,

Werte rechts und gestrichelte Linien $=$ Rotsee.

Fig. 84. Succession of chlorophyceae in the epilimnion of Horw Bay $(0-15 \mathrm{~m})$ and the Rotsee $(0-5 \mathrm{~m})$, cells $\cdot 10^{3} / \mathrm{l}$

Values on the left and solid lines $=$ Horw Bay, values on the right and dashed lines $=$ Rotsee. 


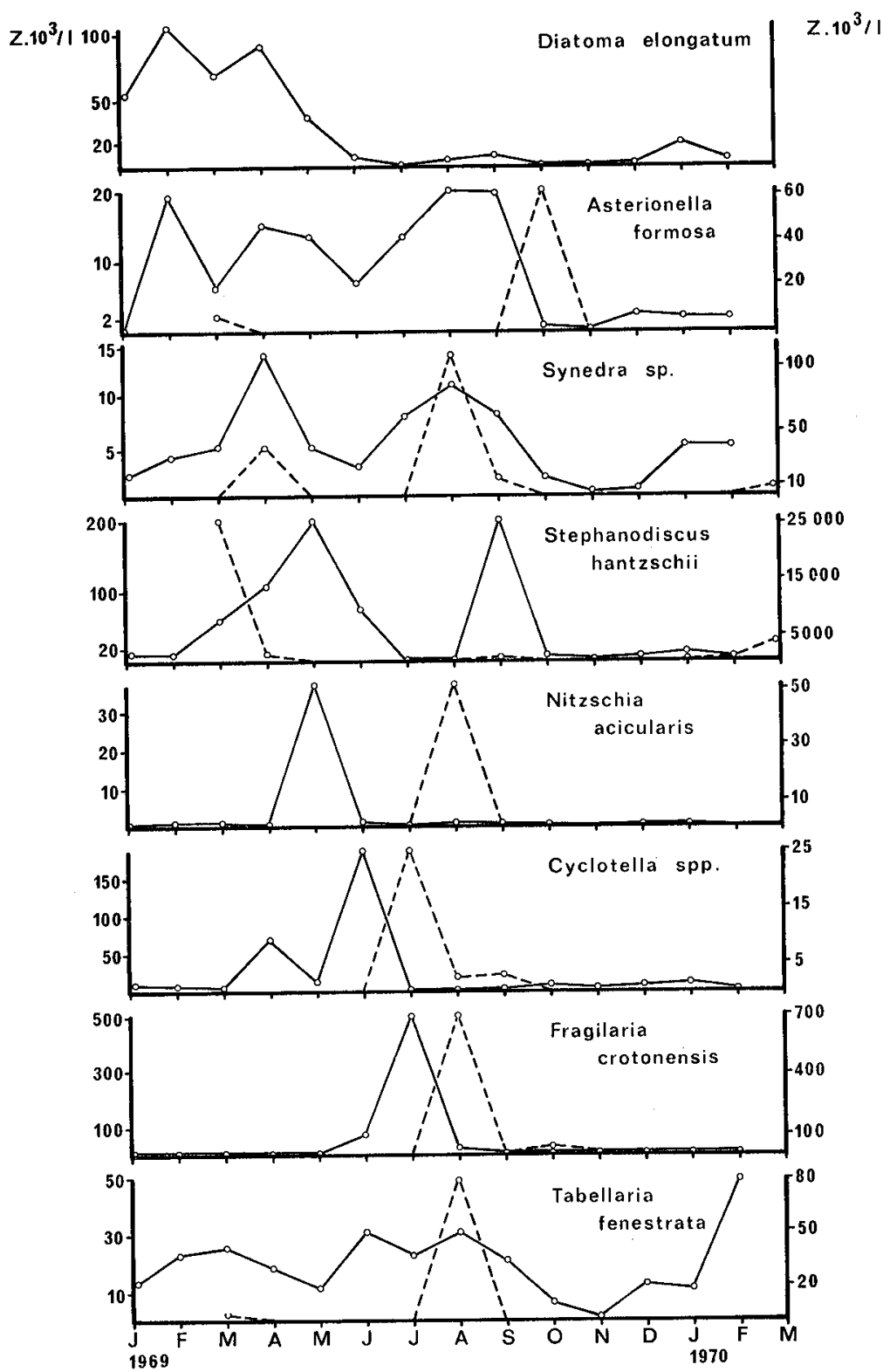

Abb. 85. Sukzession der Diatomeen im Epilimnion der Horwer Bucht $(0-15 \mathrm{~m})$ und des Rotsees $(0-5 \mathrm{~m})$, Zellen $\cdot 10^{3} / 1$

Werte links und ausgezogene Linien $=$ Horwer Bucht, Werte rechts und gestrichelte Linien $=$ Rotsee.

Fig. 85. Succession of diatomeae in the epilimnion of Horw Bay $(0-15 \mathrm{~m})$ and the Rotsee $(0-5 \mathrm{~m})$, cells $\cdot 10^{3} / 1$.

Values on the left and solid lines = Horw Bay, values on the right and dashed lines $=$ Rotsee. 
sis, Cyclotella comta und C. sp.) und die Blaualgen Oscillatoria rubescens und Aphanizomenon flos-aquae leicht höhere Absolutwerte als im Rotsee. Vorherrschend waren jedoch Cryptomonas ovata und C. erosa $(7,3 \mathrm{mg} / \mathrm{l})$, Fragilaria crotonensis $(1,5 \mathrm{mg} / \mathrm{l})$ und Rhodomonas lacustris und Rh. lens $(1,3 \mathrm{mg} / \mathrm{l})$, gefolgt mit grossem Abstand von Oscillatoria rubescens $(0,33 \mathrm{mg} / \mathrm{l})$ und Aphanizomenon flos-aquae $(0,26 \mathrm{mg} / \mathrm{l})$.

Tabelle 32. Die Bedeutung einzelner Phytoplankter als Produzenten und Trophieanzeiger im Rotsee und im Vierwaldstättersee.

Table 32. The importance of some phytoplankton species as producers and indicators of the trophic state in the Rotsee and in the Lake of Lucerne.

\begin{tabular}{|c|c|c|c|c|c|}
\hline \multirow[t]{2}{*}{$\overline{\text { Art }}$} & \multirow[b]{2}{*}{$\begin{array}{l}\text { Rotsee } \\
\text { Absolutes } \\
\text { Entwick- } \\
\text { lungs- } \\
\text { maximum } \\
\text { mg/l }\end{array}$} & \multirow[b]{2}{*}{$\begin{array}{l}\text { Prozentualer } \\
\text { Anteil des } \\
\text { Entwick- } \\
\text { lungs- } \\
\text { maximums } \\
\text { an der } \\
\text { Gesamt- } \\
\text { biomasse }\end{array}$} & \multicolumn{2}{|c|}{ Vierwaldstättersee } & \multirow{2}{*}{$\begin{array}{l}\mathrm{R} / \mathrm{V}- \\
\text { Quotient }\end{array}$} \\
\hline & & & $\begin{array}{l}\text { Absolutes } \\
\text { Entwick- } \\
\text { lungs- } \\
\text { maximum } \\
\mu \mathrm{g} / \mathrm{l}\end{array}$ & $\begin{array}{l}\text { Prozen- } \\
\text { tualer } \\
\text { Anteil des } \\
\text { Entwick- } \\
\text { lungs- } \\
\text { maximums } \\
\text { an der Gesam } \\
\text { biomasse }\end{array}$ & \\
\hline CY Coelosphaevium naegelianum & 25,5 & 92,4 & - & - & $\infty$ \\
\hline $\mathrm{CH}$ Chlamydomonas sp. & 7,77 & 24,4 & - & - & $\infty$ \\
\hline $\mathrm{CH}$ Tetrastrum $\mathrm{sp}$ & 0,016 & 0,05 & - & - & $\infty$ \\
\hline $\mathrm{CH}$ Oocystis lacustris & 1,73 & 47,1 & 0,74 & 0,08 & 590 \\
\hline $\mathrm{CH}$ Sphaerocystis schroeteri & 7,48 & 66,8 & 18,2 & 0,24 & 280 \\
\hline $\mathrm{CH}$ Characium gracilipes & 0,023 & 0,75 & 0,28 & 0,02 & 37 \\
\hline PE Peridinium sp. & 10,1 & 85,6 & 36,1 & 3,8 & 22 \\
\hline $\mathrm{CH}$ Scenedesmus quadricauda & 0,139 & 1,8 & 1,9 & 0,10 & 18 \\
\hline $\mathrm{CH}$ Ankistrodesmus convolutus & 1,43 & 4,5 & 6,0 & 0,47 & 9,6 \\
\hline CS Dinobryon spp. & 0,306 & 4,0 & 17,0 & 0,62 & 6,5 \\
\hline KO Closterium spp. & 0,586 & 2,3 & 3,4 & 0,36 & 6,4 \\
\hline PE Gymnodinium lantzschii & 5,96 & 25,4 & 54,5 & 4,3 & 5,9 \\
\hline DI Stephanodiscus hantzschii & 6,61 & 38,7 & 33,1 & 6,7 & 5,8 \\
\hline CH Coelastrum microporum & 5,10 & 91,4 & 52,2 & 16,1 & 5,7 \\
\hline CH Phacotus sp. & 0,040 & 1,5 & 2,9 & 0,31 & 4,8 \\
\hline KO Staurastrum sp. & 0,016 & 0,35 & 0,42 & 0,11 & 3,2 \\
\hline DI Synedrasp. & 0,446 & 5,8 & 59,6 & 4,9 & 1,2 \\
\hline KO Cosmarium sp. & 0,041 & 0,89 & 3,7 & 0,82 & 1,1 \\
\hline CP Cryptomonas spp. & 32,1 & 91,2 & 7330 & 92,9 & 0,98 \\
\hline DI Synedra acus var. angustissima & $a \quad 0,101$ & 2,3 & 127 & 6,5 & 0,35 \\
\hline DI Tabellaria fenestrata & 0,381 & 4,9 & 138 & 14,5 & 0,34 \\
\hline DI Nitzschia aciculavis & 0,012 & 0,28 & 10,6 & 0,84 & 0,33 \\
\hline DI Fragilaria crotonensis & 1,93 & 25,0 & 1560 & 87,4 & 0,29 \\
\hline $\mathrm{CP}$ Rhodomonas lacustris und lens & 3,06 & 13,8 & 1300 & 66,3 & 0,21 \\
\hline PE Gymnodinium helveticum & 0,352 & 2,1 & 146 & 10,9 & 0,19 \\
\hline DI Cyclotella sp. gross & 0,012 & 0,33 & 60,3 & 2,2 & 0,15 \\
\hline DI A sterionella formosa & 0,054 & 1,2 & 46,2 & 9,7 & 0,12 \\
\hline CY Oscillatoria mubescens & 0,148 & 0,87 & 333 & 74,9 & 0,012 \\
\hline CY Aphanizomenon flos-aquae & 0,069 & 0,27 & 265 & 59,4 & 0,004 \\
\hline DI Diatoma elongatum & - & - & 160 & 25,4 & 0 \\
\hline DI Cyclotella sp. klein & - & - & 20,4 & 3,4 & 0 \\
\hline DI Synedra berolinensis & - & - & 11,7 & 0,92 & 0 \\
\hline
\end{tabular}

CY Cyanophyceae, CH Chlorophyceae, KO Konjugatae, CS Chrysophyceae, DI Diatomeae, CP Cryptophyceae, PE Peridineae. 
Um ein Mass für die relative Bedeutung der einzelnen Arten für die beiden Seentypen zu erhalten, wurde der R/V-Quotient gebildet, das heisst für jede Art bzw. Gattung wurde der prozentuale Anteil des höchsten, während der Untersuchungszeit registrierten Entwicklungsmaximums an der Gesamtbiomasse errechnet und die so erhaltenen Rotseewerte durch die Vierwaldstätterseewerte dividiert (\%-Werte Rotsee: \%-Werte Vierwaldstättersee, siehe Tab. 32). Da, wie schon früher erwähnt, der Rotsee als hocheutroph (polytroph) und die Horwer Bucht als mesotroph einzustufen sind [125], gibt die Rangfolge in Tab. 32 zugleich den ungefähren Anzeigerwert der einzelnen Art innerhalb der schwierig abzugrenzenden Trophiestufen mesotroph und eutroph wieder. Angaben von Huber-Pestalozzr [49], Fott [27], Streble und KRAUTER [105] über Phytoplanktonhabitate decken sich weitgehend und insofern mit dieser Tabelle, dass Algen, die vor allem in eutrophen Gewässern vorkommen, auch in dieser Liste oben figurieren (alle Chlorococcales, die Peridineen, Stephanodiscus hantzschii und Phacotus sp.), und dass Algen, die eher in oligo- bis mesotrophen Verhältnissen gedeihen, am unteren Ende der Liste zu finden sind (die meisten Diatomeen). Aus dem Rahmen fallen dabei lediglich die als ökologische Spezialisten bekannten Cyanophyceen Oscillatoria rubescens und Aphanizomenon flos-aquae, die zu tief eingestuft erscheinen.

\subsection{Sedimentationsgeschwindigkeit des Phytoplanktons}

Die Sinkgeschwindigkeit ist abhängig vor allem von der Turbulenz des Wassers, dann auch von den einzelnen Faktoren in der Gleichung von Ostwald, die aus der Stokesschen Formel für die Sinkgeschwindigkeit von Kugeln hergeleitet ist [90]:

$$
\text { Sinkgeschwindigkeit }=\frac{\text { Übergewicht }}{\text { Formwiderstand } \cdot \text { innere Reibung }}
$$

Neben den verschiedensten Anpassungen der einzelnen Arten zur Erhöhung der Schwebefähigkeit (Verkleinern des spezifischen Gewichtes durch Gallerten, Gasvakuolen, u.ä.; Vergrössern des Formwiderstandes durch Zellanhänge, Zellkolonien, usw.), was zu Unterschieden in der Sinkgeschwindigkeit zwischen den Arten führt, ist die Sedimentationsgeschwindigkeit auch bei der gleichen Art verschieden von einem See zum andern (unterschiedliche Turbulenzverhältnisse). Im gleichen See ergeben sich Unterschiede im vertikalen Profil und in der Zeit [42]. Zunächst ist zu erwarten, dass die Sinkgeschwindigkeit zum Beispiel von Diatomeenzellen mit zunehmender Seetiefe zunimmt, weil 1. die Wasserturbulenz geringer wird und 2. infolge des fortschreitenden Abbaus (Erhöhung des Übergewichtes durch Zerstörung von Gallerten u.ä.; assimilierende Zellen schweben besser als physiologisch inaktive bzw. tote Zellen ([27], S. 463); dieser Zunahme wirken zwar die mit der Tiefe zunehmende Dichte und Viskosität des Wassers (niedrigere Temperatur) entgegen, reichen aber nicht oder nur zum Teil aus, um die Wirkung der beiden anderen Faktoren zu kompensieren [109]. Zum zweiten bewirken die hohen Sommertemperaturen (vor allem in den obersten Schichten) gegenüber dem kalten Winter eine bedeutende Erhöhung der Sinkgeschwindigkeiten (grosse Dichteunterschiede, geringere vertikale Zirkulationen).

Bestimmungen der Sinkgeschwindigkeit von Phytoplanktern liegen nur wenige vor. Gleichgültig, ob In-vitro-Versuche gemacht oder In-situ-Beobachtungen vorliegen, können grundsätzlich nur schalige Formen, insbesondere Diatomeen, in Betracht 
gezogen werden, da bei anderen Zellen Abbauvorgänge während des Absinkens wesentliche Verfälschungen der Ergebnisse hervorrufen dürften.

Versuche, die Sinkgeschwindigkeit von Diatomeen experimentell zu bestimmen, sind von Fritz [29] und Tessenow [109] durchgeführt worden. Allerdings können Ergebnisse aus solchen Experimenten nicht einfach auf den See übertragen werden, weil die In-situ-Turbulenzverhältnisse nicht berücksichtigt sind. Sie können lediglich Anhaltspunkte für grösstmögliche Sinkgeschwindigkeiten liefern.

Aus Schichtungen, Schichtungsfolgen und berechneten Verlusten an das Sediment versuchte GRIM [41] in situ die Sinkgeschwindigkeit von Diatomeen zu ermitteln. Mit Hilfe von Sedimentiergefässen lassen sich Grössenordnungen der Sedimentationsgeschwindigkeit einzelner Plankter noch genauer abschätzen, wenn die zeitlichen und räumlichen Abstände der einzelnen Proben genügend klein gehalten werden. Bereits aus den Isopletendarstellungen der Phytoplanktonsedimentation (siehe 5.1 und 5.2, S. 117 bis 143) ist ersichtlich, dass die meisten Formen nach einem Produktionsmaximum sehr rasch aussedimentierten (vgl. auch 5.34, S. 154). Die Verzögerung war gering und betrug durchschnittlich nur 2 bis 3 Wochen. Dies entspräche, unter Berücksichtigung der unterschiedlichen Seetiefe, einer durchschnittlichen Sinkgeschwindigkeit von 3 bis $5 \mathrm{~m} /$ Tag im Vierwaldstättersee und 0,7 bis $1 \mathrm{~m} / \mathrm{Tag}$ im Rotsee. Diese Schätzungen werden durch Werte bestätigt, die nach der Berechnungsmethode von GRIM [42]:

$$
\text { mittlere Sinkgeschwindigkeit }=\frac{\text { täglicher Verlust (Sedimentiergefäss) }}{\text { mittlere Dichte (Schöpfprobe) }}
$$

ermittelt wurden, obwohl die zeitlichen und räumlichen Abstände der Probenahmen im Vergleich zu den Untersuchungen Grims wesentlich höher lagen (Tab. 33). Allerdings kann mit dieser Methode nur die mittlere Sinkgeschwindigkeit ermittelt werden, ohne genauere Angaben über den Zeitpunkt der Aussedimentierung, die Länge des Sedimentationsweges und den physiologischen Zustand der absinkenden Zellen. Dementsprechend sind die verfügbaren Geschwindigkeitsangaben in der Literatur sehr variabel: GRIM [42] und JÄRNEFELT [51] geben zum Beispiel für verschiedene Kieselalgen 0,2-2,5 m/Tag an, während BACHOFEN [9] für die gleichen Formen im Sommer, wenn die Schwebefähigkeit herabgesetzt ist, 5-12 m/Tag berechnet hat. Obwohl die eigenen Werte ebenfalls beträchtlichen Schwankungen unterworfen waren, können einige Folgerungen gezogen werden:

1. Im Rotsee sanken die Phytoplankter gesamthaft gesehen eher langsamer als in der Horwer Bucht, entsprechend den Schätzungen aus den Isopletendarstellungen (unterschiedliche Sinkstrecke bei gleicher Verzögerung, siehe oben).

2. Wie zu erwarten war, schwebten die kleinen Centrales (Stephanodiscus, Cyclotella) im allgemeinen besser als die grösseren Pennales (Tabellaria, Fragilaria), obwohl diese den grösseren Formwiderstand besitzen.

3. Die Sinkgeschwindigkeiten waren in der Regel im Hypolimnion grösser als im Epilimnion; die gleiche Differenz fand sich zwischen Sommer und Winter. Es gibt jedoch jederzeit Störungen dieses Bildes durch unkontrollierbare vertikale Zirkulationsströmungen. GRIM [43] bezeichnet solche Zonen mit erhöhter Turbulenz als "ausgezeichnete Schichten»; sie wirken als "Austauschbarrieren», indem sich in ihnen die Zellen als Folge der Verlangsamung anhäufen, so dass das Sinken nicht kontinuier- 
Tabelle 33. Sinkgeschwindigkeiten einiger Phytoplankter im Vierwaldstättersee (Horwer Bucht) und im Rotsee. Angaben in $\mathrm{m} / \mathrm{Tag}$.

Table 33. The velocities of sinking of some phytoplankton species in the Lake of Lucerne (Horw Bay) and in the Rotsee. Data in m/day.

\section{A. Fragilaria crotonensis}

A 1. Horwer Bucht

\begin{tabular}{|c|c|c|c|c|c|c|c|c|c|c|c|c|c|c|}
\hline Tiefe & 1969 & & & & & & & & & & & & 1970 & \\
\hline $\mathrm{m}$ & $\mathrm{J}$ & $\mathrm{F}$ & $\mathrm{M}$ & A & M & $\mathrm{J}$ & $\mathrm{J}$ & A & $\mathrm{S}$ & $\mathrm{O}$ & $\mathrm{N}$ & $\mathrm{D}$ & $\mathrm{J}$ & $\mathrm{F}$ \\
\hline $0-7,5$ & 0,8 & 0,5 & 1,8 & 4,7 & 1,3 & 8,4 & 19,6 & 4,8 & 5,8 & 14,3 & 9,0 & 7,0 & - & - \\
\hline $7,5-15$ & 0,5 & 0,4 & 0,4 & 2,7 & 5,4 & 4,2 & 6,5 & 2,3 & 10,7 & 7,3 & 7,1 & 4,3 & 3,4 & - \\
\hline $15-25$ & 1,2 & 1,4 & 1,9 & 1,1 & 7,3 & 2,0 & 4,9 & 2,3 & 6,5 & - & 18,2 & - & - & - \\
\hline $25-45$ & 1,3 & 3,0 & - & 2,4 & 9,2 & 4,1 & 11,9 & 5,6 & 6,4 & 18,1 & 8,8 & 3,3 & 1,7 & 4,0 \\
\hline $45-60$ & 2,1 & 3,2 & 1,3 & 5,1 & 5,2 & 3,7 & 22,3 & 10,1 & 5,2 & 34,2 & 14,3 & 5,6 & - & - \\
\hline
\end{tabular}

A 2. Rotsee

\begin{tabular}{lllllll}
\hline Tiefe & \multicolumn{1}{l}{1969} & & & & \\
$\mathrm{~m}$ & $\mathrm{~J}$ & $\mathrm{~A}$ & $\mathrm{~S}$ & $\mathrm{O}$ & $\mathrm{N}$ \\
\hline $0-2,5$ & 5,3 & 4,7 & 0,3 & 0,8 & 0,5 \\
$2,5-5$ & 0,7 & 3,4 & 0,1 & - & - & \\
$5-14$ & $?$ & 5,4 & 1,4 & - & - \\
\hline
\end{tabular}

A 3. Vergleichswerte aus der Literatur

\begin{tabular}{|c|c|c|}
\hline Sinkgeschwindigkeit (m/Tag) & See & Methodik und Autor \\
\hline $\begin{aligned} 1,2-1,5 & \text { in } 0-30 \mathrm{~m} \\
3 & \text { in } 30-50 \mathrm{~m} \\
5 & \text { in } 50-100 \mathrm{~m} \\
7 & \text { in } 100-200 \mathrm{~m} \text { (Gr) }\end{aligned}$ & Bodensee (Obersee) & $\begin{array}{l}\text { Berechnungen aus } \\
\text { Schichtungsbildern } \\
\text { (Grrm [41]) }\end{array}$ \\
\hline $0,2-2,7$ in $0-50 \mathrm{~m}$ & Finnische Seen & $\begin{array}{l}\text { Sinktöpfe } \\
\text { (JÄRNEFELT [51]) }\end{array}$ \\
\hline $\begin{array}{l}1-2,5 \mathrm{im} \text { Winter } \\
8-12 \mathrm{im} \text { Sommer } \\
2-2,4\end{array}$ & $\begin{array}{l}\text { Baldeggersee } \\
-\end{array}$ & $\begin{array}{l}\text { Sinktöpfe } \\
\text { (BACHOFEN [9]) } \\
\text { Experimentell } \\
\text { (TEssEnow [109] }\end{array}$ \\
\hline
\end{tabular}

\section{B. Tabellaria fenestrata}

B 1. Horwer Bucht

\begin{tabular}{|c|c|c|c|c|c|c|c|c|c|c|c|c|c|c|}
\hline Tiefe & 1969 & & & & & & & & & & & & 1970 & \\
\hline $\mathrm{m}$ & $\mathrm{J}$ & $F$ & $\mathrm{M}$ & A & M & $\mathrm{J}$ & $\mathrm{J}$ & A & $\mathrm{S}$ & $\mathrm{O}$ & $\mathrm{N}$ & $\mathrm{D}$ & $\mathrm{J}$ & $\mathrm{F}$ \\
\hline $0-7,5$ & 1,8 & 1,6 . & 1,0 & 7,4 & 2,9 & 0,7 & 36,2 & $?$ & 14,1 & 5,0 & 7,4 & 3,5 & - & - \\
\hline $7,5-15$ & 0,9 & 0,9 & 0,4 & 1,7 & 3,1 & 1,5 & 9,0 & 7,0 & 3,1 & 3,3 & 4,4 & 2,8 & 1,8 & - \\
\hline $15-25$ & 1,1 & 1,2 & 1,0 & 2,2 & 5,3 & 1,5 & 11,2 & 5,4 & 5,6 & - & 6,9 & - & - & - \\
\hline $25-45$ & 0,9 & 0,8 & $\ldots$ & 2,9 & 6,2 & 3,0 & 17,5 & 8,4 & 6,6 & 3,6 & 8,0 & 2,1 & 0,7 & 0,5 \\
\hline $45-60$ & 0,8 & 1,5 & 1,0 & 6,8 & 6,5 & 2,9 & 19,5 & 12,0 & 6,4 & 8,9 & 10,3 & 1,2 & - & - \\
\hline
\end{tabular}


Fortsetzung Tabelle 33.

B 2. Vergleichswerte aus der Literatur

\begin{tabular}{lll}
\hline Sinkgeschwindigkeit (m/Tag) & See & Methodik und Autor \\
\hline $1-1,3$ in $1-7 \mathrm{~m}$ & Zellersee (Bodensec) & Berechnungen aus \\
$1,5-2,2$ in $10-20 \mathrm{~m}$ & & Schichtungsbildern (GRIM [43]) \\
$0,2-2,0(7$ ?) in $0-50 \mathrm{~m}$ & Finnische Seen & Sinktöpfe (JärNEFELT [51]) \\
\hline
\end{tabular}

\section{Stephanodiscus hantzschii}

C 1. Horwer Bucht

\begin{tabular}{lllllllllllllllll}
\hline $\begin{array}{l}\text { Tiefe } \\
\text { m }\end{array}$ & $\begin{array}{l}1969 \\
\text { J }\end{array}$ & F & M & A & M & J & J & A & S & O & N & D & J & F \\
\hline $0-7,5$ & 0,06 & 0,05 & 0,03 & 0,01 & 0,06 & 1,2 & 0,34 & 1,4 & 3,1 & 9,7 & 8,8 & 3,1 & - & - \\
$7,5-15$ & 0,45 & 0,13 & 0,03 & 0,01 & 0,04 & 1,3 & 0,19 & 0,08 & 0,02 & 0,51 & $?$ & $?$ & 1,5 & - \\
$15-25$ & 0,15 & 0,05 & 0,03 & 0,01 & 0,02 & 0,60 & 0,73 & 0,45 & 0,04 & - & 8,2 & - & - & - \\
$25-45$ & 0,49 & 0,10 & - & 0,01 & 0,08 & 0,95 & 1,7 & 0,27 & 0,20 & 2,0 & $?$ & 2,7 & 0,74 & 0,51 \\
$45-60$ & 0,22 & 0,16 & 0,06 & 0,03 & 0,05 & 1,1 & 5,0 & 0,46 & 0,20 & 9,4 & $?$ & 4,3 & - & - \\
\hline
\end{tabular}

C 2. Rotsee

\begin{tabular}{lllll}
\hline Tiefe & \multicolumn{2}{l}{1969} & $\mathrm{~S}$ & $\mathrm{D}$ \\
$\mathrm{m}$ & $\mathrm{A}$ & $\mathrm{M}$ & 1,5 & 0,3 \\
\hline $0-2,5$ & 0,2 & - & 0,5 & 0,2 \\
$2,5-5$ & 0,7 & 0,1 & - & 0,9 \\
$5-14$ & 0,9 & 2,0 & & - \\
\hline
\end{tabular}

D. Cyclotella spp.

D 1. Rotsee

\begin{tabular}{llllllll}
\hline $\begin{array}{l}\text { Tiefe } \\
\mathrm{m}\end{array}$ & 1969 & $\mathrm{M}$ & $\mathrm{J}$ & $\mathrm{J}$ & $\mathrm{A}$ & $\mathrm{S}$ & $\mathrm{O}$ \\
\hline $0-2,5$ & - & 0,6 & 0,8 & 6,4 & 5,1 & 4,6 \\
$2,5-5$ & - & 0,1 & 0,2 & 1,6 & $?$ & - & \\
$5-14$ & 2,1 & 0,9 & 0,4 & 5,6 & 3,6 & - \\
\hline
\end{tabular}

D 2. Vergleichswerte aus der Literatur

\begin{tabular}{|c|c|c|c|}
\hline Sinkgeschwindigkeit (m/Tag) & See & Art & Methodik und Autor \\
\hline $\begin{array}{l}2,5 \text { in } 10-15 \mathrm{~m} \\
3,0 \text { in } 15-20 \mathrm{~m} \\
3,0 \text { in } 20-25 \mathrm{~m} \\
3,5 \text { in } 25-30 \mathrm{~m} \\
5,0 \text { in } 30-50 \mathrm{~m} \\
7,0 \text { in } 50-100 \mathrm{~m} \\
8,0 \text { in } 100-200 \mathrm{~m} \mathrm{(Gr)}\end{array}$ & $\begin{array}{l}\text { Bodensee } \\
\text { (Obersee) }\end{array}$ & $\begin{array}{l}\text { kleine } \\
\text { Cyclotellen } \\
\text { (C. melosivoides } \\
\text { und } \\
\text { C. glomerata) }\end{array}$ & $\begin{array}{l}\text { Berechnungen aus } \\
\text { Schichtungsbildern (GRIM [41]) }\end{array}$ \\
\hline $\begin{array}{l}0,3-1,1 \text { in } 0-5 \mathrm{~m} \\
0,2-2,5 \text { in } 0-9 \mathrm{~m} \\
0,4-1,0 \text { in } 0-5 \mathrm{~m} \\
0,4-5,0 \text { in } 0-9 \mathrm{~m}\end{array}$ & $\begin{array}{l}\text { Schleinsee } \\
\text { (windgeschützt) }\end{array}$ & $\begin{array}{l}\text { C. melosiroides } \\
\text { C. comta }\end{array}$ & $\begin{array}{l}\text { Sinktöpfe und Biomasse } \\
\text { (GRIM [42]) }\end{array}$ \\
\hline $0,1-2,1$ in $0-50 \mathrm{~m}$ & Finnische Seen & Cyclotella sp. & Sinktöpfe (J ÄRNEFELT [51]) \\
\hline
\end{tabular}


Fortsetzung Tabelle 33.

E. Phacotus spp.

E1. Rotsee

\begin{tabular}{|c|c|c|c|c|c|}
\hline Tiefe & 1969 & & & & \\
\hline $\mathrm{m}$ & & $\mathrm{J}$ & A & $S$ & O \\
\hline $0-2,5$ & $\rightarrow$ & $?$ & $?$ & 3,0 & - \\
\hline $2,5-5$ & - & $?$ & 4,7 & 0,9 & - \\
\hline $5-14$ & 4,8 & 5,3 & 5,2 & 0,7 & 0,6 \\
\hline
\end{tabular}

lich, sondern in "Schüben» (in den sogenannten "Zwischenschichten.») erfolgt. Das Vorhandensein solcher turbulenten Schichten, welche die Sinkgeschwindigkeit sowohl des Phytoplanktons wie auch der feinsten anorganischen Schwebestoffe vermindern, stellten auch FindenEGG $[24,25]$ und NydegGer [70] fest.

\subsection{Verhältnis Standing Crop : sedimentierte Biomasse}

In den Abb. 48/49 und 38/39 sind als Beispiele die Formen Tabellaria fenestrata und Ankistrodesmus convolutus im Vierwaldstättersee dargestellt.

Bei mehr oder weniger gleichen Besiedlungsdichtemaxima $\left(60-80 \cdot 10^{3} \mathrm{Z} / \mathrm{l}\right)$ wurden von Ankistrodesmus im Sediment maximal $4 \cdot 10^{6} \mathrm{Z} / \mathrm{dm}^{2} \cdot$ Expositionszeit gezählt, von Tabellaria dagegen maximal $94 \cdot 10^{6} \mathrm{Z} / \mathrm{dm}^{2} \cdot$ Expositionszeit. Dieser Unterschied lässt auf eine starke Vermehrungsrate und ein sofortiges Aussedimentieren der Tabellariazellen schliessen (was für die meisten Diatomeen zutrifft), während die Population von Ankistrodesmus keine hohe Entwicklungsdynamik aufwies. Die nach GRIM [42] berechnete Zellproduktion im Epilimnion $(0-15 \mathrm{~m})$ bestätigt diese Vermutung (Tab. 34); die Zahlen können als ein Mittelwert ( $\pm 10-15 \%$ ) von mit Senkkulturen experimentell ermittelten Werten gelten [42]. Wenn, wie bei Tabellaria, nur eine relativ schwache Besiedelung anzutreffen ist, wird diese also nicht durch kleine Vermehrungsraten verursacht, sondern vielmehr von den sehr grossen Verlustraten durch die Sedimentation (vgl. [42]). So betrug der durchschnittliche Verlust bei Tabellaria rund 30 mal mehr pro Tag als bei Ankistrodesmus (Tab. 35).

Aufgrund dieser täglichen Verlustraten lassen sich Grössenordnungen der Wachstumsgeschwindigkeit abschätzen, indem die Verluste annäherungsweise der täglichen Zellproduktion gleichgesetzt werden (vgl. Tab. 34). Die Tabellariapopulation beispielsweise hatte sich demnach im Maximum (15. Juli bis 29. Juli) in einem Tag durchschnittlich verdreizehnfacht. Trägt man diesen Punkt der Wachstumskurve im semilogarithmischen Maßstab gegen die Zeit auf, so kann die Verdoppelungszeit herausgelesen werden. Auf diese Weise wurden minimale Generationszeiten von 3 bis $4 \mathrm{~h}$ (Cyclotella spp., Rotsee) und 6 bis $7 \mathrm{~h}$ (Tabellaria fenestrata, Vierwaldstättersee) berechnet. Diese Werte geben lediglich die Grössenordnungen an, da die Versuchsanordnung nicht zur Lösung solcher Fragen konzipiert wurde. Man muss aber annehmen, dass die Generationszeiten der Algen, die in Tab. 38 einen höheren Quotienten als 10 aufweisen, sicher unter 1 Tag lagen und bis in die Grössenordnung von $12 \mathrm{~h}$ reichten. Solche Werte wurden, allerdings in vitro unter besten Wachstumsbedingungen, schon von verschiedenen Autoren gefunden (zum Beispiel Nitzschia actinastroides $12 \mathrm{~h}$ [65], Asterionella formosa etwa $12 \mathrm{~h}$ [60], Phaeodactylum tricornutum $18 \mathrm{~h}$ [61]. Lund [60] 
Tabelle 34. Tabellaria fenestrata, Ankistrodesmus convolutus. Produzierte Zellzahlen unter $1 \mathrm{dm}^{2}(0-15 \mathrm{~m})$, Vierwaldstättersee (Horwer Bucht), 1969. Table 34. Tabellavia fenestrata, Ankistrodesmus convolutus. Number of cells produced below $1 \mathrm{dm}^{2}$ (0-15 m), Lake of Lucerne (Horw Bay), 1969 .

\begin{tabular}{|c|c|c|c|c|c|c|c|c|c|c|c|}
\hline \multirow{2}{*}{$\begin{array}{l}\text { Tabellaria fenestrata } \\
\text { Mengenänderung im See } \\
\text { Sedimentierte Zellmenge }(15 \mathrm{~m})\end{array}$} & \multicolumn{2}{|c|}{$\begin{array}{l}\text { Zellen } \cdot 10^{\mathbf{6}} \\
18.6 .-30.6\end{array}$} & \multicolumn{2}{|c|}{$30.6 .-15.7$} & \multicolumn{2}{|c|}{ 15. 7.-29. 7.} & 29. 7.-11. 8 & $11.8 .-25.8$. & 25. 8.-8.9. & 8.9.-22.9. & 22.9.-4. 10 \\
\hline & $\begin{array}{r}-0,13 \\
3,45\end{array}$ & & $\begin{array}{r}-0,13 \\
37,4\end{array}$ & & $\begin{array}{r}+0,1 \\
73,5\end{array}$ & & $\begin{array}{r}+0,13 \\
48,45\end{array}$ & $\begin{array}{r}-0,15 \\
60,39\end{array}$ & $\begin{array}{r}-0,15 \\
30,89\end{array}$ & $\begin{array}{r}-0,22 \\
12,08\end{array}$ & $\begin{array}{r}-0,22 \\
1,62\end{array}$ \\
\hline $\begin{array}{l}\text { Summe }= \\
\text { gefundene Zellproduktion }\end{array}$ & 3,32 & & 37,3 & & 73,6 & 64 & 48,58 & 60,24 & 30,75 & 11,86 & 1,40 \\
\hline Ankistrodesmus convolutus & $\begin{array}{l}\text { Zellen } \cdot 10^{6} \\
19.2 .-5.3\end{array}$ & 5.3. & -17.3 & 17.3.- & -1.4 . & 1. $4 .-30$ & . 4. $30.4 .-19$ & .5. $19.5 .-3.6$. & 3. $6 .-18.6$ & 18.6.-30.6. & 30. 6. -15.7 \\
\hline $\begin{array}{l}\text { Mengenänderung im See } \\
\text { Sedimentierte Zellmenge }(15 \mathrm{~m})\end{array}$ & $\begin{array}{r}-0,01 \\
0,03\end{array}$ & $\begin{array}{r}-0,0 \\
0,0\end{array}$ & & $\begin{array}{c}+0,11 \\
-\end{array}$ & & $\begin{array}{c}+0,54 \\
1,0\end{array}$ & $\begin{array}{r}+0,54 \\
2,59\end{array}$ & $\begin{array}{r}-0,39 \\
2,49\end{array}$ & $\begin{array}{r}-0,39 \\
0,07\end{array}$ & $\begin{array}{c}-0,28 \\
0\end{array}$ & $\begin{array}{c}-0,28 \\
0\end{array}$ \\
\hline $\begin{array}{l}\text { Summe }= \\
\text { gefundene Zellproduktion }\end{array}$ & 0,02 & 0 & & 0,11 & & 1,54 & 3,13 & 2,10 & 0 & 0 & 0 \\
\hline
\end{tabular}

Tabelle 35. Tabellaria fenestrata, Ankistrodesmus convolutus. Tägliche Verlustraten/dm² in $15 \mathrm{~m}$ Tiefe, Vierwaldstättersee (Horwer Bucht), 1969. Table 35. Tabellaria fenestrata, Ankistrodesmus convolutus. Daily rates of loss/dm² at a depth of $15 \mathrm{~m}$, Lake of Lucerne (Horw Bay), 1969 .

\begin{tabular}{|c|c|c|c|c|c|c|c|c|c|c|c|c|c|}
\hline \multirow{3}{*}{$\begin{array}{l}\text { Tabellaria fenestrata } \\
\text { Zellen } \cdot 10^{6} \\
\text { In } \% \text { der Gesamtzellzahl } \\
\text { unter } 1 \mathrm{dm}^{2}\end{array}$} & \multicolumn{3}{|c|}{$18.6 .-30.6$} & \multicolumn{2}{|c|}{ 30. 6.-15.7. } & \multicolumn{2}{|c|}{$15.7 .-29.7$} & \multicolumn{2}{|c|}{ 29. 7.-11.8. } & 11. 8.-25. 8 & \multirow{2}{*}{$\frac{25.8 .-8.9 .}{2,21}$} & \multirow{2}{*}{$\frac{8.9 .-22.9 .}{0,93}$} & \multirow{2}{*}{$\frac{22.9 \cdot-4 \cdot 10 .}{0,14}$} \\
\hline & \multicolumn{3}{|c|}{0,29} & & \multicolumn{2}{|l|}{5,25} & \multicolumn{2}{|l|}{3,73} & 4,31 & & & \\
\hline & & 71 & & 617 & & 1299 & & 922 & & 1095 & $\begin{array}{l}2,21 \\
560\end{array}$ & 446 & 65 \\
\hline Ankistrodesmus convolutus & 19. & $2 .-5.3$. & 5.3. & -17.3. & 17. 3.- & -1.4 . & 1. $4 .-30$ & 0.4 & $30.4 .-15$ & 9.5. 19.5.-3.6 & 5. 3.6.-18.6. & $18.6 .-30.6$ & $30.6 .-15.7$ \\
\hline Zellen $\cdot 10^{3}$ & 2,0 & & 0,6 & & - & & 34,5 & & 144 & 166 & 4,6 & 0 & 0 \\
\hline $\begin{array}{l}\text { In \% der Gesamtzellzahl } \\
\text { unter } 1 \mathrm{dm}^{2}\end{array}$ & 4 & & 1 & & - & & 9 & & 36 & 35 & 1 & 0 & 0 \\
\hline
\end{tabular}


Tabelle 36. Oscillatoria rubescens, Crypiomonas ovata und erosa. Produzierte Zellzahlen unter $1 \mathrm{dm}^{2}$ (0-15 m), Vierwaldstättersee (Horwer Bucht), 1969. Table 36. Oscillatoria rubescens, Cryptomonas ovata and erosa. Number of cells produced below $1 \mathrm{dm}^{2}(0-15 \mathrm{~m})$, Lake of Lucerne (Horw Bay), 1969.

\begin{tabular}{|c|c|c|c|c|c|c|c|c|}
\hline Oscillatoria rubescens & $\begin{array}{l}\text { Einheiten }(\mu \\
30.6 .-15.7 \text {. }\end{array}$ & $\begin{array}{l}\mathrm{m}) \cdot 10^{6} \\
15.7 .-29.7\end{array}$ & 29. 7.-11. 8 & $11.8 .-25.8$. & $25.8 .-8.9$ & 8.9.-22. 9. & 22. 9.-4. 10 & 4. $10 .-22.10$. \\
\hline $\begin{array}{l}\text { Mengenänderung im See } \\
\text { Sedimentierte Zellmenge }(15 \mathrm{~m})\end{array}$ & $\begin{array}{r}-273 \\
112\end{array}$ & $\begin{array}{r}+244 \\
160\end{array}$ & +244 & $\begin{array}{r}+476 \\
345\end{array}$ & $\begin{array}{r}+476 \\
259\end{array}$ & $\begin{array}{r}195 \\
949\end{array}$ & $\begin{array}{r}+195 \\
807\end{array}$ & $\begin{array}{r}+26 \\
338\end{array}$ \\
\hline $\begin{array}{l}\text { Summe }= \\
\text { gefundene Produktion an Einheiten }\end{array}$ & 0 & 404 & 475 & 821 & 735 & 1144 & 1002 & 364 \\
\hline
\end{tabular}

\begin{tabular}{|c|c|c|c|c|c|c|c|c|c|c|}
\hline $\begin{array}{l}\text { Cryptomonas ovata } \\
\text { und erosa }\end{array}$ & $\begin{array}{l}\text { Zellen } \cdot 10^{6} \\
23.1 .-6.2\end{array}$ & $6.2 .-19.2$ & 19.2.-5.3. & 5.3.-17.3. & $17.3 .-1.4$ & 1. $4 .-30.4$ & $30.4 .-19$ & $19.5 .-3.6$ & $3.6 .-18.6$ & 18.6.-30.6. \\
\hline Mengenänderung im See & $+0,07$ & $+0,07$ & $+0,02$ & $+0,02$ & $+0,002$ & $+0,94$ & $+0,94$ & $+11,27$ & $+11,27$ & $-12,12$ \\
\hline $\begin{array}{l}\text { Sedimenticrte } \\
\text { Zellmenge }(15 \mathrm{~m})\end{array}$ & 0,003 & 0,003 & 0,01 & 0,01 & - & 0,02 & 0,05 & 0,09 & 0,02 & 0 \\
\hline $\begin{array}{l}\text { Summe }= \\
\text { gefundene Zellproduktion }\end{array}$ & 0,073 & 0,073 & 0,03 & 0,03 & 0,002 & 0,96 & 0,99 & 11,36 & 11,29 & 0 \\
\hline
\end{tabular}

Talle 37. Oscillatoria rubescens, Cryptomonas ovata und evosa. Tägliche Verlustraten/dm² in $15 \mathrm{~m}$ Tiefe, Vierwaldstättersee (Horwer Bucht), 1969. Table 37. Oscillatoria rubescens, Cryptomonas ovata and erosa. Daily rates of loss/dm² at a depth of $15 \mathrm{~m}$, Lake of Lucerne (Horw Bay), 1969.




ermittelte bei In-situ-Flaschen-Experimenten mit Asterionella formosa im Lake Windermere Zellteilungsraten von maximal 13 bis 16 Teilungen pro Woche; das entspricht einer Generationszeit von 10,5 bis $13 \mathrm{~h}$.

Neben diesen beiden Verteilungstypen wurden noch zwei andere gefunden, für die als Beispiele Oscillatoria rubescens und Cryptomonas spp. ausgewählt wurden (Tab. 36 und 37). Waren bei Tabellaria geringer Standing Crop und hohe Sedimentationsraten, bei Ankistrodesmus geringer Standing Crop und tiefe Sedimentationsraten charakteristisch, so wurden bei Oscillatoria im Wasser und im Sediment viele Zellen, bei Cryptomonas im Wasser viele und im Sediment wenige Zellen gefunden. Der bei beiden Formen grosse Standing Crop lässt auf eine starke Produktion schliessen; im Sediment ergab sich ein Unterschied: Obwohl zwar Oscillatoria hohe Absolutwerte erreichte, war die Sedimentation als Folge des Aufrahmens der Fäden im Verhältnis zum Standing Crop nur gering $(1,7-7,4 \%)$; bei Cryptomonas dagegen sedimentierten nur noch minimalste Zellmengen, was mit den hohen Abbauraten zu erklären ist (siehe 5.35, S. 158).

Vergleicht man die maximal sedimentierte Zellmenge mit dem korrespondierenden maximalen Standing Crop, so ergibt sich - innerhalb der 4 Typen - eine grobe Abstufung bezüglich der Vermehrungsdynamik während der Hauptentwicklung einer Art (Tab. 38). Die Abgrenzung der 4 Verteilungstypen wurde wie folgt vorgenommen:

Gruppe 1 (Beispiel: Tabellaria fenestrata)

hohe Vermehrungsrate, rasches Aussedimentieren

Standing Crop $<5 \cdot 10^{6} \mathrm{Z}$ in der epilimnischen Wassersäule über $1 \mathrm{dm}^{2}$, Sedimentation $>10 \cdot 10^{6} \mathrm{Z} / \mathrm{dm}^{2} \cdot$ Expositionszeit am unteren Rand des Epilimnions

oder Sedimentation mehr als $10 \cdot>$ Standing Crop.

Gruppe 2 (Beispiel: Oscillatoria rubescens)

hohe Vermehrungsrate, mittlere Sedimentation

Standing Crop $>10 \cdot 10^{6} \mathrm{Z}$ in der epilimnischen Wassersäule über $1 \mathrm{dm}^{2}$, Sedimentation $\simeq$ Standing Crop.

Gruppe 3 (Beispiel: Cryptomonas ovata und erosa)

hohe Vermehrungsrate, geringste Sedimentation

Standing Crop $>10 \cdot 10^{6} \mathrm{Z}$ in der epilimnischen Wassersäule über $1 \mathrm{dm}^{2}$, Sedimentation $\ll$ Standing Crop.

Gruppe 4 (Beispiel: Ankistrodesmus convolutus)

geringe Vermehrungsrate, geringe Sedimentation

Standing Crop $<5 \cdot 10^{6} \mathrm{Z}$ in der epilimnischen Wassersäule über $1 \mathrm{dm}^{2}$, Sedimentation $<5 \cdot 10^{6} \mathrm{Z} / \mathrm{dm}^{2} \cdot$ Expositionszeit am unteren Rand des Epilimnions.

Die Flagellaten des Rotsees nehmen eine Zwischenstellung zwischen den Gruppen 2 und 3 ein und wurden, aufgrund des Quotienten, der Gruppe 2 zugeordnet.

Der Vergleich der verschiedenen Phytoplankter in Tab. 38 bestätigt die bekannte Tatsache ([100], S. 85), dass die festgestellte Besiedlungsdichte allein noch keine bestimmte Aussage über die Produktion liefern kann. Die Grösse der Verluste an sedimentierenden Zellen bietet nun eine Möglichkeit zur Abschätzung der Populationsdynamik. Um jedoch genauere Angaben über die Vermehrungsleistung einzelner Arten in situ zu erhalten, wären noch weitere, zeitlich geraffte Sedimentationsmessungen, gekoppelt mit Produktionsmessungen, nötig. 
Tabelle 38. Vermehrungsdynamik einiger Phytoplankter während ihres Entwicklungsmaximums (1969) im Vierwaldstättersee (Horwer Bucht) und im Rotsee.

Table 38. Dynamics of growth of some phytoplankton species during their maxima of development (1969) in the Lake of Lucerne (Horw Bay) and in the Rotsee.

\begin{tabular}{|c|c|c|c|c|c|c|c|}
\hline Art & $\begin{array}{l}\text { See } \\
\text { V } \\
\mathrm{R}\end{array}$ & $\begin{array}{l}\text { Standing } \\
\text { Z/dm }{ }^{2}(0 \\
Z / \mathrm{dm}^{2}(0\end{array}$ & $\begin{array}{l}\text { g Crop } \\
0-15 \mathrm{~m}) \\
0-5 \mathrm{~m})\end{array}$ & $\begin{array}{l}\text { Sedime } \\
Z / \mathrm{dm}^{2} \\
Z / \mathrm{dm}^{2}\end{array}$ & $\begin{array}{l}\text { Entation } \\
\text { - Ez }\end{array}$ & $\begin{array}{l}\text { Quotient } \\
\text { m) }\end{array}$ & Zeit \\
\hline DI Cyclotella spp. & $\mathrm{R}$ & 0,013 & $\cdot 10^{6}$ & 14,5 & $\cdot 10^{6}$ & 1100 & September \\
\hline DI Cyclotella sp. klein & $\mathrm{V}$ & 1,01 & $\cdot 10^{6}$ & 480 & $\cdot 10^{\circ}$ & 476 & April \\
\hline DI Tabellaria fenestrata & $\mathrm{V}$ & 0,47 & $\cdot 10^{6}$ & 73,5 & $\cdot 10^{6}$ & 156 & Juli-August \\
\hline DI Fragilaria crotonensis & $\mathrm{V}$ & 7,62 & $\cdot 10^{6}$ & 837 & $\cdot 10^{6}$ & 110 & Juli \\
\hline DI Fragilaria crotonensis & $\mathbf{R}$ & 2,71 & $\cdot 10^{6}$ & 269 & $\cdot 10^{6}$ & 99 & August \\
\hline $\mathrm{CH}$ Oocystis lacustris & $\mathrm{R}$ & 3,47 & $\cdot 10^{6}$ & 315 & $\cdot 10^{6}$ & 91 & Juli \\
\hline DI Asterionella formosa & $\mathrm{V}$ & 0,30 & $\cdot 10^{6}$ & 16,7 & $\cdot 10^{6}$ & 56 & August-September \\
\hline CH Scenedesmus quadricauda & $\mathrm{R}$ & 0,30 & $\cdot 10^{6}$ & 16,0 & $\cdot 10^{6}$ & 53 & August \\
\hline PE Gymnodinium lantzschii & $\mathrm{V}$ & 0,04 & $\cdot 10^{6}$ & 1,99 & $10^{6}$ & 50 & September \\
\hline DI Diatoma elongatum & $\mathrm{V}$ & 1,37 & $\cdot 10^{6}$ & 52,3 & $\cdot 10^{6}$ & 38 & April-Mai \\
\hline PE Peridinium cinctum & $\mathrm{R}$ & 1,01 & $\cdot 10^{6}$ & 38,3 & $\cdot 10^{6}$ & 38 & September \\
\hline $\mathrm{CH}$ Coelastrum microporum & $\mathrm{R}$ & 9,30 & $\cdot 10^{6}$ & 248 & $\cdot 10^{6}$ & 27 & Juli \\
\hline DI Asterionella formosa & $\mathrm{R}$ & 0,29 & $\cdot 10^{6}$ & 7,73 & $3 \cdot 10^{6}$ & 27 & Oktober \\
\hline KO Mongeotia sp. & $\mathrm{V}$ & 3,33 & $\cdot 10^{6}$ & 56,2 & $\cdot 10^{6}$ & 17 & August \\
\hline DI Stephanodiscus hantzschii & $\mathrm{R}$ & 5,16 & $\cdot 10^{6}$ & 65,5 & $\cdot 10^{6}$ & 13 & September \\
\hline CS Dinobryon spp. & $\mathrm{V}$ & 1,09 & $\cdot 10^{6}$ & 11,5 & $\cdot 10^{6}$ & 10 & Juli \\
\hline CY Oscillatoria rubescens & $\mathrm{V}$ & 889 & $\cdot 10^{6}$ & 949 & $\cdot 10^{6}$ & 1,1 & September \\
\hline DI Stephanodiscus hantzschii & $\mathrm{R}$ & 151 & $\cdot 10^{6}$ & 73,6 & $\cdot 10^{6}$ & 0,49 & Mai \\
\hline FL Flagellaten, diverse & $\mathrm{R}$ & 6,36 & $\cdot 10^{6}$ & 2,69 & $910^{6}$ & 0,42 & Oktober \\
\hline FL Flagellaten, diverse & $\mathrm{R}$ & 7,37 & $\cdot 10^{6}$ & 2,76 & $6 \cdot 10^{6}$ & 0,37 & März \\
\hline CH Ankistrodesmus convolutus & $\mathrm{R}$ & 17,4 & $\cdot 10^{6}$ & 6,21 & $1 \cdot 10^{6}$ & 0,36 & März \\
\hline CP Rhodomonas spp. & $\mathrm{V}$ & 17,6 & $\cdot 10^{6}$ & 1,38 & $8 \cdot 10^{6}$ & 0,08 & Mai \\
\hline FL Flagellaten, diverse & $\mathrm{V}$ & 13,1 & $\cdot 10^{6}$ & 0,55 & $5 \cdot 10^{6}$ & 0,04 & Mai \\
\hline CY Oscillatoria rubescens & $\mathrm{V}$ & 1110 & $\cdot 10^{6}$ & 35,4 & $\cdot 10^{6}$ & 0,03 & November \\
\hline CP Cryptomonas spp. & $\mathrm{V}$ & 12,3 & $\cdot 10^{6}$ & 0,09 & $9 \cdot 10^{6}$ & 0,007 & Juni \\
\hline GP Cryptomonas spp. & $\mathbf{R}$ & 22,2 & $\cdot 10^{6}$ & 0,14 & $4 \cdot 10^{6}$ & 0,006 & März \\
\hline CS Erkenia subaequiciliata & $\mathrm{R}$ & 10,5 & $\cdot 10^{6}$ & 0 & & 0 & September \\
\hline KO Mongeotia sp. & $\mathrm{R}$ & 0,31 & $\cdot 10^{6}$ & 2,20 & $0 \cdot 10^{8}$ & 7,1 & August \\
\hline $\begin{array}{c}\text { GH Ankistrodesmus } \\
\text { convolutus }\end{array}$ & $\mathrm{V}$ & 0,67 & $\cdot 10^{6}$ & 2,59 & $9 \cdot 10^{6}$ & 3,9 & $\mathrm{Mai}$ \\
\hline DI Tabellaria fenestrata & $\mathrm{R}$ & 0,25 & $\cdot 10^{6}$ & 0,83 & $3 \cdot 10^{6}$ & 3,3 & August \\
\hline DI Synedra acus & $\mathrm{R}$ & 0,53 & $\cdot 10^{6}$ & 0,80 & $0 \cdot 10^{6}$ & 1,5 & August-September \\
\hline CH Sphaerocystis schroeteri & $\mathrm{R}$ & 2,93 & $\cdot 10^{6}$ & 4,14 & $4 \cdot 10^{6}$ & 1,4 & Juni \\
\hline CH Characium gracilipes & $\mathrm{R}$ & 1,88 & $\cdot 10^{6}$ & 0,97 & $7 \cdot 10^{6}$ & 0,52 & Mai \\
\hline $\mathrm{PE}$ Gymnodinium helveticum & $\mathrm{V}$ & 0,08 & $\cdot 10^{6}$ & 0,02 & $2 \cdot 10^{6}$ & 0,25 & Juni \\
\hline PE Gymnodinium lantzschii & $\mathrm{V}$ & 0,57 & $\cdot 10^{6}$ & 0,02 & $2 \cdot 10^{6}$ & 0,04 & Mai \\
\hline
\end{tabular}

CX Cyanophyceae, CH Chlorophyceae, KO Konjugatae, CS Chrysophyceae, FI div. Flagellaten, DI Diatomeae, CP Cryptophyceae, PE Peridineae. (Ez $=$ Expositionszeit)

\subsection{Abbau des Phytoplanktons}

Die in den Sinktöpfen aufgefangenen Zellen können unter anderem auch Hinweise über die Abbaugeschwindigkeiten in situ liefern. Zur Berechnung der Abbauraten im Epilimnion müssen dabei die Produktionsverhältnisse bzw. die Biomasse mitbe- 
rücksichtigt werden, während der Zellzuwachs im obersten Bereich des Hypolimnions zwar vorhanden, aber vernachlässigbar klein ist. Die relativ rasche Aussedimentierung des Phytoplanktons (maximale Verzögerung der Sedimentationsmaxima gegenüber den Biomassemaxima $=2$ bis 3 Wochen, vgl. 5.33, S. 150) erlaubt zur Ermittlung der Abbauintensität die nachstehenden Ansätze, wobei folgende Abkürzungen verwendet werden:

$\begin{array}{lllll}\mathrm{B}_{1}=\text { Biomasse von } 0 \text { bis } 7,5 \mathrm{~m} & \text { (Horw) } & \text { bzw. 0 bis 2,5 } \mathrm{m} & \text { (Rotsee) } \\ \mathrm{B}_{2}=\text { Biomasse von } 7,5 \text { bis } 15 \mathrm{~m} & \text { (Horw) } & \text { bzw. 2,5 bis } 5 \mathrm{~m} & \text { (Rotsee) } \\ \mathrm{B}_{\mathrm{E}}=\text { Biomasse von } 0 \text { bis } 15 \mathrm{~m} & \text { (Horw) } & \text { bzw. 0 bis } 5 \mathrm{~m} & \text { (Rotsee) } \\ \mathrm{S}_{1}=\text { Sediment in } 7,5 \mathrm{~m} & \text { (Horw) } & \text { bzw. } 2,5 \mathrm{~m} & \text { (Rotsee) } \\ \mathrm{S}_{2}=\text { Sediment in } 15 \mathrm{~m} & \text { (Horw) } & \text { bzw. } 5 \mathrm{~m} & \text { (Rotsee) } \\ \mathrm{S}_{\mathrm{G}}=\text { Sediment in } 60 \mathrm{~m} & \text { (Horw) } & \text { bzw. } 14 \mathrm{~m} & \text { (Rotsee) } \\ \mathrm{A}_{1}=\text { Abbau von } 0 \text { bis } 7,5 \mathrm{~m} & \text { (Horw) } & \text { bzw. 0 bis } 2,5 \mathrm{~m} & \text { (Rotsee) } \\ \mathrm{A}_{2}=\text { Abbau von } 7,5 \text { bis } 15 \mathrm{~m} & \text { (Horw) } & \text { bzw. 2,5 bis } 5 \mathrm{~m} \text { (Rotsee) } \\ \mathrm{A}_{\mathrm{E}}=\text { Abbau von 0 bis } 15 \mathrm{~m} & \text { (Horw) } & \text { bzw. } 0 \text { bis } 5 \mathrm{~m} & \text { (Rotsee) } \\ \mathrm{A}_{\mathrm{H}}=\text { Abbau von } 15 \text { bis } 60 \mathrm{~m} & \text { (Horw) } & \text { bzw. } 5 \text { bis } 14 \mathrm{~m} & \text { (Rotsee) }\end{array}$

Um den relativ grossen Fehler der Auszählungsmethodik etwas auszugleichen, wurden die Abbauraten nicht in 14tägigen oder monatlichen Zeiträumen angegeben, sondern die einzelnen Werte wurden über die ganze Stagnationszeit (Mai bis Oktober 1969) aufsummiert, um so einen durchschnittlichen Abbauwert zu erhalten. Die For-

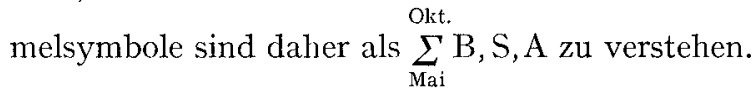

Die Ansätze der Abbauformeln lauten:

\section{Hypolimnion}

Annahme: Die Produktion bzw. Biomasse im Hypolimnion wird vernachlässigt.

Dann entspricht die Sedimentation am Grund der um den Abbau zwischen den beiden Sedimentationsstufen verminderten Sedimentation am unteren Rande des Epilimnions, also:

$$
\mathrm{S}_{\mathrm{G}}=\mathrm{S}_{\mathbf{2}}-\mathrm{A}_{\mathrm{H}} \text {. }
$$

Daraus berechnet sich der Abbau im Hypolimnion als

$$
\mathrm{A}_{\mathrm{H}}=\mathrm{S}_{\mathbf{2}}-\mathrm{S}_{\mathrm{G}} \text {. }
$$

Als $100 \%$ gilt die Zellzahl bzw. die Biomasse in $S_{2}$.

\section{Epilimnion}

Die Produktion bzw. Biomasse im Epilimnion muss berücksichtigt werden.

Die Sedimentation und der Abbau sind proportional der Biomasse in der darüberliegenden Wassersäule, also:

$$
\frac{S_{1}+A_{1}}{B_{1}}=\frac{S_{2}+A_{E}}{B_{E}}
$$

Annahme: Der Abbau im Epilimnion sei konstant, also: $A_{1} \cong A_{2}$. Wenn $B_{E}=B_{1}+$ $B_{2}$ und $A_{E}=A_{1}+A_{2} \cong 2 A_{1}$ gesetzt werden, ergibt sich durch Umformung der $A b-$ bau im Epilimnion als 


$$
\mathrm{A}_{\mathrm{E}}=\frac{2\left(\mathrm{~B}_{1} \mathrm{~S}_{1}+\mathrm{B}_{2} \mathrm{~S}_{1}-\mathrm{B}_{1} \mathrm{~S}_{2}\right)}{\mathrm{B}_{1}-\mathrm{B}_{2}} .
$$

Als $100 \%$ gilt, entsprechend der Gleichung $(1 \mathrm{~b})$, der Ausdruck $\frac{2\left(\mathrm{~B}_{1} \mathrm{~S}_{1}+\mathrm{B}_{2} \mathrm{~S}_{1}\right)}{\mathrm{B}_{1}-\mathrm{B}_{2}}$.

Bei diesen Berechnungen treten methodisch bedingte Fehler in Erscheinung ("Trichtereffekt», leichte Verzögerung der Sedimentation, mögliche aber geringe Produktion unterhalb der angenommenen Grenze Epilimnion-Hypolimnion), die sich summieren und in den Sedimentstufen eine Zunahme der Zellzahlen nach unten bewirken, was sich bei hohen Sedimentationsraten in der Aufsummierung der Werte von Mai bis Oktober besonders stark auswirkt. Dieser Fehler kann nur insofern in Rechnung gestellt werden, als Wertepaare mit $S_{2}>S_{1}$ bzw. $S_{G}>S_{2}$ nicht berücksichtigt wurden; im Normalfall $\left(\mathrm{S}_{1}>\mathrm{S}_{2}\right.$ bzw. $\left.\mathrm{S}_{2}>\mathrm{S}_{\mathrm{G}}\right)$ ist er nicht abzuschätzen, weshalb die errechneten Abbauraten eher zu tief sind. Diese Verfälschung dürfte aber durch den in den Gefässen leicht erhöhten Abbau mehr oder weniger kompensiert werden.

In den Tab. 39 und 40 sind zuerst die Phytoplanktongruppen, dann die einzelnen Arten in der Reihenfolge abnehmenden Abbaues zusammengestellt. Die berechneten Abbauraten stimmen weitgehend mit den aus den Isopletendarstellungen (vgl. 5.1 und 5.2, S. 117 bis 143) gefolgerten qualitativen Aussagen überein. Für die gesamte Biomasse lagen die Werte in beiden Seen etwa gleich hoch, in der trophogenen Schicht $77-79 \%$ und in der tropholytischen Schicht $45-48 \%$. Dieser Unterschied ist ein direkter Beweis für das Vorhandensein und die Wirksamkeit des «kleinen kurzgeschlossenen Stoffkreislaufes» im Epilimnion (siehe S. 162).

Bei den einzelnen Gruppen und Arten traten neben Parallelen auch einige Unterschiede auf. Die Cryptophyceen, Flagellaten und Chrysophyceen wurden infolge ihrer zarten Zellstruktur am stärksten zersetzt. In beiden Seen zeigte sich Cryptomonas etwas widerstandsfähiger als Rhodomonas, deren Zellen schon im Epilimnion weitgehend abgebaut wurden und nur vereinzelt ins Hypolimnion gelangten. Die nicht näher bestimmten Flagellaten scheinen im Rotsee durch abbauresistentere Formen vertreten gewesen zu sein. Die Werte der Chrysophyceen liegen in der Horwer Bucht sicher etwas zu tief, da die massenhaft angefallenen leeren Gehäuse der Hauptform Dinobryon spp. (maximal31 $10^{6} / \mathrm{dm}^{2} \cdot$ Expositionszeit im Sediment in 60 $\mathrm{m}$ [29. Juli 1969] und $134 \cdot 10^{3} / 1$ im Wasser in $15 \mathrm{~m}$ [5. August 1969]) nicht berücksichtigt sind; demgegenüber traten im Rotsee nur gehäuselose Formen (Erkenia, Uroglena) wesentlich in Erscheinung.

In beiden Seen verblüfften die hohen Abbauraten der Diatomeen. Insbesondere die Zellkörper von Stephanodiscus hantzschii, Cyclotella sp. klein, Synedra acus var. angustissima und S. berolinensis, sowie von Tabellaria fenestrata und Fragilaria crotonensis wurden während der Sedimentation stark zersetzt, so dass zum grossen Teil nur noch die leeren Kieselschalen auf den Seegrund gelangten. (Die [zu] tiefen hypolimnischen Werte von Cyclotella sp. klein [Horw] und Stephanodiscus hantzschii [Rotsee] dürften, wie bei Dinobryon, auf das Nichtberücksichtigen der leeren Schalen zurückzuführen sein.) Dieser Befund steht im Gegensatz zu den Ergebnissen Grims [44] im Bodensee, denn einzig Diatoma elongatum (Horw) schien in höherem Masse dem Abbau zu widerstehen und so dem Stoffkreislauf inkorporierten Phosphor zu entziehen.

Die Konjugaten zeigten im Rotsee im Vergleich zur Horwer Bucht einen grösseren epilimnischen und einen kleineren hypolimnischen Abbau, während die Peridineen 
Tabelle 39. Abbauraten des Phytoplanktons im Vierwaldstättersee (Horwer Bucht).

Table 39. Rates of degradation of the phytoplankton in the Lake of Lucerne (Horw Bay).

\begin{tabular}{|c|c|c|}
\hline Gruppe, Art & $\begin{array}{l}\text { Abbauraten im } \\
\text { Epilimnion }(0-15 \mathrm{~m}) \\
\text { Mai bis Oktober } 1969 \\
\%\end{array}$ & $\begin{array}{l}\text { Abbauraten im } \\
\text { Hypolimnion }(15-60 \mathrm{~m}) \\
\text { Mai bis Oktober } 1969 \\
\%\end{array}$ \\
\hline Phytoplankton total & 76,6 & 47,9 \\
\hline FL diverse Flagellaten & 100,0 & 100,0 \\
\hline CP Cryptophyceae & 75,4 & 94,3 \\
\hline PE Peridineae & 76,2 & 78,6 \\
\hline DI Diatomeae & 85,5 & 48,5 \\
\hline KO Konjugatae & 73,9 & 57,2 \\
\hline CS Chrysophyceae & 59,4 & 69,6 \\
\hline $\mathrm{CH}$ Chlorophyceae & 55,1 & 63,7 \\
\hline CY Cyanophyceae & 65,4 & 9,7 \\
\hline DI Stephanodiscus hantzschii & 100,0 & 100,0 \\
\hline CP Rhodomonas lacustris und lens & 100,0 & 100,0 \\
\hline $\mathrm{PE}$ Gymnodinium helveticum & 100,0 & 100,0 \\
\hline DI Synedra acus var. angustissima & 95,8 & 83,8 \\
\hline CH Characium sp. & 91,6 & 83,3 \\
\hline CH Coelastrum reticulatum & 71,9 & 100,0 \\
\hline CP Cryptomonas ovata und erosa & 74,2 & 94,7 \\
\hline DI Synedra berolinensis & 100,0 & 56,5 \\
\hline DI Tabellaria fenestrata & 75,4 & 73,1 \\
\hline DI Fragilaria crotonensis & 96,3 & 51,3 \\
\hline $\mathrm{CH}$ Oocystis sp. & 95,6 & 49,1 \\
\hline CH Sphaerocystis sp. & 52,8 & 84,8 \\
\hline DI Synedrasp. & 84,3 & 51,7 \\
\hline $\mathrm{CH}$ Scenedesmus sp. & 89,1 & 44,6 \\
\hline DI Cyclotella sp. klein & 100,0 & 33,0 \\
\hline KO Mougeotia sp. & 74,2 & 58,1 \\
\hline DI Asterionella formosa & 78,2 & 47,2 \\
\hline $\mathrm{CH}$ Ulothrix amphigranulata & 91,9 & 26,5 \\
\hline $\mathrm{CH}$ Ankistrodesmus convolutus & 48,7 & 66,7 \\
\hline DI Cyclotella comta gross & 60,1 & 42,9 \\
\hline PE Gymnodinium lantzschii & 67,1 & 23,7 \\
\hline DI Diatoma elongatum & 47,9 & 37,2 \\
\hline CY Oscillatoria rubescens & 70,7 & 9,7 \\
\hline
\end{tabular}

in der Horwer Bucht dank Gymnodinium helveticum wesentlich höhere Abbauraten erreichten als im Rotsee.

Am schlechtesten wurden die Chlorophyceen und die Cyanophyceen abgebaut. Auffallend sind die tiefen Werte von Ankistrodesmus (Horw), Ulothrix (Horw), Scenedesmus (Horw und Rotsee im Hypolimnion), Coelastrum (Rotsee), Characium (Rotsee) und Oocystis (Horw und Rotsee im Hypolimnion). Daneben wurden aber auch höchste Werte ermittelt (Sphaerocystis, Rotsee und Coelastrum, Hypolimnion Horw). Die Cyanophyceen (Oscillatoria rubescens) der Horwer Bucht wurden vorwiegend im Epilimnion abgebaut, was mit dem Aufrahmen in Zusammenhang steht, ein Effekt, der im Rotsee nicht auftrat (Coelosphaerium). 
Tabelle 40. Abbauraten des Phytoplanktons im Rotsee.

Table 40. Rates of degradation of the phytoplankton in the Rotsee.

\begin{tabular}{|c|c|c|}
\hline$\overline{\text { Gruppe, Art }}$ & $\begin{array}{l}\text { Abbauraten im } \\
\text { Epilimnion }(0-5 \mathrm{~m}) \\
\text { Mai bis Oktober } 1969 \\
\%\end{array}$ & $\begin{array}{l}\text { Abbauraten im } \\
\text { Hypolimnion }(5-14 \mathrm{~m}) \\
\text { Mai bis Oktober } 1969 \\
\%\end{array}$ \\
\hline Phytoplankton total & 79,4 & 45,1 \\
\hline CS Chrysophyceae & 100,0 & 100,0 \\
\hline CP Cryptophyceae & 83,9 & 97,2 \\
\hline DI Diatomeae & 85,1 & 75,0 \\
\hline FL diverse Flagellaten & 66,1 & 82,5 \\
\hline KO Konjugatae & 91,7 & 39,2 \\
\hline CY Cyanophyceae & 60,9 & 63,1 \\
\hline CH Chlorophyceae & 62,0 & 48,3 \\
\hline PE Peridineae & 66,5 & 38,2 \\
\hline CH Sphaerocystis schroeteri & 100,0 & 100,0 \\
\hline CP Rhodomonas lacustris und lens & 89,5 & 100,0 \\
\hline CP Cryptomonas spp. & 84,0 & 98,5 \\
\hline DI Tabellaria fenestrata & 75,4 & 92,6 \\
\hline DI Fragilavia crotonensis & 84,4 & 81,8 \\
\hline CH Ankistrodesmus convolutus & 72,6 & 72,4 \\
\hline DI Asterionella formosa & 54,3 & 79,8 \\
\hline DI Cyclotella spp. & 78,8 & 47,2 \\
\hline DI Synedra spp. & 75,3 & 49,4 \\
\hline $\mathrm{CY}$ Coelosphaerium naegelianum & 63,5 & 60,4 \\
\hline $\mathrm{CH}$ Oocystis lacustris & 88,8 & 23,4 \\
\hline DI Stephanodiscus hantzschii & 80,8 & 29,8 \\
\hline $\mathrm{CH}$ Characium gracilipes & 40,6 & 57,3 \\
\hline CH Coelastrum microporum & 57,7 & 31,6 \\
\hline $\mathrm{CH}$ Scenedesmus quadricanda & 66,9 & 5,7 \\
\hline
\end{tabular}

Will man die Ergebnisse in ihrer Gesamtheit beurteilen, so ist klar ersichtlich, dass die biologischen Untersuchungen am Phytoplankton jene chemischen Resultate voll bestätigen, welche immer wieder auf den intensiven "kleinen Stoffkreislauf» in der trophogenen Schicht hindeuten (vgl. auch Abschnitt 6, S. 167 bis 178). Das wird verdeutlicht, wenn man die Abbauraten im Hypolimnion mit dem epilimnischen Abbau in Beziehung setzt. So wurden im Rotsee zum Beispiel von 20,6\% (Horw: 23,4\%) im Epilimnion nicht abgebauter Biomasse im Hypolimnion noch 45,1\% (Horw : 47,9\%) zusätzlich abgebaut, das sind nur 9,3\% (Horw: 11,2\%) der epilimnischen Biomasse oder etwa 9mal (Horw: $7 \mathrm{mal}$ ) weniger als im Epilimnion selber $(79,4 \%$; Horw: $76,6 \%$ ). Das Erstaunliche dabei ist, dass die Intensität des «kurzgeschlossenen Stoffkreislaufes» in der mesotrophen Horwer Bucht die gleiche Grössenordnung erreichte wie im eutrophen Rotsee.

In der Literatur findet man diese Werte weitgehend bestätigt. Nach OHLE [74] werden bis zu 90\% des Phytoplanktons abgebaut, bevor es die Sprungschicht erreicht hat, während der Abbau im Hypolimnion relativ langsam verläuft und erst im Bodenschlamm wieder erheblich ansteigt. Auch KLEEREKOPER [53] kam aufgrund seiner Sedimentationsmessungen zum Schluss, dass der grösste Teil des herabsinkenden Planktons und Detritus in den obersten Schichten mineralisiert wird. Diese Destruk- 
tion ist ganz wesentlich an die bakterielle Tätigkeit gekoppelt $[78,79,80,92,93]$. Invitro-Versuche an Zooplankton [54, 55, 56] und an Phytoplankton [39, 40] ergaben übereinstimmend eine äusserst rasche Mineralisierung während der ersten Stunden nach der Abtötung der Organismen. Bei einem Gesamtsubstanzverlust von etwa 50\% wurden so nach 1 Tag über 70\% des Phosphors in löslicher Form ins Wasser abgegeben. Im Gegensatz zu KLEEREKOPER [53] konnten die Autoren mit ihren Experimenten zeigen, dass der Phosphor wesentlich rascher freigesetzt wird als der Stickstoff. CooPER [16] wies nach, dass das Zooplankton rascher zersetzt wird als das Phytoplankton. Den Einfluss des $\mathrm{O}_{2}$-Gehaltes auf die Mineralisation studierte KrausE [54, 56]. Er stellte fest, dass unter anaeroben Bedingungen nur unwesentlich höhere Gesamtsubstanzverluste eintreten als bei aeroben, dass sich aber eine bedeutsame Differenzierung bei den verschiedenen Fraktionen ergibt: so findet bei Aerobie ein gesteigerter Fett-Lipid-Abbau statt, und bei Anaerobie erhöht sich die N-Abgabe. Neueste Untersuchungen von OTTO und BENNDORF [76] zeigten ferner, dass auch der physiologische Zustand der Zellen beim Abbauvorgang eine wichtige Rolle spielt.

\subsection{Methodik: Probenahme-Intervalle}

Die Tatsache, dass die Sedimentprobenahmen in 14tägigen Zeitintervallen genommen wurden - im Gegensatz zu den monatlichen Schöpfproben -, hatte nicht unerwartete Folgen. Bei einem hocheutrophen See wie dem Rotsee ist es offenbar möglich, dass bei grösseren Probenahmeintervallen kurzfristige Entwicklungsmaxima nicht erkannt werden. So konnte zum Beispiel aufgrund der verkürzten Intervalle, bei den Diatomeen eine bedeutsame Erweiterung der von ScHEGG [93] publizierten Artenzahl festgestellt werden (Fragilaria crotonensis, Asterionella formosa). Das Diatomeen-Plankton des Rotsees setzte sich demnach aus folgenden Arten bzw. Gattungen zusammen:

Von Bedeutung sind Stephanodiscus hantzschii

Fragilaria crotonensis

A sterionella formosa

Synedra acus

\author{
In geringen Mengen vorhanden sind \\ Cyclotella operculata \\ Cyclotella sp. \\ Stephanodiscus alpinus \\ Stephanodiscus astraea \\ Tabellaria fenestrata \\ Diatoma elongatum \\ Nitzschia acicularis \\ Synedra acus var. angustissima \\ diverse
}

Auch die Diatomeen-Sukzession kann aufgrund der Sedimentationsergebnisse genauer verfolgt werden als anhand der Seewasseruntersuchungen allein (Abb. 86). Es ist bemerkenswert, dass im Rotsee bei 1monatigen Probenahmeintervallen Produktionsmaxima gewisser Arten richtiggehend «verpasst» werden können, während solche Effekte beim Vierwaldstättersee nicht auftreten.

\section{Phosphorhaushalt und Sedimentation}

\subsection{Die Jahressedimentation im Vierwaldstättersee (Horwer Bucht) und im Rotsee}

Die Jahressedimentation 1969/70 betrug in der Horwer Bucht 1277,4 g Trockensubstanz $/ \mathrm{m}^{2} \cdot$ Jahr und im Rotsee $879,3 \mathrm{~g}$ Trockensubstanz $/ \mathrm{m}^{2} \cdot$ Jahr (Tab. 41). Bei 

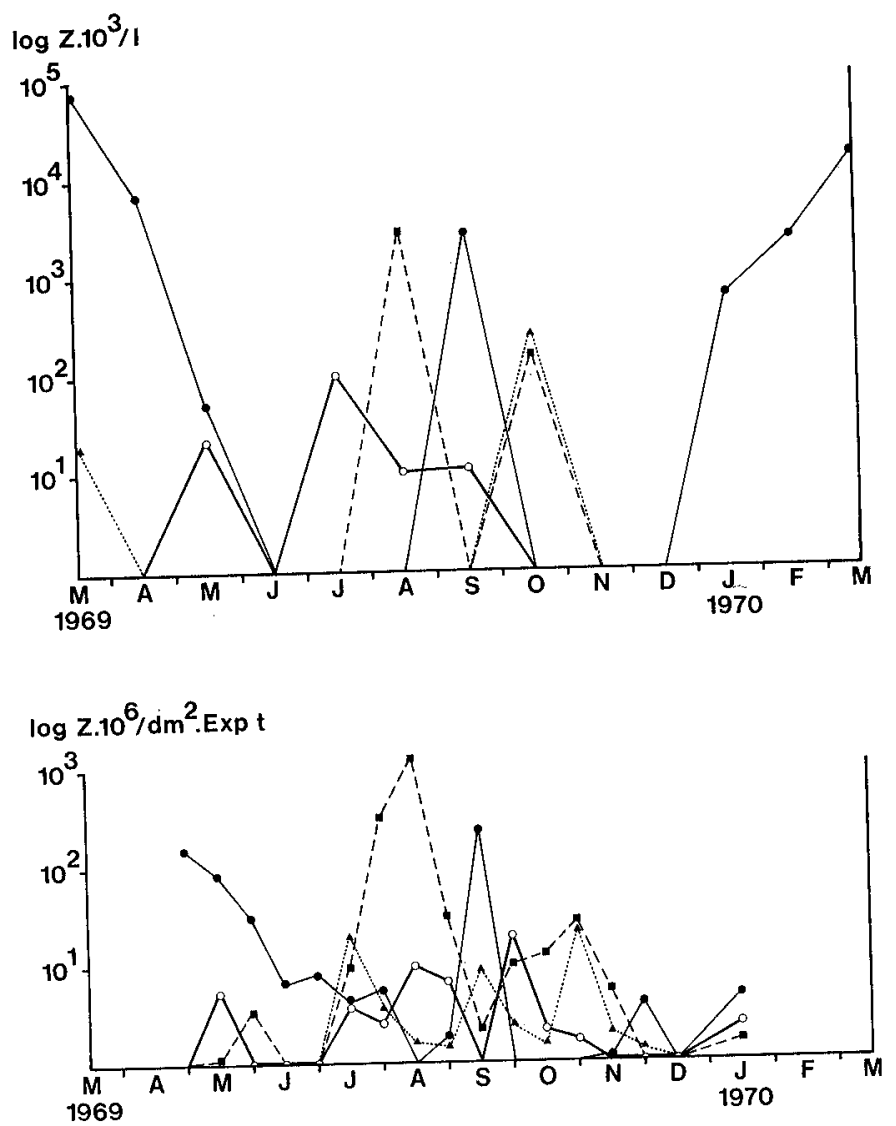

Abb. 86. Sukzession einiger Diatomeen im Rotsee.

Oben: Seewasser, Zellzahlen $\left(\log\right.$ Zellen $\left.\cdot 10^{3} / \mathrm{l}\right)$ im ganzen Profil $(0-14 \mathrm{~m})$, Summe aus 6 Proben. Unten: Sediment, Zellzahlen ( $\log$ Zellen $10^{6} / \mathrm{dm}^{2} \cdot$ Expositionszeit) im ganzen Profil $(0-14 \mathrm{~m})$, Summe aus 3 Proben. —— Stephanodiscus hantzschii, _-_-_ Fragilaria crotonensis, A..... A sterionella formosa, o- - C Cyclotella $\mathrm{sp}$.

Fig. 86. Succession of some diatoms in the Rotsee.

Above: Lake water, number of cells $\left(\log\right.$ cells $\left.\cdot 10^{3} / 1\right)$ in the whole profile $(0-14 \mathrm{~m})$, sum total of 6 samples. - Below: Sediment, number of cells (log cells $\cdot 10^{6} / \mathrm{dm}^{2} \cdot$ exposure) in the whole profile

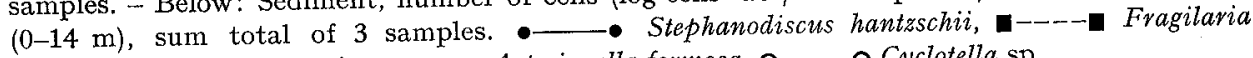

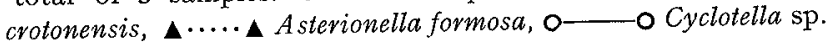

der Ermittlung des Frischgewichtes ist zu beachten, dass die aufgefangenen Sedimente selbst nach 3 Stunden Absetzzeit noch einen sehr hohen Wassergehalt aufweisen und durch Zentrifugieren auf 30-50\% des ursprünglichen Volumens reduziert werden können [112, 9]. Die Berechnungen des Frischgewichtes und der Mächtigkeit der Sedimentschicht basieren auf den Resultaten von BACHOFEN [9] am Baldegger- und Hallwilersee, aus denen ein Verhältnis Trockengewicht : Frischgewicht : Volumen (zentrifugiert) $=1: 3,3: 2,9$ hervorgeht. Mit der Zentrifugation wird die natürliche 
Tabelle 41. Jahressedimentation im Vierwaldstättersee (Horwer Bucht) und im Rotsee. Table 41. Annual sedimentation in the Lake of Lucerne (Horw Bay) and in the Rotsee.

\begin{tabular}{llr}
\hline $\begin{array}{l}\text { Sedimentationsraten, } \\
\text { ausgedrückt als }\end{array}$ & $\begin{array}{l}\text { Horwer Bucht } \\
\text { 23.1.1969-30.1.1970 }\end{array}$ & $\begin{array}{l}\text { Rotsee } \\
\text { 20.3. 1969-12. 1. 1970 } \\
\text { extrapoliert bis 21.3. 1970 }\end{array}$ \\
\hline Trockengewicht & $15 \mathrm{~m}: 1153,6 \mathrm{~g} / \mathrm{m}^{2} \cdot \mathrm{Jahr}$ & $5 \mathrm{~m}: 992,2 \mathrm{~g} / \mathrm{m}^{2} \cdot \mathrm{Jahr}$ \\
& $60 \mathrm{~m}: 1277,4 \mathrm{~g} / \mathrm{m}^{2} \cdot \mathrm{Jahr}$ & $14 \mathrm{~m}: 879,3 \mathrm{~g} / \mathrm{m}^{2} \cdot \mathrm{Jahr}$ \\
Frischgewicht & $60 \mathrm{~m}: 4215,4 \mathrm{~g} / \mathrm{m}^{2} \cdot \mathrm{Jahr}$ & $14 \mathrm{~m}: 2901,7 \mathrm{~g} / \mathrm{m}^{2} \cdot \mathrm{Jahr}$ \\
Volumen & $60 \mathrm{~m}: 3704,4 \mathrm{~cm}^{3} / \mathrm{m}^{2} \cdot \mathrm{Jahr}$ & $14 \mathrm{~m}: 2550,0 \mathrm{~cm}^{3} / \mathrm{m}^{2} \cdot \mathrm{Jahr}$ \\
Sedimentzuwachs & $60 \mathrm{~m}: \quad 3,7 \mathrm{~mm} / \mathrm{Jahr}$ & $14 \mathrm{~m}: \quad 2,5 \mathrm{~mm} / \mathrm{Jahr}$ \\
\hline
\end{tabular}

Kompaktierung der Sedimente auf dem Seegrund zu einem grossen Teil berücksichtigt. Die Jahressedimentation im Rotsee wurde vom gemessenen Zeitraum (20. März 1969 bis 12. Januar 1970) mit einer angenommenen Durchschnittssedimentation von $1 \mathrm{~g} \mathrm{TS} / \mathrm{m}^{2}$. Tag (vgl. Sedimentationsraten S. 108) auf $1 \mathrm{Jahr}$ extrapoliert.

Trotz der höheren Trophiestufe und der $>10 \mathrm{mal}$ grösseren Biomasse war die Sedimentation pro Flächeneinheit im Rotsee kleiner als in der Horwer Bucht, entsprechend auch der jährliche Sedimentzuwachs. Dies ist erklärbar durch die Tatsachen, dass im Hypolimnion des Rotsees infolge der anaeroben Verhältnisse grosse Mengen an organischem und anorganischem partikulärem Material in Lösung gehen können (organisch gebundener $\mathrm{P}$ und $\mathrm{N}$ durch erhöhte Mineralisation, siehe $[54,56]$; $\mathrm{CaCO}_{3}, \mathrm{Fe}, \mathrm{Mn}$, usw. durch chemische Reduktionsprozesse [vgl. Kapitel 4.3, S. 99, und 4.4, S. 107]), und dass in der Horwer Bucht der mineralische Anteil im Sediment grösser ist (allochthone Zufuhren); zudem zeichnet sich die Horwer Bucht wegen der höheren Zufuhren durch einen grösseren Seerückhalt aus als der Rotsee (siehe 6.2, S. 167).

Betrachtet man die Sedimentationsraten am oberen Rand des Hypolimnions, fällt auf, dass im Rotsee die Sedimentationsmenge bei einem Sedimentationsweg von $9 \mathrm{~m}$ um 112,9 $\mathrm{g} \mathrm{TS} / \mathrm{m}^{2}$. Jahr abnahm, während in der Horwer Bucht bei einer Sinkstrecke von $45 \mathrm{~m}$ eine Zunahme um $123,8 \mathrm{~g} \mathrm{TS} / \mathrm{m}^{2} \cdot \mathrm{Jahr}$ registriert wurde. Offenbar nimmt der jährliche Sedimentzuwachs mit zunehmender Eutrophierung infolge der Rücklösungsvorgänge im anaeroben Milieu ab. NIPkow [69] (nach [90], S. 240, aus [63]) fand in den Jahren 1895 bis 1919 für den Zürichsee bei beginnender Eutrophie in Schlammbohrkernen, von durch Uferrutschungen gestörten Jahren abgesehen, einen durchschnittlichen Jahreszuwachs von 3,6 bis 5,4 mm. ZüLLIG [129] nimmt für den oligotrophen Walensee $5 \mathrm{~mm} / \mathrm{J}$ ahr an und mass aufgrund seiner Bohrkerne für den oligo-mesotrophen Bodensee 3-5mm/Jahr und den eutrophen Zugersee1,2-1,5mm/Jahr.

Um die Jahressedimentation genauer charakterisieren zu können, wurden in Tab. 42 zusammenfassend die durchschnittlichen Tagessedimentationsraten der einzelnen Komponenten während der Stagnationszeit bzw. Zirkulationszeit dargestellt. Bei beiden Seen wurden während der Sommerstagnation durchwegs höhere Sedimentationsraten gemessen als während der Zirkulation, mit Ausnahme des Mangans im Rotsee, das sich streng nach den $\mathrm{O}_{2}$-Verhältnissen richtete (siehe 4.46, S. 113). 
Tabelle 42. Durchschnittliche Sedimentationsraten im Vierwaldstättersee (Horwer Bucht) und im Rotsee.

Table 42. Average rates of sedimentation in the Lake of Lucerne (Horw Bay) and in the Rotsee.

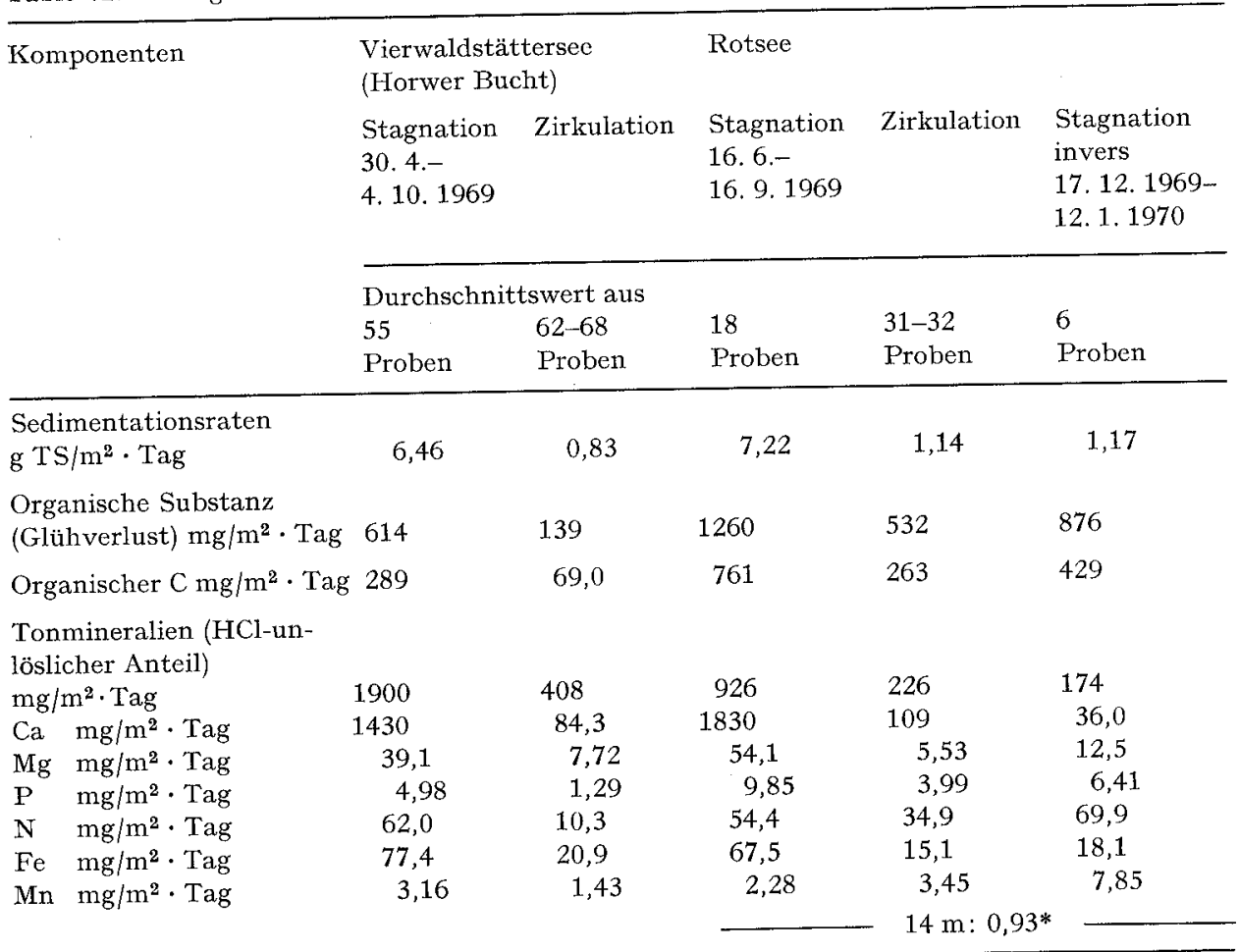

* Durchschnittswert aus 19 Proben über die ganze Untersuchungszeit.

Die meisten Sedimentbestandteile erreichten im Rotsee die höheren Werte, so die organische Substanz, der organische Kohlenstoff, das Kalzium und Magnesium (letzteres nur während der Stagnation) und der Phosphor, was auf die höhere Trophiestufe und die erhöhte Produktion zurückzuführen ist. Demgegenüber waren die Tonmineralien und das Eisen, als Folge der grossen allochthonen Zufuhr, im Vierwaldstättersee höher. Eine Zwischenstellung nehmen das Mangan und der Stickstoff ein: Während der Stagnation waren die Werte in der Horwer Bucht höher, während der Zirkulation im Rotsee. Beim Mangan lässt sich dies wiederum mit der engen Verknüpfung mit dem $\mathrm{O}_{2}$-Regime des Sees erklären (die grossen, im Hypolimnion unter $\mathrm{O}_{2}$-Schwund gelösten Mn-Mengen wurden durch die Zirkulation nach oben verfrachtet und ausgefällt). Der Unterschied beim Stickstoff deutet im Rotsee auf eine mögliche N-Limitierung für die Primärproduktion während der Sommermonate hin.

Die Situation während der inversen Winterstagnation ist im Rotsee im wesentlichen dieselbe wie im Sommer, jedoch sind einige Abweichungen festzustellen. Die meisten Komponenten wurden in geringerer Menge aufgefangen als im Sommer (Ausnahmen: $\mathrm{Mn}$ und $\mathrm{N}$ !), aber ausser den Tonmineralien und dem Kalzium waren alle 
Werte höher als während der Zirkulation, was zu erwarten war. Der geringe Anteil an Tonmineralien weist auf die durch die winterlichen Verhältnisse reduzierte allochthone Zufuhr hin, und die niedrigen Ca-Raten sind wohl durch Rücklösungsprozesse zu erklären.

\subsection{Phosphorhaushalt im Vierwaldstättersee (Horwer Bucht) und im Rotsee}

Der Stoffhaushalt eines Sees kann, unter Berücksichtigung seiner Tiefe und seiner Schichtungsverhältnisse, wichtige Anhaltspunkte zur Beurteilung des Trophiezustandes liefern $[112,9,125]$. Zunächst wurde eine P-Jahresbilanz in beiden Seen aufgestellt (Abb. 87 und 88).

Horwer Bucht: Die Seeoberfläche beträgt 1,69 $\mathrm{km}^{2}$ [93]. Das Volumen wurde nach den Angaben von G⿺̈̈CHTER [31] auf 22,925 $\cdot 10^{6} \mathrm{~m}^{3}$ (Epilimnion 0-15 $\mathrm{m}$ ) und auf $46,145 \cdot 10^{6} \mathrm{~m}^{3}$ (Hypolimnion 15-60 m) berechnet; für die Sedimentberechnungen wurde allerdings nur das prismatisch über dem Hypolimnion stehende epilimnische Volumen berücksichtigt $\left(21,45 \cdot 10^{6} \mathrm{~m}^{3}\right)$. Das Einzugsgebiet der Horwer Bucht beträgt $16 \mathrm{~km}^{2}$ und besteht zu je etwa $2 / 5$ aus Wald und Wiesland [101]. Den Berechnungen der natürlichen Zufuhr wurde das Gebiet des Sarnersees zugrundegelegt, welches in Klima und Topographie demjenigen der Horwer Bucht entspricht; aus den Werten von GÄCHTER und FURRER [34, Tab. 9] wurde eine mittlere Gesamt-P-Ausschwemmung von $37 \mathrm{~kg} \mathrm{P} / \mathrm{km}^{2}$. Jahr angenommen. Der Hauptzufluss, der Horwer Steinibach, hatte eine mittlere Wasserführung von $0,5 \mathrm{~m}^{3} / \mathrm{s}$ [75]; da er im Zeitraum der Untersuchungen das ungereinigte Abwasser der Gemeinde Horw (10000 Einwohner) mit sich führte, wurde der See-Eintrag mit $3 \mathrm{~g}$ P/Einwohner - Tag veranschlagt [128].

Úber die atmosphärische Phosphorzufuhr liegen, im Gegensatz zu den N-Niederschlägen, nur sehr wenige Untersuchungen vor; da für schweizerische Verhältnisse keine Werte bekannt sind, wurden, nach Angaben von ChAlupa [13], $2 \mathrm{mg} \mathrm{P} / \mathrm{m}^{2}$ · Jahr in Rechnung gestellt.

Der Abfluss der Horwer Bucht kann nicht direkt bestimmt werden. Der einzige Abfluss des ganzen Vierwaldstättersees, die Reuss, führt im Mittel $111 \mathrm{~m}^{3} / \mathrm{s}$ [23, 75] und $0,03 \mathrm{mg}$ Gesamt-P/1 [23]. Die abfliessende P-Fracht/1 kann als für die Horwer Bucht repräsentativ angesehen werden, da sich das Wasser der Bucht mit dem angrenzenden Seewasser intensiv vermischt [75], und da im Kreuztrichter keine wesentlich anderen P-Konzentrationen gemessen werden als im Horwer Becken (vgl. dazu [5]). Weil der Horwer Steinibach mit seinen $0,5 \mathrm{~m}^{3} / \mathrm{s}$ rund $0,5 \%$ des Gesamtzuflusses zum Vierwaldstättersee $\left(108,5 \mathrm{~m}^{3} / \mathrm{s}\right.$, [75]) ausmacht, wurde der Abfluss von der Horwer Bucht zu $0,5 \%$ des Reussabflusses berechnet $\left(0,555 \mathrm{~m}^{3} / \mathrm{s}\right)$.

Die Differenz zwischen Zufluss und Abfluss wird als Seerückhalt bezeichnet.

Rotsee: Die Seeoberfläche des Rotsees beträgt $0,47 \mathrm{~km}^{2}$ [101], das Volumen des Epilimnions $(0-5 \mathrm{~m}) 2,015 \cdot 10^{6} \mathrm{~m}^{3}$ und dasjenige des Hypolimnions $(5-14 \mathrm{~m}) 1,59 \cdot 10^{6}$ $\mathrm{m}^{3}$; für das dem Hypolimnion überstehende Epilimnion wurden $1,70 \cdot 10^{6} \mathrm{~m}^{3}$ berechnet. Das Einzugsgebiet des Rotsees beträgt $4,6 \mathrm{~km}^{2}$, wovon $1,3 \mathrm{~km}^{2}$ kanalisiert sind und direkt in die Reuss entwässern [101]. Für die natürliche P-Auswaschung wurde ein schweizerischer Mittelwert von $40 \mathrm{~kg}$ Gesamt-P $/ \mathrm{km}^{2}$. Jahr berücksichtigt [4]. Der einzige Rotseezufluss besteht aus einem Stollen, durch den (von der Stadt Luzern bis Ende 1973 abwasserbelastetes) Reusswasser eingeleitet wurde; der 

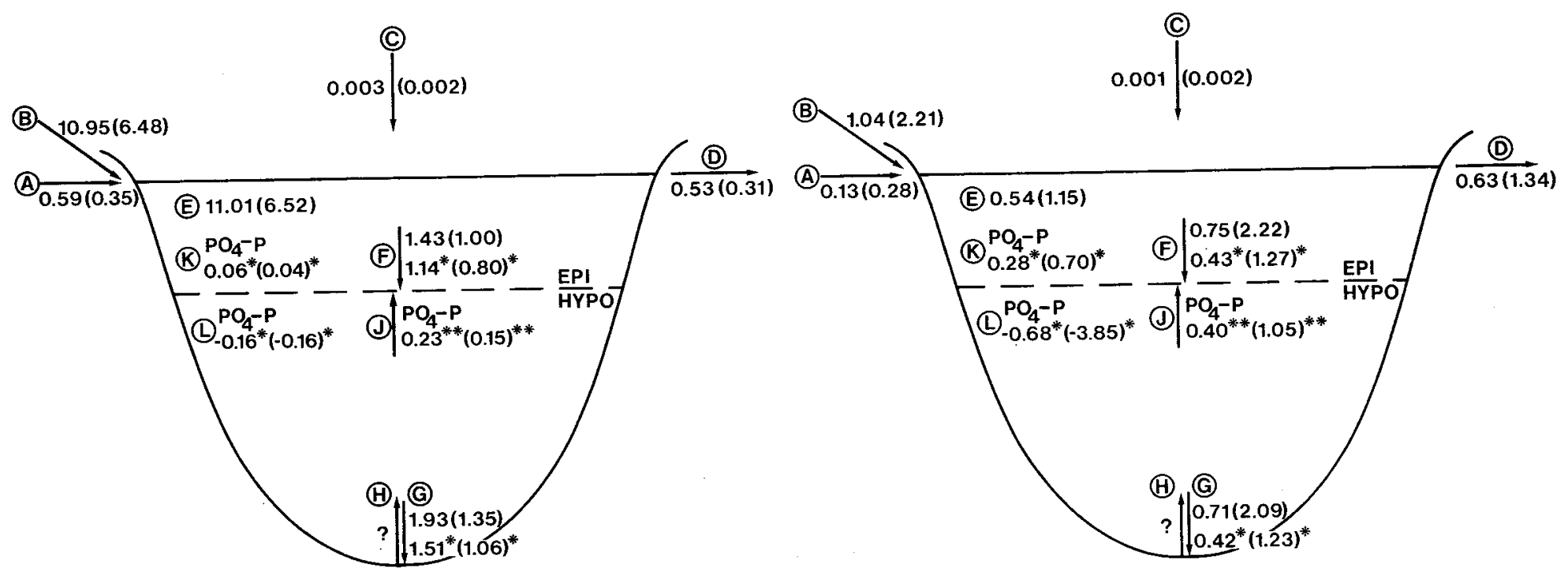

Abb. 87 und 88. P-Bilanz im Vierwaldstättersee (Horwer Bucht, links) und im Rotsee (rechts) 1969/70.

Angaben in $\mathrm{t} \mathrm{P} / \mathrm{Jahr}$ (Werte in Klammern in $\mathrm{g} \mathrm{P} / \mathrm{m}^{2} \cdot \mathrm{Jahr}$ ); Werte mit * gelten nur für das Sommerhalbjahr 1969 (Stagnationszeit, April bis OktoAn Abfluss, $E$ Seerückhalt, $F$ Sedimentation Epilimnion, $G$ Sedimentation Hypolimnion (Grund), $H$ Rücklösung vom Bodensediment, $J$ PO ${ }_{4}$-P-Eintrag Abfluss, $E$ Seerückhalt, $F$ Sedimnion während der Zirkulation, $K \mathrm{PO}_{4}-\mathrm{P}$-Winterüberschuss Epilimnion, $L \mathrm{PO}_{4}$-P-Winterüberschuss $\mathrm{H}_{y p o l i m n i o n}$.

Fig. 87 and 88. Phosphorus balance in the Lake of Lucerne (Horw Bay, left) and in the Rotsee (right) 1969/70.
Amount in tons of $\mathrm{P} /$ year (values in parentheses in $\mathrm{g}$ of $\mathrm{P} / \mathrm{m}^{2} \cdot$ year); values with * are valid only for the stagnation period, April to October 1969 ; Amount in tons of $P / y e a r$ (values in parentheses in values with ${ }^{* *}$ are valid only for the circulation in autumn 1969. $A$ natural inflow, $B$ inflow containing waste water, from bottom deposit, $J \mathrm{PO}_{4}-\mathrm{P}$ flow, $E$ residue in the lake, $F$ sedimentation in the epilimnion, $G$ sedimentation in the hypolimnion (ground), $H$ release from bottom deposit, $J \mathrm{PO}_{4}^{-\mathrm{P}}$ input from the hypolimnion into the epilimnion during circulation, $K \mathrm{PO}_{4}-\mathrm{P}$ hypolimnion. 
Reuss-Stollen führte im Mittel 0,3 $\mathrm{m}^{3} / \mathrm{s}$ und 0,11 $\mathrm{mg}$ Gesamt-P/1 [101]. Der Abfluss des Rotsees (Ronkanal) führt nach Messungen von STadelmann (unveröffentlicht) im Mittel $0,4 \mathrm{~m}^{3} / \mathrm{s}$ und $0,05 \mathrm{mg}$ Gesamt-P/1.

Für beide Seen wurde schliesslich die Phosphatzehrung während der Sommerstagnation berechnet; die Differenz der Aprilwerte minus Oktoberwerte bezeichnete THOMAS [112] als sogenannten «Winterüberschuss». Dazu wurden die Sedimentationsraten im Epilimnion und Hypolimnion in Beziehung gesetzt.

Diskussion: Die allochthonen Zufuhren, rund 11,5 t P/Jahr für die Horwer Bucht und 1,2 $\mathrm{t} \mathrm{P/Jahr} \mathrm{für} \mathrm{den} \mathrm{Rotsee,} \mathrm{liegen} \mathrm{vergleichsweise} \mathrm{unter} \mathrm{den} \mathrm{Werten,} \mathrm{die} \mathrm{für}$ verschiedene Mittellandseen gemessen wurden [112, 9, 82]. Da jedoch Absolutwerte allein noch wenig aussagen, wird der Begriff der spezifischen Zufuhr oder Oberflächenbelastung (Zufuhr/Oberfläche) eingeführt [125]. Dadurch wird der erste Eindruck bedeutend korrigiert. Die spezifischen allochthonen Zufuhren sind sehr hoch, insbesondere beim Becken des Vierwaldstättersees $\left(6,8 \mathrm{~g} \mathrm{P} / \mathrm{m}^{2}\right.$. Jahr), welches den Rotsee $\left(2,5 \mathrm{~g} \mathrm{P} / \mathrm{m}^{2}\right.$. Jahr) auch so noch immer um mehr als das Doppelte übertrifft.

Setzt man nun die spezifische Belastung mit biologisch aktivem Gesamt-P in Relation zur mittleren Seetiefe (Volumen/Oberfläche), so erhält man eine mögliche Abgrenzung von oligotrophen, mesotrophen und eutrophen Seen (Abb. 89) [32], nach [125]. Nach GÄCHTER [32] sind im Mittel nur etwa 50\% des ausgeschwemmten Gesamtphosphors biologisch aktiv; dieselbe Grössenordnung ist, aus den Untersuchungen von Thomas [115] und WuHRmanN [128] zu schliessen, auch für den Restphosphor im Abfluss von Kläranlagen mit dritter Reinigungsstufe anzunehmen; für kommunales Abwasser liegt dieser Anteil bei 80\% [17]. Wie GÄchTER [32] am ganzen Vierwaldstättersee gezeigt hat, ist bereits die natürliche, schwer beeinflussbare Restzufuhr an wirksamem Phosphor genügend, um den See trophisch zu gefährden (V). Für die Horwer Bucht liegen die Verhältnisse genau gleich, während der Rotsee wegen seiner geringen Tiefe als natürlich eutroph eingestuft werden muss $\left(\mathrm{H}_{1}\right.$ und $\mathrm{R}_{1}$ ). Der durch das ungereinigte Abwasser der Gemeinde Horw eingebrachte Phosphor verschlechtert nun die Situation der Bucht gewaltig $\left(\mathrm{H}_{2}\right)$. Nimmt man an, dass eine Kläranlage mit mechanisch-biologischer Stufe etwa 30\% des Gesamtphosphors eliminiert und mit chemischer Phosphatfällung (3. Stufe) $85-95 \%$ [128], so ergäben sich folgende Belastungsreduktionen:

$\begin{array}{ll}\text { bei } 30 \% \text { Elimination: } & \text { noch } 4,54 \mathrm{~g} \mathrm{P} / \mathrm{m}^{2} \cdot \mathrm{Jahr} \text {, } \\ \text { bei } 85-95 \% \text { Elimination: } & \text { noch } 0,32-0,97 \mathrm{~g} \mathrm{P} / \mathrm{m}^{2} \cdot \mathrm{Jahr} .\end{array}$

Selbst die gewaltige Verminderung der P-Zufuhr um $95 \%$ würde nicht ąusreichen, um die Horwer Bucht vollständig zu sanieren $\left(\mathrm{H}_{3}\right)$. Da zu erwarten ist, dass sich der Zufluss im Epilimnion einschichtet [116] und die zugeführten Pflanzennährstoffe direkt am Stoffumsatz beteiligt sind, kann bei Einleitung auch der gereinigten Abwässer unterhalb der Sprungschicht eine weitere Verminderung der Primärproduktion und damit das Verlangsamen des Eutrophierungsprozesses erreicht werden. Im vorliegenden Fall der Gemeinde Horw wurde, nachdem unsere Untersuchungen abgeschlossen waren, statt einer Kläranlage mit 3. Reinigungsstufe die bei den gegebenen Verhältnissen weit bessere Lösung einer Ringleitung gewählt (seit Ende 1972 vollständiges Fernhalten der Abwässer), so dass seit 1973 die Situation $\mathrm{H}_{1}$ erreicht ist. Nebst dieser Sanierung wird man allerdings nicht darum herumkommen, zusätzlich auch die diffuse Phosphorzufuhr, verursacht durch die landwirtschaftliche 




Abb. 89. Die P-Belastung des Vierwaldstättersees (Horwer Bucht) und des Rotsees.

$\mathrm{R}_{1}$ : Rotsee: $50 \%$ Auswaschung

$\mathrm{R}_{2}$ : Rotsee: $50 \%$ Auswaschung $+80 \%$ abwasserbelasteter Zufluss

$\mathrm{H}_{1}$ : Horwer Bucht: $50 \%$ Auswaschung

$\mathrm{H}_{2}$ : Horwer Bucht: 50\% Auswaschung $+80 \%$ abwasserbelasteter Zufluss

$\mathrm{H}_{3}$ : Horwer Bucht: $50 \%$ Auswaschung $+50 \%$ gereinigtes Abwasser (mit 3. Stufe)

$\mathrm{V}$ : Vierwaldstättersee total: $50 \%$ Auswaschung [32].

Fig. 89. Phosphorus load of the Lake of Lucerne (Horw Bay) and of the Rotsee.

$\mathrm{R}_{1}$ : Rotsee: $50 \%$ wash out

$\mathrm{R}_{2}$ : Rotsee: $50 \%$ wash out $+80 \%$ inflow containing waste water

$\mathrm{H}_{1}$ : Horw Bay: $50 \%$ wash out

$\mathrm{H}_{2}$ : Horw Bay: $50 \%$ wash out $+80 \%$ inflow containing waste water

$\mathrm{H}_{3}$ : Horw Bay: $50 \%$ wash out $+50 \%$ purified waste water (3rd step of purification)

V: Lake of Lucerne total: $50 \%$ wash out [32].

Düngung, zu verringern. Nur durch die Koordinierung aller Gewässerschutzmassnahmen kann es gelingen, die von VolLENWEIDER [125] ermittelte gefährliche Belastungsgrenze (bei $50 \mathrm{~m}$ mittlerer Tiefe) von $0,5 \mathrm{~g} \mathrm{P} / \mathrm{m}^{2}$. Jahr wesentlich zu unterschreiten oder sogar die tolerierbare Belastung von $0,25 \mathrm{~g} \mathrm{P} / \mathrm{m}^{2}$. Jahr zu erreichen. Dagegen wird es beim polytrophen Rotsee aufgrund seiner morphometrischen Verhältnisse (wenig Tiefe, windstille Lage, geringe Wassererneuerung) schwierig sein, eine Sanierung herbeizuführen; für einen See mit $10 \mathrm{~m}$ mittlerer Tiefe liegt die tolerierbare Belastung bei $0,1 \mathrm{~g} \mathrm{P} / \mathrm{m}^{2}$. Jahr und die gefährliche Belastung über $0,2 \mathrm{~g} \mathrm{P} / \mathbf{m}^{2} \cdot$ Jahr. 
Als Folge der hohen externen P-Belastung ist auch der Seerïckhalt in der Horwer Bucht enorm (95\% der Zufuhren). Thomas [112] fand vergleichsweise für die eutrophen Pfäffikersee und Greifensee Rückhaltwerte von 3,2 bzw. 3,0 g P/m² - Jahr oder $77 \%$ bzw. $62 \%$ der Zuflüsse. Pleisch [82] gab 16 Jahre später für die gleichen Seen P-Rückhalte von $70 \%$ und $53 \%$ an und stellte einen erhöhten Stoffrückhalt im Sommer fest (80-90\% der Zufuhren), wenn die Nährstoffe dem Epilimnion durch Sedimentation zum Teil entzogen werden (vgl. die gesteigerten P- und N-Sedimentationsraten während der Stagnationszeit, Abschnitte 4.25, S. 96, und 4.45, S. 111). Der polytrophe Rotsee weist demgegenüber einen erstaunlich bescheidenen Seerückhalt von $1,15 \mathrm{~g} \mathrm{P} / \mathrm{m}^{2}$. Jahr oder $46 \%$ der Zufuhr auf. Trotz der grossen Belastung hat die Horwer Bucht noch lange nicht den hohen Eutrophiegrad des Rotsees erreicht, weil sie infolge der grösseren Tiefe und des Wasseraustausches mit dem offenen See eine grösssere Zufuhr verkraften kann. Der Seerückhalt allein sagt noch nichts darüber aus, was mit den im See zurückgebliebenen Stoffen geschieht. In der Horwer Bucht, die ein aerobes Hypolimnion aufweist, dürfte der dem Stoffkreislauf entzogene Phosphor zum grössten Teil irreversibel im Sediment festgehalten werden. Im eutrophen Rotsee dagegen liegt, bei der herrschenden Anaerobie, ein grosser Anteil des Seerückhaltes in gelöster Form vor (hypolimnische $\mathrm{PO}_{4}{ }^{3-}$-Akkumulation), der dem See deshalb nicht verlorengeht, weil der Abfluss nur die obersten, an Nährstoffen verarmten Schichten erfasst.

Der Winterüberschuss an Phosphaten und die P-Sedimentationsraten bringen die in beiden Seen unterschiedlichen aktuellen Verhältnisse deutlich zum Ausdruck. Die Phosphatzehrung während der Sommerstagnation, durch welche bis zum September praktisch alle Phosphate im Epilimnion aufgebraucht werden (vgl. S. 87 und 103), ist im Rotsee bedeutend grösser. Ihm stehen, trotz geringerer allochthoner Zufuhr und kleinerem Seerückhalt, im. Frühling mehr Nährstoffe zur Verfügung, die vor allem durch die autochthone Zufuhr geliefert werden. Die Frühlingszirkulation bringt grosse Mengen von im Hypolimnion angereicherten Nährstoffen in die trophogene Schicht (im Durchschnitt etwa $200 \mu \mathrm{g} \mathrm{PO}_{4}-\mathrm{P} / 1$ ), wo die andauernde, schon von Stadelmann [101] und SchegG [93] festgestellte, intensive Nährstoffnachlieferung durch den «kleinen Stoffkreislauf» erfolgt. Der im Rotsee intensivere Stoffumsatz findet seinen Ausdruck in den extremen Verhältnissen der tropholytischen Schicht (Winterüberschuss $-3,85 \mathrm{~g} \mathrm{PO}_{4}-\mathrm{P} / \mathrm{m}^{2}$ ). Die Phosphatrücklösung im Hypolimnion ist infolge der anaeroben Bedingungen teils chemisch, teils autolytisch und bakteriell bedingt. Die heterotrophe bakterielle Tätigkeit ist so gross, dass SchEGG [93] das Hypolimnion des Rotsees als eine "trophogene Schicht» bezeichnet, was als Indiz einer irreversiblen Schädigung angesehen werden könnte.

Dem höheren Trophiegrad entsprechend sind die P-Sedimentationsraten im Rotsee höher $\left(2,1 \mathrm{~g} \mathrm{P} / \mathrm{m}^{2}\right.$. Jahr oder $0,24 \%$ der TS) als in der Horwer Bucht $(1,35 \mathrm{~g}$ $\mathrm{P} / \mathrm{m}^{2}$. Jahr oder $0,10 \%$ der TS). Die höheren Werte dürften vor allem auf den grösseren Anteil an organischem Material (Biomasse) zurückzuführen sein.

Über Rücklösungsraten aus den Sedimenten liegen keine eigenen Untersuchungen vor. Thomas [112] bestimmte experimentell eine Rücklösung von $2,0 \mathrm{~g} \mathrm{P} / \mathrm{m}^{2}$ · Jahr bzw. 2,8 g P $/ \mathrm{m}^{2}$. Jahr im aufgefangenen Sediment des Greifensees und Pfäffikersees. BACHOFEN [9] fand im Baldeggersee und Hallwilersee 24-28\% Rücklösung der sedimentierten P-Menge und nimmt diese als $1 / 3$ der natürlichen Phosphatakkumu- 
lierung im Hypolimnion an. Die-P-Rücklösung ist im Rotsee sicher grösser als in der Horwer Bucht; nebst den höheren $\mathrm{PO}_{4}-\mathrm{P}$-Konzentrationen im Tiefenwasser ist dies auch daraus ersichtlich, dass im Rotsee die P-Sedimentationsraten mit der Tiefe abnehmen, und dass während der Stagnation nur etwa $60 \%$ der Jahressedimentation abgelagert werden (Horw: 80\%).

6.3 Stickstoffbilanz und N:P-Verhältnis im Vierwaldstättersee (Horwer Bucht) und im Rotsee

Eine N-Bilanz für beide Seen während der Stagnation hat STAdELMANN [101] aufgestellt. Es seien hier lediglich die Ergebnisse aufgeführt, die zum Teil modifiziert und durch eigene Berechnungen ergänzt wurden und die in einer Jahresbilanz dargestellt sind (Abb. 90 und 91). Als Grundlagen dienten die in Abschnitt 6.2 und bei StADELmann genannten Bedingungen.

Die Stickstoffbilanz ist derjenigen des Phosphors sehr ähnlich, weshalb auf eine eingehende Diskussion verzichtet wird. Erwähnt sei nur, dass der «kurzgeschlossene Kreislauf», berechnet aus Primärproduktion minus Zufuhr, in der Horwer Bucht 57\% und im Rotsee 28-48\% des Stickstoffs nachliefert, und dass die Verluste an das Sediment in der Horwer Bucht 20,9\% und im Rotsee 15,4\% der Primärproduktion betragen. Die gegenüber STADELMANN [101] etwas verminderten Werte resultieren aus der Korrektur an der Primärproduktion, die mit Hilfe der genauen Angaben GÄCHTERs [33] über die Abhängigkeit der Primärproduktion von der Jahreszeit angebracht wurde (vgl. auch 6.4, S. 174). Die N-Nachlieferung durch den «kleinen Stoffkreislauf» ist in beiden Seen etwas geringer als diejenige des Phosphors und dementsprechend die N-Sedimentationsverluste um etwa $7 \mathrm{mal}$ (Rotsee) bis 10mal (Horwer Bucht) grösser als die P-Raten. Da das N : P-Verhältnis in der Nährstoffnachlieferung im Rotsee nur 3,3:1 gegenüber 6,8:1 in der Horwer Bucht beträgt (siehe Abb. 92 und 93) und so wesentlich unter das ideale $\mathrm{N}: \mathrm{P}$-Verhältnis von 7,2:1 [107] sinkt, liegt die Vermutung nahe, dass im Rotsee zeitweise der Stickstoff limitierend sein könnte (vgl. auch die Experimente von STADELMANN [101]).

Das bei den vorliegenden Untersuchungen ermittelte $N: P$-Verhältnis nimmt beim Durchlaufen des Stoffkreislaufes von der Zufuhr bis zur Sedimentation stetig ab (Abb. 92 und 93). In den natürlichen Zufuhren ist, als Folge der wesentlich grösseren N-Ausschwemmung, das N:P-Verhältnis (40-200:1) noch stark zugunsten des Stickstoffs verschoben. In den abwasserbelasteten Zuflüssen ist der Quotient bedeutend kleiner. Der Reuss-Stollen liegt in der Grössenordnung der Reuss beim Seeabfluss ( $\mathrm{N}: \mathrm{P}=21,6: 1$, aus [23]), während das $\mathrm{N}: \mathrm{P}-$ Verhältnis des wesentlich stärker belasteten Horwer Steinibaches demjenigen eines mittleren Abwassers $(\mathrm{N}: \mathrm{P}=5: 1)$ recht nahe kommt. Bei etwa gleichen Abflussverhältnissen bleibt das $\mathrm{N}$ : P-Verhältnis im Seerückhalt des Rotsees rund $4 \mathrm{mal}$ höher als in der Horwer Bucht.

Das ideale N:P-Gewichtsverhältnis, welches für die Primärproduktion in Rechnung gestellt wurde, beträgt in Algen- und Bakterienbiomasse 7,2:1 [107]. Wie schon StadelmanN [101] bemerkte, ist die generelle Annahme dieses Verhältnisses allerdings problematisch, weil es bei verschiedenen Algenarten (Zusammenstellung bei Hemens et al. [46]) und bei der gleichen Art bei verschiedener Nährstoffversorgung $[30,37,85,103]$ schwankt. Im partikulären Material beider Seen fand STADELMANN [101] ein N:P-Verhältnis, das nicht nur saisonal, sondern auch in der Tiefen- 


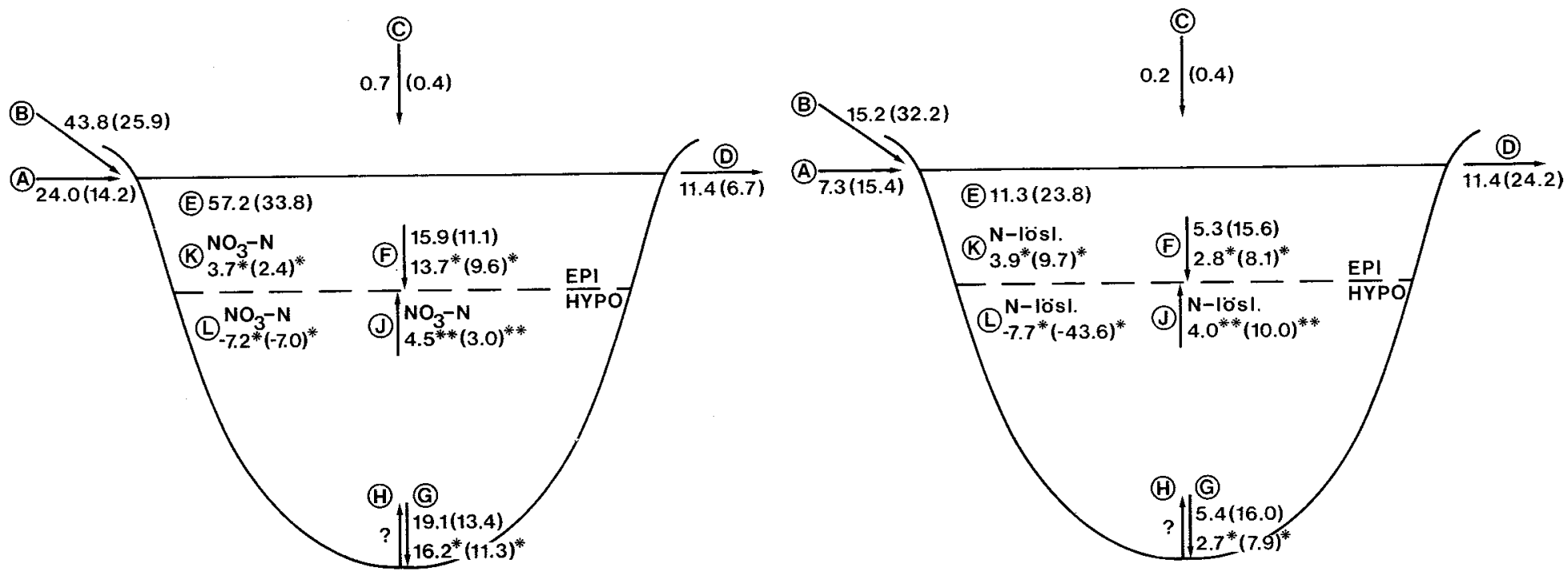

Abb. 90 und 91. N-Bilanz im Vierwaldstättersee (Horwer Bucht, links) und im Rotsee (rechts) 1969/70.

Angaben in $\mathrm{t} \mathrm{N} / \mathrm{Jahr}$ (Werte in Klammern in $\mathrm{g} \mathrm{N} / \mathrm{m}^{2} \cdot \mathrm{Jahr}$ ); Werte mit * gelten nur für das Sommerhalbjahr 1969 (Stagnationszeit, April bis Oktober) ; Werte mit ** gelten nur für die Herbstzirkulation 1969. A natürliche Zufuhr, $B$ abwasserbelasteter Zufluss, $C$ atmosphärische $Z$ ufuhr, $D$ Abfluss, $E$ Seerückhalt, $F$ Sedimentation Epilimnion, $G$ Sedimentation Hypolimnion (Grund), $H$ Rücklösung vom Bodensediment, $J$ NO ${ }_{3}$-Nbzw. lösl. N-Eintrag vom Hypolimnion ins Epilimnion während der Zirkulation, $K \mathrm{NO}_{3}-\mathrm{N}$ - bzw. lösl. N-Winterüberschuss Epilimnion, $L$ NO${ }_{3}-\mathrm{N}-$ bzw lösl N-Winterüberschuss Hypolimnion.

Fig. 90 and 91. Nitrogen balance in the Lake of Lucerne (Horw Bay, left) and in the Rotsee (right) 1969/70.

Amount in tons of $\mathrm{N} /$ year (values in parentheses in $\mathrm{g}$ of $\mathrm{N} / \mathrm{m}^{2}$. year); values with * are valid only for the stagnation period, April to October 1969; values with ** are valid only for the circulation in autumn 1969. $A$ natural inflow, $B$ inflow containing waste water, $C$ atmospheric input, $D$ outflow, $E$ residue in the lake, $F$ sedimentation in the epilimnion, $G$ sedimentation in the hypolimnion (ground), $H$ release from bottom deposit, $J$ $\mathrm{NO}_{3}-\mathrm{N}$ resp. dissolved $\mathrm{N}$ input from the hypolimnion into the epilimnion during circulation, $K \mathrm{NO}_{3}-\mathrm{N}$ resp. dissolved $\mathrm{N}$ winter surplus in the epilimnion, $L \mathrm{NO}_{3}-\mathrm{N}$ resp. dissolved $\mathrm{N}$ winter surplus in the hypolimnion. 
verteilung Unterschiede zeigte. Im Winter sank der Quotient oft unter 7,2:1, in den hochproduktiven Sommermonaten mit schlechter P-Versorgung stieg er meist über 7,2:1 an; dabei traten in der Horwer Bucht im Juni und August in den Zonen, wo Oscillatoria rubescens eingeschichtet war, Extremwerte bis zu 22:1 auf. Mit zunehmender Tiefe sank das Verhältnis auf 5,6:1. Auch Holm-Hansen [48] stellte ein mit der Tiefe abnehmendes N:P-Verhältnis im partikulären Material fest. STADELmanN [101] erklärte diese Verschiebung zugunsten des Phosphors mit Denitrifikationsprozessen. Die Denitrifikation berechnet sich nach VollenweIder [125] als Differenz von $\mathrm{N}$-Seerückhalt minus $\mathrm{N}$-Sedimentrückhalt und beträgt in der Horwer Bucht $20,4 \mathrm{~g} \mathrm{~N} / \mathrm{m}^{2}$. Jahr und im Rotsee $17,9 \mathrm{~g} \mathrm{~N} / \mathrm{m}^{2}$. Jahr. Erstaunlich dabei ist die Tatsache, dass im Vierwaldstättersee der höhere Wert erreicht wird, was die von STADELMANN [101] offengelassene Frage nach dem tatsächlichen Vorhandensein der Denitrifikation bejahen lässt. (Nach BüHRER [mündliche Mitteilung] befinden sich im Bodensediment der Horwer Bucht $10^{4}-10^{5}$ zur Denitrifikation befähigte Bakterien pro g Nassgewicht.) Beim polytrophen Rotsee ist diese Abnahme nur angedeutet, denn in $14 \mathrm{~m}$ Tiefe nimmt das $\mathrm{N}: \mathrm{P}-$ Verhältnis infolge der im sauerstofffreien Milieu begünstigten Phosphatrücklösung wieder zu.

Das N:P-Verhältnis im aufgefangenen Sediment (Abb. 92 und 93, vgl. 4.25, Abb. 17 und 4.45, Abb. 31) beträgt im Vierwaldstättersee während der Sommerstagnation, summarisch berechnet, 10,7-12,0:1 und im Rotsee 6,4:1. Es sei hier nochmals auf den frappanten Unterschied der beiden Seen hingewiesen. Im Sommer ist das $\mathrm{N}: \mathrm{P}$-Verhältnis in der Horwer Bucht grösser, im Winter aber deutlich kleiner als im Rotsee. Die Situation im Sommer weist darauf hin, dass zur Zeit der höchsten Produktion der Stickstoff im Rotsee (zeitweise) limitierend sein kann. (In die gleiche Richtung deutete schon die verminderte N-Zufuhr aus dem «kleinen Stoffkreislauf», vgl. S. 172.) In der Horwer Bucht wird dieser Zustand möglicherweise im Winter, also während der produktionsärmsten Zeit im Vierwaldstättersee, erreicht. Nebst dieser Differenz sind aber auch die hohen Korrelationen im N:P-Verhältnis beider Seen zu beachten, die im Winter berechnet wurden. Die höheren Sommersedimentationsraten streuen offensichtlich weit mehr als die tieferen Winterwerte, was durch die grössere und fluktuierende Produktionsdynamik erklärt werden kann. Die $\mathrm{N}$ : P-Verhältnisse im aufgefangenen Sediment sind nur in der Horwer Bucht höher als im partikulären Material und ebenso im oberen Bereich der von verschiedenen Autoren gefundenen Werte vergleichbarer Seen (Tab. 43). Auch hier ist jedoch nur in der Horwer Bucht eine Abnahme nach der Tiefe hin festzustellen; dies wird noch dadurch verdeutlicht, wenn man die Untersuchungen UNGEMACHs [119] am Bodensediment beider Seen beizieht.

\subsection{Der «kurzgeschlossene" P-Kreislauf im Vierwaldstättersee (Horwer Bucht) und im Rotsee während der Sommerstagnation 1969}

Im folgenden wird versucht, mit verschiedenen Berechnungsmethoden die Grösse des internen epilimnischen Phosphorkreislaufes abzuschätzen. Als Vergleichsbasis dient dabei die Primärproduktion des Phytoplanktons bzw. die bei der C-Assimilation inkorporierte Phosphormenge. Die auf unterschiedliche Art ermittelten Produktionswerte sind in Tab. 44 dargestellt. 

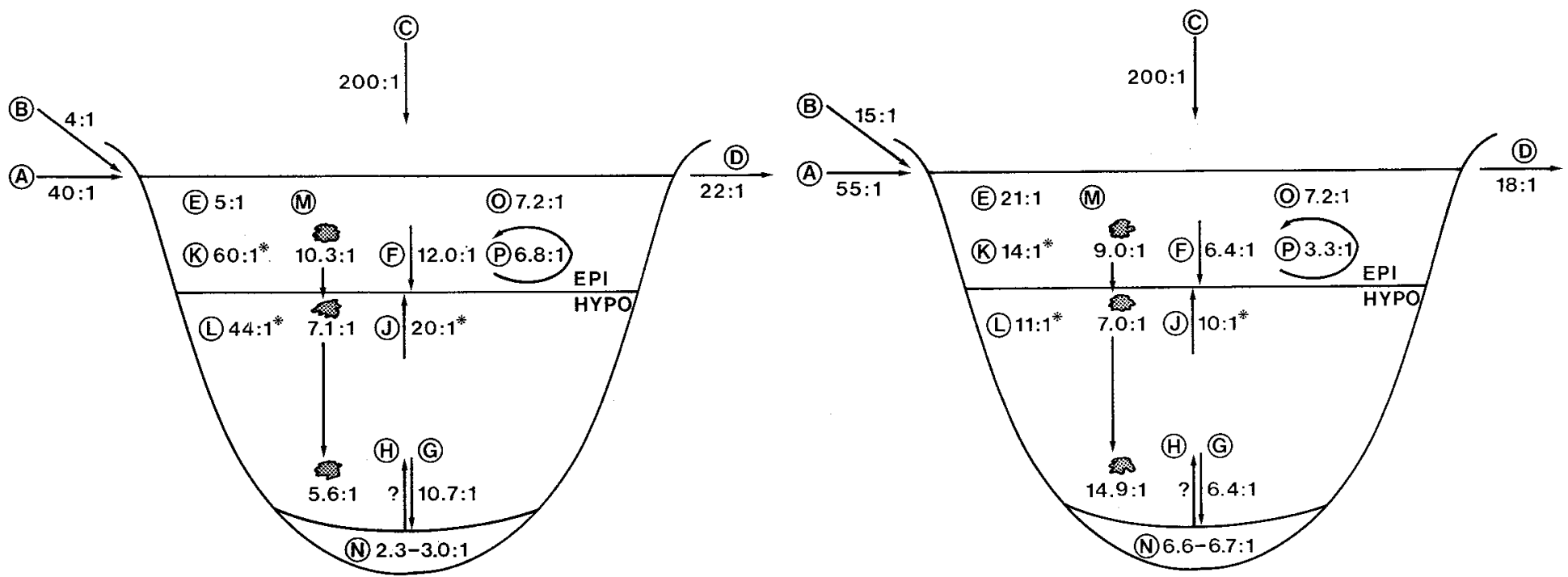

Abb. 92 und 93. N:P-Verhältnis im Verlaufe des Stoffkreislaufes im Vierwaldstättersee (Horwer Bucht, links) und im Rotsee (rechts), Sommerstagnation 1969

Bei den mit * bezeichneten Werten handelt es sich um $\mathrm{NO}_{3}: \mathrm{PO}_{4}$ (Horwer Bucht)- bzw. lösl. $\mathrm{N}: \mathrm{PO}$ (Rotsee)-Verhältnisse. $A$ natürliche $Z$ ufuhr, $B$ abwasserbelasteter Zufluss, $C$ atmosphärische Zufuhr, $D$ Abfluss, $E$ Seerückhalt, $F$ Sedimentation Epilimnion, $G$ Sedimentation Hypolimnion (Grund), $H$ Rücklösung vom Bodensediment, $J$ Eintrag vom Hypolimnion ins Epilimnion während der Zirkulation (Herbst), $K$ Winterüberschuss Epilimnion, $L$ Winterüberschuss Hypolimnion, $M$ partikuläres Material in verschiedenen Tiefenstufen [101], $N$ Bodensediment [119], $O$ Primärproduktion (ideales N:P-Gewichtsverhältnis [107]), $P$ «kurzgeschlossener» epilimnischer Stoffkreislauf.

Fig. 92 and 93. The N:P ratio, running through the nutrient cycle, in the Lake of Lucerne (Horw Bay, left) and in the Rotsee (right), sunmer stagnation 1969

Values with * indicate $\mathrm{NO}_{3}: \mathrm{PO}_{4}$ ratios (Horw Bay) resp. dissolved N: $\mathrm{PO}_{4}$ ratios (Rotsee). $A$ natural inflow, $B$ inflow containing waste water, $C$ atmospheric input, $D$ outflow, $E$ residue in the lake, $F$ sedimentation in the epilimnion, $G$ sedimentation in the hypolimnion (ground), $H$ release from bottom deposit, $J$ input from the hypolimnion into the epilimnion during circulation (autumn), $K$ winter surplus in the epilimnion, $L$ winter surplus in the hypolimnion, $M$ particulate material at different levels $[101], N$ bottom sediment $[119], O$ primary production (idecl $\mathrm{N}$ : P weight ratio $[107]), P$ intrabiocoenotic nutrient cyclei $n$ the epilimnion. 
Tabelle 43. Literaturzusammenstellung von $\mathrm{N}: \mathrm{P}$-Verhältnissen in Sedimenten.

Table 43. Review of literature on $N$ : P ratios in sediments.

\begin{tabular}{|c|c|c|c|c|}
\hline $\begin{array}{l}\text { Gesamt-N } \\
\mathrm{g} / \mathrm{m}^{2} \cdot \mathrm{Jahr}\end{array}$ & $\begin{array}{l}\text { Gesamt-P } \\
\mathrm{g} / \mathrm{m}^{2} \cdot \mathrm{Jahr}\end{array}$ & $\mathrm{N}: \mathrm{P}$ & Art des Sedimentes & $\begin{array}{l}\text { See } \\
\text { Literaturangabe }\end{array}$ \\
\hline $\begin{array}{r}3,488 \\
10,128 \\
9,040 \\
11,324 \\
20,10 \\
12,00 \\
13,40 \\
12,20\end{array}$ & $\begin{array}{l}0,840 \\
2,070 \\
1,850 \\
1,460 \\
9,40 \\
5,66 \\
9,55 \\
5,80\end{array}$ & $\begin{array}{l}4,1 \\
4,9 \\
4,9 \\
7,8 \\
2,1 \\
2,1 \\
1,4 \\
2,1\end{array}$ & $\begin{array}{l}\text { aufgefangen } \\
\text { aufgefangen } \\
\text { aufgefangen } \\
\text { aufgefangen } \\
\text { aufgefangen } \\
\text { aufgefangen } \\
\text { aufgefangen } \\
\text { aufgefangen }\end{array}$ & 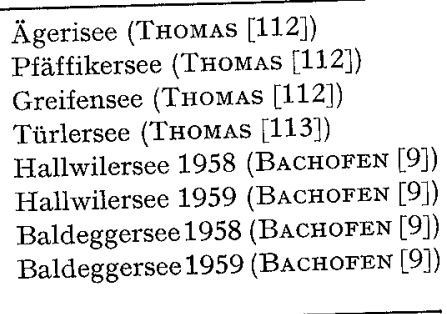 \\
\hline $\begin{array}{l}\text { Gesamt-N } \\
\% \text { TS }\end{array}$ & $\begin{array}{l}\text { Gesamt-P } \\
\% \text { TS }\end{array}$ & $\mathrm{N}: \mathrm{P}$ & Art des Sedimentes & $\begin{array}{l}\text { See } \\
\text { Literaturangabe }\end{array}$ \\
\hline $0,18-0,30$ & $0,077-0,10$ & $2,3-3,0$ & Bohrkern & $\begin{array}{l}\text { Vierwaldstättersee (Kreuz- } \\
\text { trichter) (UNGEMACH [119]) }\end{array}$ \\
\hline $0,66-0,80$ & $0,10-0,12$ & $6,6-6,7$ & Bohrkern & Rotsee (UNGEMACH [119]) \\
\hline
\end{tabular}

Die Berechnung der Produktion mit der $\mathrm{C}^{\mathbf{1 4}}$-Methode hat den grossen Nachteil, dass als Messwerte nur einzelne Momentaufnahmen vorliegen. Aufgrund der Bewölkungsangaben von STADELMANN [101] kann jedoch angenommen werden, dass bei der Extrapolation auf den gesamten Zeitraum ein Durchschnittswert errechnet wird, dessen Fehler etwa 10-20\% nicht überschreiten sollte. Die Produktionswerte von StadelmanN [101] und SchegG [93] wurden dahingehend korrigiert, dass die generelle Annahme einer durchschnittlichen stündlichen Assimilationsleistung von $10 \%$ der Tagesproduktion (während der Standardexpositionszeit von 10 bis $14 \mathrm{Uhr}$ ) durch die genaueren Angaben GÄCHTERs [33] ersetzt wurde.

Das nach OHLE [72] angewandte Berechnungsverfahren mit Hilfe der hypolimnischen $\mathrm{CO}_{2}$-Akkumulation wurde durch den Umstand erschwert, dass für die Untersuchungszeit keine analytischen Bestimmungen der freien Kohlensäure vor-

Tabelle 44. Primärproduktion im Vierwaldstättersee (Horwer Bucht) und im Rotsee (April bis Oktober 1969).

Table 44. Primary production in the Lake of Lucerne (Horw Bay) and in the Rotsee (April to October 1969).

\begin{tabular}{|c|c|c|}
\hline Methode & $\begin{array}{l}\text { Horwer Bucht } \\
\mathrm{g} \mathrm{C}_{\text {ass }} / \mathrm{m}^{2}\end{array}$ & $\begin{array}{l}\text { Rotsee } \\
\mathrm{g} \mathrm{C}_{\text {ass }} / \mathrm{m}^{2}\end{array}$ \\
\hline \multicolumn{3}{|l|}{$1 \mathrm{C}^{\mathbf{1 4}}$-Methode } \\
\hline $\begin{array}{l}\text { (SteEMANN Nielsen [104]; SChEGG [93]; } \\
\text { Stadelmann [101], korrigiert nach GÄChTER [33]) }\end{array}$ & 308,2 & 292,2 \\
\hline $2 \mathrm{O}_{2}$-Methode & 98,3 & -* \\
\hline $3 \mathrm{CO}_{2}$-Methode (OHLE [72], Schmassmann [95]) & 94,4 & 133,4 \\
\hline $4 \mathrm{CO}_{2}$-Methode (OHLE [72], RutTNER [90]) & 91,7 & 143,8 \\
\hline 5 Gesamt-C-Methode (HARVEY und RodHE [45]) & 85,5 & 145,8 \\
\hline Durchschnitt von 2 bis 5 & 92,5 & 141,0 \\
\hline
\end{tabular}

* Anwendung nicht möglich, da totaler hypolimnischer $\mathrm{O}_{2}$-Schwund. 
liegen und diese demzufolge rechnerisch (nach SchMASSMANn [95] und nach RUTTNER [90], S. 83) ermittelt werden musste. Dennoch ergab diese Methode Produktionswerte gleicher Grössenordnung wie die Berechnungen anhand der hypolimnischen Gesamt-C-Akkumulation (ermittelt nach Harvey und RodHE [45], aus SchwoerbeL [99]) und des hypolimnischen $\mathrm{O}_{\mathbf{2}}$-Defizites. Alle diese Berechnungen liefern erwartungsgemäss kleinere Werte als die $\mathrm{C}^{\mathbf{1 4}}$-Methode, weil nur das ins Hypolimnion absinkende organische Material und damit nur ein Teil der epilimnischen Primärproduktion erfasst wird.

Die Differenz dieser beiden Produktionsgrössen einerseits und das Verhältnis der Primärproduktion (C ${ }^{14}$-Methode) zur Sedimentation und zur Zufuhr andrerseits ermöglichen es nun, den "kurzgeschlossenen" epilimnischen P-Kreislauf grob abzuschätzen. Zunächst wurde die produzierte C-Menge auf der Basis des idealen C:PVerhältnisses von 41:1 [107] in die assimilierte P-Menge umgerechnet. Wie die Ergebnisse in Tab. 45 zeigen, schwanken die ermittelten Grössen für den «kleinen PKreislauf » von Methode zu Methode recht stark, was aufgrund der zum Teil summarischen Annahmen nicht weiter erstaunt. Immerhin geht aus diesen Berechnungen mit aller Deutlichkeit hervor, dass der P-Umsatz im «kurzgeschlossenen» Kreislauf beträchtliche Ausmasse erreicht. Im Durchschnitt werden daraus etwa $2 / 3$ des zur Produktion benötigten Phosphors geliefert. Bemerkenswert ist dabei die Tatsache, dass die Horwer Bucht einen leicht höheren Wert erreichte als der Rotsee. Dass ähnliche Werte zu erwarten waren, wurde schon bei den Planktonberechnungen angedeutet (siehe 5.35 Abbauraten, S. 158 bis 163). Wie auch ScHEGG [93] feststellte, steht der intensive epilimnische Stoffumsatz der Horwer Bucht demjenigen des Rotsees keineswegs nach, obwohl sich der Rotsee in einem bedeutend eutrophierteren

Tabelle 45. «Kurzgeschlossener» P-Kreislauf im Vierwaldstättersee (Horwer Bucht) und im Rotsee während der Sommerstagnation 1969.

Table 45. Intrabiocoenotic phosphorus cycle in the Lake of Lucerne (Horw Bay) and in the Rotsec during the stagnation period 1969.




Zustand befindet. Während hier zu Beginn der Sommerstagnation vor allem die interne P-Belastung aus dem Hypolimnion überwiegt, wird der "kleine Kreislauf» in der Horwer Bucht vorwiegend durch die sehr hohe, kontinuierliche externe Zufuhr in Gang gebracht (vgl. Abb. 87 und 88). Wir stehen also vor der Tatsache, dass die P-Düngung durch landwirtschaftliche Erosions- und Dränagewässer und ungereinigtes Abwasser den gesamten Stoffumsatz eines noch nicht alarmierend verschmutzten Sees in die Grössenordnung eines natürlich eutrophierten (polytrophen) Kleinsees zu steigern vermag, obwohl die aktuellen P-Konzentrationen wegen des grösseren Verduinnungsfaktors wesentlich tiefer liegen. Die Folge davon sind stetig zunehmende P-Gehalte im Vierwaldstättersee [5] und damit eine rasch fortschreitende Eutrophierung. Die schon lange erhobene Forderung nach umfassender Fernhaltung der Nährstoffe, insbesondere des Phosphors, findet durch die vorstehenden Ergebnisse eine detaillierte Bestätigung.

\section{Zusammenfassung}

1. In den Jahren 1969/70 wurden im mesotrophen Vierwaldstättersee (Horwer Bucht) und im polytrophen Rotsee die chemischen und physikalischen Verhältnisse, das Phytoplankton und die Sedimente in Sinktöpfen untersucht. Spezielles Gewicht wurde dabei auf den Phosphor gelegt. Diese Untersuchungen ergänzen frühere Arbeiten von Stadelmann [101] und SchegG [93], welche den Stickstoffkreislauf bzw. die bakterielle Destruktion zum Thema hatten.

2. Bezüglich Chemie zeigen sich die trophischen Unterschiede beider Seen deutlich. Während die Horwer Bucht im Sommer ein hypolimnisches $\mathrm{O}_{2}$-Defizit von etwa $4 \mathrm{mg} \mathrm{O} / \mathrm{l}$ aufweist, ist der Rotsee von $5 \mathrm{~m}$ bis Grund $(14 \mathrm{~m})$ völlig sauerstofffrei. Der Phosphor ist in beiden Seen als Minimumsstoff $z u$ bezeichnen. Die Phosphate im Epilimnion werden bis zum Herbst praktisch aufgezehrt. Im Rotsee gibt es jedoch Anzeichen dafür, dass zeitweise der Stickstoff ins Minimum gelangen könnte.

3. Die in verschiedenen Tiefenstufen aufgefangenen Sedimentationsraten widerspiegeln die unterschiedlichen Trophieverhältnisse ebenfalls. Im Rotsee ist der organische Anteil wesentlich höher (12-70\% der TS) als in der Horwer Bucht (7-22\% der TS). Die auf dem Seegrund gemessene jährliche P-Sedimentation betrug in der Horwer Bucht bei einer TS-Sedimentationsrate von $1277,4 \mathrm{~g}$ TS $/ \mathrm{m}^{2}$. Jahr 1,35 g $\mathrm{P} / \mathrm{m}^{2} \cdot$ Jahr oder $0,11 \%$ der TS, im Rotsee bei $879,3 \mathrm{~g} \mathrm{TS} / \mathrm{m}^{2} \cdot \mathrm{Jahr} 2,09 \mathrm{~g} \mathrm{P} / \mathrm{m}^{2} \cdot \mathrm{Jahr}$ oder $0,24 \%$ der TS. Nebst dem Glühverlust und dem Phosphor wurden im Sediment noch die Komponenten Tonmineralien, org. C, N, Ca, Mg, Fe und Mn bestimmt.

4. Das Phytoplankton wurde sowohl im Wasser wie im Sediment ausgezählt. Die maximale Biomasse betrug in der Horwer Bucht 1,2-2,7 mg/l und im Rotsee 31,9$35,2 \mathrm{mg} / \mathrm{l}$. Die Verteilung einzelner Arten und Gruppen sowie die Sukzession werden diskutiert. Anhand der sedimentierten Zellen wurden für ausgewählte Arten Berechnungen der Sinkgeschwindigkeit, des Abbaus, der Vermehrungsdynamik und des Trophiezeigerwertes angestellt.

5. Es wurde eine P-Bilanz beider Seen aufgestellt und mit der N-Bilanz [101] verglichen. Das N:P-Verhältnis, das eingehend diskutiert wird, nimmt beim Durchlaufen des Stoffkreislaufes von der natürlichen Zufuhr (40-200:1) bis zur Einlagerung 
ins Sediment $(2,3-6,7: 1)$ stetig ab; im frisch aufgefangenen Sediment betrug es in der Horwer Bucht durchschnittlich 10,7-12,0:1 und im Rotsee 6,4:1. Die grosse Intensität des "kurzgeschlossenen" epilimnischen P-Kreislaufes wird mit verschiedenen Berechnungsmethoden (chemisch und planktologisch) nachgewiesen. Er deckt in beiden Seen etwa $2 / 3$ des zur gemessenen Produktion benötigten Nährstoffnachschubes.

Die Forderung nach möglichst vollständiger Fernhaltung des Phosphors zur Sanierung unserer Seen wird aufgrund dieser und ähnlicher Arbeiten (zum Beispiel: $[31,101,93])$ wissenschaftlich gestützt.

\section{RÉSUMÉ}

1. Dans une période de recherches d'un an (1969 à 1970), le Lac des Quatre-Cantons (la baie de Horw), qui est mésotrophe, et le Rotsee, un lac très eutrophe, ont été examinés. Par d'amples analyses chimiques et physiques de l'eau de ces lacs et par des inventaires planctonologiques, la sédimentation récente a été mesurée à diverses profondeurs, en employant des récipients en PVC (de propre fabrication) pour recueillir les sédiments (fig. 2 et 3 ).

2. Les différences trophiques des deux lacs se manifestaient avant tout dans les concentrations actuelles de matières nutritives et dans les taux d'oxygène. En été, le Rotsee présente un hypolimnion totalement libre d'oxygène (fig. 21). Les phosphates, facteur limitant, de façon intégrale dans la baie de Horw, et de façon temporaire dans le Rotsee, sont pratiquement épuisés au cours de l'été dans l'épilimnion (fig. 10 et 23).

3. La sédimentation annuelle au fond du lac était de $1277,4 \mathrm{~g} / \mathrm{m}^{2}$ (poids sec) dans la baie de Horw et de $879,3 \mathrm{~g} / \mathrm{m}^{2}$ dans le Rotsee (tab. 41), ce qui correspond à un accroissement annuel de la sédimentation de $3,7 \mathrm{~mm}$ et de $2,5 \mathrm{~mm}$. En hiver, la sédimentation était faible; en été, les taux de sédimentation dépassaient $2 \mathrm{~g}$ pour atteindre jusqu'à $11 \mathrm{~g} / \mathrm{m}^{2}$ et jour (poids sec) (fig. 16 et 30). Dans la distribution verticale les différences n'étaient pas importantes, on trouvait tantôt une augmentation, tantôt une diminution dans un ordre irrégulier vers le fond du lac.

4. L'analyse chimique du sédiment comprenait les composants suivants: substance organique (perte d'ignition), C organique, les minéraux d'argile (part insoluble dans $\mathrm{HCl}$ ), $\mathrm{Ca}, \mathrm{Mg}, \mathrm{P}, \mathrm{N}, \mathrm{Fe}$ et Mn. Les résultats - en \% du poids sec total - sont cités dans les tableaux 6-16 (baie de Horw) et 19-31 (Rotsee). Dans la plupart des cas, les taux de sédimentation étaient plus hauts dans le Rotsee que dans le lac des Quatre-Cantons (exceptions: les minéraux d'argile, Fe, en partie $\mathrm{N}$ et Mn) (tab. 42).

5. Le phytoplancton a été déterminé et dénombré dans les deux lacs, dans l'eau et dans le sédiment. La distribution verticale de la biomasse totale, des différents groupes et de quelques espèces choisies a été représentée en forme d'isoplètes (fig. 32-55 [baie de Horw] et 56-82 [Rotsee]). La biomasse maximale se situait entre 1,2 et $2,7 \mathrm{mg} / 1$ dans la baie de Horw et entre 31,9 et $35,2 \mathrm{mg} / \mathrm{l}$ dans le Rotsee; dans le sédiment recueilli on a trouvé des valeurs maxima de $400-600 \mathrm{mg} / \mathrm{dm}^{2}$ et temps d'exposition (baie de Horw) et $420-1164 \mathrm{mg} / \mathrm{dm}^{2}$ et temps d'exposition (Rotsee) (temps d'exposition $=$ environ 14 jours).

6. Dans les deux lacs, les successions des chlorophycées et des diatomées (fig. 84 et 85 ) étaient absolument indépendantes l'une de l'autre. Certaines espèces montraient les mêmes périodes de dévéloppement (par exemple Phacotus lenticularis), d'autres produisaient des maximums à des époques nettement différentes (par exemple Oocystis lacustris).

7. En vertu des maximums relatifs de dévéloppement des algues (part de la biomasse totale), on pouvait déterminer une valeur indiquant la trophie pour certaines espèces. Pour le Rotsee eutrophe, c'étaient avant tout les algues vertes chlorococcales qui étaient typiques, tandis que, pour la baie mésotrophe de Horw, c'étaient les diatomées.

8. A l'aide des cellules recueillies, la vitesse moyenne de sédimentation a été calculée pour quelques espèces. Les résultats variaient de quelques $\mathrm{cm} /$ jour à $20 \mathrm{~m} /$ jour environ (tab. 33). 
9. En ce qui concerne la dynamique de la prolifération on pouvait distinguer 4 types différents (p. 157 et tab. 38). Il en résultaient, en cas extrêmes, des temps de génération de quelques heures (par exemple Cyclotella spp., Tabellaria fenestrata).

10. Les taux de dégradation sont représentés dans les tableaux 39 et 40 . Environ les deux tiers du phytoplancton total se décomposait déjà dans l'épilimnion; le tiers restant, parvenant dans I'hypolimnion, était réduit à son tour de moitié avant d'atteindre le fond du lac. Les formes délicates des chrysophycées, des cryptophycées et des flagellés se decomposaient le plus vite. Les cyanophycées avant tout, et quelques chlorophycées s'avéraient résistentes à la dégradation. I1 était étonnant que les corps cellulaires de beaucoup de diatomées se décomposent si rapidement.

11. Les différences dans le métabolisme des deux lacs ont été démontrées à l'aide du bilan de phosphore (fig. 87 et 88). Celui-ci était comparé avec le bilan de l'azote (après STADELmanN [101], fig. 90 et 91). On y constatait que le rapport $\mathrm{N}: \mathrm{P}$ diminue continuellement au cours du cycle nutritif, de l'apport jusqu'à l'incorporation dans le sédiment (fig. 92 et 93). Le quotient $N: P$ du sédiment recueilli était, dans la baie de.Horw, en moyenne de 10-11:1 (hiver 4-8:1, été 9-27:1; fig. 17), dans le Rotsee en moyenne de 7-8:1 (hiver 10:1, été 5,5:1; fig. 31). Les taux annuels de sédimentation du phosphore se situaient à $1,35 \mathrm{~g} \mathrm{P} / \mathrm{m}^{2}$ ou $0,11 \%$ du poids sec total dans la baie de Horw, et à $2,09 \mathrm{~g} \mathrm{P} / \mathrm{m}^{2}$ ou $0,24 \%$ du poids sec total dans le Rotsee.

12. Le cycle intrabiocénotique du phosphore dans l'épilimnion a été déterminé à l'aide de différentes méthodes de calcul (chimique et planctonologique). Il couvrait, dans les deux lacs, environ les deux tiers de l'approvisionnement nutritif nécessaire pour la production primaire mesurée.

13. Ce travail confirme scientifiquement que la revendication de tenir le phosphore éloigné pour l'assénissement de nos lacs est justifiée.

\section{SUMMARY}

1. The mesotrophic Lake of Lucerne (Horw Bay) and the highly eutrophic Rotsee were investigated over a one-year cycle (1969/70). In addition to extensive chemical and physical investigations of lake water and a survey of phytoplankton, recent sedimentation was measured at different levels. PVC collecting vessels specially designed for this purpose were used (Fig. 2 and 3 ).

2. The difference in trophic state of the two lakes expressed itself primarily in the present nutrient concentration as well as in the $\mathrm{O}_{2}$-content. The Rotsee was characterised in summer by a totally $\mathrm{O}_{\mathbf{2}}$-free hypolimnion (Fig. 21). 'The phosphates, limiting factor in Horw Bay integrally and in the Rotsee at times, are practically completely consumed in the epilimnion during summer (Fig. 10 and 23 ).

3. The annual sedimentation at the lake bottom came to $1277.4 \mathrm{~g}$ of dry matter $/ \mathrm{m}^{2}$ in Horw Bay and to $879.3 \mathrm{~g}$ of dry matter $/ \mathrm{m}^{2}$ in the Rotsee (Table 41). This corresponds to an accumulation in bottom sediments of $3.7 \mathrm{~mm} /$ year and of $2.5 \mathrm{~mm} /$ year respectively. The sedimentation in winter was low; in summer the rates of sedimentation rose from an average of $2 \mathrm{~g}$ of dry matter $/ \mathrm{m}^{2} \cdot \mathrm{day}$ to an average of $11 \mathrm{~g}$ of dry matter $/ \mathrm{m}^{2}$. day (Fig. 16 and 30). There was no discernible pattern in the variation of sedimentation rate with depth, and partly an increase, partly a decrease was found in irregular order to the bottom of the lake.

4. The chemical analysis of sediments included the following components: total organic substance (loss on ignition), organic $\mathrm{C}$, clay minerals (HCl-insoluble fraction), $\mathrm{Ca}, \mathrm{Mg}, \mathrm{P}, \mathrm{N}, \mathrm{Fe}$ and Mn. The results are represented - in \% of dry matter - in Tables 6-16 (Horw Bay) and 19-31 (Rotsee). For most components the rates of sedimentation were higher in the Rotsee than in the Lake of Lucerne (exceptions: clay minerals, $\mathrm{Fe}$, to a certain extent $\mathrm{N}$ and $\mathrm{Mn}$ ) (Table 42).

5. The phytoplankton was examined by detailed counting in both lakes in the water and in the sediment. The vertical distribution of the total biomass, of the different systematic groups, and of some selected species have been drawn in isopleths (Fig. 32-55 [Horw Bay] and 56-82 [Rotsee]). The maximum standing crop was measured in Horw Bay as $1.2-2.7 \mathrm{mg} / 1$ and in the Rotsee as $31.9-35.2 \mathrm{mg} / \mathrm{l}$; in the collected sediments maximum values of $400-600 \mathrm{mg} / \mathrm{dm}^{2} \cdot \mathrm{expo-}$ sure and $420-1164 \mathrm{mg} / \mathrm{dm}^{2} \cdot$ exposure respectively have been found (exposure = approx. 14 days). 
6. In both lakes, the successions of the chlorophyceae and the diatomeae (Fig. 84 and 85 ) were completely independent of each other. Some species (e.g. Phacotus lenticularis) showed the same periods of development, other species (e.g. Oocystis lacustvis) produced maxima at different seasons.

7. On the basis of the relative maxima of development of algae (fraction of the total standing crop) a measure of trophic state for single species could be calculated. Typical for the eutrophic Rotsee were after all the green algae (chlorococcales), and for the mesotrophic Horw Bay the diatoms.

8. With the help of the collected cells the average velocity of sinking of some species has been calculated. The values ranged from several $\mathrm{cm} /$ day up to about $20 \mathrm{~m} /$ day (Table 33 ).

9. Four different types of growth dynamics could be distinguished (p. 157 and Table 38). Generation times of some hours resulted in extreme cases (e.g. Cyclotella spp., Tabellaria fenestrata).

10. The rates of degradation are represented in the Tables 39 and 40 . Two thirds of the entire phytoplankton decomposed in the epilimnetic zone; one half of the remaining third was destroyed between entry into the hypolimnion and arrival at the bottom of the lake. The delicate forms of the chrysophyceae, cryptophyceae and various other flagellates decayed most rapidly. Above all the cyanophyceae and some chlorophyceae proved to be resistant to degradation. The cell bodies of most diatomeae decayed remarkably rapidly.

11. The differences in the metabolism of both lakes were shown by the example of the phosphorus balance (Fig. 87 and 88). This balance was compared with the nitrogen balance (according to Stadelmann [101], Fig. 90 and 91). It was confirmed that the $N: P$ ratio continually decreases running through the nutrient cycle from the input to the storing into the bottom sediments (Fig. 92 and 93). On the average the $\mathrm{N}: \mathrm{P}$ ratio came to $10-11: 1$ (winter $4-8: 1$, summer 9-27:1; Fig. 17) in Horw Bay, and to 7-8:1 (winter 10:1, summer 5.5:1; Fig. 31) in the Rotsee. The rates of phosphorus sedimentation amounted to $1.35 \mathrm{~g}$ of $\mathrm{P} / \mathrm{m}^{2}$ year or $0.11 \%$ of dry matter in Horw Bay and to $2.09 \mathrm{~g}$ of $\mathrm{P} / \mathrm{m}^{2}$ year or $0.24 \%$ of dry matter in the Rotsee.

12. With different methods of calculation (chemically and planktologically), the intrabiocoenotic phosphorus cycle in the epilimnion was ascertained. It supplied approximately two thirds of the nutrient requirements used for the measured primary production in both the Horw Bay and the Rotsee.

13. The demand to bar the discharge of phosphorus into our lakes to restore them to a more oligotrophic state is scientifically supported by this thesis.

\section{VERDANKUNG}

Ich danke den Herren Prof. Dr. W. Stumm, Direktor der EAWAG, Prof. Dr. O. Jaag, alt Direktor der EAWAG, und Prof. Dr. H. AmbühI, Leiter der Limnologischen Abteilung an der EAWAG. Sie haben mir die Durchführung dieser Arbeit ermöglicht. Gedankt sei auch meinen Teamkollegen Heinrich Bührer, Dr. Ernst Schegg und Dr. Pius Stadelmann. Mein Dank gilt ferner Herrn Dr. R. Gächter für die Durchführung der Phosphoranalysen im Seewasser der Horwer Bucht, Herrn Dr. H. Leidner für die Sedimentanalyse mit dem C, H, N-Analyzer,

Herrn Dr. H. R. Hegi für die Sedimentanalyse mit dem Atomabsorptions-Spektrophotometer, den Herren E. Szabo, dipl. chem., F. Pfister und B. Ribi für die Mithilfe bei der chemischen Sedimentanalyse,

den Herren Dr. Schlichenmeier und Wyden von der Firma Mettler für die Durchführung zweier Thermoanalysen,

Herrn Prof. Dr. W. Stumm für Hinweise zur Sedimentchemie,

Frau P. Weber für die Auszählung von Phytoplanktonproben,

Herrn P. Schlup für die Übernahme der photographischen Laborarbeiten,

und den Herren Prof. Dr. H. Ambühl und Dr. R. Gächter für die Durchsicht des Manuskriptes. Schliesslich danke ich Herrn A. Keller für die vielen anregenden Diskussionen und Hinweise.

Die Arbeit wurde mit Unterstützung der "Stiftung der Wirtschaft zur Förderung des Gewässerschutzes in der Schweiz" durchgeführt. 


\section{LITERATURVERZEICHNIS}

[1] Aввотт, W., Unusual Phosphorus Source for Plankton Algae, Ecology 38, 152 (1957).

[2] AlsterberG, G., Die Winklersche Bestimmungsmethode für in Wasser gelösten, elementaven Sauerstoff sowie ihre Anwendung bei Anwesenheit oxydierbarer Substanzen, Biochem. Z. 170, 30 (1926).

[3] АмвӥнL, H., Die praktische Anwendung der elektrochemischen Sauerstofbestimmung im Wasser, Schweiz. Z. Hydrol. 22/1, 23-39 (1960).

[4] АмвӥнL, H., Der Einfluss chemischer Düngung auf stehende Oberflächengewässer, GWF 107 , 357-363 (1966).

[5] АмвӥнL, H., Die neueste Entwicklung des Vierwaldstättersees (Lake of Lucerne), Verh. Int. Ver. Limnol. 17, 219-230 (1969).

[6] АмвÜHL, H., Diskussionsbeitvag aus: Proc. $4^{\text {th }}$ Int. Conf. Prague 1969, Adv. Wat. Poll. Res., S. 162-165 (1969).

[7] Амв $\mathrm{UL}, \mathrm{H}$., Forderungen an die Gestaltung von Trinkwasserschutzgebieten zur Verhinderung der Eutrophierung stehender Gewässer, Gewässerschutz, Wasser, Abwasser; Gefährdung und Schutz von Grund- und Oberflächenwässern, Teil II, Tagung vom 24. bis 26. Juni 1970 in Essen, 351-372 (Aachen 1971).

[8] АмвÜHL, H., und SchмID, M., Die Bestimmung geringster Mengen von Phosphation im Wasser von Binnenseen, Schweiz. Z. Hydrol. 27/1, 172-183 (1965).

[9] BACHOFEN, R., Stofhaushalt und Sedimentation im Baldegger- und Hallwilersee, Diss. (JurisVerlag Zürich 1960), $118 \mathrm{~S}$.

[10] BLoEsch, J., Messung der Sedimentation in verschiedenen Tiefenstufen des. Vievwaldstattersees (Horwer Bucht), mit besondever Berüchsichtigung des Phosphors, Diplomarbeit an der EAWAG/ ETH Zürich, Herbst 1967 (unveröffentlicht).

[11] BÜHRER, H., Diss. EAWAG/ETH Zürich, in Vorbereitung.

[12] BÜRGI, H. R., Die Wirkung von NTA auf das Wachstum des Phytoplanktons unter besondever Berücksichtigung des Eisens als Mikroelement, Diss. EAWAG/ETH Zürich, Schweiz. Z. Hydrol, 36/1, 1-70 (1974).

[13] Chalupa, J., Eutrophication of Reservoirs by Atmospheric Phosphorus, Sbornik, VSCHT (Scientific Papers from Inst. Chem. Technol., Prague, Fac. Technol. Fuel. and Wat.) 4/1, 295-308 (1960).

[14] CHU, S. P., The Utilisation of Organic Phosphorus by Phytoplankton, J. mar. biol. Ass. U. K. 26, 285-295 (1946).

[15] ClASEN, J., Leptothrix echinata und die Mangankonzentration in der Wahnbachtalsperve, Städtehygiene 20/7, 171-174 (1969).

[16] Cooper, L. H. N., The Rate of Liberation of Phosphate in Sea Water by the Breakdown of Plankton Organisms, J. mar. biol. Ass. U. K. 20, 197-200 (1935).

[17] DoвoLyi, E., Efficient Biological Waste-Water Purification is a Precondition for Chemical Phosphate Removal, Wat. Res. 7/1-2, 329-342 (1973).

[18] DüGGELI, M., Bakteriologische Studien am Wasser des Rotsees, Schweiz. Z. Hydrol. 6/3-4, 216 (1943).

[19] Einheitsverfahren, Deutsche, 3. völlig neubearbeitete Auflage (Verlag Chemie Weinheim 1960).

[20] EINSELE, W., Über die Beziehungen des Eisenkreislaufs zum Phosphatkreislauf im eutrophen See, Arch. Hydrobiol. 29, 664-686 (1936).

[21] EInsele, W., Physikalisch-chemische Betrachtungen einiger Probleme des limnischen Manganund Eisenkreislaufs, Verh. Int. Ver. Limnol. 8/3, 69-84 (1937).

[22] EINSELE, W., Über chemische und kolloidchemische Vorgänge in Eisen-Phosphat-Systemen unter limnochemischen und limnogeologischen Gesichtspunkten, Arch. Hydrobiol. 33, 361-387 (1938).

[23] Eschmann, K. H., et al., Die Verunveinigung der Reuss zwischen Luzern und der Mündung in dic Aare. Bericht ïber die limnologischen Untersuchungen vom 5./6. September 1962, WEW 5,5/6 177-198 (1963).

[24] FindenegG, I., Phytoplankton und Primärproduktion einiger ostschweizerischer Seen und des Bodensees, Schweiz. Z. Hydrol. 28/2, 148-172 (1966).

[25] FindenegG, I., Die Bedeutung des Austausches für die Entwicklung des Phytoplanktons in den Ostalpenseen, Schweiz. Z. Hydrol. 29/1, 125-144 (1967). 
[26] Forsberg, C., Jinnerot, D., und Davidsson, L., The Influence of Synthetic Detergents on the Growth of Algae, Vatten 23/1, 2-16 (1967).

[27] Foтt, B., Algenkunde, 2. völlig umgearbeitete Auflage (VEB Gustav-Fischer-Verlag, Jena 1971).

[28] FREIER, R. K., Wassevanalyse. Physiko-chemische Untersuchungsverfahren wichtiger Inhaltsstoffe (De-Gruyter-Verlag, Berlin 1964).

[29] Fritz, Fr., Über die Sinkgeschwindigkeit einiger Phytoplanktonorganismen, Int. Rev. Hydrobiol. Hydrogr. 32, 424 431 (1935).

[30] Furs, G. W., Rates of Phosphorus-Controlled Growth in the Diatoms Cyclotella nana and Thalassiosira fluviatilis, J. Phycol. 5, 312-321 (1969).

[31] GÄchTER, R., Phosphorhaushalt und planktische Primärproduktion im Vievwaldstättersee (Horwer Bucht), Schweiz. Z. Hydrol. 30/1, 1-66 (1968).

32] GÄCHTER, R., Zur Frage dev Einleilung von gereinigtem Abwasser in Seen, Schweiz. Z. Hydrol. $33 / 1,73-84(1971)$.

[33] GÄCHTER, R., Die Bestimmung der Tagesraten der planktischen Primärproduktion-Modelle und In-situ-Messungen, Schweiz. Z. Hydrol. 34/2, 211-244 (1972).

[34] Gä̈hteR, R, und FurRer, O. J., Der Beitrag der Landwirtschaft zur Eutrophierung der Gewässer in der Schweiz. I. Ergebnisse von divehten Messungen im Einzugsgebiet verschiedener Vorfluter, Schweiz. Z. Hydrol. 34/1, 41-70 (1972).

[35] Gächter, R., SzABó, E., und MAREš, A., Die lokale Beeinflussung eines stehenden Gewässers durch eine punktförmige Abrasserbelastung; ein direkter Nachweis der wachstumsbegrenzenden Wirkung des Phosphors im Vierwaldstattersee, Schweiz. Z. Hydrol. 33/1, 66-72 (1971).

[36] Gallowax, R. A., und Krauss, R. W., Microalgae and Photosynthetic Bacteria, Japanese society of plant physiologists, the Univ. of Tokyo Press (1963).

[37] Gerloff, G. C., und Skoog, F., Cell Contents of Nitrogen and Phosphorus as a Measure of Their Availability for Growth of Microcystis aeruginosa, Ecology 35, 348-353 (1954).

[38] Gessner, F., Hydrobotanik, Band 1 (VEB Deutscher Verlag der Wissenschaften, Berlin 1955), S. 403-404.

[39] Golterman, H. L., Studies on the Cycle of Elements in Fresh Water, Acta Bot. Neerl. 9, 1-58 (1960).

[40] Golterman, H. L., Mineralization of Algae under Sterile Conditions or by Bacterial Breakdoren, Verh. Int. Ver. Limnol. 15, 544-548 (1964).

[41] Grim, J., Beobachtungen am Phytoplankton des Bodensees (Obersee) sowie deven rechnerische A uswertung, Int. Rev. Hydrobiol. Hydrogr. 39, 193-315 (1939).

[42] Grim, J., Versuche zur Ermittlung der Produktionskoeffizienten einiger Planktophyten in einem flachen See, Biol. Zbl. 69, 147-174 (1950).

[43] GrTM, J., Ein Vergleich der Produktionsleistung des Bodensee-Untersees, des Obersees und des Schleinsees, Abh. Fisch. 4, 787-841 (1951).

[44] Grim, J., Der Phosphor und die pflanzliche Produktion im Bodensee, GWF 708/44, 1261-1271 (1967).

[45] Harvey, H. W., The Chemistry and Fertility of Sea Waters (Cambridge University Press, London 1955).

[46] Hemens, J., und Mason, M. S., Sewage Nutrient Removal by a Shallow Algal Stream, Wat. Res. 2, 277-287 (1968).

[47] Höhne, E., und ODRICH, E., Sedimentationsraten, Limnologica (Berlin) 4/2, 313-320 (1966).

[48] Holm-Hansen, $O$., The Distribution and Chemical Composition of Particulate Material in Marine and Fresh Waters, Mem. Ist. Ital. Idrobiol. 29 Suppl., $37-51$ (1972).

[49] Huber-Pestalozzi, G., Das Phytoplankton des Süsswassers, Teil 1-6, in Thienemand, A., Die Binnengewässer, Band 16 (E. Schweizerbartsche Verlagsbuchhandlung, Stuttgart 1961-1972).

[50] JAAG, O., Die zunehmende Gefährdung unsever Seen - Warum Gewässerschutz? Föderation Europäischer Gewässerschutz (FEG), Informationsblatt Nr. 14, 1-10 (1967).

[51] JÄrnefelt, H., Übev die Sedimentation des Sestons, Verh. Int. Ver. Limnol. 12, 144-158 (1955).

[52] Klekrekoper, H., A New Apparatus for the Study of Sedimentation in Lakes, Can. J. Zool. 30 , $185-190(1952)$. 
[53] Kleerekoper, H., The Mineralization of Plankton, J. Fish. Res. Bd. Can. 10/5, 283-291 (1953).

[54] Krause, H. R., Biochemische Untersuchungen ïber den postmortalen Abbau von totem Plankton unter aevoben und anaeroben Bedingungen, Arch. Hydrobiol. Suppl. 24/3-4, 297-337 (1959).

[55] Krause, H. R., Abbau organischer Phosphorkomponenten aus totem Siisswasser-Zooplankton, Naturwissenschaften 47, 401-402 (1960).

[56] Krause, H. R., Zur Chemie und Biochemie der Zersetzung von Sïsswasserorganismen, unter besondever Berïcksichtigung des Abbaues dev organischen Phosphorkomponenten, Verh. Int. Ver. Limnol. 15, 549-561 (1964).

[57] Kusnezow, S. I., Die Rolle der Mikroorganismen im Stoffkreislauf der Seen (VEB Deutscher Verlag der Wissenschaften, Berlin 1959).

[58] Lebensmittelbuch, Schweizerisches, 4. Auflage (1937).

[59] Lohmann, H., Untersuchungen zur Feststellung des vollständigen Gehaltes des Meeves an Plankton, Wiss. Meeresunters. 10, 131 (1908).

[60] Lund, J. W. G., Studies on Asterionella. I. The Origin and Nature of the Cells Producing Seasonal Maxima, J. Ecol. 37/2, 389-419 (1949).

[61] Mann, J. E., und Myers, J., On Pigments and Photosynthesis of Phaeodactylum tricornutum, J. Phycol. 4, 349-355 (1968).

[62] MärKt, E., et. al., Untersuchung des Trink- und Betriebswassers, aus: Handbuch der Lebensmittelchemie, Band 8, Teil 1 und 2, (Springer-Verlag Berlin, Heidelberg und New York 1970), S. 686-689.

[63] Minder, L., Dev Zürichsee im Lichte der Seetypenlehre, Neujahrsbl. Naturf. Ges. Zürich (1943), $83 \mathrm{~S}$.

[64] Minder, L., Der Rotsee, Schweiz. Z. Hydrol. 17, 245-253 (1949).

[65] Müller, H., Wachstum und Phosphatbedarf von Nitzschia actinastroides (Lemm.) v. Goor in statischer und homokontinuierlicher Kultur unter Phosphatlimitierung, Arch. Hydrobiol. Suppl. 38/4, 399-484 (1972).

[66] Müller, R., und Widemann, O., Die Bestimmung des Nitrat-Ions imWasser, Jb. "Vom Wasser" 22, 247-271 (1955)

[67] Nauwerck, A., Die Beziehungen zwischen Zooplankton und Phytoplankton im See Erken, Symb. bot. Upsal. 17/.5, 1-163 (1963).

[68] NikLaus, M., Geomorphologische und limnologische Untersuchungen am Öschinensee, Beitr. Geol. Schweiz, Hydrologie Nr. 14 (Verlag Kümmerly \& Frey, Bern 1967).

[69] Nipkow, F., Vorläufige Mitteilungen über Untersuchungen des Schlammabsatzes im Zürichsee Z. Hydrol. 1, 1-23 (1920).

[70] NyDEGGER, P., Untersuchungen über Feinststoftransport in Flüssen und Seen, ïber Entstehung von Trübungshorizonten und zuflussbedingten Strömungen im Brienzersee und einigen Vergleichsseen, Beitr. Geol. Schweiz, Hydrologie Nr. 16 (Verlag Kümmerly \& Frey, Bern 1967).

[71] OHLE, W., Zur Vervollkommnung der hydrochemischen Analyse. III. Die Phosphorbestimmung, Z. anorg. Chemie 51, 906-911 (1938).

[72] OнLE, W., Die hypotimnische Kohlendioxyd-Akkumulation als produktionsbiologischer Indikator, Arch. Hydrobiol. 46, 153-285 (1952).

[73] OHLE, W., Der Stoffhaushalt der Seen als Grundlage einer allgemeinen Stoffwechseldynamik der Gewässer, Kieler Meeresforsch. 18/3, 107-120 (1962).

[74] OHLE, W., Chemische und mikrobiologische Aspekte des biogenen Stoffhaushaltes der Binnengewässer, Mitt. Int. Ver. Limnol. 14, 122-133 (1968).

[75] O'Melia, Ch. R., An Approach to the Modeling of Lakes, Schweiz. Z. Hydrol. 34/1, 1-33 (1972).

[76] OтTо, G., und BenNdoRF, J., Über den Einfluss des physiologischen Zustandes sedimentievender Phytoplankter auf die Abbauvorgänge während der Sedimentation, Limnologica (Berlin) 8/2, 365-370 (1971).

[77] OvERBECK, J., Untersuchungen zum Phosphathaushalt von Grïnanlagen. I. Phosphathaushalt und Fortpflanzungsrhythmus von Scenedesmus quadricauda (Turp.) Bvéb. am natürlichen Standort. II. Die Verwertung von Pyrophosphat und organisch gebundenen Phosphaten und ihre Beziehung zu den Phosphatasen von Scenedesmus quadricauda (Turp.) Bréb., Arch. Hydrobiol. 58, 162-209 und 281-308 (1962).

[78] Overbeck, J., Primärproduktion und Gewässerbakterien, Naturwissenschaften 51, 145 (1965). 
[79] Overbeck, J., Zur Bakteriologie des Sïsswassersees - Evgebnisse und Probleme, GWF 108/44, 1258-1260 (1967).

[80] Overbeck, J., Prinzipielles zum Vorkommen der Bakterien im See, Mitt. Int. Ver. Limnol. 14. 134-144 (1968).

[81] Pavoni, M., Die Bedeutung des Nannoplanktons im Vergleich zum Netzplankton, Schweiz. Z. Hydrol. 25/2, 219-341 (1963).

[82] Pleisch, P., Die Herkunft eutrophievender Stoffe beim Pfäffkev-und Greifensee, Vjschr. Naturf. Ges. Zürich 115/2, 127-229 (1970).

[83] Provasoli, L., Nutrition and Ecology of Protozoa and Algae, Ann. Rev. Mikrobiol. 12, 279-308 (1958).

[84] Rheinheimer, G., Mikrobiologie der Gewässer (Gustav-Fischer-Verlag, Stuttgart 1971).

[85] Richardson, B., Orcutt, D. M., Schwertner, H. A., Martinez, C. I., und Witchline, H. E., Effects of Nitrogen Limitation on the Growth and Composition of Unicellular Algae in Continuous Cultuve, Appl. Microbiol. 78, 245-250 (1969).

[86] Rigler, F. H., The Phosphorus Fractions and the Tumover Time of Inorganic Phosphorus in Different Types of Lakes, Limnol. Oceanogr. 9, 511-518 (1964).

[87] RoDhe, W., Environmental Requirements of Freshwater Plankton Algae. Experimental Studies in the Ecology of Phytoplankton, Symb. bot. Upsal. 10, 1-149 (1948).

[88] RoDhe, W., Standard Correlations between Pelagic Photosynthesis and Light, Mem. Ist. Ital. Idrobiol. Suppl. 18, 365-381 (1965).

[89] Round, F. E., Biologie dev Algen (Georg-Thieme-Verlag, Stuttgart 1968).

[90] Rutiner, F., Grundriss der Limnologie, 3. neubearbeitete und erweiterte Auflage (De-GruyterVerlag, Berlin 1962).

[91] Sauberer, F., Empfehlungen für die Durchführung von Strahlungsmessungen an und in $G e-$ wässern, Mitt. Int. Ver. Limnol. 17, 1-77 (1962).

[92] SchegG, E., Beziehungen zwischen Planktonentwicklung und Bakterien im Vierwaldstättersee und Rotsee, Schweiz. Z. Hydrol. 30/2, 289-296 (1968).

[93] Schegg, E., Produktion und Destruktion in der trophogenen Schicht. Untersuchungen ökologischer Parameter im polytrophen Rotsee und in der mesotrophen Horwer Bucht (Vievwaldstättersee), Schweiz. Z. Hydrol. 33/2, 425-532 (1971).

[94] Schindler, P. W., Heterogeneous Equilibria Involving Oxides, Hydroxides, Carbonates, and Hydroxide Carbonates, in Stumm, W., Equilibrium Concepts in Natural Water Systems (Advances in Chemistry Series 67, Am. Chem. Soc. Washington 1967), S. 196-221.

[95] Schmassmann, H., Die theoretischen Grundlagen beider Bestimmung und Berechnung von aggressiver Kohlensäure in natürlichen Wässern, Schweiz. Arch. Wiss. Techn. 13/9, 275-283 (1947).

[96] Schмid, M., Die Bestimmung kleiner Mengen von organischem Stickstoff im Wasser von Binnenseen, Schweiz. Z. Hydrol. 30/1, 244-266 (1968).

[97] Schmid, M., und AmbüHL, H., Die Bestimmung gevingster Mengen von Gesamtphosphor im Wasser von Binnenseen, Schweiz. Z. Hydrol. 27/1, 184-192 (1965).

[98] Schwarzenbach, G., Komplexon. Titvationen mit Hilfe von Komplexon, Siegfried Aktiengesellschaft Zofingen (1963).

[99] Schwotrbei, J., Methoden der Hydrobiologie (Kosmos, Franckhsche Verlagshandlung Stuttgart 1966).

[100] Scrwoerbel, J., Einführung in die Limnologie, Uni-Taschenbücher (UTB), Nr. 31. (GustavFischer-Verlag Stuttgart 1971).

101] StadelmanN, P., Stickstoffkeislauf und Primärproduktion im mesotrophen Vievwaldstättersee (Howwer Bucht) und im eutrophen Rotsee, mit besonderer Berücksichtigung des Nitrats als limitievenden Faktors, Schweiz. Z. Hydrol. 33/1, 1-65 (1971).

102] Standard Methods for the Examination of Water and Wastewater, 12. Auflage (American Public Health. Association New York 1965).

103] STAUB, R., Ernährungsphysiologisch-autökologische Untersuchungen an der planktischen Blaualge Oscillatoria rubescens D. C., Schweiz. Z. Hydrol. 23/1, 82-198 (1961).

[104] Stemmann Nielsen, E., The Use of Radio-Active Carbon (C ${ }^{14}$ ) for Measuring Organic Produktion in the Sea, J. Cons. int. Explor. Mer 18, 117-140 (1952).

[105] Streble, H., und Krauter, D., Das Leben im Wassertropfen. Mikroflora und Mikrofauna des Süsswassers (Kosmos-Naturführer, Franckhsche Verlagshandlung, Stuttgart 1973). 
[106] Strickland, J. D. H., und Parsons, T. R., A Practical Handbook of Seawater Analysis, 2. Auflage, Fish. Res. Bd. Can. Bull. 167 (Ottawa 1972).

[107] Sтимм, W., Diskussionsbeitrag zum Vortrag von G. A. Rohlich, Adv. Wat. Poll. Res. (London) 2, 216-230 (1964).

[108] Stumm, W, und Morgan, J. J., Aquatic Chemistry. An Introduction Emphasizing Chenical Equilibria in Natural Waters (Wiley-Interscience, New York 1970).

[109] Tessenow, U., Untersuchungen über den Kieselsäurehaushalt der Binnengewässer, Arch. Hydrobiol. Suppl. 32/1, 1-136 (1966).

[110] Thienemann, A., Der Sauerstoff im eutrophen und oligotrophen See, in Die Binnengewässer, Band 4 (E. Schweizerbartsche Verlagsbuchhandlung, Stuttgart 1928).

[111] Thomas, E. A., Beitrag zur Methodik der Produktionsforschung in Seen, Schweiz. Z. Hydrol. 12/1, 25-37 (1950).

[112] Tномаs, E. A., Stofhaushalt und Sedimentation im oligotrophen Ägerisee und im eutrophen Pfäffker- und Greifensee, Mem. Ist. Ital. Idrobiol. Suppl. 8, 357-465 (1955).

[113] Thomas, E. A., Sedimentation und Stofhaushalt im Türlersee, Monatsbull. Schweiz. Ver. Gasu. Wasserfachm. 36/12, 297-307 (1956).

[114] Thомas, E. A., Sedimentation und Typeneinteilung des Türlersees, Verh. Int. Ver. Limnol. 13, 191-195 (1958).

[115] Thomas, E. A., Phosphat-Elimination in der Belebtschlammanlage von Männedorf und Phosphat-Fixation in See- und Klärschlamm, Vjschr. Naturf. Ges. Zürich 110/4, 419-434 (1965).

[116] Thомas, E. A., Untersuchungen ïber Auswirkungen und Folgen der Einschichtung von Abwässern in Seen, Gas-Wasser-Abwasser 49/11, 378-386 (1969).

[117] Tutin, W., Preliminary Observations on a Year's Cycle of Sedimentation in Windermere, England, Mem. Ist. Ital. Idrobiol. Suppl, 8, 467-484 (1955).

[118] Uehlinger, V., Etude statistique des méthodes de dénombrement planctonique, Arch. Sci. Genève 17/2, 121-223 (1964).

[119] Ungemach, H., Sedimentchemismus und seine Beziehung zum Stoffhaushalt in 40 europäischen Seen, Diss. Univ. Kiel, 420 S. (1960).

[120] UTERMÖHL, H., Zur Vervollkommnung der quantitativen Phyioplankton-Methodik, Mitt. Int. Ver. Limnol. 9, 1-38 (1958).

[121] Vernet, J.-P., und Thomas, R. L., The Occurrence and Distribution of Mercury in the Sediments of the Petit Lac (Western Lake Geneva), Eclogae geol. Helv. 65/2, 307-316 (1972).

[122] VoGLer, P., Zur Analytik dev Phosphorverbindungen in Gewässern, Limnologica (Berlin) 4/2, 437-444 (1966)

[123] Vogler, P., Zur Analytik kondensierter Phosphate und organischer Phosphate bei limnologischen Untersuchungen, Int. Rev. ges. Hydrobiol. 51/5, 775-785 (1966).

[124] VoGLER, P., Die getvennte quantitative Bestimmung von gelösten Orthophosphorsäureestern ("COP-Phosphat») und gelösten kondensievten Phosphaten ("POP-Phosphat»), Limnologica (Berlin) 7/2, 309-324 (1970).

[125] Vollenweider, R. A., Die wissenschaftichen Grundlagen der Seen- und Fliessgewässereutrophievung, unter besondever Beriucksichtigung des Phosphors und des Stickstoffs als Eutrophierungsfaktoren, OECD/DAS/CSI/68.27 (1968).

[126] Williams, J. D. H., Syers, J. K., Shukla, S. S., und Harris, R. F., Levels of Inorganic and Total Phosphorus in Lake Sediments as Related to other Sediment Parameters, Envir. Sci. Tech. 5, 1113 (1971).

[127] Winkler, L. W., Die Bestimmung des im Wasser gelösten Sauerstoffs und die Löslichkeit des Sauerstoffs im Wasser, Ber. Dt. Chem. Ges. 21, 2843 (1888), und 22, 1764 (1889).

[128] Wuhrmann, K., Probleme dev dritten Reinigungsstufe von Abwässern, Föderation Europäischer Gewässerschutz (FEG), Informationsblatt Nr. 14, 67-74 (1967).

[129] ZüLliG, H., Sedimente als Ausdruck des Zustandes eines Gewässers, Schweiz. Z. Hydrol. 18/1, 5-143 (1956).

Adresse des Autors:

Dr. Jürg Bloesch, EAWAG, Überlandstrasse 133, CH-8600 Dübendorf, 